\title{
Shaping or Making Policy in a Melting Arctic: Examining the Institutional Effectiveness of the Arctic Council
}

\author{
by
}

Jennifer Spence

A thesis submitted to the Faculty of Graduate and Postdoctoral Affairs in partial fulfillment of the requirements for the degree of

Doctor of Philosophy

in

Public Policy

Carleton University

Ottawa, Ontario

(C) 2017, Jennifer Spence 


\section{Abstract}

The Arctic Council has achieved a position of prominence in the environmental management and sustainable development of the circumpolar region. And yet, as the Arctic continues to experience dramatic environmental changes, the number and diversity of opinions about the role the Council should play in the governance of the region have grown. However, how the Council works and what has made it effective in the past remains poorly understood. In this dissertation, I introduce a new analytical framework to support an in-depth and systematic analysis of the Arctic Council and its governance model. I use the concept of institutional effectiveness as a foundation and incorporate the concepts of network governance, boundary work and institutional logics. Through the application of these concepts, this dissertation conceives new lenses for examining and understanding the recent history of Arctic governance and the Arctic Council's place within it: How does the Arctic Council work? And to what extent has it been effective? What factors explain the effectiveness of the Arctic Council? What criteria should be used to assess its effectiveness? To what extent can we attribute the effectiveness of the Council to its governance model? And could the governance model that contributed to the Council's effectiveness also presage its failure? I demonstrate that the Arctic Council's effectiveness as an international institution has been inconsistent, the product of a complex mix of endogenous and exogenous factors. This dissertation concludes that the governance model that originally contributed to the Arctic Council's effectiveness, as an institution that generated knowledge and provided policy advice (i.e. policy shaping), has not evolved to support an effective policymaking role. This dissertation does not prescribe a particular path for the Council; however, I 
conclude that its future effectiveness depends on an alignment between the role it is assigned to play and its governance model. The analytical framework that I have developed to support an analysis of the Arctic Council yields new tools that I propose may be useful in studying the effectiveness of other institutions that are confronting an array of policy issues in different geographical settings. 


\section{Acknowledgements}

This dissertation has been a journey that I could not have done alone. The support that I received came in many forms. My doctoral supervisor, Dr. Frances Abele, shared many insights and demonstrated amazing patience in guiding me on my wandering path. I enjoyed many conversations with Dr. Graeme Auld, who always had useful advice that helped me untangle my ideas. And I benefitted from the knowledge and experience of Dr. James Meadowcroft, who challenged me to be clear in my thinking and logically develop my ideas.

I have to extend my thanks to the many people that influenced my work through their writing and/or through great conversations over the years. These people include: Oran Young, Sheila Watt-Cloutier, Mary Simon, Franklyn Griffith, Tom Axworthy, Heather Nicol, Whitney Lackenbauer, Michael Byers, Klaus Dodds, John English, Heather Exner-Pirot, Joël Plouffe, Lassi Heininen, Paula Kankaanpää, Leslie Pal, Timo Koivurova, Tony, PenikettJohn Higginbotham, Douglas Nord, Olav Schram Stokke, Cindy Dickson, Jim Gamble, Jessica Shadian, Rob Huebert, Vincent Rigby, Gosia Smieszek, Mat Paterson, Sue Harper, Sebastien Knecht, Jutta Wark, Robert Kadas and Bev Young. It has been a pleasure to learn from all of you and I look forward to more opportunities in the future. I also want to acknowledge the support of Terry Fenge in particular. His energy and passion for the Arctic Council was infectious. On days when I could not find the motivation to push through the next phase of this project, I thought of Terry and I always found more energy. 
In addition, I have to thank all the unnamed interviewees and survey respondents. Each of you spent the time to provide your insights and opinions about the Arctic Council. You gave me so much to work with and so much to think about. I hope that you find this dissertation of interest. I know I have learned a great amount from all of you.

Finally, some personal words of thanks. First, to all the family and friends that have been so understanding of my anti-social tendencies over the couple of years. I'm very much looking forward to catching up with all of you. Next, I have to thank Bonnie and Karl, who were so generous with letting me use their cottage as a writing retreat many, many times. I also want to thank my mother, Jeanette King, whose gift with words saved me on more than one occasion. In addition, a huge thank you to the two little people (now not so little!!!), Simone and Renée, that were so understanding of the many, many hours that I sat in front of my computer. I promised you it wouldn't be forever, but it has taken me a little longer than I expected. And last, but certainly not least, I truly share this dissertation with my amazing husband, Pablo Sobrino, who cheered me on, supported me, fed me, and drove me to the library many, many times. Any success I have achieved was only with your love and support. Thank you. 


\section{Table of Contents}

ABSTRACT II

ACKNOWLEDGEMENTS IV

LIST OF TABLES $\quad$ X

LIST OF ILLUSTRATIONS XI

LIST OF APPENDICES XII

ACRONYMS XIII

CHAPTER 1: INTRODUCTION

$\begin{array}{ll}\text { The Institutions of the Arctic } & 6\end{array}$

$\begin{array}{ll}\text { Putting the Arctic Council Front and Centre } & 10\end{array}$

$\begin{array}{ll}\text { Institutional Effectiveness as an Analytical Framework } & 14\end{array}$

$\begin{array}{ll}\text { Research Methods } & 17\end{array}$

$\begin{array}{lr}\text { Dissertation Overview } & 19\end{array}$

$\begin{array}{lr}\text { Conclusion } & 22\end{array}$

CHAPTER 2: ARCTIC COUNCIL AT A CRITICAL JUNCTURE 24

$\begin{array}{ll}\text { Arctic Council } 101 & 24\end{array}$

$\begin{array}{ll}\text { Arctic Council Literature } & 32\end{array}$

Arctic Council Governance $\quad 36$

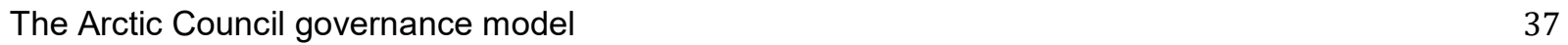

Working groups and the role of science in policymaking $\quad 39$

Consensus-based decision making $\quad 41$

Role of Arctic Indigenous peoples $\quad 42$

Role of observers $\quad 44$

Critiques of Arctic Council governance $\quad 45$

$\begin{array}{ll}\text { Arctic Council: Found or Lost? } & 46\end{array}$

$\begin{array}{lr}\text { Conclusion } & \mathbf{5 0}\end{array}$

CHAPTER 3: INSTITUTIONAL EFFECTIVENESS AND THE ARCTIC COUNCIL 52 
Determinants of Institutional Effectiveness 5

Governance environment 58

Problems to be solved $\quad 60$

Institutional design $\quad 62$

Institutional logics

Applying the Institutional Effectiveness Framework $\mathbf{7 0}$

Mapping the governance environment 72

Tracking the Arctic Council's agenda 75

Analyzing the Arctic Council institutional design 76

Exposing multiple institutional logics 77

\begin{tabular}{ll} 
Conclusion & 78 \\
\hline
\end{tabular}

CHAPTER 4: THE ARCTIC COUNCIL CREATION STORY (PRE-1996) 80

$\begin{array}{lr}\text { Governance Environment } & \mathbf{8 1}\end{array}$

Fading Cold War tensions 82

Arctic region of "peace and cooperation" 90

Institutional Design $\quad 97$

Defining the Arctic 98

Arctic state cooperation 103

A vision for Arctic governance 106

Problems to be Solved
116

$\begin{array}{ll}\text { Conclusion } & 123\end{array}$

CHAPTER 5: BOUNDARY WORK THROUGH THE ARCTIC COUNCIL (1996-2005)126

$\begin{array}{ll}\text { Governance Environment } & 127\end{array}$

Problems to be Solved $\quad 135$

Cooperation and trust building $\quad 137$

$\begin{array}{ll}\text { Environmental protection } & 138\end{array}$

Indigenous participation and the human dimension 140

Sustainable development 141

Institutional Design $\quad 144$

Raison d'être $\quad 145$

$\begin{array}{ll}\text { Organizational culture } & 148\end{array}$

Governance features $r$

$\begin{array}{ll}\text { Conclusion } & 162\end{array}$

CHAPTER 6: THE WORLD FINDS THE ARCTIC COUNCIL (2006-2015) 166

$\begin{array}{ll}\text { Governance Environment } & 167\end{array}$

$\begin{array}{ll}\text { Environmental changes } & 168\end{array}$ 
$\begin{array}{ll}\text { Economic opportunities } & 169\end{array}$

$\begin{array}{ll}\text { Political prominence } & 170\end{array}$

International governance norms 172

Problems to be Solved 176

Cooperation and trust building 178

Environmental protection 180

Indigenous participation and the human dimension 182

Sustainable development 183

Institutional Design 186

Raison d'être 186

Organizational culture 190

Governance features 193

$\begin{array}{ll}\text { Conclusion } & 219\end{array}$

CHAPTER 7: THE UNEXPLORED DETERMINANT OF EFFECTIVENESS 222

Institutional Formation and Defining Effectiveness (Pre-1996) 224

The Original Institutional Logics (1996-2005) 229

Defining effectiveness 229

How effectiveness is measured 235

Institutional logics of boundary work 239

Navigating Conflicting Institutional Logics (2006-2015) 240

Signs of original institutional logics 241

Emergence of a new institutional logic 242

A struggle of institutional logics 248

Implications of Conflicting Institutional Logics 250

For the Arctic Council $\quad 250$

For member states $\quad 252$

For permanent participants $\quad 254$

$\begin{array}{ll}\text { For observers } & 256\end{array}$

$\begin{array}{ll}\text { Conclusion } & 258 \\ \end{array}$

$\begin{array}{ll}\text { CHAPTER 8: CONCLUSION } & 261\end{array}$

$\begin{array}{ll}\text { Revisiting the Arctic Council's Effectiveness } & 261\end{array}$

$\begin{array}{ll}\text { Informing the Future Effectiveness of the Arctic Council } & 267\end{array}$

Implications for Region 276

Relevance Beyond the Arctic 277

Contributions to Theory 279

Final Reflections on the Study 282 
APPENDIX 1: DATA COLLECTION METHODOLOGY 315

Interview Data $\quad 315$

Breakdown of interview participants 316

Interview procedures and conditions 316

Sample 1: Semi-structured interviews for those involved with the Arctic Council 317

Sample 2: Semi-structured interviews for those not involved with the Arctic Council 319

$\begin{array}{ll}\text { Observational Data } & 321\end{array}$

$\begin{array}{ll}\text { Primary Source Material } & 323\end{array}$

$\begin{array}{ll}\text { Survey Data } & 324\end{array}$

Breakdown of survey respondents $\quad 324$

Arctic Council effectiveness survey tool $\quad 325$

$\begin{array}{ll}\text { Data Management } & 331\end{array}$

APPENDIX 2: MULTILATERAL INSTITUTIONS INVOLVED IN ARCTIC ENVIRONMENTAL GOVERNANCE AND SUSTAINABLE DEVELOPMENT 332

APPENDIX 3: CONTENT ANALYSIS OF ARCTIC COUNCIL-RELATED 


\section{List of Tables}

TABLE 4.1: RESULTS OF CONTENT ANALYSIS TO IDENTIFY FREQUENCY OF REFERENCES TO THEMES IN THE AEPS AND THE ARCTIC COUNCIL PANEL REPORT. 117

TABLE 4.2: POTENTIAL ARCTIC COUNCIL AGENDA ITEMS

TABLE 5.1: RESULTS OF CONTENT ANALYSIS TO IDENTIFY FREQUENCY OF REFERENCES TO

THEMES IN ARCTIC COUNCIL DECLARATIONS (1996 TO 2005)

TABLE 6.1: RESULTS OF CONTENT ANALYSIS TO IDENTIFY FREQUENCY OF REFERENCES TO THEMES IN ARCTIC COUNCIL DECLARATIONS (2006 TO 2015). 178

TABLE A1.1: BREAKDOWN OF INTERVIEW PARTICIPANTS 316

TABLE A1.2: BREAKDOWN OF SURVEY PARTICIPANTS

TABLE A2.1: MULTILATERAL INSTITUTIONS INVOLVED IN ARCTIC ENVIRONMENTAL MANAGEMENT AND SUSTAINABLE DEVELOPMENT

TABLE A3.1: RESULTS OF CONTENT ANALYSIS TO IDENTIFY FREQUENCY OF REFERENCES TO THEMES IN KEY ARCTIC COUNCIL-RELATED DOCUMENTS 


\section{List of Illustrations}

FIGURE 1.1: ORGANIZATIONAL STRUCTURE OF THE ARCTIC COUNCIL 3

FIGURE 2.2: BOUNDARIES OF THE ARCTIC

FIGURE 3.1: CONCEPTS EMPLOYED TO ANALYZE THE ARCTIC COUNCIL

FIGURE 3.2: ARCTIC GOVERNANCE MAP - SAMPLE

FIGURE 4.1: ARCTIC GOVERNANCE MAP 1986

FIGURE 4.2: ARCTIC GOVERNANCE MAP 1995

FIGURE 5.1: ARCTIC GOVERNANCE MAP 2005

FIGURE 5.2: SOCIAL WORLDS OF THE ARCTIC COUNCIL 152

FIGURE 5.3: MULTIPLE STAGES OF BOUNDARY WORK IN THE ARCTIC COUNCIL. 156

FIGURE 6.1: ARCTIC GOVERNANCE MAP 2015

FIGURE 6.2: FRAGMENTATION WITHIN THE ARCTIC COUNCIL 217

FIGURE 8.1: FACTORS AND CRITERIA FOR INSTITUTIONAL EFFECTIVENESS IDENTIFIED THROUGH AN EMPIRICAL ANALYSIS OF THE ARCTIC COUNCIL. 262 


\section{List of Appendices}

APPENDIX 1: DATA COLLECTION METHODOLOGY

APPENDIX 2: MULTILATERAL INSTITUTIONS INVOLVED IN ARCTIC ENVIRONMENTAL GOVERNANCE AND SUSTAINABLE DEVELOPMENT

APPENDIX 3: CONTENT ANALYSIS OF ARCTIC COUNCIL-RELATED DOCUMENTS 1991-2015 


\section{Acronyms}

\begin{tabular}{|c|c|}
\hline A5 & Ilulissat Declaration (Arctic 5) \\
\hline AAC & Arctic Athabaskan Council \\
\hline AAECO & Association of Arctic Expedition Cruise Operators \\
\hline AARI & Arctic and Antarctic Research Institute \\
\hline ABF & Arctic Business Forum \\
\hline AC & Arctic Council \\
\hline ACAP & Arctic Contaminants Action Program \\
\hline $\mathrm{ACe}$ & Arctic Centre, University of Lapland \\
\hline ACGF & Arctic Coast Guard Forum \\
\hline $\mathrm{ACIA}$ & Arctic Climate Impact Assessment \\
\hline ACOPS & Advisory Committee on Protection of the Sea \\
\hline ACPB & Agreement on the Conservation of Polar Bears \\
\hline $\mathrm{AEC}$ & Arctic Economic Council \\
\hline AEPS & Arctic Environmental Protection Strategy \\
\hline $\mathrm{AF}$ & Arctic Frontiers \\
\hline AFF & Arctic Forum Foundation \\
\hline AFoPs & Asian Forum for Polar Sciences \\
\hline AHDR & Arctic Human Development Report \\
\hline $\mathrm{Al}$ & Arctic Institute: Center for Circumpolar Security Studies \\
\hline AIA & Aleut International Association \\
\hline AINA & Arctic Institute of North America (University of Calgary) \\
\hline AMAP & Arctic Monitoring and Assessment Programme \\
\hline AMERN & Arctic Marine Ecosystem Research Network \\
\hline APECS & Association of Polar Early Career Scientists \\
\hline APRI & Austrian Polar Research Institute \\
\hline ARC & Arctic Research Centre, Aarhus University \\
\hline $\operatorname{ArC}$ & Arctic Circle \\
\hline ARCUS & Arctic Research Consortium of the United States \\
\hline ASF & Arctic Shipping Forum \\
\hline ASP & Arctic Science Partnership \\
\hline AWI & Alfred Wegener Institute for Polar and Marine Research \\
\hline AWRH & Association of World Reindeer Herders \\
\hline BDF & Baltic Development Forum \\
\hline BEAC & Barents Euro-Arctic Council \\
\hline BF & Bellona Foundation \\
\hline BRC & Barents Regional Council \\
\hline & Agreement Between Denmark, Finland, Iceland, Norway and Sweden \\
\hline CA & $\begin{array}{l}\text { Concerning Cooperation in Measures to Deal with Pollution of the Sea by } \\
\text { Oil or Other Harmful Substances (Copenhagen Agreement) }\end{array}$ \\
\hline CAA & Circumpolar Agriculture Association \\
\hline CAFF & Conservation of Arctic Flora and Fauna \\
\hline
\end{tabular}




\begin{tabular}{|c|c|}
\hline CARD & Centre for Arctic Resource Development \\
\hline CBSS & Council of the Baltic Sea States \\
\hline $\mathrm{CCU}$ & Circumpolar Conservation Union \\
\hline CEARC & $\begin{array}{l}\text { research centre CEARC (Cultures, Environment, Arctic, Representation, } \\
\text { Climate) }\end{array}$ \\
\hline $\mathrm{CHNL}$ & Centre for High North Logistics \\
\hline CHRN & Circumpolar Health Research Network \\
\hline CICERO & Center for International Climate and Environmental Research \\
\hline CPAR & Conference of Arctic Parliamentarians \\
\hline EBCD & European Bureau for Conservation \& Development \\
\hline EJ & Earthjustice \\
\hline ELOKA & Exchange of Local Observations and Knowledge of the Arctic \\
\hline EPB & European Polar Board \\
\hline EPPR & Emergency Prevention, Preparedness and Response \\
\hline EUP & EU-PolarNet \\
\hline FARO & Forum of Arctic Research Operators \\
\hline $\mathrm{FNI}$ & Fridtjof Nansens Institute \\
\hline FOE & Friends of the Earth \\
\hline GA & GRID-Arendal \\
\hline $\mathrm{GCl}$ & Gwich'in Council International \\
\hline GP & Greenpeace \\
\hline IAAR & Institute of Arctic And Alpine Research (University of Colorado) \\
\hline $\mathrm{IAB}$ & Institute of Arctic Biology (University of Alaska) \\
\hline IACS & International Association of Cryosphereic Sciences \\
\hline IAP & Institute for Arctic Policy \\
\hline IARC & International Arctic Research Center \\
\hline IASC & International Arctic Science Committee \\
\hline IASS & Institute for Advanced Sustainability Studies \\
\hline IASSA & International Arctic Social Sciences Association \\
\hline ICC & Inuit Circumpolar Conference/Council \\
\hline $\mathrm{ICCl}$ & International Cryosphere Climate Initiative \\
\hline ICES & International Council of the Exploration of the Sea \\
\hline ICMM & International Council on Mining and Metals \\
\hline IFRC & International Federation of Red Cross \& Red Crescent Societies \\
\hline IGO & Intergovernmental Organization \\
\hline IMO & International Maritime Organization \\
\hline INTERACT & International Network for Terrestrial Research and Monitoring in the Arctic \\
\hline ION & Institute of the North \\
\hline IPA & International Permafrost Association \\
\hline IPCCA & Indigenous Peoples' Biocultural Climate Change Assessment Initiative \\
\hline IPF & International Polar Foundation \\
\hline IPIECA & International Petroleum Industry Environmental Conservation Association \\
\hline IPS & Indigenous Peoples Secretariat \\
\hline
\end{tabular}




\begin{tabular}{|c|c|}
\hline ISA & International Seabed Authority \\
\hline $\mathrm{IUCH}$ & International Union for Circumpolar Health \\
\hline IUCN & International Union for the Conservation of Nature \\
\hline IUGS & International Union of Geological Sciences \\
\hline IWC & International Whaling Commission \\
\hline IWGIA & International Work Group for Indigenous Affairs \\
\hline NAMMCO & North Atlantic Marine Mammal Commission \\
\hline NASCO & North Atlantic Salmon Conservation Organization \\
\hline NATO & North Atlantic Treaty Organization \\
\hline NC & Nordic Council \\
\hline NCM & Nordic Council of Ministers \\
\hline ND & Northern Dimension \\
\hline NEAFC & North-East Atlantic Fisheries Commission \\
\hline NF & Northern Forum \\
\hline NGO & Non-Governmental Organization \\
\hline No & Nordregio \\
\hline NPAFC & North Pacific Anadromous Fish Commission \\
\hline NRF & Northern Research Forum \\
\hline $\mathrm{NSaC}$ & Nordic Saami Council \\
\hline NSAPR & Norwegian Scientific Academy for Polar Research \\
\hline NWAFO & Northwest Atlantic Fisheries Organization \\
\hline $\mathrm{OC}$ & Ocean Conservancy \\
\hline OGP & International Association of Oil \& Gas Producers \\
\hline $\mathrm{OHCHR}$ & Office of the United Nations High Commissioner for Human Rights \\
\hline OSPAR & $\begin{array}{l}\text { Protection of the Marine Environment of the North-East Atlantic } \\
\text { Commission }\end{array}$ \\
\hline PAME & Protection of the Arctic Marine Environment \\
\hline PBI & Polar Bears International \\
\hline PF & Pew Foundation, Environment \\
\hline PNWER & Pacific Northwest Economic Region, Arctic Caucus \\
\hline PRIC & Polar Research Institute of China \\
\hline RAIPON & Russian Association of Indigenous Peoples of the North \\
\hline RAIPON & Russian Association of Indigenous Peoples of the North \\
\hline RAS & Russian Academy of Sciences \\
\hline $\mathrm{SaC}$ & Saami Council \\
\hline SAl & Stefansson Arctic Institute \\
\hline SAO & Senior Arctic Official \\
\hline SAON & Sustaining Arctic Observing Networks \\
\hline SATA & Sustainable Arctic Tourism Association \\
\hline SDWG & Sustainable Development Working Group \\
\hline $\mathrm{SnC}$ & Snowchange Cooperative \\
\hline SPRI & Scott Polar Research Institute (University of Cambridge) \\
\hline TE & European Federation for Transport and Environment \\
\hline
\end{tabular}




$\begin{array}{ll}\text { TI } & \text { Thule Institute } \\ \text { UA } & \text { UArctic } \\ \text { UN } & \text { United Nations } \\ \text { UNCCC } & \text { United Nations Framework Convention on Climate Change } \\ \text { UNCLOS } & \text { United Nations Convention on the Law of the Sea } \\ \text { UNDP } & \text { United Nations Development Programme } \\ \text { UNEP } & \text { United Nations Environment Programme } \\ \text { UNESCO } & \text { United Nations Educational, Scientific and Cultural Organization } \\ \text { WAF } & \text { World Arctic Forum (no longer active) } \\ \text { WEF } & \text { World Economic Forum, Global Agenda Council on the Arctic (no longer } \\ \text { WHO } & \text { active) } \\ \text { WI } & \text { World Health Organization } \\ \text { WMO } & \text { Wetlands International } \\ \text { WNC } & \text { World Meteorological Organization } \\ \text { WOC } & \text { West Nordic Council } \\ \text { WWF } & \text { World Ocean Council } \\ \text { YAC } & \text { World Wide Fund for Nature }\end{array}$




\section{Chapter 1: Introduction}

"We are 'One Arctic' and together we help forge 'One Future' for our people"

- Duane Ningasiq Smith, President of ICC Canada, July 21, 2014, ICC General Assembly

Global climate change has catapulted the Arctic into the centre of geopolitics, as melting Arctic ice transforms the region from one of primarily scientific interest into a maelstrom of competing commercial, national security and environmental concerns, with profound implications for the international legal and political system (Ebinger \& Zambetakis, 2009, p. 1215).

This dissertation is about the Arctic Council, its governance model and its role in policymaking. In particular, I study how the Arctic Council works and to what extent it has been effective over time. The Arctic Council was established in 1996 "as a high level forum to provide a means for promoting cooperation, coordination and interaction among the Arctic States, with the involvement of Arctic indigenous communities and other Arctic inhabitants on common Arctic issues, in particular issues of sustainable development and environmental protection ${ }^{1}$ in the Arctic" (Arctic Council, 1996). In its early years, it was a small, research-driven discussion forum that was largely unknown both in and outside the region; however, more recently, it has been identified as the focal point of regional governance and received international attention as "the preeminent forum for international diplomacy on Arctic matters" (Ziff, 2015). If you have

\footnotetext{
${ }^{1}$ In the Declaration on the Establishment of the Arctic Council, environmental protection includes as "the health of the Arctic ecosystems, maintenance of biodiversity in the Arctic region and conservation and sustainable use of natural resources" and sustainable development includes "economic and social development, improved health conditions and cultural well-being" (Arctic Council, 1996, p. 1).
} 
followed circumpolar issues in recent years, you've heard about the success of the Arctic Council and its importance in the region.

Its member states include: Canada, Denmark, Finland, Iceland, Norway, Russia, Sweden, and the United States. The chairmanship is held by each member state for a 2-year period and rotates through all 8 states. The Arctic Council also includes permanent participants - a unique category of membership "to provide for active participation and full consultation with the Arctic Indigenous representatives within the Arctic Council" (Arctic Council, 1998a, p. 4). As of 2015, there were 6 organizations with this designation: the Aleut International Association (AIA), Arctic Athabaskan Council (AAC), Gwich'in Council International (GCI), Inuit Circumpolar Council (ICC), Russian Association of Indigenous Peoples of the North (RAIPON), and Saami Council (SC). All meetings and activities of the Arctic Council are open to permanent participants and all decisions of the Arctic Council are made by consensus of the member states with the participation of permanent participants. However, there is a provision that allows for private meetings of the member states and states are the only signatories to Arctic Council declarations and decisions. Since its inception, observer status in the Arctic Council has been open to non-Arctic states, intergovernmental and inter-parliamentary organizations (IGOs), and non-governmental organizations (NGOs) "that the Council determines can contribute to its work" (Arctic Council, 1996). As of 2015, the Council included 12 non-Arctic states, 9 IGOs, and 11 NGOs that held observer status. 
Most of the work of the Arctic Council is conducted by a collection of thematic working groups - the Arctic Council Action Plan (ACAP), the Arctic Monitoring and Assessment Programme (AMAP), Conservation or Arctic Flora and Fauna (CAFF), Emergency Prevention, Preparedness and Response (EPPR), Protection of the Arctic Marine Environment (PAME), and the Sustainable Development Working Group (SDWG)

(Figure 1.1). These working groups report to Senior Arctic Officials (Heads of Delegation for member states) and senior representatives of permanent participant organizations. Senior Arctic Officials (SAOs) meet at least every 6 months and ministerial meetings take place every two years.

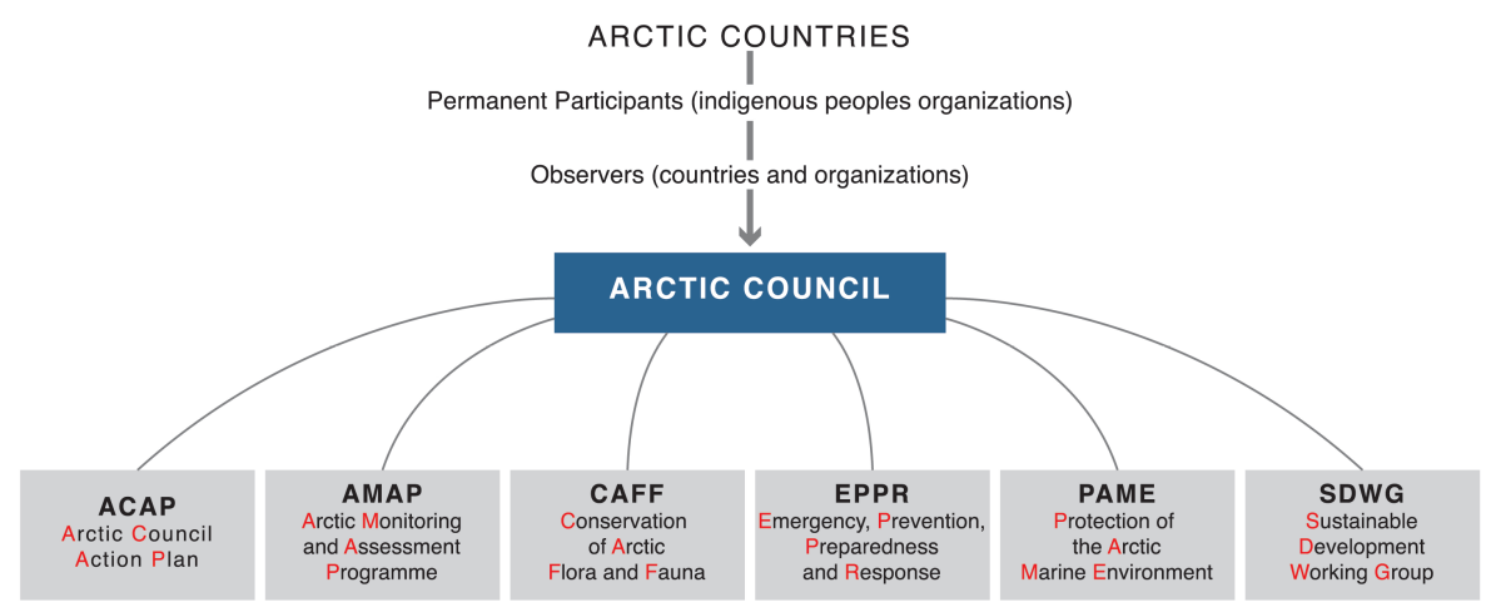

Figure 1.1: Organizational Structure of the Arctic Council (Arctic Monitoring and Assessment Programme, 2015)

I was attracted to this area of research because the Arctic has become a persuasive poster child for the proliferating symptoms of climate change and global environmental degradation - a real-world laboratory for studying the speed, magnitude and impact of changes to a region's human and natural systems. An overwhelming environmental 
transformation is being communicated through a wealth of graphic images, including cruise ships travelling through clear seas, houses sinking as permafrost melts, and polar bears clinging to small icebergs. These dramatic images of environmental change have captured the public imagination and fundamentally altered both the real and perceived opportunities and challenges facing the region. The Arctic Council is the most prominent institution working at the circumpolar level that supports environmental management and sustainable development.

As the issues facing the region grow in number and complexity, so do the pressures and expectations placed on the Arctic Council. Accordingly, there is no lack of advice and opinions emanating from participants and experts about what role the Arctic Council could play in the future. In particular, whether the Arctic Council should continue to generate knowledge and provide policy advice that informs and influences policies (i.e. a policy shaping institution) or shift its focus to negotiating intergovernmental agreements, setting guidelines and standards, and monitoring the implementation of policies (i.e. a policymaking institution) (Koivurova, 2010; Nord, 2016). By extension, there are numerous experts willing to weigh in on how to "strengthen" the Arctic Council to support its envisioned role (Huebert, 2009; Kankaanpää \& Young, 2012a; Koivurova, 2010; Nord, 2016; Spence, 2013). Underlying all of this commentary is the inference that the Arctic Council has reached a critical juncture and its leadership must now make choices and decisions about the functions the Council will assume and the role it will play in the future. 
And yet, despite the multitude of opinions about what the Arctic Council should do or be, there has been limited empirical work done to examine how the Arctic Council works or to study the Council's governance model in a detailed and systematic manner. This dissertation contributes to filling this gap by making the Arctic Council the focus of analysis. In particular, I set out to respond to the research questions: How does the Arctic Council work? To what extent has it been effective? What factors explain the effectiveness of the Arctic Council? What criteria should be used to assess its effectiveness? To what extent can we attribute the effectiveness of the Council to its governance model? And could the governance model that contributed to the Council's effectiveness also presage its failure?

In answering these questions, I develop a new analytical framework that uses the concept of institutional effectiveness as a foundation to undertake a detailed analysis of the Arctic Council over time. The scholarly literature provides no single definition of institutional effectiveness. For the purposes of this study, I employ a definition informed by Underdal (2002b) in which I propose that an institution is considered effective to the extent that it successfully performs a certain (set of) function(s) or solves the problem(s) that motivate actors to invest time and energy toward sustaining the institution. To operationalize this concept, I identify four determinants of institutional effectiveness as categories to organize the analysis and factors that explain the effectiveness of the Arctic Council. These determinants include: the Council's governance environment; the nature of the problems to be solved; the institutional design; and institutional logics. The concepts of network governance (Kahler, 2009) and boundary work (Guston, 1999, 
2001) are also employed. Building upon these concepts, I introduce a new lens for examining the recent history of Arctic governance and the Arctic Council's place within

it. This study of the Arctic Council uses qualitative research methods and is driven by intense empirical work in the form of semi-structured interviews, an online questionnaire, primary source materials, and field observation.

Based on my analysis, I conclude that the Arctic Council's effectiveness has varied over time and is the product of factors that are endogenous and exogenous to the institution. This dissertation demonstrates that the governance model that originally contributed to the Arctic Council's effectiveness, as a policy shaping institution, has not evolved to support an effective role for the Council in policymaking.

In the next section, I provide a brief discussion of the network of institutions in the Arctic that are relevant to an analysis of the role of the Arctic Council, by way of explaining why the Arctic Council is central to understanding the future of international governance in the circumpolar region. I then explain at more length the dissertation's analytical framework and chapter-by-chapter organization.

\section{The Institutions of the Arctic}

Perhaps future scholars will consider the evolving dynamics of the circumpolar Arctic basin in recent decades as a showcase example of a new world order in which states and non-state actors cooperate. At the very least, other scholars should follow Oran Young's interest in affording the complex intergovernmental and inter-organizational relations of the circumpolar basin further study for what these may teach us about the denser byways of international affairs in which non-state nations and peoples and their various organizations have an impact on state behaviour and on outcomes. (Abele \& Rodon, 2007, pp. 58-9) 
The Arctic Council does not exist in isolation. It is part of a complex and dynamic network of institutions involved in Arctic governance and policymaking. To understand the Arctic Council, its governance model and its role in policymaking, the Council must take its place in time and space within this network of institutions. There is a wellestablished literature dedicated to the study of institutions -as well as a diversity of opinions within this literature about what an institution is and what functions it performs. For example, rational choice scholars primarily focus on institutions as coordinating mechanisms that structure and constrain actors (Keohane, 1984; North, 1991; Snidal, 1985); while scholars committed to historical institutionalism see institutions as a legacy of historical processes and consider the relevance of both exogenous and endogenous factors (Mahoney \& Thelen, 2010; Skocpol, 1985; Weaver \& Rockman, 1993). The school of sociological institutionalism examines the social construction of institutions and how culture impacts strategies, interests and the relationship between actors (Dobbin, 1994; W. R. Scott, 1994; Swidler, 1986).

I employ an historical approach and adopt the definition of an institution provided by Hall, which states that an institution is a "the formal and informal procedures, routines, norms and conventions embedded in the organizational structure of the polity" (1996, p. 938). Furthermore, consistent with Hall, I begin from the premise that institutions can take many forms (e.g. organizations, regimes, conventions, etc.).

This study examines the network of institutions that support Arctic environmental management and sustainable development. More specifically, I focus on institutions 
that are transboundary and involve multiple (three or more) public and/or private actors, which I refer to throughout this dissertation as multilateral institutions. I limit my analysis to these types of institutions because I am interested in the governance of the circumpolar region as a whole and institutions that are tasked with responding to problems that require transboundary solutions (e.g. climate change and loss of biodiversity) (Young, 1994). The operating conditions for multilateral institutions are unique because they sit outside the policymaking power and authority of any one state - this creates a governance environment that Hafner-Burton et al. (2009) refer to as inherently dynamic and Waltz (2010) describes as anarchic. I do not explicitly examine domestic or bilateral institutions in the region; however certain examples are introduced to support the analysis.

At the international level, there is a rich collection of multilateral institutions that are involved in work relevant to the environmental management and sustainable development of the Arctic. The graphic changes in the Arctic resulting from climate change continue to feed global concern and policy discussions, including the 2015 United Nations Climate Change Conference (the $21^{\text {st }}$ Conference of the Parties to the United Nations Framework Convention on Climate Change or COP 21) in Paris because of the region's symbolic role in confirming the impacts of global climate change and because the region plays a unique role in the global climate system. ${ }^{2}$ As well, efforts to implement the 1982 United Nations Convention on the Law of the Sea in the

${ }^{2}$ Despite the recognized importance of the Arctic for global climate change, those people calling for commitments focused on the Arctic were disappointed by the absence of Arctic-specific commitments in the resulting Paris Agreement (United Nations, 2016). 
Arctic are ongoing. In this regard, each Arctic state has undertaken the work of mapping the boundaries of its continental shelf for the purpose of submitting its claims to the United Nations Commission on the Limits of the Continental Shelf (UNCLOS), a process that enables states to claim extensions of up to 150 nautical miles in addition to their 200 nautical mile exclusive economic zones. ${ }^{3}$ And most recently, the International Maritime Organization (IMO) led the way in negotiating the International Code for Ships Operating in Polar Waters (Polar Code), which came into force on January 1, 2017.

Sub-regions of the Arctic are also supported by a diverse collection of multilateral institutions involved in environmental management and sustainable development. For example, the Nordic Council of Ministers and the Barents Euro-Arctic Council have both supported cooperation on a broad suite of policy issues for decades. Meanwhile, the North Atlantic Marine Mammal Commission, the Agreement on the Conservation of Polar Bears and the North Atlantic Salmon Conservation Organization are examples of institutions working at the sub-regional level that support specific policy issues or topics.

However, as I examine in more detail in the coming chapters, multilateral institutions with a mandate to work at the circumpolar level are a relatively new phenomena. And yet, over the past 25 years, the number of institutions focusing on environmental management and sustainable development at this level has mushroomed - institutions such as the Arctic Council, International Arctic Science Committee (IASC), Northern

${ }^{3}$ Although the United States is not a signatory to the UNCLOS, it is still actively conducting work to map it boundaries as defined by the UNCLOS. 
Forum (NF), Conference of Arctic Parliamentarians (CPAR), University of the Arctic (UA), the Sustainable Arctic Tourism Association (SATA), and the Arctic Circle (ArC). This demonstrates that a diversity of actors are willing and interested in being involved with institutions that work at this level.

Climate change will continue to transform the Arctic and the pace is noticeably accelerating, but the implications of these changes remain uncertain. Given the global significance of these environmental changes and anticipated global demands for natural resources, ${ }^{4}$ it is reasonable to expect that interest in the Arctic among private and public actors from within and outside the Arctic will continue to increase. These actors will look to the institutions of the Arctic to find ways to influence the policies of the region.

\section{Putting the Arctic Council Front and Centre}

Not so long ago the notion of an international council of arctic states was difficult even to conceive. The seemingly inexorable grip of militarism still held at bay genuine efforts to foster circumpolar cooperation, and many spoke of the coming era as one which would witness the emergence of the Arctic as a strategic theatre for global warfare. That was then, this is now. (Arctic Council Panel, 1991)

We should not assume, therefore, that the Arctic Council simply exists... It is, like all organizations, precarious and capable of being weakened as well as strengthened - as reflected in ongoing debates about its status as a soft-law intergovernmental forum. There is nothing inevitable about the trajectory of the Arctic Council as an organization both in the present and in the future. (Dodds, 2012, p. 10)

While the number of institutions involved with environmental management and sustainable development in the Arctic has grown over the last 25 years, there are

\footnotetext{
${ }^{4}$ Although immediate demand for the Arctic's natural resources has slowed in recent years because of depressed oil and gas prices, the region still represents a largely untapped source of high-demand resources that are becoming scarce elsewhere. As a result of climate change, these resources will become increasingly accessible in the Arctic.
} 
currently no other institutions positioned to assume the central position the Arctic Council has acquired in regional governance. The Arctic Council has taken centre stage among the multilateral institutions in the region (Young \& Kankaanpää, 2012; Young, 2013). Some participants suggest this is a result of the Arctic Council's high quality and salient research and policy advice that raised the Council's international profile at a critical time for the Arctic and the globe (Kankaanpää \& Young, 2012b). The prominence of the Council may also be a product of the decision of Arctic states and Indigenous groups to dedicate their time and resources to the Council over other circumpolar institutions. Irrespective of the reason(s), the Arctic Council has become the main forum for states, Indigenous organizations, IGOs, and NGOs to influence circumpolar policies related to environmental management and sustainable development. Over a surprisingly short period of time, the Arctic Council appears to have gained the credibility and legitimacy with actors inside and outside the region to establish policy positions and priorities on a broad range of issues. Its central position in the network of multilateral institutions in the region underscores the importance of better understanding how the Arctic Council works and to what extent it has been effective.

To explain the success of the Arctic Council, participants and experts often point to the issues the Council has championed, such as: its influence in advancing important international agreements, such as the Stockholm Convention on Persistent Organic Pollutants (United Nations, 2001) and the Minamata Convention on Mercury (United Nations, 2013) (Nord, 2016; Stone, 2016), or the important connections the Council has made between global pollution and the health and well-being of the region's people 
(English, 2013; Watt-Cloutier, 2015). Furthermore, the success of the Arctic Council is often attributed to its governance model, including the unique role of Indigenous groups, the prominent position of science and the value the Council places on its consensusbased decision-making approach. Its unique and innovative governance model is held up by experts as something that other institutions and regions can learn from (Abele \& Rodon, 2007; Heininen, 2005; Kankaanpää \& Young, 2012a; Stokke, 2011).

At the same time, the Arctic Council has continued to change and grow. Although the Council was established in 1996 as a "discussion forum," by 2013 Arctic states had signed two "binding" agreements under the auspices of the Arctic Council. ${ }^{5}$ And in 2015, the Arctic Council created a "binding agreements" page on its website ${ }^{6}$ to profile these agreements. The decision to link these agreements to the Arctic Council are likely multifold; however, they are more legitimately characterized as multilateral agreements among Arctic states rather than direct products of the Arctic Council. The agreements do not assign the Council any powers or responsibilities to support the agreements' execution. Nevertheless, the impact of positioning the Arctic Council as an institution that produces binding international agreements has certainly increased the Council's

\footnotetext{
${ }^{5}$ The agreements include the Agreement on Cooperation on Aeronautical and Maritime Search and Rescue in the Arctic (Arctic Council, 2011a) and the Agreement on Cooperation on Marine Oil Pollution Preparedness and Response in the Arctic (Arctic Council, 2013a). The Council's role in securing these agreements was limited to providing the forum for signatories (Arctic states) to negotiate and the Arctic Council has no authority or responsibility assigned to it by the signatories to hold them to account in meeting the commitments in these agreements.

6 The title of the web page was recently changed to "Agreements." As well, the language on the page was revised to more accurately reflect the role of the Arctic Council-that is, the "Arctic Council has provided a forum for the negotiation of two important legally binding agreements among the eight Arctic states"(Arctic Council, 2017).
} 
credentials and served to animate discussions about its current and future role in the region's policymaking. Some experts argue that the Council offers the best potential to be the central forum for managing all policy issues and relationships in the region (Conley \& Melino, 2016; Nord, 2016).

Moreover, despite a limited understanding of the Council's governance model in its entirety, each Arctic Council chairmanship programme since 2004 has included "strengthening" or "improving" the governance of the Arctic Council as a priority. This has generated interesting discussions over the years concerning how the Council's working groups are organized, how to enhance the capacity and participation of Indigenous representatives (permanent participants), and what role observers should play in the Council. However, the outcome of efforts to "strengthen" the Council have often translated into vague goodwill statements about increasing its influence, recognition and legitimacy (Breum, 2012, p. 119). Furthermore, those changes that the Council has implemented to achieve the goal of "strengthening" its governance have been limited to administrative measures. These include the release of an Arctic Council Observer Manual for Subsidiary Bodies (2013c) that outlined the rules and procedures for participation, a review of the working groups' terms of references, and the creation of a secretariat with a mandate to support the Arctic Council chair by improving administration, document management and internal and external communications.

As the challenges confronting the region grow in number and complexity, so do the expectations for the Arctic Council. And yet in recent years, some participants and 
experts that follow the Council's work are more frequently questioning its effectiveness. In particular, they have raised concerns that the Council's current governance model is not up the task of responding to the challenges that the region currently faces ( $\mathrm{L}$. Axworthy \& Simon, 2015; Conley \& Melino, 2016; Nord, 2016; Spence, 2015). This suggests that the demands being placed on the Council are not only expanding, but people's ideas about what the Council should do and how it should work may be diverging - some interviewees and survey respondents want to strengthen the Council's governance features that support policy shaping (e.g. knowledge generation and policy advice), while others advocate an enhanced role in policymaking (e.g. setting guidelines and standards and establishing binding agreements). However, despite the recognition that the Council has received and the expectations placed upon it, limited empirical work has been done to understand the Council's governance model in its entirety. This is a gap in understanding that this dissertation aims to fill.

\section{Institutional Effectiveness as an Analytical Framework}

Understanding the how of an organization not only enables evaluations of why particular future visions emerge from the institutions as praxis, but also how human resources are deployed and arranged in certain ways in order to stabilize such visions that are then used to lend credence to particular courses of action (Dodds, 2012, p. 8).

The analytical framework used to examine the Arctic Council directly affects our understanding of how this institution works and to what extent it has been effective. For example, the existing literature focused on governance in the Arctic remains heavily concentrated on geopolitics, approaches for policymaking and the mechanisms for monitoring and enforcement (Heininen, 2010; Huebert, 1999; Koivurova, 2010). These analyses emphasize the core building block that states hold primary policymaking 
authority for their citizens at the international level. As the geopolitics of the region continues to shift and change, these analyses continue to serve an important purpose. However, a geopolitical analysis will tend to emphasize state power because, in geopolitical approaches, states are the main actors. This has the analytical consequence of obscuring the roles of non-state actors.

But the arena of policymaking is changing. It is no longer the exclusive domain of states. A broad range of actors - from NGOs and IGOs, the private sector and communities - now play a role in policymaking at the local, national, regional and global levels (Pal, 2014). The Arctic and the Arctic Council are not exceptions to this trend. Drawing on preliminary analyses of interview and observational data about the Arctic Council, I argue that the authority vested in Arctic states provides them with only limited legitimacy to make policy decisions in the region. A focus on states and their policymaking authority conceals important aspects of the governance dynamics in the region. A variety of non-state actors are now involved in a variety of international institutions, such as the Arctic Council; therefore, an analysis premised on the assumption that states are the primary institutional actors in the international arena is not sufficient to establish an in-depth understanding of the dynamics that have shaped the region's governance environment or the dynamics at play within the Arctic Council. Actors of all types and at all levels now navigate an increasingly complex network of actors and institutions - creating a dynamic governance environment that has implications for the effectiveness of its institutions. 
With this in mind, an overarching objective of this dissertation is to propose an alternative analytical framework that produces unique and constructive insights about how the Arctic Council has functioned and evolved in this rapidly changing environment. This dissertation constructs a new analytical framework that is founded on the concept of institutional effectiveness. This framework provides a lens to inform and structure an analysis of the effectiveness of the Arctic Council as an international institution. The literature on institutional effectiveness remains limited and has not yet established a cohesive perspective on the factors and issues that are most critical, although Young's article in Proceedings of the National Academy of Sciences (2011) goes to great lengths to draw together common threads in the literature and set a research agenda to move the concept forward. This literature is heavily focused on the effectiveness of international environmental institutions; however, the value of this concept for institutions with different mandates is acknowledged (Keohane, Haas, \& Levey, 2001; Mitchell, 2006; Underdal, 2002a; Young, 2011).

I employ institutional effectiveness as the foundation for my analytical framework to better understand the factors that explain the effectiveness of the Arctic Council and to specifically explore to what extent the Council's governance model has contributed to its effectiveness. The definition of institutional effectiveness that I employ is: the extent to which an institution successfully performs a certain (set of) function(s) or solves the problem(s) that motivate actors to invest time and energy toward sustaining the institution. This particular definition is useful because it not only recognizes the importance of an institution's contribution to performing particular functions or solving 
specific problems to assess its effectiveness, it also acknowledges that actors involved with the institution must believe that the institution deserves the investment of their limited time and resources.

This analysis is also informed by Ostrom (1990), who emphasizes that there is no reason to assume that an institution will be equally effective over space, time and issue area and Mitchell (2008), who stresses that effectiveness can vary as a result of factors that are endogenous and exogenous to the institution. These observations informed my decision to study the Council's effectiveness over time and broaden the scope of the analysis to consider the Council's governance environment. The approach adopted to apply this concept to support my analytical framework is discussed in more detail in Chapter 3.

\section{Research Methods}

This dissertation employs a qualitative research methodology to study the Arctic Council. The analysis that follows draws on multiple data collection sources, which support 'thick description.' Data was collected through semi-structured interviews with representatives of relevant international bodies, governments, communities, and other public and private sector actors. I conducted a total of 67 interviews, of which 55 interviewees were directly involved with the Arctic Council. Interviews were guided by an initial set of research questions related to the Arctic governance environment and how the Arctic Council works; however, in the early stages of the study, I maintained an open-ended approach so that different themes, issues and lines of inquiry could emerge. 
This dissertation also benefits from data collected from a study conducted by Kankaanpää and Young that resulted in an article entitled The effectiveness of the Arctic Council (2012a). As part of this study, the authors conducted a survey with a total of 90 respondents. The analysis presented in this dissertation draws on and benefits from this survey data, which is used with the authors' generous permission (2012b). ${ }^{7}$ Kankaanpää and Young asked respondents a series of questions about their perspective on what has made the Arctic Council effective and what could improve its effectiveness.

Another important source of understanding are field observations made during attendance at 9 meetings and 6 conferences, discussions with Arctic Council staff and officials, and meetings, discussions and conferences of the broader policy community. I also reviewed primary source material, such as the Arctic Council declarations, meeting records and reports. Finally, I collected basic information about multilateral institutions involved in or relevant to environmental management and sustainable development in the region from early 1945 to 2015 , including: date of founding, main actors involved and primary scale of activity (international, circumpolar or sub-regional). Nvivo software was used to organize, code, identify themes and analyze the data collected from interviews, surveys, field notes and primary source material. Further details about the data collection and analysis methodology are provided in Appendix 1.

\footnotetext{
${ }^{7}$ For the reminder of the dissertation, references to data drawn from the Kankaanpää and Young survey will be cited using (Kankaanpää \& Young, 2012b). The authors removed the names of the participants prior to providing the data file and requested that any data used in the dissertation be anonymous.
} 


\section{Dissertation Overview}

This dissertation has 3 main components. The first section (Chapters 2 and 3 ) provides the context and introduces in more detail the analytical framework that structures the analysis presented in subsequent chapters. In Chapter 2, I provide a general overview of how the Arctic Council is organized, and then discuss key observations and themes in the existing literature about the Arctic Council to articulate where this study fits in the existing literature.

Chapter 3 presents the analytical framework. I use institutional effectiveness as the core concept to study the Arctic Council and its governance model. This chapter includes a review of the existing literature related to institutional effectiveness and introduces the governance environment, nature of the problems to be solved, institutional design and institutional logics as determinants of institutional effectiveness that structure an analysis of the Arctic Council. Network governance (Kahler, 2009) and boundary work (Guston, 2001) are also introduced as complementary concepts that support an analysis of the Arctic Council. Chapter 3 concludes by explaining how the analyses in subsequent chapters are presented using the determinants of institutional effectiveness.

The second section of the dissertation is composed of 4 chapters. It presents the empirical analysis and findings of this study. The first 3 chapters in the section present the analysis and findings for three time periods (1986-1995, 1996-2005, and 20062015). Each chapter examines the governance environment, nature of the problems to 
be solved, and the Council's institutional design to inform our understanding of how the Arctic Council works and to what extent it has been effective.

Chapter 4 examines the period between 1986 and 1995, which begins one year prior to an important speech by U.S.S.R. President Mikhail Gorbachev in 1987 proposing that the Arctic become a zone of peace and cooperation, and ends one year prior to the official creation of the Arctic Council. An analysis of this period provides an opportunity to examine developments that contributed to the creation of the Arctic Council with a particular interest in those factors that influenced the institutional design of the Council. This chapter examines two initiatives that were specifically important precursors to the creation of the Arctic Council. The Finnish Initiative culminated in the 1991 creation of the Arctic Environmental Protection Strategy (AEPS) ${ }^{8}$, which was subsumed by the Council in 1996; whereas, the Canadian Initiative was initiated by Canadian Indigenous leaders and NGOs to champion broad multilateral cooperation in the circumpolar region. It resulted in the Canadian government leading negotiations among Arctic states that culminated in the creation of the Arctic Council.

Chapter 5 analyzes the period between 1996 and 2005. 1996 marks the official launch of the Arctic Council with the signing of the Ottawa Declaration; while 2005 is one year after the release of the Arctic Council's Impacts of a Warming Arctic: Arctic Climate Impact Assessment Report (2004b), which is often credited with contributing to global

${ }^{8}$ The AEPS was an intergovernmental agreement that was signed in 1991 by the Arctic states (Canada, Denmark, Finland, Iceland, Norway, Russia, Sweden and the United States) to establish an action plan to respond to pollution concerns and protect the Arctic environment. 
awareness of the impacts of climate change and the beginning of the Arctic Council's rise to international prominence. The Arctic Council was not well known outside the Arctic during the first 10 years of its existence; therefore, an examination of this period offers an important glimpse at how the Arctic Council worked and what made it effective during its fledgling years. I propose that the Council's effectiveness in this period is due to its focus on policy shaping, supported by a governance model that facilitated boundary work between political, Indigenous and scientific social worlds.

Chapter 6 examines the period between 2006 and 2015. This complex and dynamic period is when the Arctic and the Arctic Council attracted increasing attention from nonArctic state and non-state actors. 2006 marks the beginning of the Council's rise in prominence and 2015 was the final year of Canada's second term as chair. This chapter examines the impact of rising expectations on the Arctic Council to assume responsibility for a growing range of issues and, in some cases, a more direct role in policymaking and policy action. I argue that during this period the Arctic Council governance model was under strain as it was pressed to meet diverging ideas about what the Arctic Council was, what it should do and how it should work.

Chapter 7 examines a new factor that contributes to institutional effectiveness that has not been discussed in the scholarly literature - the institutional logics within the Arctic Council. I revisit the time periods introduced in Chapters 4, 5 and 6 and I propose that how interviewees and survey respondents define and measure the Council's effectiveness exposes distinct institutional logics - "socially constructed, historical 
patterns of cultural symbols and material practices, including assumptions, values and beliefs, by which individuals and organizations provide meaning to their daily activity, organize time and space, and reproduce their lives and experiences" (Thornton \& Ocasio, 1999, p. 804). Moreover, whereas the institutional logics introduced through the Finnish and Canadian Initiatives were able to co-exist in the Council's early years; a new institutional logic focused on policy action and results emerged during the second half of the Council's existence that conflicted with the original institutional logics. I argue that the conflict between these institutional logics produced ambiguity within the Arctic Council, which had implications for member states, permanent participants and observers.

In conclusion, Chapter 8 reviews the analysis presented in previous chapters and considers its contribution to our understanding of the Arctic Council and the governance of the Arctic region. I propose that this study of the Arctic Council has a broader relevance for our understanding of multilateral institutions in other regions and issue areas. I then consider how this dissertation contributes to the literature about institutional effectiveness and the other concepts that are adopted to support this study of the Arctic Council. I conclude by discussing what I learned from this study and reflect on how I can further contribute to research related to the Arctic Council, the Arctic region and international institution more broadly.

\section{Conclusion}

The current and future circumstances in the Arctic warrant attention because of the rapid environmental changes it is experiencing and their implications for the globe. By 
extension, so does the Arctic Council. It is an institution that is credited by many participants and observers as being the region's primary international institution. As more and more state and non-state actors from outside the region arrive on the Council's doorstep expressing a desire to participate in this institution, there is a value in undertaking empirical research to better understand the Arctic Council, its governance model and its role in the policy process. In other words, as the region grapples with endogenous and exogenous pressures to sustain effective governance mechanisms in the region, this research informs discussions on the current and future role the Arctic Council is positioned to play.

This chapter has introduced the core research questions and it has explained how this dissertation seeks to answer them. The next chapter focuses on introducing the basic features of the Arctic Council and reviewing the literature that has informed our understanding of this institution. 


\section{Chapter 2: Arctic Council at a Critical Juncture}

This chapter sets the context for the analysis that is to follow. It begins with a general introduction to the history and evolution of the Arctic Council, followed by an overview of secondary literature. In particular, I examine the different theoretical constructs used and discuss how these different constructs shape our understanding of the Arctic Council as an institution. Subsequently, I focus in on the literature dedicated to studying the governance of the Arctic Council. I review those authors that have discussed the Council's governance model and I summarize discussions within the literature related to its notable governance features. Finally, I introduce an emerging narrative in the popular and scholarly literature that suggests the Arctic Council has reached a critical juncture, poised between playing a role in policy shaping or in policymaking.

\section{Arctic Council 101}

The Arctic Council was created in 1996 "as a high level forum to provide a means for promoting cooperation, coordination and interaction among the Arctic States, with the involvement of Arctic indigenous communities and other Arctic inhabitants on common Arctic issues, in particular issues of sustainable development and environmental protection in the Arctic" (Arctic Council, 1996). Its membership includes Canada, Denmark, Finland, Iceland, Norway, Russia, Sweden, and the United States. The chairmanship is held by each member state for a 2-year period and rotates through all 8 states. At its formation, the Arctic Council replaced and assumed many of the priorities and governance features of the Arctic Environmental Protection Strategy (AEPS), which had been adopted in 1991 by the same Arctic states that established the Arctic Council. 
The status of permanent participant for Arctic Indigenous groups is recognized as one of the unique and most important governance features of the Arctic Council (T. S. Axworthy \& Dean, 2013; English, 2013). This category was created during negotiations of the Arctic states that led to the creation of the Arctic Council "to provide for active participation and full consultation with the Arctic Indigenous representatives within the Arctic Council" (Arctic Council, 1998a, p. 4). As specified in the Arctic Council's founding declaration, permanent participant status is open to "Arctic organizations of indigenous peoples with majority Arctic indigenous constituency, representing: a) a single indigenous people resident in more than one Arctic state; or b) more than one Arctic indigenous people resident in a single Arctic state" (Arctic Council, 1996). As of 2015, the organizations designated as permanent participants included the Aleut International Association (AIA), Arctic Athabaskan Council (AAC), Gwich'in Council International (GCI), Inuit Circumpolar Council (ICC), Russian Association of Indigenous Peoples of the North (RAIPON), and Saami Council (SaC).

In principle and in practice, this means that all meetings and activities of the Arctic Council are open to permanent participants. Although, there is a provision that allows for private meetings of the Heads of Delegation of member states. This provision has been used on occasion (e.g. when ministers discussed the applications for observer status in 2013 that included requests from China, India and the European Union). The importance of permanent participants in the work of the Arctic Council is heightened by the fact that, at its inception, the Arctic Council also adopted a consensus-based decision-making approach. Decisions of the Arctic Council are made by consensus of 
the member states with the "active participation and full consultation" of permanent participants (Arctic Council, 1996). As a general practice, consensus is sought among member states and permanent participants.

The category of observer was established by the Arctic states during negotiations to establish the Council because the Netherlands, Germany, the United Kingdom and Poland had already received observer status to the Arctic Environmental Protection Strategy (AEPS) and these countries had expressed an interest in acquiring the same status with the Arctic Council. From its inception, observer status in the Council was open to non-Arctic states, intergovernmental and inter-parliamentary organizations (IGOs), and non-governmental organizations (NGOs) "that the Council determines can contribute to its work" (Arctic Council, 1996). However, the role of observers and the process for admitting observers were not fully articulated until the release of the Arctic Council Observer Manual for Subsidiary Bodies (2013c). Prior to 2013, the role and involvement of observers was informal and varied greatly by interest, issue, capacity and working group. After 2013, observers were limited to observing meetings of the Arctic Council and could only make a statement or submit materials at the discretion of the meeting chair. Furthermore, the Observer Manual indicated that the total financial contributions of observers could not exceed the financing of the member states. As of 2015, the Arctic Council had 12 non-Arctic states, 9 intergovernmental and inter- 
parliamentary organizations (IGOs), and 11 non-governmental organizations (NGOs)

that held observer status. ${ }^{9}$

The Arctic Council is currently organized into a collection of thematic working groups the Arctic Council Action Plan (ACAP), the Arctic Monitoring and Assessment Programme (AMAP), Conservation or Arctic Flora and Fauna (CAFF), Emergency Prevention, Preparedness and Response (EPPR), Protection of the Arctic Marine Environment (PAME), and the Sustainable Development Working Group (SDWG) (as presented in Figure 1.1). The AMAP, CAFF, EPPR, and PAME working groups were established as part of the Arctic Environmental Protection Strategy (AEPS) and therefore pre-date the creation of the Arctic Council. The permanent participants are also provided with administrative and coordination support by the Indigenous Peoples Secretariat (IPS) that was established in 1994, as part of the AEPS. The SDWG was conceived of by the AEPS member states, but the Arctic Council launched the working group in 1998. The Arctic Council also established the ACAP in 2006, giving it

\footnotetext{
${ }^{9}$ In 2015, the 12 non-Arctic states included: France, Germany, the Netherlands, Poland, Spain, United Kingdom, People's Republic of China, Italian Republic, Japan, Republic of Korea, Republic of Singapore and the Republic of India. The 9 Intergovernmental and InterParliamentary Organizations included: International Federation of Red Cross \& Red Crescent Societies, International Union for Conservation of Nature, Nordic Council of Ministers, Nordic Environment Finance Corporation, North Atlantic Marine Mammal Commission, Standing Committee of the Parliamentarians of the Arctic Region, United Nations Economic Commission for Europe, United Nations Development Program and United Nations Environment Program. The 11 Non-Governmental Organizations included: The Advisory Committee on Protection of the Seas, Arctic Institute of North America, Association of World Reindeer Herders, Circumpolar Conservation Union, International Arctic Science Committee, International Arctic Social Sciences Association, International Union for Circumpolar Health, International Work Group for Indigenous Affairs, Northern Forum, University of the Arctic, World Wide Fund for Nature - Global Arctic Program.
} 
responsibility for managing activities that were initiated in 1998 to address pollution sources identified by the AMAP.

Each of the working groups has a distinct membership, including scientific experts and specialists from relevant government departments of the member states. This scientific expertise is also drawn from a variety of other sources, including non-Arctic states, NGOs, IGOs and academia, as needed. A representative of a member state chairs each working group; the process for selecting the chair and the length of the chairmanship is not consistent across working groups.

Each working group has the authority to invite the advice and involvement of any experts or stakeholders that it feels are relevant to the issues it is working on. The working groups each have their own terms of reference that define their mandates and how they work. Direct secretariat support available to the working groups varies. The AMAP, CAFF and PAME working groups have dedicated staff and permanent secretariats that support their work. Whereas, the SDWG has funds to hire staff, but the staff are co-located with the chair of the working group, which changes every two years. For many years, the Arctic Council itself and the EPPR and ACAP working groups had no dedicated secretariat support. This changed in 2013 when the member states agreed to establish a permanent Arctic Council secretariat that was mandated to provide administrative, organizational, communication, and outreach support to the Council chair. The Arctic Council secretariat also provides secretariat support to the EPPR and ACAP working groups. 
The chairs of the working groups report to the Senior Arctic Officials (SAOs). An SAO is the official designated by each Arctic state to serve as a focal point for all Arctic Council matters (Arctic Council, 1996, 1998a). Ministers and SAOs can assign work to a working group or set up a taskforce to "work on specific issues for a limited amount of time" (Arctic Council, 2015e). SAOs report biennially to the lead ministers of each member state. States most commonly designate officials from their ministries of foreign affairs to play the role of SAO and the state that holds the chairmanship of the Council also identifies a government official who serves as SAO chair for the duration of the chairmanship. As defined in the Arctic Council's founding declaration and its rules of procedure, permanent participants also identify a representative to serve as a focal point for their organizations and to attend SAO and ministerial meetings, but they are not officially referred to as SAOs.

With the exception of funds dedicated by Arctic Council member states to support the Arctic Council secretariat, the working group secretariats and the Indigenous Peoples Secretariat (IPS), the Arctic Council has no core funding. There is currently no set formula for the financial contributions of the member states. Furthermore, the annual costs of operating the Arctic Council have not been tracked, which was cause for concern for the Supreme Audit Institutions of Denmark, Norway, Russia, Sweden, and the United States (2015). In 2016, the SAOs tasked the Arctic Council Secretariat (ACS) with compiling an overview of the Arctic Council's funding sources; however, the initial report was descriptive and did not produce any funding estimates (Arctic Council Secretariat, 2016). The ACS does report annually to the SAOs on its budget and 
spending. In 2015 , the approved budget for the ACS was just under $\$ 1.4$ million (USD) (Arctic Council Secretariat, 2015). Further work to capture the full annual operating costs of the Arctic Council is still necessary.

Permanent participant organizations are funded directly by individual member states and, as a general rule, states only provide funding to permanent participant representatives that live in that state. For example, the United States only funds the travel and activities of permanent participant representatives that live in the United States and Canada only funds travel and activities for permanent participant representatives that live in Canada. There have been exceptions: Canada and the ICC Canada, in particular, have arranged to cover the costs of Indigenous representatives from Russia on a number of occasions (Personal communication, January 7, 2015).

Most Arctic Council activities depend on project-based funding and in-kind contributions. A majority of project-based funding comes from member states, while in-kind contributions have been received from a broad range of public and private organizations (Arctic Council Secretariat, 2016). Arctic Council projects and activities can be identified at the ministerial or SAO level. In addition, working groups can select their own priorities and secure their own project funding support from interested states, IGOs and NGOs; however, working group work plans do require approval by the SAOs and ministers. In addition, in 2013, the Arctic Council put in place a rule that all Arctic Council projects must be proposed through either a member state or permanent 
participant and a majority of the financing for a project must come from a member state unless decided otherwise by the SAOs (Arctic Council, 2013c).

The level of participation at Arctic Council meetings has increased over time. By way of comparison, the first Arctic Council ministerial meeting in Iqaluit, Canada in 1998 was hosted in a small church meeting room, while participation in the 2015 ministerial meeting in Iqaluit was accompanied by concerns that there was not a large enough venue for the meeting and not enough hotel rooms in the city to accommodate all the people interested in attending. The final list of delegates for the 2015 Iqaluit ministerial meeting included 114 people. Participation in SAO meetings has also increased. The participant list for the SAO meeting in Yellowknife, Canada in 2014 included 120 representatives. Finally, the level of participation in working group meetings has also increased; however, the attendance at meetings varies greatly depending on the working group, topics on the agenda and the location of the meeting.

This provides a general overview of the Arctic Council. While this information offers an important foundation, it offers limited insight to develop a deeper understanding of how the Arctic Council works. Before this dissertation begins to build on this introductory material to examine to what extent the Council has been effective, I review the existing scholarly literature that has shaped our understanding of the Council. I then examine the literature specifically focused on the governance of the Arctic Council. 


\section{Arctic Council Literature}

The public policy literature recognizes that how topics are framed both structures and contains how a given topic is analyzed and presented. Framing plays a critical role in shaping how problems are defined, what questions are posed and how solutions are characterized (Dodds, 2012; Dryzek, 2005; Gregg, 1974; Young, 2002a). The literature that has framed scholarly understanding of the Arctic Council can be analyzed in terms of three distinct but interrelated features: the theoretical constructs, scales of analysis, and units of analysis that have been adopted. This section briefly considers the themes and issues discussed in the existing literature organized around these features. I emphasize that the nature of the discourse serves to construct meaning and relationships, define legitimate knowledge and establish coherent stories (Dryzek, 2005).

The first feature of the literature that deserves attention is the theoretical constructs used to structure and inform research about the Arctic Council. Given the prominent place that the Arctic held as a theatre for Cold War and Post-Cold War politics, it is no surprise that geopolitics has dominated much of the analyses of the region and the Arctic Council. At its inception, participants and scholars recognized the Arctic Council as both a product of and a forum for efforts to thaw Cold War tensions (Huebert, 1999; Lamb, 2012; Young, 2013); while more recently, observers have speculated about the impact on the Council of tensions between the member states because of Russian activities in the Ukraine (Conley \& Melino, 2016; Young, 2016). In all commentary, the state emerges as the dominant actor. These studies of the geopolitics of the region and 
the Arctic Council sometimes consider the impact of state relations on other actors (e.g. Indigenous peoples, business, civil society); however, they are generally unapologetic that other actors are secondary in these analyses.

As a result of the history of the region, it is similarly unsurprising that International Relations theories that examine the actions and motives of states have also held a strong place in the literature about the Arctic and the Arctic Council. Focusing on the authority of the state has enabled a rich discussion about how this region of "peace and cooperation" is made possible because states have committed to comply with a system of international laws and policies that provides the certainty necessary for the cooperation and discussion that takes place at the Arctic Council (Ebinger \& Zambetakis, 2009; Jarashow, Runnels, \& Svenson, 2006; Koivurova, 2010).

Theories that identify the state as the central actor also focus attention regarding the management of the region on the effectiveness of bilateral and multilateral state relations and the advantages and disadvantages of states maintaining their regulatory authority versus transferring that authority to formal international regulatory regimes. For example, Ebinger and Zambetakis (2009) point to the legal and regulatory certainty required in the Arctic to attract further international investment and development; while Fenge (2012a) places primary importance on the legal mechanisms needed to ensure that development in the Arctic is undertaken in a responsible and sustainable manner. This framing presents state-to-state relations as the key factor to understand the institutional dynamics within the region. These authors largely attribute the importance 
of the state to their dominant role in international policymaking. Again these analyses recognize that the region includes other actors; however, because of the unique role of states, these authors are equally unapologetic about their heavy emphasis on Arctic and non-Arctic states. I propose that this state-centric framing limits our ability to observe important features of the political and social dynamics evolving in the circumpolar region.

More recently, scholarly understanding of the Arctic Council has benefitted from analyses that adopt a broader range of theoretical constructs. Historical accounts of the formation and evolution of the Arctic Council (English, 2013; Fenge, 2012b; Griffiths, 2011; Lamb, 2010), geographic accounts of how the Arctic is defined and the implications for the Arctic Council (Dodds, 2012; Griffiths, 2012b; Young, 2009b), analyses of how the Arctic Council has played a role in responding to specific environmental issues and, on the flipside, how environmental changes may affect the organizational culture of the Arctic Council (The Aspen Institute, 2011).

In a similar vein, the scales of analysis used in the scholarly literature to analyze the Arctic Council are commonly focused on the national, regional or international levels of analysis (Bloom, 1999; Huebert, 2009); however, the sub-national and local scales of analysis are capturing increasing attention (Koivurova \& Heinämäki, 2006; Shadian, 2010). There is also a growing scholarly literature that adopts multiple scales of analysis to understand the Arctic Council's work (Breum, 2012; Dodds, 2012; Nuelend, 2014; Young, 2009b). Those scholars recognize the analytical richness of exploring the 
interplay between these scales to understand the complex connections that exist between the Arctic Council and other institutions at all levels - for example, Stone's (2016) efforts to trace the influence of the Arctic Monitoring and Assessment Programme (AMAP) working group on the UN Stockholm Convention on Persistent Organic Pollutants or Watt-Cloutier's (2015) work to demonstrate a connection between the experiences of the people of the Arctic and global discussions about the impacts of climate change.

The third feature that defines the Arctic Council literature is the unit of analysis, which refers to "the subject (the who or what) of study" (Lewis-Beck, Bryman, \& Futing Liao, 2004). Examples of different units of analysis used in the context of the Arctic Council include: 1) the important role played by specific individuals in the creation or advancement of the Arctic Council, such as Mary Simon, Sheila Watt-Cloutier, Rosemarie Kuptana, Franklyn Griffith, Kalevi Sorsa or Kaj Barlund (English, 2013; Stone, 2016; Watt-Cloutier, 2015); 2) the contributions of specific organizations to the work of the Arctic Council, including the International Arctic Research Cooperation (IASC), Inuit Circumpolar Council (ICC) or the World Wide Fund for Nature (WWF) (Bravo \& Rees, 2006; Koivurova, 2010; Rogne, Rachold, Hacquebord, \& Corell, 2015; Young, 2009b) or 3) the involvement and activities of both Arctic states and non-Arctic states related to the Arctic Council (Exner-Pirot, 2011; Fenge, 2012a; Lackenbauer, 2014; Spence, 2013). Each of these units of analysis offers unique insights that inform our understanding of how the Arctic Council functions. 
This overview demonstrates that there is a growing body of literature that employs new ideas, perspectives and theoretical constructs. Collectively these different analytical approaches reveal complexity and nuance that contribute to the depth with which we understand the Arctic Council. This dissertation follows this trend by employing the concepts of institutional effectiveness, network governance, boundary work and institutional logics. These concepts facilitate an examination of factors and dynamics at different scales of analysis that inform our understanding of what has made the Arctic Council effective. My unit of analysis is institutions with the Arctic Council being a focal point; however, I consider the role of particular individuals, groups or states to support my analysis as needed. These concepts and how they are applied are examined in detail in the next chapter (Chapter 3).

\section{Arctic Council Governance}

Irrespective of the theoretical construct and scale or unit of analysis used in the literature, there is a general consensus among scholars that the Arctic Council has been a success. Furthermore, the success of the Council is presumed to play a critical role in explaining the prominent position that it is increasingly positioned to play in policymaking in the region. Despite differences of opinion about aspects of the Arctic Council's mandate or core functions, the actors that should be allowed to participate, or the role that the Arctic Council should assume in the future, scholars commonly argue that the Arctic Council benefits from a unique governance model and this is a source of pride for those who have dedicated their time to studying this region and the Council. Celebrated not only for its personification of the region's "mosaic of cooperation at the highest levels" (Brown, 2013, p. 88), Arctic governance experts recognize the Arctic 
Council as an innovative and successful model of regional governance (Collins, Virginia, Yalowitz, \& Sfraga, 2013; Sugarman, 2013).

While scholars have discussed the governance features of the Arctic Council in general terms, this has not directly translated into a research agenda dedicated to an in-depth empirical analysis the Council's governance model in its entirety. While the quantity of commentary and opinions about the Arctic Council has expanded recently, discussions about the Arctic Council's governance model are often touched on in passing as part of analyses focused on a particular issue (ex. short-lived organic pollutants) (Stone, 2016), type of actor (e.g. the capacity of permanent participant organizations) (Lackenbauer, Arthur-Lackenbauer, Exner-Pirot, \& Lajeunesse, 2014; Lackenbauer, Lajeunesse, Exner-Pirot, \& Arthur-Lackenbauer, 2014) or aspect of the Council's governance (the role of observers) (Chaturvedi, 2012).

In the following subsections, I begin by introducing the few authors who have provided commentary on the Arctic Council's governance model. I then examine the literature that has discussed specific governance features of the Council, including working groups and the role of science in policymaking, consensus-based decision making, the role of Arctic Indigenous peoples, and the role of observers. I explore what makes these features important and summarize key issues that have been raised.

\section{The Arctic Council governance model}

Oran Young is the scholar with the longest and most extensive experience analyzing the Arctic Council. In various articles and book chapters, he has examined everything 
from the Arctic Council's place in Arctic governance to the unique role of permanent participants; he has commented on the Council's place in the policymaking process and the role of observers; he has studied its past and its future (2012a; 2009a, 2009b, 2013, 2016). Furthermore, this dissertation benefits directly from a research project conducted by Kankaanpää and Young (2012b) that examines participants' perspectives on the effectiveness of the Arctic Council. His ideas and expertise are fundamental to this dissertation; however, as of yet, he has not taken on the task of conducting an empirical analysis of the Council's governance model in its entirety.

More recently, there have been additional publications that contribute to our understanding of the Arctic governance model. In Ice and Water: Politics, Peoples and the Arctic Council, John English (2013) has produced a detailed historical account of the creation and evolution of the Arctic Council. His book provides a rich report of the events and players that established the Arctic Council as an important policy forum. Sheila Watt-Cloutier (2015) shares important and compelling personal insights about how the Arctic Council worked in its early years in her memoir, The Right to be Cold. In particular, she demonstrates the important role that permanent participants have played in advancing issues on the Council's agenda.

Andrew Chater (2015) and Douglas Nord (2016) are the first authors to make the Arctic Council, as an institution, the focus of dedicated scholarly research. Chater systematically applies different international relations theories (functionalism, neorealism and neoliberalism) to test their ability to explain how the Arctic Council has 
evolved. He concludes that the international relations theory of neoliberalism best explains the evolution of the Council because the expanding role of the Council can be linked to states' absolute gains from the increasing economic potential of the Arctic. However, he argues neorealism best explains the outcomes of the process because states control what the Council has evolved into.

Nord (2016) takes a less theoretical approach and focuses more on documenting the Arctic Council's governance features in order to compare and contrast the Council with more traditional international organizations. He also examines in detail the more recent governance challenges that the Arctic Council has faced and proposes a path the Arctic Council should follow in the future. His ultimate message is that it is time for the Council to mature - to have the features of a traditional international organization, including a more reliable funding base, delegated authorities from its member states, enhanced powers for the chair, and a broader and more action-oriented agenda.

\section{Working groups and the role of science in policymaking}

Given the Arctic Council's focus on environmental management and sustainable development, scholars have studied the role that the Arctic Council has played in empowering scientists to contribute to policymaking. Furthermore, they have identified the quality and relevance of the scientific work produced by the Council as a driving force behind the rise in prominence of the Arctic and the Arctic Council in global environment and climate change discussions (Breum, 2012; Dodds, 2010; English, 2013; Jackson School of International Studies Arctic Task Force, 2013; Koivurova, 2010; Stokke, 2007). Some academics have subsequently argued that the Arctic 
Council should maintain the governance structures necessary to protect the scientific integrity of its work and the role and voices of scientists in the work of the Arctic Council to support evidence-based policymaking (Stone, 2016). This raises questions about the independence of the Arctic Council working groups, the nature of the relationship between scientists and policymakers in the Arctic Council, the process by which scientific assessments are translated into policy recommendations (Molenaar, 2012), and observations about the need for better coordination between the working groups (Kankaanpää \& Young, 2012a).

A related theme is the need to properly support the working groups as they conduct their work. Commentators often criticize the Council for the shoestring budgets they are afforded and the limitations of the project-based funding approach that the Council has adopted (Fenge, 2012a). Others emphasize the importance of mechanisms to support collaboration and inclusion of scientists and scientific data across state boundaries both within and outside the Arctic, so that Arctic policies can be informed by the best science available (Graczyk, 2012).

And finally, certain scholars focus on efforts by the Council to consider and include both western science and the traditional and local knowledge of the Indigenous peoples of the Arctic (Brown, 2013; Huebert, 2009; Kankaanpää, 2012; Sugarman, 2013). Reports prepared by the Sustainable Development Working Group (SDWG), Arctic Monitoring and Assessment Programme (AMAP) and Conservation of Arctic Flora and Fauna (CAFF), such as the Arctic Climate Impact Assessment and the Arctic Human 
Development Reports, have included traditional knowledge and Arctic Council declarations have consistently emphasized the importance of the meaningful participation of Arctic Indigenous peoples and the value of incorporating traditional knowledge in its work.

The inclusion of traditional knowledge is an area where the Arctic Council has received both credit and criticism for its efforts. Some experts point out that much of the work of the Arctic Council working groups are still dominated by western science; other experts emphasize that the Arctic Council has done more than other bodies to acknowledge the value of traditional knowledge and find ways to integrate this knowledge into its work (Dodds, 2012; Fenge, 2012b; The Aspen Institute, 2011). Not surprisingly, permanent participants have been constant champions of ensuring that traditional knowledge has a meaningful place in Arctic Council's work (Watt-Cloutier, 2015); however, their ability to advance this is made more challenging as the agenda of the Council expands, the capacity of Indigenous organizations are stretched, and permanent participants have to make hard choices about where to invest their time and resources (Fenge, 2012b). Many questions remain about the processes used to include traditional knowledge holders in preparing policy advice and how this knowledge is integrated with Western science in the activities and products of the Arctic Council.

\section{Consensus-based decision making}

The Arctic Council governance literature also provides various perspectives and insights regarding the Council's consensus-based decision-making approach used by member states together with the "active participation and full consultation" of permanent 
participants (Arctic Council, 1996). Experts have debated the pros and cons of this approach and its impact on what and how decisions are made (Brown, 2013; Koivurova, 2010; Molenaar, 2012). However, the agreement of member states to adopt a consensus-based decision-making approach allowed states to demonstrate their commitment to participate in a multilateral institution; while providing them with the confidence that they could avoid contentious political issues, like military security (Molenaar, 2012; Sugarman, 2013; Young, 2009b).

Scholars and Arctic Indigenous leaders also argue the consensus-based decisionmaking approach adopted by the Council empowers permanent participants. A consensus-based approach is seen to level the playing field between member states and permanent participants - offering Indigenous representatives a meaningful space to participate in decision formation and decision making (Molenaar, 2012). There are even those authors who assert that the consensus-based decision-making approach was inspired by Indigenous governance methods; therefore, it is a governance approach that Arctic Indigenous peoples are much more comfortable with than their state counterparts (English, 2013; Lynge, 1993).

\section{Role of Arctic Indigenous peoples}

The governance feature of the Arctic Council that has garnered the most attention is the inclusion of the region's Indigenous peoples as permanent participants in the Council (Brown, 2013). Beginning very early on in discussions to envision an Arctic Council, Canadian NGOs championing the creation of the Arctic Council recognized the importance of Indigenous rights and interests and their unique contributions to the 
governance of the region (T. S. Axworthy \& Dean, 2013; Brown, 2013; English, 2013; Griffiths, 2012a; Vigni, 2013). This culminated in a distinctive role for Indigenous groups in the Arctic Council and today Indigenous leaders and champions of the Arctic Council speak with great pride about the important role that permanent participants play and the fact that the Arctic Council is the only international body that provides such a strong voice for Indigenous peoples to influence policymaking (Brown, 2013). In particular, analysts point to the heightened status, visibility and awareness of Indigenous issues at regional and international levels through the Arctic Council (Brown, 2013; Koivurova, Molenaar, \& Vanderzwaag, 2009). A recent example is Canada's resistance to granting the European Union (E.U.) observer status in the Arctic Council because of the impact the E.U.'s ban on seal products has had on the region's Indigenous peoples. Furthermore, there are those who emphasize that the permanent participants lend the Arctic Council legitimacy, credibility and moral standing as an institution that it could not achieve in their absence (T. S. Axworthy \& Dean, 2013; Fenge, 2012b; Rhemann, 2012). The inclusion of Indigenous peoples in the Arctic Council is recognized as a notable precedent with implications for other institutions and regions - a unique and innovative governance feature with important impacts for both Indigenous peoples and the institutions in which they participate (Young, 2009b).

The Council is not without critics, however. Analysts have cautioned against an overly simplistic understanding of permanent participants' ability to meaningfully contribute to Arctic Council work and policies. There are authors who note that while permanent participants can hold a powerful position, they are also vulnerable because they depend 
heavily on the funding of member states to function and participate in Arctic Council meetings (Brown, 2013; Lackenbauer, Lajeunesse, \& Exner-Pirot, 2014). Furthermore, despite a recognition by Arctic Council participants that past, present and future support for permanent participants have fallen short of what these organizations need to effectively and meaningfully participate in Arctic Council business, permanent participants' resource and capacity issues have persisted and even grown (Collins et al., 2013; Lackenbauer, Lajeunesse, \& Exner-Pirot, 2014; WWF, 2013). As the Arctic Council's work becomes more prominent and it takes on more responsibilities, activities and projects, the limited capacity and resources of permanent participants are further stretched.

\section{Role of observers}

As a governance feature, the idea of assigning observer status to interested states is not unique for regional or international institutions. Furthermore, providing IGOs and NGOs with this status is less common, but not unique to the Arctic Council. This is something that many United Nations bodies were doing well before the Arctic Council was created. And yet discussions and debates about what role Arctic Council observers can or should play has consumed a large quantity of ink in recent years especially with respect to powerful actors, like China, India and the E.U.. Some authors express concern about the economic interests, influence and power of the states and organizations seeking observer status; others focus on the impact of an increased number of participants on how the Arctic Council functions (Fenge, 2012a; Lackenbauer, 2014). Overall, experts expressed unease that the participation of high 
profile observers could dilute the influence of permanent participants (L. Axworthy \& Simon, 2015; Brown, 2013).

\section{Critiques of Arctic Council governance}

The Arctic Council has been criticized for poor outreach and communication along with a lack of transparency in making records of discussions, activities and decisions publicly available (Breum, 2012; Lackenbauer, Lajeunesse, Exner-Pirot, et al., 2014; Spence, 2015). Somewhat in response to these criticisms, the Arctic Council established a secretariat with a mandate to improve the communications, outreach and archiving of Arctic Council documents in 2013. ${ }^{10}$

Some scholars have also raised questions about the Arctic Council funding model (Fenge, 2012b; Koivurova, 2010; Nord, 2016). Working groups are not supported equally with some groups having established secretariats with permanent staff (AMAP, CAFF) and others that have only recently acquired secretarial support with the creation of the Arctic Council Secretariat (ACS). The stability of these working groups is also affected by the Council's project-based funding model. Member states with other interested actors agree to support projects on a case-by-case basis - meaning the projects are funded because of the availability and interests of funders rather than as a result of the priorities set by a working group. The same is true at the SAO and ministerial levels where chairmanship priorities depend on commitment by one or more

\footnotetext{
${ }^{10}$ Prior to 2013 , secretariat functions were the responsibility of the member state that held the chairmanship. In 2006, Norway, Denmark and Sweden reached an agreement to share secretariat for the duration of their chairmanships (2006-2013). This joint secretariat was hosted by the Norwegian Polar Institute in Tromso, Norway. The permanent secretariat is now based in Tromso.
} 
member states to lead and fund the necessary activities. This helps to explain the complex, diverse and sometimes confusing mix of projects that the Arctic Council is working on at any given time. ${ }^{11}$

With only a few exceptions, the literature about the governance of the Arctic Council has been piecemeal. This section has reviewed the most prominent governance features of the Council and examined key issues related to these features as discussed in the literature. I have highlighted the attention given to establishing a role for science in policymaking, the value assigned to the Council's consensus-based decision-making approach, the importance placed on the inclusion of Indigenous representatives as permanent participants, and the evolving role of observer organizations. I have also touched on some of the criticisms that have emerged.

\section{Arctic Council: Found or Lost?}

The final aspect of the Arctic Council literature that deserves attention is an emerging discourse about the role of the Arctic Council in a changing governance environment. Over the last 10 years, the environmental and political circumstances in the region have dramatically changed. As a result, some scholars argue that the region and the Arctic Council now rest at a critical juncture. Nord (2016), Conley (2016) and Fenge (2012b) see a need for the Council's governance model to change to ensure its effectiveness and relevance in the region and in the broader international arena. These authors

${ }^{11}$ During the Canadian chairmanship, the Council created a project-tracking tool to better monitor progress on its programs and activities. This tool prompted discussions at the SAO level about the number of ongoing projects and the alignment of some of the projects with the stated priorities of the Council. 
recognize that the existing governance model of the Arctic Council has contributed to its success; however, they argue that the Arctic Council must better align its governance model with the changing governance environment and needs of the region. In fact, Nord (2016) proposes that, as a result of its success, the Arctic Council has the opportunity to expand its reach and influence.

For these authors, the present conjuncture brings an important opportunity for the Arctic Council to evolve from a policy shaping to a policymaking body. They point out that despite the prominent place that the Arctic Council has assumed, when you scratch the surface, it is a "talk shop" focused primarily on environmental issues during a time when the region needs an institution with the authority to make decisions on a broad range of circumpolar issues, including economic development, transportation safety and emergency preparedness and response. They argue that the Council's current governance model has left it with limited ability to translate the reports and assessments it has prepared into policy action. These authors point to the signing of the Oil Spill Emergency Preparedness and Response Agreement and the Arctic Search and Rescue Agreement by Arctic Council member states as evidence that the Arctic Council can make the transition to a policymaking body. They believe that the region would benefit most if the Arctic Council were granted the authority that would enable it to evolve from a soft-law discussion forum into a international regime or treaty-based organization (Conley \& Melino, 2016; Exner-Pirot, 2011; Fenge, 2012b; Nord, 2016). Some experts point to the legal and regulatory certainty required in the Arctic to attract further international investment and development (Ebinger \& Zambetakis, 2009); while others 
place primary importance on the legal mechanisms needed to ensure that development in the Arctic is undertaken in a responsible and sustainable manner (Fenge, 2012b; Koivurova, 2010). Overall they imply that the Arctic Council's future success depends on its ability to acquire and leverage formalized, hard-law status and authority and they suggest that the Arctic will be best served by the Council continuing its evolution from a policy shaping to a policymaking body.

In contrast, other experts are skeptical that the Arctic states have the political will or even interest to empower the Council with the necessary treaty-making and enforcement authority required to become a policymaking body (Pedersen, 2012; Spence, 2013; Young, 2013, 2016). Littoral Arctic states (Canada, Denmark, Norway, Russia, United States) have consistently taken the position that no new international regimes are necessary to manage the region (Ilulissat Declaration, 2008; Koivurova et al., 2009; Pedersen, 2012). They point to prominent international regimes, such as the United Nations Convention on the Law of the Sea (UNCLOS) and the International Code for Ship Operating in Polar Waters (Polar Code), which co-exist in the region and hold the authority that the Council lacks. These analysts point out that Arctic states are focusing on efforts, under UNCLOS, to confirm their extended exclusive economic zones, which is intimately linked to securing international recognition of their sovereignty. As a growing number of states and non-state actors turn their attention to the Arctic, these scholars argue that states believe they are best served by focusing their energy on confirming their authority to manage the region before entertaining any formal multilateral arrangements. They are keen to extinguish any confusion or doubt 
that the Arctic could be managed using a similar model to Antarctica, which is done through an international treaty. In reality, based on UNCLOS rules, there is extremely limited international space to be managed. As Figure 2.2 illustrates, the current claims of the Arctic littoral states leaves only small unclaimed areas that would be managed as international waters.

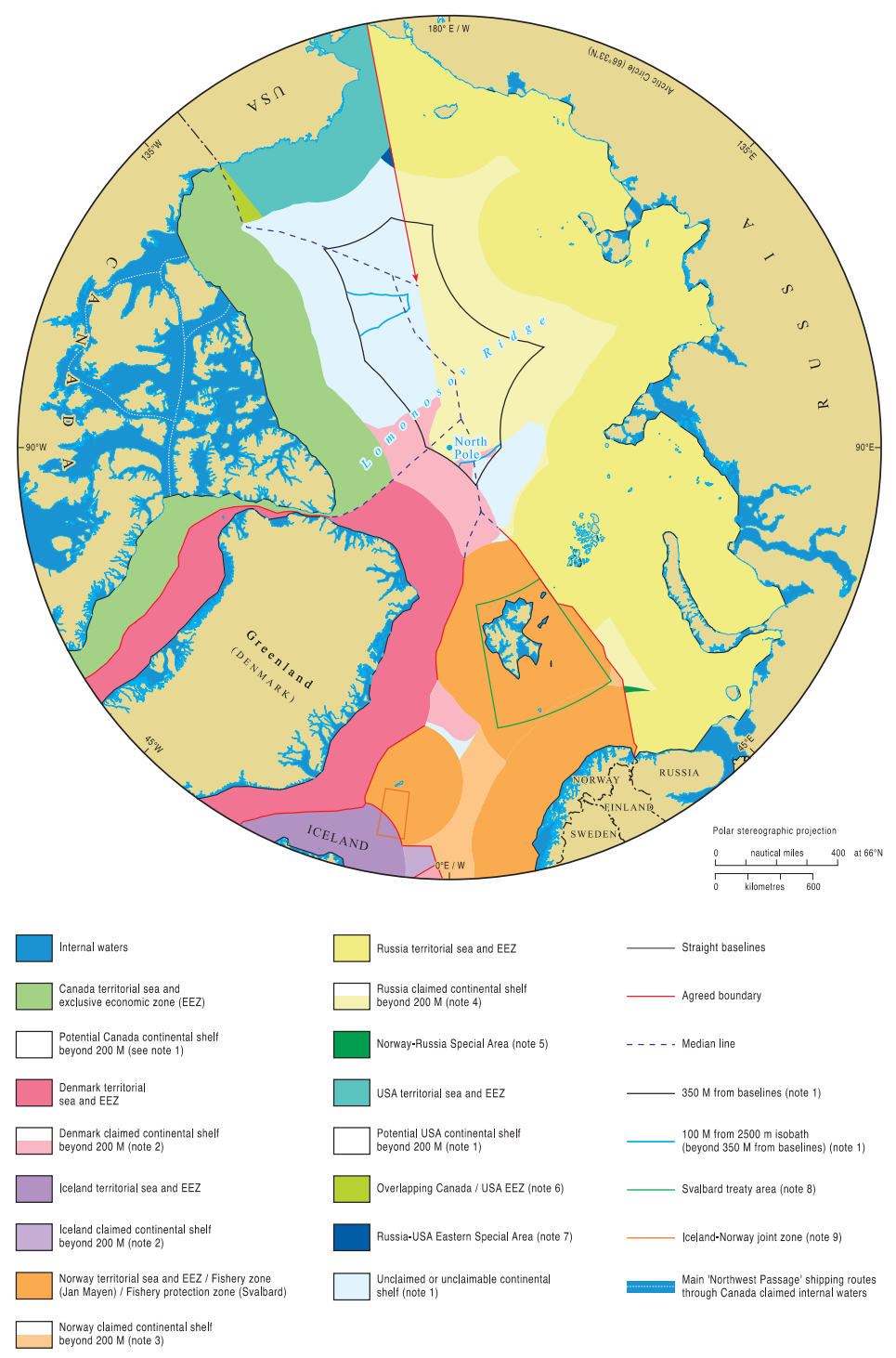

Figure 2.2: Boundaries of the Arctic (IBRU Durham University, 2015) 
Overall, although participants and commentators have perceived the Arctic Council as an effective and successful international institution, it has reached a point of uncertainty. The Arctic Council rests at a cross roads and there are diverging visions of what it should do and where it should go. In fact, based on the commentary of some scholars, we are left with the impression that the Arctic Council could fail because of its governence model. As a result, I propose that, now more than ever, empirical work to study how the Arctic Council works and to what extent it has been effective is needed to inform the future of the Arctic Council.

\section{Conclusion}

This chapter provided the background necessary to begin an in-depth study of the Council. I presented a general overview of the governance features of the Arctic Council. This chapter considered the dominance of geopolitical and state-centric International Relations analyses and pointed to a newly arising diversity of theoretical frameworks that enhance our understanding of the Arctic Council. I then examined the literature dedicated to the governance of the Arctic Council, including its governance model as a whole, the role of the working groups and contributions of science, the value placed on the consensus-based decision-making approach, the unique role assigned to permanent participants, and the growing discussions about the role of observers. This chapter argued that, while different governance features of the Arctic Council have received attention, there is no empirical work that has analyzed the Council's governance model in its entirety. Finally, this chapter introduced more recent discussions about the changing governance environment of the region and the subsequent debates about what role the Arctic Council should play in the future. The 
following chapter builds on this base to introduce the analytical framework, concepts and methodology that inform and structure this study. 


\section{Chapter 3: Institutional Effectiveness and the Arctic Council}

The academic discourse about the Arctic region and the Arctic Council has been strongly influenced by experts who are focused on the geopolitics of the region and by state-centric International Relations theories; however, there is a growing body of literature that draws on a wider range of theories and concepts. This dissertation contributes to this broadening of the discourse, by employing the concept of institutional effectiveness as a foundation to organize my analysis. This chapter begins by providing an overview of the institutional effectiveness literature and then introduces four determinants of institutional effectiveness to examine to what extent the Arctic Council has been effective. These determinants include: the governance environment, nature of the problems to be solved, institutional design and institutional logics. I introduce the concepts of network governance and boundary work to complement and support my analysis. Figure 3.1 illustrates the relationships between the different concepts that are introduced.

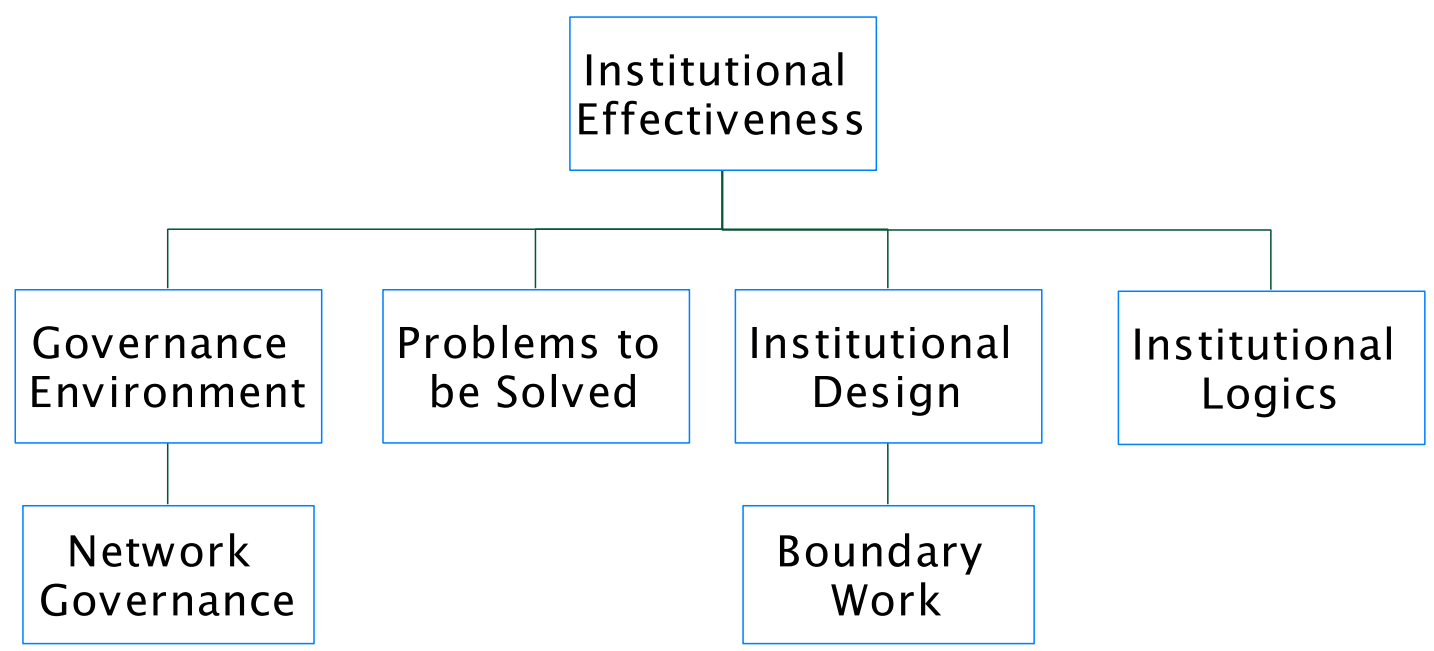

Figure 3.1: Concepts employed to analyze the Arctic Council 
This analytical frame provides a structure for a detailed and systematic assessment of the Arctic Council and its governance model - both in terms of how the governance model has contributed to the Arctic Council's effectiveness over time and what role it can play in supporting the Council's future direction(s). This chapter also provides an overview of the data analysis methods that are used and explains how this analysis is presented in the subsequent four chapters.

\section{Institutional Effectiveness: A Framework to Analyze the Arctic Council}

The literature focused on the effectiveness of international institutions is not extensive or cohesive. Like the literature dedicated to institutions, there is no consensus on how institutional effectiveness should be defined. The concept originates from a literature specifically focused on international environmental institutions; therefore, it focuses on institutions tasked with governing issues that are complex, transboundary and often global in nature - for example, the management of fisheries in the Barents Sea (Stokke, Anderson, \& Mirovitskays, 1999), the work of the International Whaling Commission (Andresen, 2002), and the Montreal Protocol and stratospheric ozone depletion (Wettestad, 2002). Furthermore, perhaps because this concept has a close relationship to the environmental governance literature, there is a strong emphasis on research and analyses that are relevant and useful to practitioners and findings that inform efforts to design and strengthen international institutions. A primary driver of much of this literature is to move beyond a general discussion about whether institutions matter to the more practitioner-relevant discussion about how to design international institutions to support policymaking (Wendt, 2001; Young, 2011). 
The critical question underlying any definition of effectiveness is: effective at what? When looking at environmental institutions, there are those scholars that define effectiveness by the institution's contribution to solving or mitigating the environmental problem to be addressed (Stokke, 2007; Underdal, 2002a). Alternatively, there are those authors who feel that it is difficult to draw a causal link between an institution's actions and its contribution to resolving a problem and they, therefore, focus on defining effectiveness based on specific outputs (e.g. a regulation) or outcomes (e.g. change in a behavior) (Bernauer, 1995; Young, 2011).

Alternatively, Keohane et al (2001) introduce the issue differently by focusing on the sources of effectiveness of international institutions that lack the enforcement power of states. Using this approach, they propose that effectiveness be defined by concentrating on where the institution is positioned to contribute in relation to the different stages in policymaking and implementation processes. By using this understanding of effectiveness, Levy et al conclude that the definition of effectiveness is best framed around the functions that these institutions are positioned to play or their "paths of effectiveness" (2001, p. 406). Based on their research, Levy et al propose that these functions include boosting concern, building capacity and facilitating agreement.

To further complicate matters, some scholars have moved the definition of effectiveness beyond its pure problem solving capacity or policy function to consider an array of "good governance" features such as efficiency, fairness and transparency (Coleman \& Porter, 
2000; Woods, 1999; Young, 2011). Defining effectiveness of an institution based on these features introduces multiple process-oriented criteria of effectiveness. Finally, certain authors emphasize that the effectiveness of an institution may vary over space, time and issue area for both endogenous and exogenous reasons (Mitchell, 2008; Ostrom, 1990).

As a starting point for this study, I draw from Underdal, who argues that an institution is "considered effective to the extent that it successfully performs a certain (set of) function(s) or solves the problem(s) that motivated its establishment" (2002b, p. 4). However, I revise this definition slightly and propose that an institution is considered effective to the extent that it successfully performs a certain (set of) function(s) or solves the problem(s) that motivate actors to invest time and energy toward sustaining the institution. This refined definition provides a useful starting point for a study of the Arctic Council because it acknowledges the central position of the institution and emphasizes the importance of performing assigned functions or solving specific problems; however, it also draws attention to what motivates actors to participate, which can involve a broad spectrum of factors that are both endogenous and exogenous to the institution and change over time. As a result, it expands our view of the types of factors that explain an institution's effectiveness and provides a foundation for a nuanced and fertile analytical framework.

Closely linked to how institutional effectiveness is defined, is the issue of how institutional effectiveness is measured. Looking at the different approaches to defining 
effectiveness referenced above, it is easy to see how the measures for each are different. For example, if you are focused on the role of an institution in contributing to the clean up of nuclear waste within a specific geographical region, you would expect to see output measures related to the number of agreements signed or outcome measures like the number of sites cleaned under the agreement. However, the literature is silent on how to assess less results-oriented measures of institutional effectiveness - for example, the Arctic Council has gained legitimacy with various states, Indigenous groups, NGOs, IGOs inside and outside the region because of the inclusion of Arctic Indigenous peoples as permanent participants. Clearly, it is harder to establish a causal link between the inclusion of permanent participants and the legitimacy of the Arctic Council; however, this by no means diminishes the importance of considering the impact of the Council's legitimacy on its perceived effectiveness.

The following section introduces the determinants of institutional effectiveness that serve as pillars of the analytical framework that I have developed to examine how the Arctic Council works and to what extent the Council has been effective. I present further elements of the institutional effectiveness literature as I explain each determinant.

\section{Determinants of Institutional Effectiveness}

For this study, I define a determinant of institutional effectiveness as a category of factors that explain the Council's effectiveness. The analysis begins with three categories of factors that are discussed in the institutional effectiveness literature:

- The international governance environment that the institution must operate in; 
- The nature of the problem(s) an institution is tasked with managing or solving; and

- The design of the institution.

These determinants are used to organize and present the data in Chapters 4,5 and 6 to support an assessment of the effectiveness of the Arctic Council over time. The subsection dedicated to the governance environment also introduces the concept of network governance, which provides the conceptual tools to analyze the complex network of institutions that support environmental management and sustainable development in the circumpolar region. Similarly, the concept of boundary work is presented in the subsection that examines institutional design to explain how the Arctic Council has worked and better understand its governance model.

In addition, I identify institutional logics as a fourth category that has not been discussed in the institutional effectiveness literature. Through an analysis of interview and survey data, I argue the institutional logics within the Arctic Council provide a distinct determinant. This determinant exposes meta-level factors that have had an impact on the Council's institutional effectiveness; therefore, it complements the first three determinants, but benefits from separate treatment. An analysis of this determinant is the focus of Chapter 7.

An assessment of the Arctic Council using these determinants of institutional effectiveness is not intended to capture every nuance of how the Arctic Council works or what has made it effective; rather, I propose that these categories, individually and collectively, enable an analysis that follows a tradition of the environmental governance 
literature - it operationalizes the concept of institutional effectiveness in a manner that is relevant to practitioners, advances understanding, and provides useful guidance to those who will determine the role of the Arctic Council in the future. The following subsections elaborate on the characteristics of each determinant.

\section{Governance environment}

I begin my analysis of the Arctic Council by examining the governance environment as a determinant of institutional effectiveness. No institution exists in a vacuum. Institutions must function within a complex mix of actors, issues and events. Furthermore, an analysis of the Council's effectiveness must be sensitive to the unique features of the wider international governance environment and ever evolving contextual factors (Bernauer, 1995; Keohane et al., 2001; Ostrom, 1990; Young, 2011). This determinant includes primarily exogenous factors - in other words, people interested in maintaining or improving the effectiveness of the Arctic Council are not expected to have the ability to control the factors identified in this category. Although later in this dissertation I will argue that the governance environment can provide windows of opportunity, "unique and temporary conjunction of events" that provide actors with the possibility to influence policy or take action (Howlett \& Fraser, 2007, p. 543). I identify these people as policy entrepreneurs, who recognize these opportunities and mobilize to take advantage of them (Pal, 2014).

While the institutional effectiveness literature identifies the importance of the governance environment for the effectiveness of an international institution, it does not offer guidance on how to analyze the impact of the governance environment on an 
institution's effectiveness. For this purpose I draw on the network governance literature. The concept of networks has emerged as a popular metaphor in the social sciences (Klijn, 1996; Klijn \& Koppenjan, 2000) to explain the connections between a complex, multi-dimensional mix of actors (individuals, organizations, states, etc.). In the context of international relations, this concept has been applied in many ways; however, for the purposes of this dissertation I examine the collection of multilateral institutions that are involved in Arctic environmental management and sustainable development and consider how policymaking can be understood and managed in a networked environment (Hajer \& Wagenaar, 2003).

Kahler (2009) differentiates between adopting "networks-as-actors" and "networks-asstructures." The literature on networks-as-actors is primarily interested in the network itself as a governance mechanism for collective action that stands in contrast to the traditional, hierarchical governance mechanisms of states (Kahler, 2009; Sorensen \& Torfing, 2005). By contrast, the literature on networks-as-structures studies the relationships among actors in the network and analyzes the features and dynamics within the network itself. It informs our understanding of the relationships between actors and how flows of information and influence take place across multiple scales (Jones, Hesterly, \& Borgatti, 1997). Both streams of the network governance literature have produced interesting insights into the international governance environment and offer interesting concepts to inform our understanding of the Arctic; however, for the purposes of this study, I am interested in the explanatory power of networks-asstructures. 
This stream of the network governance literature provides a way to understand the Arctic Council as a focal point in a complex network of institutions and actors that support (or not) environmental management and sustainable development in the Arctic region. The concept of the network allows us to see the relationships that exist among people and institutions that collectively shape how public policy is developed and implemented. This concept is not constrained by traditional ideas regarding units and scales of analysis; helps to breakdown artificial analytical boundaries between institutions working at the international, circumpolar and sub-regional levels. Furthermore, it offers the advantage of creating a means to recognize and analyze the roles of a rich collection of non-state actors in the policymaking process. It is through the lens of network governance that we can visualize a dynamic and evolving Arctic governance environment and understand the Arctic Council's position in this broader network of institutions. Finally, network governance provides us with direction about specific factors that explain institutional effectiveness. It provides an approach to analyze the position the Arctic Council holds in a network of multilateral institutions in the circumpolar region and consider the relationships that exist among these institutions. The analysis in Chapters 4, 5 and 6 considers how the position of the Arctic Council in this network of institutions is a factor that explains its effectiveness.

\section{Problems to be solved}

In the early literature on institutional effectiveness, heavy emphasis was placed on the nature of the problem that an institution is designed to solve (or contribute to solving) and, by extension, an institution's effectiveness was linked to its ability to solve or 
manage that problem (Underdal, 2002a). Given the focus on environmental institutions in the literature, this means solving or managing complex issues that are transnational, international and even global in scale (Young, 2011). The general idea is that certain issues are more amenable to solution, while others have features that make them more intractable and, therefore, less responsive to efforts to be solved. For example, Underdal provides compelling evidence that problem malignancy (malignant problems are those that are difficult to solve) can be expected to have an impact on the effectiveness of an institution. He also argues that while institutions may still demonstrate effectiveness when tasked with responding to malignant problems, malignancy combined with uncertainty about the seriousness and causes of a problem can be lethal (2002a, p. 469).

Interestingly, other analyses have demonstrated that the relationship between the nature of the problem and the effectiveness of an institution is not consistently predictable. Some institutions tasked with responding to "easy" environmental problems may make very little progress, while other institutions tasked with responding to highly complex problems may make unanticipated progress (Young, 2011). To further complicate matters, this unpredictability can be caused any number of endogenous (e.g. institutional design) or exogenous (e.g. rising public concern about a hole in the ozone layer) factors.

As a result, I consider both exogenous and endogenous factors in this category. The characteristics of a problem may be exogenous to the institution; however, a choice is 
made to place a problem on the agenda of an institution and the act of identifying (or not) a problem is a conscious choice that has an impact on the effectiveness of an institution (Pal, 2014). Furthermore, problems must be defined and framed and the act of articulating what the problem is has the potential to directly affect how the issue is understood, the solutions available and the institution's effectiveness at responding to the problem identified (Kingdon, 2011).

Environmental issues have been and continue to be an important focus of the work of the Arctic Council; however, since its inception, sustainable development has also been an explicit part of its mandate. Therefore, the Council has incorporated environmental considerations, but also integrates social and economic issues that can have very different characteristics. In addition, the Arctic Council was established as a forum to facilitate peace and cooperation in the region. When considering the relationship between the nature of the problem to be solved and the effectiveness of an international institution, the experience of the Arctic Council illustrates that an institution is often tasked with responding to multiple issues with different characteristics.

\section{Institutional design}

The category of institutional design brings us to a systematic analysis of the Arctic Council governance model. To what extent can we attribute the effectiveness of the Council to its governance model? Research related to factors identified under this determinant has varied. Some authors focus on the elements of design that contribute to an institution's effectiveness. This has been treated as a relative (e.g. consensusbased decision making produces better policy than majority voting) (T. S. Axworthy \& 
Dean, 2013; Griffiths, 2012a) or absolute (e.g. consensus-based decision making produces good policy) assessment of a particular design feature (Saunders, 1991).

I propose that a core factor in an explanation of the institutional effectiveness of the Arctic Council is that its institutional design is aligned with the role it has been assigned in the policy process. Consistent with Levy et al (2001), the Arctic Council's effectiveness is directly linked to the functions it is assigned (e.g. boosting concern, building capacity, facilitating agreement, etc.). This approach is also supported by Young's idea of institutional fit. He states: "the effectiveness of environmental and resource regimes.... is determined in considerable measure by the degree to which they are compatible with the biogeophysical systems with which they interact" (2002b, p. 55). His discussion of institutional fit is focused on environmental institutions specifically; however, I believe that the basic premise is appropriate for a broader range of policy issues to emphasize that there is a dynamic relationship between the determinants of institutional effectiveness. As a result, I propose that an analysis of institutional design is of limited value in isolation of a consideration of other factors that explain institutional effectiveness. This highlights the importance of examining the interplay between these determinants and considering the alignment of Council's institutional design with the factors related to the governance environment and nature of the problems to be solved (Mitchell, 2006; Young, 2011).

Over the years, the Arctic Council has primarily been identified as a policy shaping institutions. In other words, it has influenced policy development by generating 
knowledge and providing policy advice. Recognizing this function in the policy process, the concept of boundary work supports an analysis of the Arctic Council's institutional design. Boundary work focuses on the governance mechanisms that enable the cocreation of knowledge among actors from different social worlds (Guston, 2001). This concept helps explain how the Council works while providing the means to more carefully assess the past and present effectiveness of the Council. The literature about boundary work concentrates on analyzing governance mechanisms within an institution that are designed to engage different social worlds to facilitate knowledge generation in support of policymaking - they are designed to internalize negotiation processes between different social worlds. This concept concentrates on the mechanisms and operating conditions that enable the flow of ideas, concepts, information and skills between social worlds (Cash et al., 2003; Fujimura, 1992; Guston, 2001). Inherent in the concept of boundary work is the idea that its processes and products have an impact on each side of a boundary.

The concept of a "boundary" was first introduced in the field of Science and Technology Studies (S\&TS) to refer to how scientists distinguish science from politics, religion and other systems of knowledge (Gieryn 1983). This literature proposes that scientists create and maintain boundaries with other knowledge holders to differentiate how knowledge is generated and to protect their objectivity, neutrality and cognitive authority (Gieryn 1995, 1999). For example, the social world of science is demarcated by the norms and values of the scientific method. It assumes that there is an objective reality and that generalizable knowledge is created through repeatable, systematic observation 
and experimentation. In this social world the scientist seeks to be objective and neutral and this ideal is protected through highly structured methods of inquiry and processes of observation (Gieryn, 1983; Jasanoff, 1990). This is contrasted with the social world of policymakers, which is shaped by multiple layers of laws, regulations and policies that define systems and structures of governance. It is portrayed as a world of competing actors, interests and issues. In this social world, policymakers must make decisions and take action with a recognition of shifting priorities, power dynamics and finite resources (Cash \& Moser, 2000).

This concept was extended within the S\&TS literature with the introduction of the concept of "boundary work" to analyze the interactions between the communities of science and politics that was recognized to be a reality of modern science and policymaking (Gieryn, 1983; Guston, 1999; Miller, 2001; Star \& Griesemer, 1989). The literature grew up as a challenge to efforts to maintain a clean separation between different social worlds. It acknowledges the importance of institutions that enable and even foster an interface between science and politics. This literature is unconvinced that a mixing of interests should be characterized as an intrusion of politics into science or "scientization of politics" (Guston, 2001, p. 405). Furthermore, more recently, the boundary work concept has been used to acknowledge and consider institutions that facilitate the integration of scientific and political social worlds with other forms of knowledge — such as Indigenous social worlds (Cash et al., 2002; Robinson \& Wallington, 2012). 
The social world of Indigenous people stands in contrast to Western science in both method and underlying assumptions. The defining features of this social world are that knowledge is site-specific and created through generations of experiential learning passed down through families and communities through stories and on-the-land teaching. The Indigenous worldview does not isolate specific issues or policy areas. Everything is interconnected; therefore, problems and solutions must be considered in a holistic manner (Berkes, 2009; Cash et al., 2006; Robinson \& Wallington, 2012). Given the importance placed on the role of Indigenous organizations in the Arctic Council, the integration of the social world of Indigenous people further enhances the potential value of this concept to inform our understanding of how the Arctic Council works. The boundary work literature provides an important foundation for an analysis of the Arctic Council because it recognizes that multiple social worlds exist to be reconciled and that the co-creation of knowledge and the solutions to the Arctic's many complex issues requires the ideas, buy in and efforts of many diverse actors (Cash et al., 2002, 2006; Mollinga, 2010).

Analyzing the means by which knowledge is co-produced across boundaries also focuses attention on the unique and potentially important functions of generating knowledge and policy advice within the policymaking process (Cash et al., 2006; Guston, 1999, 2001; Jasanoff, 1990; Lemos \& Morehouse, 2005) - a function that is often overlooked and under appreciated by policymakers and understudied in the International Relations literature. Studying this function acknowledges the importance of institutions positioned to inform and shape policy decisions rather than limiting our 
attention to institutions that can demonstrate a more direct causal connection to policy decisions (Cash et al., 2002, 2003). It provides a lens to examine how an institution can be designed to produce knowledge and policy advice that is credible, salient and legitimate for different types of actors.

Initially, research on boundary work was primarily focused on the translation of knowledge in a United States domestic environment (Guston, 1999; Star \& Griesemer, 1989). However, in the early 2000 s, the literature began to consider the unique form and function of boundary work in an international context. To date this research has been limited to studying institutions involved in environmental policy, in particular, the Intergovernmental Panel on Climate Change (IPCC), the Subsidiary Body for Scientific and Technological Advice (SBSTA) to the United Nations Framework Convention on Climate Change, and the United Nations Convention on Biodiversity (Cash, 2001; Hoppe, Wesselink, \& Cairns, 2013; Hulme \& Mahony, 2010; Koetz, Farrell, \& Bridgewater, 2012; Miller, 2001).

To support this analysis of the Arctic Council, I draw on the work of Guston (1999, 2001), who identifies three key features of boundary work. These include:

1. Involvement of actors from both sides of a boundary;

2. Provision of opportunities or incentives to work across social worlds; and

3. Maintenance of distinct lines of responsibility and accountability to their respective social worlds. 
These features provide important guideposts to assess the boundary work taking place within the Arctic Council and the governance features that support it. This concept is central to the analysis of the Arctic Council's institutional design that is presented in in Chapters 5 and 6 in particular.

The outputs from boundary work can take many forms - assessments, models, reviews, and policy recommendations. These different products are referred to as "boundary objects" because they are designed to be used, hold a purpose and maintain an identity in each social world (Cash et al., 2003; Guston, 2001; Star \& Griesemer, 1989). The level of impact that a boundary object has on either side of the boundary will vary. In some cases, boundary objects may be treated as one small contribution in a mountain of information that informs research or policymaking; however, at the other end of the continuum, these products may have the ability to alter practices on one or both sides of a boundary - introducing the idea that boundary work may alter not only knowledge, but the actions of participants.

Consequently, to remain effective, institutions engaged in boundary work must be useful to actors on each side of a boundary. Furthermore, these institutions play a distinctive role that actors on one side of a boundary are unlikely to have the credibility or legitimacy to perform unilaterally (A. Scott, 2000). Therefore, when considering the institutional design of the Council, a focus on boundary work emphasizes the importance of mechanisms for translation across unique knowledge and value systems that must respect each way of knowing and maintain appropriate lines of accountability 
back to participants' communities. Institutions engaged in boundary work gain stability by being accountable and responsive to actors from different social worlds.

Adopting this concept to examine the institutional design of the Arctic Council provides unique and important insights about the governance features the Arctic Council, which created a forum for scientific and Indigenous social worlds to influence policymaking domestically, regionally and internationally.

\section{Institutional logics}

The final determinant of institutional effectiveness is institutional logics. Thorton and Ocasio define institutional logics as "socially constructed, historical patterns of cultural symbols and material practices, including assumptions, values and beliefs, by which individuals and organizations provide meaning to their daily activity, organize time and space, and reproduce their lives and experiences" (2008, p. 101). Institutional logics are frames of reference that condition actors' choices for sensemaking, the vocabulary they use to motivate action, and their sense of self and identity (Thornton, Ocasio, \& Lounsbury, 2012, p. 2). An examination of the Council's institutional logics provides a new approach to "probe the guts of organizations without neglecting wider processes and influences that shape intraorganizational behaviour" (Thornton et al., 2012, p. 134).

Furthermore, recognizing that institutional logics are a "key foundation for identities of organizations, groups and individuals" (Thornton et al., 2012, p. 129), we can see how these logics embed interests, values and assumptions about individuals and institutions (Thornton \& Ocasio, 2008). Introducing the concept of institutional logics as an 
unexplored determinant of institutional effectiveness complements the analysis presented in the other categories. This concept offers a useful lens to examine crosslevel effects because it creates space to balance and integrate the role of structure and agency (Thornton et al., 2012).

The literature on institutional logics leads us to understand that the logics within the Arctic Council are influenced by factors and forces at the individual, organizational and societal levels (Thornton et al., 2012). As Friedland and Alford explain, institutional logics are "symbolically grounded, organizationally structured, politically defended, and technically and materially constrained, and hence have specific historical limits" (1991, p. 249). These logics, in turn, shape institutional identities that constrain and enable the day-to-day practices of the Arctic Council. Furthermore, this literature acknowledges that an institution can have multiple institutional logics that can lead to "variegated organizational identities." In some situations these institutional logics can co-exist; however, these logics can also conflict, potentially reducing the effectiveness of an institution (Thornton et al., 2012, p. 180). As a result, it is useful to examine the institutional logics within the Council and consider the impact of these logics on the institutional effectiveness of the Council over time. This I will do in Chapter 7.

\section{Applying the Institutional Effectiveness Framework}

Like any international institution, the Arctic Council has evolved over time as the governing context changes, new ideas about governance emerge, and governance expectations and norms change (Buthe, 2002). It has followed a path that serves to shape its present and its future (Hall, 2010; Pierson \& Skocpol, 2002; Thelen, 1999). 
With this in mind, the analysis presented in Chapters 4,5 and 6 is organized into three time periods. These time segments are aligned with important milestones in the evolution of governance in the region and are appropriately spaced to capture changes in the governance environment. Chapter 4 is focused on the period prior to the official creation of the Arctic Council (1986-1995). 1986 is one year prior to President Mikhail Gorbachev's Murmansk speech (1987), which is credited with creating a window of opportunity for dialogue amongst various actors about the potential for a new collaborative governance environment in the Arctic. An analysis of this time period allows us to understand key factors and issues that led to the formation of the Arctic Council in its initial design. The second time period, presented in Chapter 5, is dedicated to the period between 1996 and 2005. 1996 marks the official launch of the Arctic Council with the signing of the Ottawa Declaration and 2005 is one year after the release of the Arctic Council's Impacts of a Warming Arctic: Arctic Climate Impact Assessment Report (2004b), which is credited with contributing to global awareness of the environmental changes being observed in the region. It is commonly accepted that this was a period when global interest in the Arctic and the Arctic Council was relatively limited. The final time period, 2006 to 2015 is analyzed in Chapter 6 . This is the period when the Arctic and the Arctic Council grew in prominence globally. 2015 marks the conclusion of the second Canadian chairmanship and the introduction of the U.S. chairmanship that would span from 2015 to 2017.

The data and analysis presented in Chapters 4,5 , and 6 follow a similar structure. Chapter 4, which studies the period prior to the creation of the Arctic Council introduces 
the determinants in a slightly different order; however, each chapter examines the governance environment in the Arctic, the nature of problems to be solved and the institutional design for the time period being studied. Chapter 7 incorporates all three time periods and is dedicated to examining how effectiveness has been defined and measured by Arctic Council participants over time to expose distinct institutional logics. The following subsections explain how the analysis is presented for each of these determinants.

\section{Mapping the governance environment}

Emphasizing that we cannot understand the Arctic Council governance model in isolation of its complex governance environment, the analyses presented in future chapters begins by mapping the multilateral institutions involved in Arctic environmental management and sustainable development at the sub-regional, circumpolar and international levels over the last 30 years. Drawing on the concept of network governance, this analysis is premised on the assumption that the governance environment in the Arctic is evolving and state authority, as the central building block, is not sufficient to establish an in-depth understanding of the dynamics that are shaping the region. Actors at all levels are now navigating an increasingly complex governance environment. Therefore, to establish a more complete picture, data was collected about multilateral institutions that play a role in environmental management and sustainable development in the region. I limited the collection of data to multilateral institution involved in environmental management and sustainable development in the Arctic to contain and focus the analysis and not overwhelm the network analysis with bilateral institutions or domestic institutions that have very different governance characteristics 
and tend to have more focused mandates and responsibilities.

Data was collected about multilateral institutions active in the region from 1986 to 2015 to trace the evolving characteristics of the governance environment. Basic data was gathered about each institution, including: date of founding, main actors involved and primary scale of activity (international, circumpolar or sub-regional). Appendix 2 provides a complete list of the institutions that are identified and includes details about data selection and coding decisions.

The data collected is presented in Chapters 4, 5 and 6 as a series of governance maps. ${ }^{12}$ These maps illustrate how the governance environment in the Arctic has changed over time measured by the number of multilateral institutions active in the region, the level at which institutions are functioning, and the types of actors involved. Figure 3.1 introduces how the governance maps are structured. First, the map identifies five types of actors that are active in Arctic governance: government, private sector, Indigenous organizations, NGOs, and research/academia. Using a Venn diagram, institutions are assigned to different zones on the map based on the types of actors that participate - some institutions engage single actor-types and others engage multiple actor-types. This serves to highlight the relationships that exist between different actors through institutions operating in the region. Finally, institutions that are

\footnotetext{
${ }^{12}$ The idea of mapping the actors in the Arctic governance environment was inspired by Abbot and Snidal's concept of a governance triangle (2009); however, I found it necessary to alter the approach for mapping Arctic institutions because of the importance of differentiating Indigenous actors, NGOs and research/academia in the Arctic governance context.
} 
mapped on to the Venn diagram are colour-coded to show the primary level at which the institution functions. Blue represents international institutions that are relevant to sustainable development and environmental governance in the region; however, the scope of their work is global (e.g. United Nations Framework Convention on Climate Change (UNFCCC)) or includes actors located in areas outside the Arctic (e.g. the Pacific NorthWest Economic Region (PNWER)). For the purposes of this analysis, those institutions with "Polar" rather than "Arctic" mandates (e.g. Scott Polar Research Institute (SPRI)) are also identified as international. Red represents institutions with a focus on the circumpolar region (e.g. Arctic Council (AC)) and green represents institutions focused on a sub-region of the Arctic (e.g. the Saami Council (SaC)).

The information about the Arctic governance environment, as presented through these governance maps, is used in Chapters 4,5 , and 6 to identify and analyze changes, trends and dynamics over time. The analysis also considers the relevance of this changing governance environment for the effectiveness of the Arctic Council. 


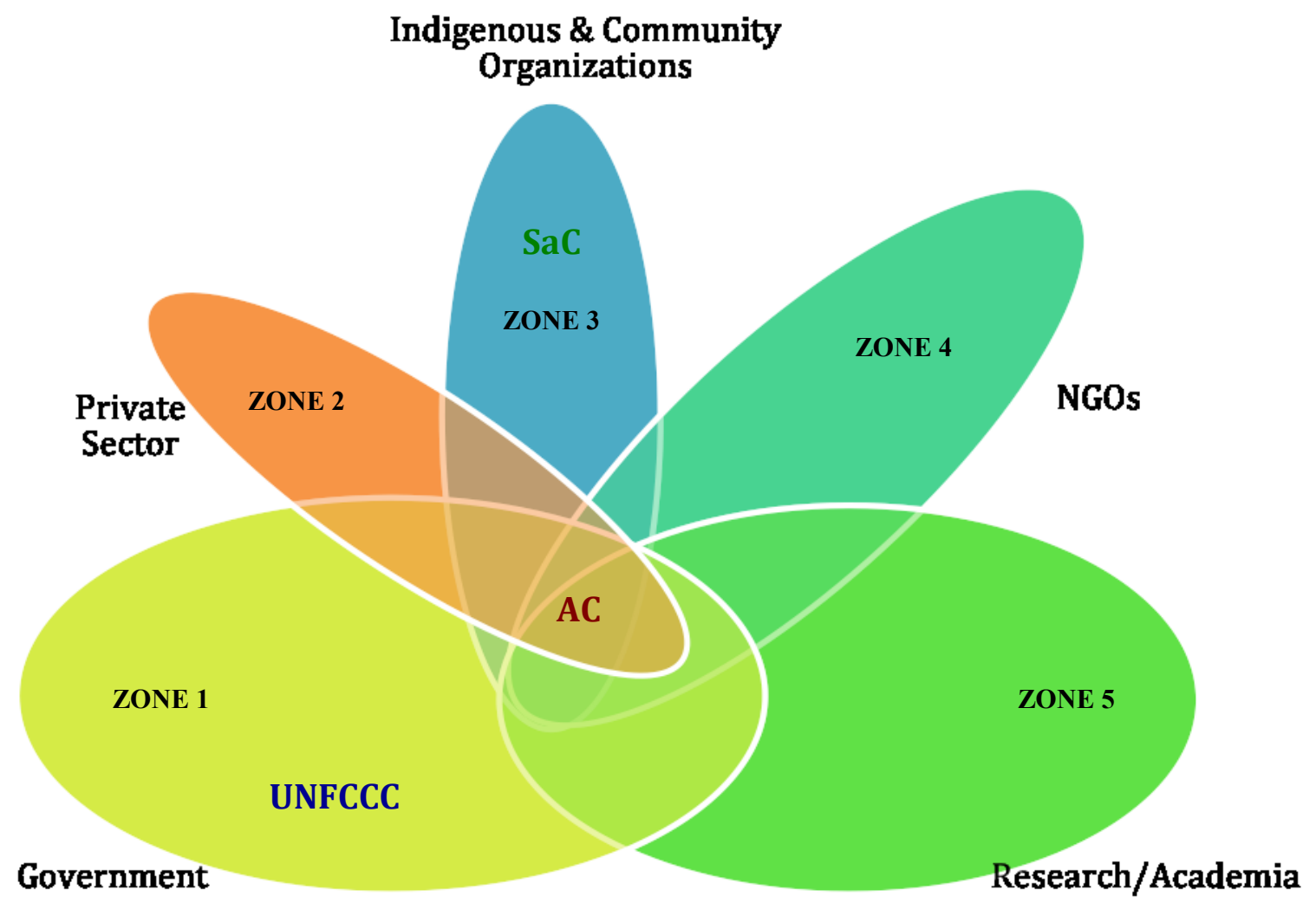

Figure 3.2: Arctic governance map - sample

This includes a mapping of the scale at which the institution functions (Blue International Institutions, Red - Circumpolar Institutions, Green - Sub-Regional Institutions) and the actor-types involved (Zone 1 - Government, Zone 2 - Private Sector, Zone 3 - Indigenous \& Community Organizations, Zone 4 - NGOs, Zone 5 Research/Academia, Zone 6 - Government \& Science/Academia, Zone 7 Research/Academia \& NGOs, Zone 8 - Government, Private Sector \& Research/Academia, Zone 9 - Government, Indigenous and Community Organizations, NGOs and Research/Academia, Zone 10: Open to All).

\section{Tracking the Arctic Council's agenda}

In 1996, the founding declaration of the Arctic Council mandated this "intergovernmental forum" with "promoting cooperation, coordination and interaction among the Arctic States, with the involvement of Arctic indigenous communities and other Arctic inhabitants on common Arctic issues, in particular issues of sustainable development and environmental protection in the Arctic" (Arctic Council, 1996). While this inaugural statement may seem sufficient to confirm the scope of the Arctic Council's mandate and 
the problems and issues that this institution was faced with managing, in fact an investigation of how this mandate has been interpreted over time reveals changes in the scope and scale of the issues on the Arctic Council's agenda.

To support this analysis, I conducted a content analysis of all Arctic Council declarations and key documents released in advance of the creation of the Arctic Council. Themes related to the Arctic Council mandate and priorities were coded using Nvivo, a qualitative and mixed methods research tool. The frequency of particular themes over time provided a launching point for an in-depth analysis and comparison of each theme and how these themes were characterized in each document. A complete list of the themes identified and their frequency is presented in Appendix 3. More details about methods and coding decisions are also provided in Appendix 3.

Specific results for each time period are presented in Chapters 4, 5, and 6 . The analysis in each chapter examines the issues that have consistently been present on the Arctic Council agenda and considers those priorities that have emerged over time. This analysis also examines how the problem structuring has evolved over time exposing both the introduction of new facts and an evolution of values. The analysis in each chapter also considers how the priorities identified for the Arctic Council over time fit with its institutional design.

\section{Analyzing the Arctic Council institutional design}

Institutional design is a broad determinant of effectiveness that encompasses a variety of factors and issues. The analyses presented under this category in Chapters 4, 5 and 
6 were established as a result of a thematic analysis of interview and survey data. The findings related to institutional design are organized into three distinct segments. Under the banner of the Council's raison d'être, I examine how the primary purpose of the Council is defined. This analysis goes beyond the stated mandate, objectives or priorities of the Council and focuses on the themes and issues that stand out as defining the Council. Next, I discuss the Council's organizational culture, the shared assumptions among Arctic Council participants that guide action by defining appropriate behavior in different situations (Ravasi \& Schultz, 2006), and draw out its defining characteristics. And finally, I consider the governance features of the Council - placing particular attention to those elements of the Council's governance model that have gained attention in the literature and that are credited with contributing to the Council's effectiveness.

As discussed in the previous section, the analysis presented in Chapters 5 and 6 also draws on the concept of boundary work to analyse the Arctic Council governance model. In particular, I propose that the Council's effectiveness is linked to the governance mechanisms that have enabled communication, translation and mediation across social worlds; therefore, I place specific attention on examining to what extent the institutional design the Council meets the needs of political, Indigenous and scientific actors over time.

\section{Exposing multiple institutional logics}

The analysis in Chapter 7 examines the institutional logics that have existed within the Arctic Council. This final determinant of institutional effectiveness facilitates a cross- 
level analysis that highlights the interplay between actors, institutions and their operating environment. It is particularly valuable because it enables an analysis that incorporates structure and agency. Furthermore, it provides space to acknowledge the cultural foundations of institutions and highlights the subjectivity with which institutional effectiveness can be defined and measured.

The analysis presented in Chapter 7 revisits the three time periods examined in Chapter 4, 5, and 6. It draws on primary source material (e.g. the AEPS, the Arctic Council Panel Report, Arctic Council Ministerial statements) and interview and survey data to study how participants define and measure the effectiveness of the Arctic Council and what this tells us about the distinct institutional logics that have existed within the Arctic Council over time. Drawing on the institutional logics literature, Chapter 7 demonstrates that the multiple institutional logics of the Arctic Council have affected the Council's identity, day-to-day practices and its institutional effectiveness.

\section{Conclusion}

This chapter introduced institutional effectiveness as the analytical framework that structures a study of how the Arctic Council works and to what extent it has been effective. It describes the features of the four determinants of institutional effectiveness that serve as the pillars of this analytical framework: the governance environment, the nature of the problems to be solved, the institutional design, and the institutional logics. This chapter also introduces network governance and boundary work as concepts that complement and support an analysis of the Arctic Council. This analytical framework is applied in Chapters 4, 5, 6 and 7 with particular attention to the factors that explain the 
Council's effectiveness and the criteria that can be used to assess the effectiveness of the Council. I also consider the relationship between different factors. 


\section{Chapter 4: The Arctic Council Creation Story (pre-1996)}

An in-depth analysis of the effectiveness of the Arctic Council cannot be achieved without considering the circumstances from which it was born. This chapter provides an analysis of the years leading up to the creation of the Arctic Council (pre-1996). The analysis in this chapter is structured around the first three determinants of institutional effectiveness introduced in Chapter 3. I begin by examining the governance environment in the region leading up to the creation of the Arctic Council, I move on to study the work that culminated in the Council's institutional design, and I conclude by exploring the nature of the problems to be solved that prompted various actors to initiate efforts to create an institution to support cooperation in the Arctic region.

The network of multilateral institutions that supported governance in the Arctic was small and disaggregated in the mid-1980s. Calls to establish the Arctic as a zone of peace and cooperation by U.S.S.R. President Gorbachev in 1987 created a window of opportunity that enabled policy entrepreneurs in Norway, Finland and Canada to initiate multiple initiatives in the Arctic to facilitate enhanced coordination and collaboration across state boundaries in various policy areas. The creation of the Arctic Council in 1996 was one product of these many efforts. The story told in this chapter is not new. There is a solid popular and scholarly literature that examines this period of Arctic history; however, this chapter focuses on how the events leading up to the creation of the Arctic Council inform our understanding of how the Arctic Council works and to what extent it has been effective. 


\section{Governance Environment}

The first determinant of institutional effectiveness that I examine is the governance environment. Beginning an analysis of this period with an examination of the governance environment emphasizes the importance of exogenous factors to explain how an institution works and its effectiveness. This is of particular importance in the period leading up to the creation of an institution.

The Arctic governance environment prior to 1996 bears little resemblance to the busy and interconnected network of multilateral institutions that support governance in the region today. Although certain changes to the region's governance environment have been incremental, the literature is consistent in recognizing that a speech delivered in Murmansk by U.S.S.R. President Mikael Gorbachev on October 1, 1987 created a window of opportunity that triggered efforts on several fronts to transform the Arctic from a stage for Cold War tensions to a zone of peace and cooperation (T. S. Axworthy \& Dean, 2013; English, 2013; Griffiths, 2012a; Nord, 2016). With this in mind, this section introduces two distinct periods that pre-date the creation of the Arctic Council: a period of fading Cold war tensions (pre-1987) and a period of emerging "peace and cooperation" (1987-1995). Both of these periods provide insights about how the Arctic Council was designed, the expectations that were initially place upon it and the important factors, even at this formative stage, that explain the Arctic Council's effectiveness. I demonstrate that the governance environment prior to the Council's creation was a determinant of its institutional effectiveness because the Council filled a gap in the existing network of multilateral institutions involved in Arctic environmental 
management and sustainable development. Furthermore, the establishment of an institution like the Arctic Council was relevant for multiple actors involved in Arctic cooperation and policy.

\section{Fading Cold War tensions}

The Arctic, as a region, has received substantial scholarly attention as a critical forum where Cold War tensions played out. Five of the twelve founding members of the North Atlantic Treaty Organization (NATO), established in 1949, were Arctic states (Canada, Denmark, Iceland, Norway and the United States) and this alliance culminated in intense military and security-related activities in the region in the 1950s and 60s. The U.S.S.R. responded by establishing the Warsaw Pact in 1955 and it conducted extensive military activity in its northern waters (Huebert, 2009; Slipchenko \& Hannigan, 2010; Stone, 2016). As a result of the Cold War, very little multilateral cooperation took place in the Arctic after 1945 (Slipchenko \& Hannigan, 2010; Stone, 2016). However, by the 1970 s and 80 s, East-West tensions were starting to ease and Arctic states began to engage in a growing number of non-security related discussions at bilateral and sub-regional levels (e.g. Agreement on the Conservation of Polar Bears (1973), the Norway-Russia Grey Zone Agreement for the Co-Management of Fisheries (1978), and the Canada-Russia Scientific and Technical Exchange Protocol (1984)). Cold War tensions eased further with Gorbachev's 1986 twin policies of Glasnost and Perestroika (Jackson School of International Studies Arctic Task Force, 2013; Slipchenko \& Hannigan, 2010; Stone, 2016). 
The second dominant issue for Arctic states that began to emerge as a priority in the 1970s was discovering and extracting new, abundant sources of hydrocarbons and minerals in the region. For Norway and Russia, these natural resources very quickly became central to their national economies because of their accessibility (Ryggvik, 2015). Non-renewable resource development also became a critical part of the Alaska economy during this period; although these resources were much less central to the United States' economy (Grant, 2010). Finally, Canada also turned its attention to its northern resources in the early 1970s; however, the cost and challenges associated with resource development in Canada's North meant that it was not an immediate contributor to the Canadian economy and the economies of Canada's Northern communities suffered from a boom and bust phenomenon (Abele, 1989). During this period, transboundary fish stocks were another important resource for the Arctic littoral states - in particular, Iceland, whose economy was heavily dependent on fishing and whaling (Directorate-General for Internal Policies of the Union, 2015; Stokke et al., 1999).

Closely related to Arctic states' growing interest in resource development in the region, the Arctic littoral states also became more active in their efforts to secure their sovereignty and resolve territorial claims in the region (Dosman, 1976a). The first manifestation of this was efforts to resolve bilateral territorial disputes in the region. Some of these territorial issues were resolved through bilateral negotiations - for example, in 1970, Norway and Russia began informal talks to resolve boundary issues in the Barents Sea (that were not resolved until 2010), in 1973, Canada and Denmark 
resolved boundary issues between Greenland and Ellesmere Island (with the exception of Hans Island) and, in the early 1980s, the United States and the Soviet Union began negotiations to resolve their respective claims in the Bering Strait (with an agreement being reached in 1990).

However, in the case of the Canadian Arctic archipelago, Canada was forced to take unilateral actions to assert its sovereignty after the United States made it clear that it would not recognize Canada's claim. In 1969, the U.S. Government notified Canada that their coast guard would support the S.S. Manhattan, a commercial tanker, to test the feasibility of transit through the Northwest Passage - challenging Canada's sovereignty over this area. Canada responded by providing a Canadian Coast Guard vessel to accompany the S.S. Manhattan through both U.S. and Canadian northern waters; therefore, temporarily sidestepping the challenge to Canadian sovereignty (Dosman, 1976b). Shortly after, the Canadian government enacted the Arctic Waters Pollution Prevention Act (1970), which identified a 100-nautical-mile offshore zone where Canada claimed authority to enforce antipollution regulations - this was seen by the Canadian government as an imperfect stop gap measure that by no means provided the certainty that its government was looking for (Byers, 2009; Grant, 2010). Finally, in 1985, the United States more explicitly challenged Canadian sovereignty by notifying Canada that a U.S. icebreaker would sail the Northwest Passage as "an exercise of navigational rights and freedoms." Canada sought to avoid the issue again by "permitting" the vessel to enter Canadian waters. Then, only a month after the voyage, Canadian Foreign Affairs Minister Joe Clark announced that Canada would use straight 
baselines to define the outer limit of Canada's internal waters ${ }^{13}$ and attributed Canada's legal claim over the area to its unique ice-covered nature and the Inuit's occupation and use of the area "from time immemorial" (Byers, 2009).

The second manifestation of Arctic littoral states' efforts to secure and even enhance their sovereignty claims in the region was their active participation in the negotiations to establish the United Nations Convention on the Law of the Sea III (UNCLOS III) that took place between 1973 and 1982. All of the Arctic states, with the exception of the United States, signed the Convention immediately after negotiations were finalized in December 1982. ${ }^{14}$ UNCLOS III defined specific technical methods for identifying a coastal state's baselines, continental shelf and boundaries. Based on the data collected by a coastal state, the UNCLOS III also set out rules and procedures for how a state could claim rights to internal waters and exclusive economic zones. Furthermore, the UNCLOS III provided Arctic states with a means to claim substantially larger areas of control and confirm sovereignty (Huebert, 2009).

Despite the attention placed by Arctic states on their northern territories during this period, their economies and natural resources were predominantly managed as domestic affairs and managed in isolation, with the exception of certain bilateral and

${ }^{13}$ Straight baselines, a line drawn between outer headlands or fringing islands, was a practice that had already been employed by other states, including Denmark, Iceland and Russia.

${ }^{14}$ The Arctic states took varying amounts of time to ratify the UNCLOS III: Iceland 1985, Finland 1996, Norway 1996, Sweden 1996, Russia 1997, Canada 2003 and Denmark 2004. The UNCLOS III came into force in 1994 when it had been ratified by 60 states. As of 2015, the United States was still not a party to the Convention. 
sub-regional arrangements to manage common pool resources such as transitory fish stocks (Ebinger \& Zambetakis, 2009). There was no express interest by Arctic states in multilateral cooperation at the circumpolar level. Furthermore, the Arctic, as a region held little or no interest for non-Arctic states during this period (English, 2013; Fenge, 2012b; Griffiths, 2012a; Lamb, 2010, 2012; Young, 2013). The popular conception of the Arctic outside of the region remained based on a relatively static image of a harsh, barren and frozen landscape, where the challenges that garnered attention included state security and sovereignty, treacherous marine transportation and managing some of the region's unique animal populations that attracted public affection, such as polar bears and seals (Ebinger \& Zambetakis, 2009; Jackson School of International Studies Arctic Task Force, 2013).

Data collected about multilateral institutions and presented in the 1986 governance map (Figure 4.1) is consistent with the scholarly narrative introduced about this period. The map confirms that there were a relatively limited number of multilateral institutions active in the region in 1986. International institutions (blue text) are the most prevalent. These institutions have mandates that are relevant to environmental management and sustainable development in the region; however, the scope of their work is global or includes regions outside the Arctic. For example, the family of United Nations organizations that manage Arctic-relevant conventions (e.g. the International Maritime Organization (IMO) with its responsibilities related to marine shipping), the Russian Academy of Science (RAS) that undertakes a broad spectrum of scientific work both 
within and beyond the Arctic, or the World Wide Fund for Nature (WWF) that may take on projects or issues in the region, but has a global mandate.

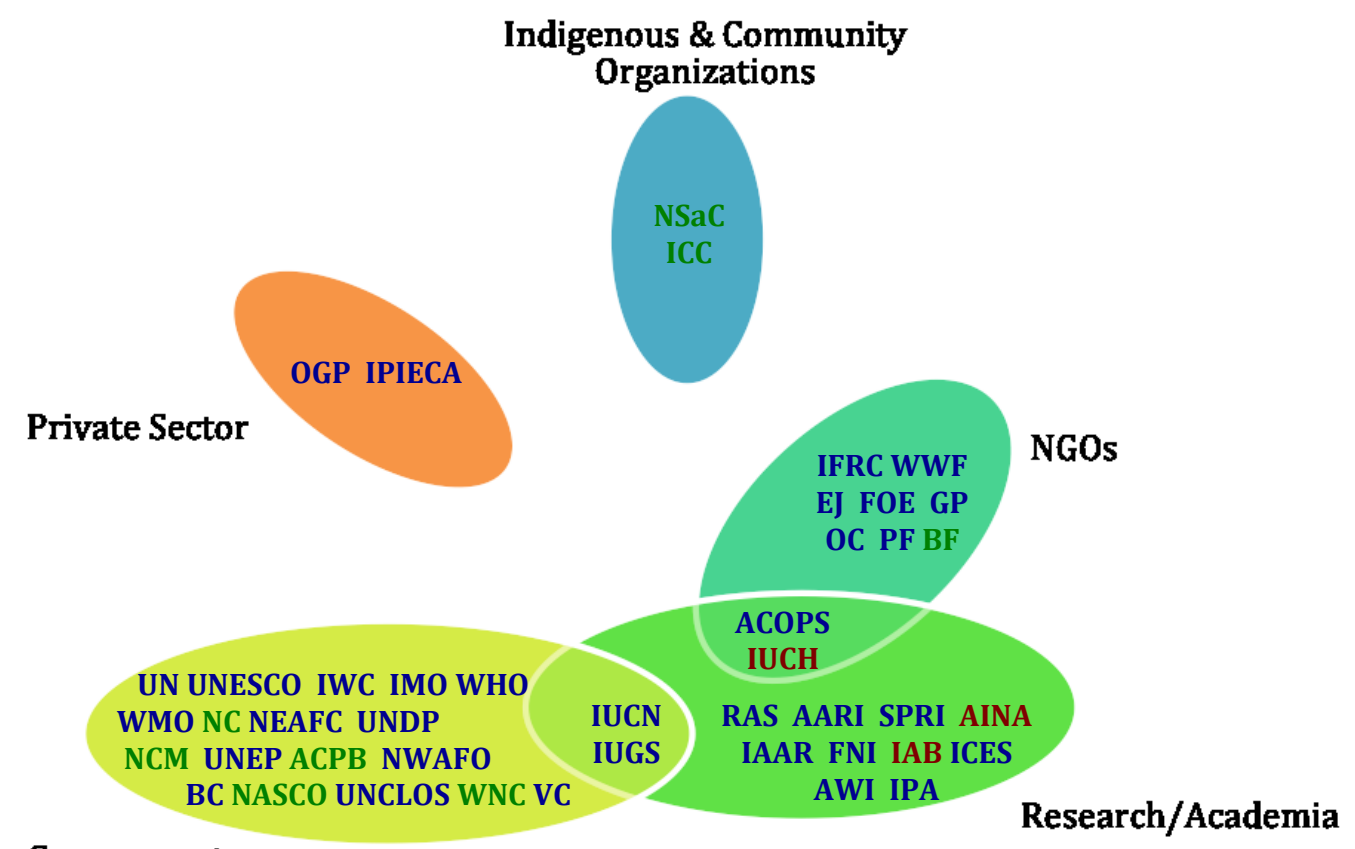

Government

\section{Figure 4.1: Arctic governance map 1986}

Blue: International institutions, Red: Circumpolar institutions, Green: Subregional institutions (Full list of institutions in Appendix 2).

At the circumpolar level (red text), Figure 4.1 highlights that activity was limited to a few research and academic institutions, such as the Arctic Institute of North America (AINA). Given a period of tense political relations these regionally focused institutions were conducting work that could be interpreted as apolitical and therefore not constrained in the same manner from forming transboundary linkages - although this is not intended to imply that it was easy for apolitical institutions to adopt a circumpolar focus with transboundary linkages during this period. 
Figure 4.1 also illustrates that a number of primarily government-led institutions with a sub-regional (green text) mandate or focus also existed during this period. Looking more closely at the sub-regional institutions presented in Figure 4.1, we observe that these transboundary connections were made up of institutions that supported Nordic cooperation, such as the Nordic Council of Ministers (NCM), and issue specific institutions such as the Agreement on the Conservation of Polar Bears (ACPB).

Figure 4.1 illustrates that government-led institutions were the most prevalent, followed by research/academia and then NGOs. Despite the challenges of establishing or maintaining cross-border relations, Figure 4.1 also highlights the active efforts of some of the region's Indigenous peoples to establish connections across state boundaries. In 1956, the Nordic Saami Council (NSaC) was established that served as an umbrella organization for Saami organizations in Norway, Sweden and Finland to promote Saami rights and interests (Saami Council, 2016). Similarly, in 1977, the Inuit Circumpolar Conference (ICC), later renamed the Inuit Circumpolar Council, was established to "speak with a united voice on issues of common concern and combine their energies and talents to protecting and promoting their way of life" (Inuit Circumpolar Council, 2016). What this emphasizes is that while the Arctic region was not the center of attention in traditional political circles, by many accounts, the push to establish connections across state boundaries was initiated by the region's Indigenous peoples, who had been separated for decades by Cold War politics (English, 2013; Griffiths, 
2012a; Heininen, 2010; Lamb, 2012). ${ }^{15}$ These efforts also highlight that many of the people of the Arctic felt more socially and culturally attached to Northern peoples of other states, than to Southerners within their own countries even after decades of separation (Abele \& Rodon, 2007). As one interviewee indicated, "In the Arctic, Indigenous peoples have a long history of engaging across states, even though they didn't have funds or a mandate to do this work" (personal communication, November $10,2014)$.

Another feature of the Arctic governance environment underscored in Figure 4.1 is the clear lack of multilateral institutions in the private sector zone. Although two international oil and gas associations are identified as having a presence in the region at this time, their international mandates could imply that the amount of attention directed at the Arctic was minimal relative to more active oil and gas producing regions. This is not to suggest that there was not a business presence in the Arctic. Rather, business opportunities were domestically managed; therefore, private sector actors did not see a need to establish or participate in multilateral institutions related to the Arctic.

Finally, the governance map illustrates that institutions that served a single actor-type were the most prevalent with only 4 institutions designed to work across actor-types the International Union for the Conservation of Nature (IUCN) and the International Union of Geological Services (IUGS) being international bodies that bring together

\footnotetext{
${ }^{15}$ The Inuit Circumpolar Conference, a NGO representing Inuit from the United States, Canada, Denmark (Greenland) and Russia, is specifically credited with being intimately involved in the creation of the Arctic Council (English, 2013; Griffiths, 2012a; Lamb, 2010).
} 
government and research/academia and the Advisory Committee of Protection of the Sea (ACOPS) and the International Union for Circumpolar Health (IUCH) seeking to engage both NGOs and research/academia.

Overall, the data collected about multilateral institutions that is presented in Figure 4.1 corroborates scholarly accounts of the period. It confirms that this was a phase when Arctic states were concentrated on domestic interests and issues in their respective northern territories, bilateral arrangements or multilateral institutions that were issue specific or focused on particular sub-regions. In contrast, Indigenous peoples of the region dedicated substantial attention and energy to establishing institutions that would work across boundaries established by states in the region. Furthermore, Figure 4.1 demonstrates that, during this period, multilateral institutions overwhelmingly represented and engaged a single actor-type - notably emphasizing the absence of multilateral institutions that involved multiple actor-types. Finally, despite the current discourse regarding private sector interest in the region for both its untapped resources and potential new transportation routes, this governance map is striking for its lack of multilateral institutions that involved this actor-type.

\section{Arctic region of "peace and cooperation"}

On October 1, 1987, U.S.S.R. President Gorbachev delivered a speech in Murmansk that called on Northern countries to establish the Arctic as "a genuine zone of peace and fruitful cooperation" (1987). This speech is consistently credited as creating a window of opportunity that enabled a shift in the geopolitics of the Arctic region from being a theatre for Cold War tensions to a region of dialogue and cooperation (Fenge, 
2012b; Griffiths, 2011; Huebert, 2009; Koivurova, 2010; Lamb, 2012; Stone, 2016; Young, 2009a). The speech facilitated a shift in the policy priorities of states in the region and reframed relationships in a manner that policy entrepreneurs in Norway, Finland and Canada were the most eager to respond to. Actors in Norway played a leadership role in the creation of the International Arctic Science Committee (IASC) (Rogne, 2015; Stone, 2016). ${ }^{16}$ Actors in Finland, on the other hand, saw this as an opportunity to initiate multilateral cooperation between Arctic states to respond to pollution concerns in the region (T. S. Axworthy \& Dean, 2013; Rogne, 2015; Stone, 2016). Meanwhile, actors in Canada saw this as an opportunity to expand bilateral and multilateral relations with Arctic states (T. S. Axworthy \& Dean, 2013; Slipchenko \& Hannigan, 2010). ${ }^{17}$ The efforts of policy entrepreneurs in these countries are examined in more detail in the following section.

However, examining the period immediately following Gorbachev's speech more closely, there is evidence that doubt and skepticism remained among Western states about the significance of Gorbachev's political gesture, especially with relation to demilitarization (T. S. Axworthy \& Dean, 2013; Rogne et al., 2015; Saunders, 1991; Stone, 2016). And even those people interested in championing a response to Gorbachev's call to action were slowed by the rapid decline and subsequent collapse of

\footnotetext{
${ }^{16}$ IASC is an international science organization that facilitates cooperation in all aspects of Arctic research with all countries involved in Arctic research (International Arctic Science Committee, 2016).

${ }^{17}$ Slipchenko indicates that bilateral relations between Canada and the U.S.S.R. on science cooperation provided important conduits for future multilateral relationships (2010).
} 
the U.S.S.R. in 1991. Both skeptics and advocates needed time to confirm the position that Russia's new leader, Boris Yeltsin, would take regarding Arctic cooperation (Slipchenko \& Hannigan, 2010).

The proposition that there was initial scepticism and hesitance to act is supported by the data collected about multilateral institutions. It confirms that no new institutions were established in the region in 1987 and 1988 (complete list in Appendix 2). However, what this data does not show is that there were individuals and organizations both within and outside government in the region that seized on this window of opportunity and acted as policy entrepreneurs to reframe the policy agenda (Howlett, 1998). Their efforts would culminate in the formation of new multilateral institutions at all levels and in many spheres as the decade progressed.

Figure 4.2 illustrates that in 1995 international institutions (blue text) with Arctic-relevant mandates were still the most prominent multilateral institutions and 13 new institutions at this level joined the Arctic governance network. However, the number of multilateral institutions with an Arctic focus (red text) more than tripled with 7 circumpolar institutions being established between 1987 and 1995 across multiple actor zones. Furthermore, it is a period where we see the emergence of 6 new sub-regional institutions (green text). 


\section{Indigenous \& Community \\ Organizations}

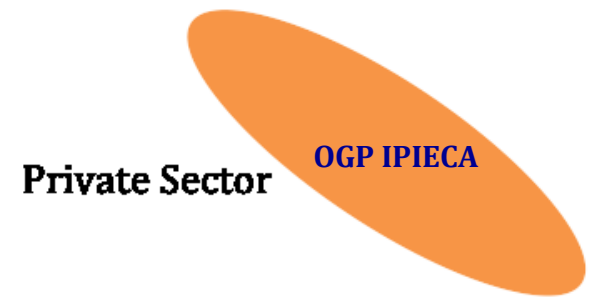

UN UNESCO IWC IMO WHO WMO NC NEAFC UNDP NCM UNEP ACPB NWAFO

BC NASCO UNCLOS VC WNC CBSS NAMMCO NPAFC OSPAR CBD UNFCCC CA BEAC BRC CPAR NF OHCHR ISA

\section{Government}

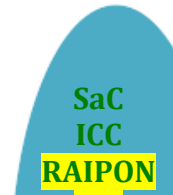

IPS
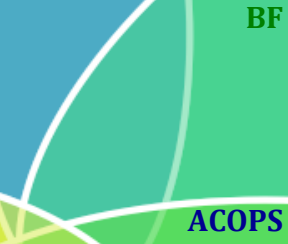

AEPS

IUCN IUGS IASC
IFRC WWF

EJ FOE GP OC PF

BF EBCD GA TE

PBI CAA

CCU WI

NGOS

NGOs

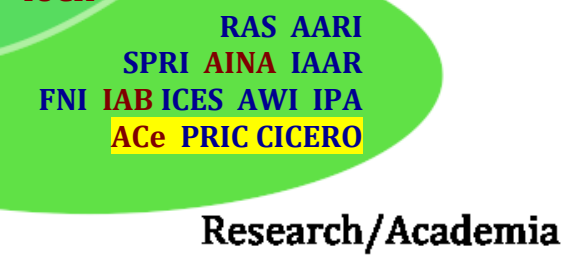

Figure 4.2: Arctic governance map 1995

Blue: International institutions, Red: Circumpolar institutions, Green: Subregional institutions. Institutions highlighted in yellow were established between 1987 and 1995 (Full list of institutions in Appendix 2).

In looking at the formation of institutions in different actor zones between 1987 and 1995, we see an increase in NGO and scientific/academic-focused institutions beginning in 1989. Figure 4.2 illustrates the notable growth of institutions in the NGO spheres, including institutions that continue to play important governance roles today, such as Wetlands International (WI) and GRID-Arendal (GA). Furthermore, researchers and academia active in the region during this period sought opportunities to capitalize on the increased willingness of governments to share data, information and expertise across borders, including the creation of the Arctic Centre in Finland (ACe) and the Center for International Climate and Environmental Research in Norway (CICERO). 
Figure 4.2 also demonstrates that despite any suspicion about the U.S.S.R.'s intentions or concerns about its stability, this was a period of "thawing" of state affairs and active dialogue to improve relationships and establish the Arctic as a region of "peace and cooperation." Sub-regional institutions, such as the Barents Euro-Arctic Council (BEAC) and the Barents Regional Council (BRC) were established in 1993 that focused on enabling cooperation between national and sub-national governments in these subregion on issues related to sustainable development. In addition, 1993 saw the creation of the Conference of Arctic Parliamentarians $(\mathrm{CPAR})^{18}$ and the Northern Forum (NF) ${ }^{19}-$ two regionally focused institutions that sought to build bridges across state lines.

It is also important to note that this was a period when Indigenous organizations continued to be active in taking advantage of changing geopolitics in the region. The ICC leadership was busy solidifying its connections across borders, which was facilitated by changing government relations (Slipchenko \& Hannigan, 2010), the Russian Association of Indigenous Peoples of the North (RAIPON) was established in 1990 and, in 1992, the Nordic Saami Council (NSaC) became the Saami Council (SaC) as Russian Saami were able to participate.

\footnotetext{
${ }^{18}$ CPAR is a parliamentary body with delegates from the parliaments of each of the Arctic states and Indigenous representation (Conference of Parliamentarians of the Arctic Region, 2015). ${ }^{19}$ The Northern Forum brings together the leadership of sub-national governments of the 8 Arctic states to discuss common issues (Northern Forum, 2016).
} 
There was also a small, but notable growth in institutions with multiple actor-types - in particular, the establishment of the International Arctic Science Committee (IASC) in 1990 and the Arctic Environmental Protection Strategy (AEPS) in 1991. These two regionally focused institutions played important roles in the formation of the Arctic Council and they receive more attention in the following section dedicated to the institutional design of the Arctic Council. The only sphere that did not see an increase in institutions was the private sector. This suggests that economic interests and business opportunities in the region were still domestically focused.

The governance environment between 1987 and 1995 is of particular importance because it is during this period that the design of the Arctic Council was conceived and negotiated. There are three particular observations from the 1995 governance map (Figure 4.2) that are of direct relevance to the Arctic Council. First, the region's Indigenous peoples and researchers were on the front lines of efforts to build connections across borders. This provided these actors with unique opportunities to define the policy priorities and shape the governance features of institutions emerging in the region.

Secondly, concerns about the environmental impacts of Cold War military activity was an obvious focal point for the region's Indigenous peoples, scientists, governments, and NGOs. Establishing multilateral institutions related to environmental management and sustainable development in the region simultaneously fulfilled a pressing need, while allowing opportunities for cross-border dialogue that were removed from more sensitive 
topics directly associated with security and military issues (T. S. Axworthy \& Dean, 2013). Finally, pollution and environmental concerns in the Arctic were of high importance to those living and working in the region; however, this was a period when most people did not make the connection to global environmental issues and environmental issues in general held relatively low political salience for the citizens and their governments all over the world (English, 2013; Watt-Cloutier, 2015).

This overview of the governance environment in the Arctic region, prior to the creation of the Arctic Council, highlights important factors during the period leading up to the creation of the Arctic Council that contributed to its institutional design and its institutional effectiveness. The first factor was the position the Arctic Council assumed in the existing network of institutions. The governance maps (Figure 4.1 and 4.2) visually illustrate the limited number of multilateral institutions working at the circumpolar level. There were also only a small number of institutions that involved multiple types of actors and moved beyond sector-specific mandates and agendas. Therefore, the Arctic Council's creation filled an institutional gap in the existing network of institutions involved in Arctic environmental management and sustainable development.

The second factor was the relevance of an institution like the Arctic Council for the various actors involved and interested in Arctic cooperation and policy. Here we observe that Arctic states generally had sufficient political will to support efforts to improve state relations in the Arctic; however, actual political interest in circumpolar cooperation related to environmental management and sustainable development 
remained relatively low. This emphasizes that it was the motives and efforts of specific policy entrepreneurs in and outside government that enabled the creation of the Arctic Council. The significance of this for the institutional design and institutional effectiveness of the Council is examined in more detail in the next section and in future chapters. The following section focuses in on those activities in the region that were most directly connected to the creation of the Arctic Council and considers how these specific initiatives contributed to defining the purpose of the Council and its institutional design.

\section{Institutional Design}

Mapping the governance environment in the Arctic provides important context to introduce specific initiatives that contributed to the creation of the Arctic Council, its future design and its effectiveness. This section highlights three initiatives that directly and indirectly informed the creation of the Arctic Council. These include the establishment of the International Arctic Science Committee (IASC) that was led by the Norwegian government in partnership with the scientific communities active in the region, the 'Finnish Initiative' that was led by the Finnish government to create the Arctic Environmental Protection Strategy (AEPS) and the 'Canadian Initiative' that was initially

led by non-governmental actors to champion the creation of an Arctic Council. Each of these initiatives were critical precursors to the 1996 establishment of the Arctic Council and, therefore, inform my analysis of the institutional design of the Council as a determinant of its institutional effectiveness. In particular, I examine how these initiatives defined the boundaries of the Arctic as a region, laid the groundwork for intergovernmental cooperation, established a place for the involvement of scientists and 
academia, and created a meaningful role for Arctic Indigenous groups in the Arctic Council. Furthermore, through an analysis of these initiatives, I confirm that the formation of the Arctic Council filled a gap in the existing network of institutions and that it was established because multiple actors within the region recognized its relevance. In addition, I examine how the work of policy entrepreneurs during this period contributed to creating a governance model for the Council that was well aligned with the policy functions that the Council assumed when it was created.

\section{Defining the Arctic}

In current discussions about the Arctic Council, there is an abundance of commentary on the role of non-Arctic states in the region (Brown, 2013; Graczyk, 2012; Lackenbauer, 2014). While this is an interesting discussion to explore in its own right, for the purposes of this analysis what it highlights is how little debate there is about the legitimacy of those states that have acquired the status of 'Arctic state' and, by extension, a position as member of the Arctic Council. As one interviewee observed, "The eight Arctic countries is constructed. The five Arctic Ocean littoral states is a more natural connection" (personal communication, November 16, 2014). And yet, the status of Arctic state has become so well entrenched that more recent efforts by the littoral states -branded the Arctic 5 - to hold discussions specific to their marine responsibilities in the Arctic Ocean has been met by strong and public criticism by the three excluded Arctic states (Iceland, Finland and Sweden) and other actors involved and interested in the work of the Arctic Council because the Arctic 5 is seen as undermining the work of the Arctic Council (Canwest New Service, 2008; Nielsson \& Magnusson, 2015; Rothwell, 2008). 
And yet the use of the term 'Arctic state' is a relatively recent phenomenon that was contested as recently as the late 1980 s and early 90 s. In fact, as late as 1991 , the Arctic Council Panel commented that:

Though the Arctic has physical characteristics and socio-economic problems all its own, it has no generally accepted definition. It is variously defined as the area north of the beeline, north of $60^{\circ} \mathrm{N}$, or north of the Arctic Circle at $66^{\circ} \mathrm{N} 33$; or above the [10] $]^{\circ} \mathrm{C}$ isotherm for the warmest month on land (and $15^{\circ} \mathrm{C}$ at sea). But any one characterization of the region is sure to leave someone and something out. The problem here is significant in that negotiations to establish an Arctic Council will have to produce broad agreement on (1) who is entitled to representation, (2) what does and does not constitute an international arctic issue, and (3) how the agenda is to be set and what the mandate of the new body should be (1991, p. 4).

This quotation highlights not only how modern the concept of the Arctic region is, but also how arbitrary the lines that have established the Arctic are. ${ }^{20}$ Moreover, it highlights some of the geopolitical implications of how the boundaries of this region are set. So if well-informed advisors were posing this question in 1991, how did the Arctic Council end up with 8 member states in 1996?

Piecing together historical accounts of the creation of the IASC, the Arctic Environmental Protection Strategy (AEPS) and the Arctic Council help to clarify that it was discussions around membership in, and the structure of the IASC, that initially led to identifying 8 Arctic states. As the previous section elaborates, the research and academic communities were among the first to begin work to establish multilateral

${ }^{20}$ Hamelin (1978) exposes the diverse criteria used to define the North. The definition of Arctic used to establish the Arctic Council confirms Hamelin's observation that "[d]efinitions of the North are primarily functions of criteria chosen to embrace the situation" (1978, p. 15). 
institutions in the Arctic as the Cold War began to ease. Efforts to establish the IASC provide a prominent early example of efforts to strengthen multilateral connections amongst researchers and experts working in the region. ${ }^{21}$ Odd Rogne (2015), who at the time was the Director of the Norwegian Polar Institute, explains that an initial informal meeting to discuss opportunities for Arctic research cooperation took place on the sidelines of meetings of the Scientific Committee of Antarctic Research (SCAR) in June 1986. This meeting about potential Arctic cooperation included "representatives from countries undertaking Arctic research" (Rogne, 2015, p. 10), which a letter of invitation indicates included representatives from the United States, Norway, Germany, the U.S.S.R., Canada, Sweden and Japan (Rogne et al., 2015, p. 11). The outcome of this gathering was an agreement to organize a meeting of Arctic nations to further explore the creation of an Arctic science committee; however, people at this initial meeting did not discuss how "Arctic nations" would be defined.

Rogne recognized the importance of clarifying this issue before another meeting could take place and proceeded to consult informally with the Arctic littoral states (or 'Arctic rim nations' as he refers to them). Based on these consultations, "Arctic nations" was defined as "countries with territories north of the Arctic Circle" (Rogne, 2015, p. 10). This was initially assumed to include 7 states (Canada, Denmark, Finland, Norway, Sweden, the U.S. and the U.S.S.R). However, organizers were subsequently contacted by Iceland, who pointed out that Iceland also had territory that rested above the $60^{\text {th }}$

\footnotetext{
${ }^{21}$ See IASC after 25 years (Rogne et al., 2015) for more information and a detailed account of the formation of the IASC.
} 
parallel, which brought the total number of Arctic nations to 8 . Representatives of these Arctic nations subsequently met in Oslo for a scoping meeting in February $1987 . .^{22}$ This was followed by a series of conferences that culminated in the creation of the IASC in August 1990.

Rogne admits that the arbitrariness of this criterion did not sit well with countries, such as France, Germany, Poland, the Netherlands and Japan, who had an interest in Arctic science and had been involved in Arctic exploration and research for decades and even centuries. Rogne reports that Canada and the U.S.S.R. were the most insistent that countries from the region should maintain control of Arctic research priorities and activities. This was likely a product of unresolved sovereignty claims and a desire to clearly communicate their sovereign rights over Arctic resources.$^{23}$ Rogne admits that in this post-Cold War context, organizers were particularly sensitive to Canada and the U.S.S.R.'s desires to maintain control of the region; therefore, it did not seem like an appropriate time to challenge efforts to contain how membership would be defined.

While this criterion for membership in IASC was altered during the first regular meeting of the IASC in January 1991 to allow non-Arctic states to be members (Hacquebord, 2015), the definition of Arctic nation seemed to stick with Finland, who followed the precedent set through the IASC negotiations and adopted the same "North of 60"

\footnotetext{
${ }^{22}$ In his article, Rogne indicates that he was "informally told" that minutes from the Oslo meeting were given to President Gorbachev's speech writer and this material informed Gorbachev's often cited Murmansk speech in October 1987 (2015, p. 13).

${ }^{23}$ In 1990, the UNCLOS III had not yet come into force and only Iceland had ratified the Convention.
} 
membership criterion to invite states to participate in negotiations that led to the creation of the Arctic Environmental Protection Strategy (AEPS) in 1991. As a result, the practice of recognizing the Arctic as being made of these 8 states was further entrenched and "non-Arctic" states were offered 'observer status' at meetings of the AEPS. Moreover, in 1996, when the AEPS was subsumed within the Arctic Council, there are no records of questions being raised regarding how membership was defined. Membership in the Council was presumed to be the 8 states that had been signatories to the AEPS.

This review of the origins of the Arctic Council membership criterion serves to highlight that the delineation between Arctic and non-Arctic states was a product of sovereignty concerns and sensitive geopolitics at the end of the Cold War when the desires of specific states to maintain control of the research priorities of the region took precedence over any desire to reach consensus on objective features or factors that should inform how the Arctic was defined. To this day, there is no agreed to definition of the Arctic and yet the Arctic Council has successfully retained its definition of membership. While one interviewee proposed that "the founding of the Arctic Council created a boundary. No one else can be a member" (personal communication, January 19, 2015); this section demonstrates that the Arctic Council may have served to further solidify this boundary, but it was following a path set by the IASC and AEPS. Furthermore, as we see in future chapters, this construct of the Arctic has been tightly held by Arctic states to inform who has the authority to create Arctic policy, who is at the core of Arctic cooperation, and who should lead Arctic governance. 


\section{Arctic state cooperation}

The Finnish Initiative (or Rovaniemi Process) began in tandem with the creation of the IASC. ${ }^{24}$ This process, initiated by Finland in 1989 , focused on the urgent need for intergovernmental cooperation in the region to respond to serious pollution concerns. Sandwiched between the U.S.S.R. and its Nordic neighbours, Finland was well positioned and motivated to actively respond to Gorbachev's invitation to begin a new era of peace and cooperation in the region. As mentioned above, Finland adopted the definition of Arctic state established by IASC and reached out to these states to encourage participation in the development of a regional strategy focused on environmental protection. ${ }^{25}$ The result was the Arctic Environmental Protection Strategy (AEPS), which was signed by representatives of all 8 states in June 14, 1991 (Elferink, 1992; Rogne et al., 2015; Stone, 2016).

The AEPS introduced several governance features that would endure and maintain a central place in the Arctic Council's institutional design. The first feature introduced through the AEPS was establishing a mandate and agenda focused on actively responding to environmental concerns in the region. From the beginning, Finland introduced the AEPS as an important institution to address real and immediate environmental "threats" to the "fragile Arctic ecosystem" (Arctic Environmental

\footnotetext{
${ }^{24}$ In fact, Rogne (2015) suggests that Finland originally initiated efforts to establish the AEPS after discussions about which country would host the IASC secretariat. Both Norway and Finland had expressed interest in hosting the IASC secretariat and, after bilateral negotiations, Norway was identified as the host. Shortly after this decision the Finnish Initiative to establish the AEPS was launched.

${ }^{25}$ It is worth noting that it was the Finnish Ministry of Environment that led efforts to create the AEPS and not the Ministry of Foreign Affairs.
} 
Protection Strategy, 1991). The AEPS identified six problems that would serve as priorities - persistent organic contaminants, oil pollution, heavy metals, noise, radioactivity and acidification. These priorities not only defined the policy agenda of the AEPS, they served as a lens to review the "existing and proposed international and bilateral agreements and policy declarations pertaining to the Arctic environment" to identify important gaps and articulate how the AEPS and Arctic states could proceed to fill those gaps for each of its policy priorities (Arctic Environmental Protection Strategy, 1991, p. 20). Consequently, the AEPS articulated an action plan that would guide the cooperation of the Arctic states, while emphasizing that this initial plan would "begin the process of addressing environmental issues" and "[t]hese issues [would] require regular updates...on the progress being made, and to advise on possible new courses of action" (Arctic Environmental Protection Strategy, 1991, p. 25).

The second governance feature introduced through the AEPS was the establishment of international cooperation built on the foundation of scientific research. This meant that immediate attention was placed on efforts to collaboratively monitor the Arctic environment, harmonize methods and share data. The AEPS established an organizational culture that valued science and evidence-based policymaking and proceeded to set up a working group structure that protected the integrity of science ("only scientists can sign off on science" (personal communication, January 15, 2015)), but also prioritized science that would inform policy and emphasized the importance of incorporating governance mechanisms to enable a strong connection between policymakers and scientists. In fact, four of the six working groups of the Arctic Council 
(AMAP, PAME, CAFF and EPPR ${ }^{26}$ ) were established under the AEPS and then incorporated into the Council. While the CAFF and EPPR working groups were not effectively mobilized prior to the creation of the Arctic Council, the AMAP and PAME working groups were well-established by 1996 to the point where one interviewee proposed that these 2 working groups were so strong that it was better to think of them as "organizations inside an organization" (personal communication, November 19, 2014).

It was through the AEPS that regular Ministerial oversight was introduced. The Ministers of Environment were scheduled to meet every two years. This arrangement was carried over to the Arctic Council; however, given the broadened mandate of the Council, it would be led by Ministers of Foreign Affairs. The AEPS also introduced the role of senior Arctic official - a bureaucrat appointed by their government to lead the work of the AEPS in between ministerial meetings. The role of Senior Arctic Official (SAO) would later become a core governance feature of the Arctic Council (T. S. Axworthy \& Dean, 2013).

And finally, although credit is often given to the Canadian Initiative for creating a place for Indigenous organizations, it is important to acknowledge that the value of including

\footnotetext{
${ }^{26}$ The Arctic Monitoring and Assessment Programme (AMAP), Protection of the Arctic Marine Environment (PAME), Conservation of Arctic Flora and Fauna (CAFF), and Emergency Prevention, Preparedness and Response (EPPR) working groups.
} 
the region's Indigenous peoples was acknowledged in the AEPS ${ }^{27}$ and, while Arctic Indigenous groups were not provided with the unique status of permanent participant that they would achieve in the Arctic Council, the AEPS did offer Arctic Indigenous organizations observer status, responding to Arctic Indigenous groups active efforts to mobilize during this period.

Thanks to the AEPS, intergovernmental cooperation in the Arctic was well underway in the region prior to the creation of the Arctic Council in 1996. Furthermore, the environmental priorities that required attention in the Arctic were already on governments' agendas, scientific research and advice were at the heart of the AEPS and it was supported through an established governance structure. The nuts and bolts of intergovernmental cooperation were in place; however, as I demonstrate in the next section, a vision for a new form of Arctic governance was simultaneously being born on the other side of the Arctic.

\section{A vision for Arctic governance}

Following on the heels of Gorbachev's 1987 speech was a parallel initiative launched in Canada. While the Canadian Minister of Foreign Affairs, Joe Clark, expressed a desire to foster stronger bilateral and multilateral ties with Canada's Arctic neighbours around this time, bureaucrats in the Department of Foreign Affairs were more focused on bilateral relations, in particular with the U.S.S.R., and had no mandate or intention to prioritize multilateral cooperation immediately following Gorbachev's speech (T. S.

${ }^{27}$ The ICC and Canada were strong champions of Indigenous participation during negotiations of the AEPS. 
Axworthy \& Dean, 2013; Slipchenko \& Hannigan, 2010). Therefore, in the absence of action by the government, in 1988, several organizations in Canada with an interest in arms control in the Arctic began their own efforts to articulate a plan for demilitarization and multilateral cooperation - This included the Walter and Duncan Gordon Foundation, the Inuit Circumpolar Conference (ICC), Scientists for Peace, the Canadian Centre for Arms Control and Disarmament (CCACD) and the Canadian Arctic Resources Committee (CARC). They were inspired by Gorbachev's call for an era of peaceful relations in the region and they saw an opportunity to facilitate new relationships and new types of engagement in the region (T. S. Axworthy \& Dean, 2013).

For these early champions of the Canadian Initiative, the Arctic Council was conceived of as an important venue in a larger project of peace and security both regionally and globally (Heininen, 2010; Lamb, 2010, 2012). Therefore, it is not surprising that significant effort was expended to include Arctic security issues generally, and military disarmament specifically, on the mandate of the envisioned Arctic Council (English, 2013; Griffiths, 2011; Lamb, 2012). This effort not only signaled the high importance that this issue held for the people concerned about the future of the region, but also stemmed from a recognition that security issues in the region were intimately linked to the health of the Arctic ecosystem (both the people and the natural environment).

However, these organizations quickly realized that, due to ongoing tensions and sensitivities between Arctic states, direct discussions about security issues or demilitarization in the region were not feasible in the short term. Instead, they adopted 
an indirect approach and focused on how such an institution should function rather than attempting to identify specific policy priorities. They believed that the Arctic Council needed to provide a place for real dialogue and cooperation. It was a means for formerly frosty neighbours to demonstrate their commitment to a peaceful multilateral forum (Dodds, 2012; Lamb, 2012; Munk-Gordon Arctic Security Program, 2012; Young, 2009b).

After several years of championing an Arctic multilateral institution behind the scenes of frontline Canadian politics, in November 1989, Prime Minister Mulroney visited the Soviet Union and, during a speech in Leningrad, he broadcast his first public signs of interest in Arctic multilateral cooperation. He introduced the vague idea of a council of Arctic countries to promote cooperation (T. S. Axworthy \& Dean, 2013; Slipchenko \& Hannigan, 2010). ${ }^{28}$ Subsequently, the organizations involved in developing and championing the idea of an Arctic Council began using a variety of channels to connect with government officials in Canada and other Arctic states to further encourage the idea. They also took the step of creating the Arctic Council Panel that worked to articulate a governance model for this proposed institution (Griffiths, 2012a). ${ }^{29}$ This

\footnotetext{
${ }^{28}$ John Lamb, of the CCACD, is credited with encouraging Mulroney's speech writer to include this idea in the speech (T. S. Axworthy \& Dean, 2013).

${ }^{29}$ The Arctic Council Panel was chaired by Rosemarie Kuptana (former president of the Inuit Broadcasting Corporation) and Franklyn Griffith (University of Toronto). The members of the Panel included John Amagoalik (president of Inuit Tapirisat of Canada and former vice chair of the Inuit Circumpolar Council), Bill Erasmus (president of Dene Nation), Cindy Gilday (formerly with Indigenous Survival International), Stephen Hazell (executive director of the Canadian Arctic Resources Committee), Mary Simon (president of the Inuit Circumpolar Council) and John Lamb (executive director of the Canadian Centre for Arms Control Centre) (T. S. Axworthy \& Dean, 2013).
} 
Panel was co-chaired by Rosemarie Kuptana, a Canadian Inuit leader, and Franklyn Griffith, an academic and leading expert on Arctic issues. The Panel consulted extensively with Canadian Northerners, and Arctic Indigenous peoples in particular, to discuss what role the Arctic Council could have and how it would work.

In November 1990, the efforts of the Arctic Council Panel got a further boost when Foreign Affairs Minister Joe Clark made a speech at a conference on Canadian-Soviet relations and specifically indicated that Canada would be proposing an Arctic Council to the 7 other Arctic states (T. S. Axworthy \& Dean, 2013; Slipchenko \& Hannigan, 2010). ${ }^{30}$ Officials in the Department of Foreign Affairs now had a clear mandate to engage the governments of the other Arctic states and involve people outside of government in the development of the Arctic Council (Slipchenko \& Hannigan, 2010). Government officials from the Canadian Department of Foreign Affairs began reaching out to their counterparts in other Arctic states to further advance the idea (Slipchenko \& Hannigan, 2010). In May 1991, the Panel released a framework report, which outlined the proposed mandate and structure of the Arctic Council. This document focused on outlining the institutional form that regional cooperation could take (T. S. Axworthy \& Dean, 2013).

Canada hosted the first official meeting of Arctic state to discuss the formation of a multilateral Arctic Council in May 1992 (Slipchenko \& Hannigan, 2010). Canada's

\footnotetext{
${ }^{30}$ Franklyn Griffith is credited with having provided information and advice to Minister Clarks speech writer (T. S. Axworthy \& Dean, 2013).
} 
proposal to create the Arctic Council was supported by the other Arctic states with the exception of the United States. The Bush administration had no interest in being involved with a multilateral institution in the Arctic and was strongly opposed to the Council having a mandate related to security (Nord, 2016). Russia was fully supportive of Canada's proposal, based to some extent on the strong bilateral relationship that the two countries had forged on scientific cooperation (Slipchenko \& Hannigan, 2010). The Nordic states were supportive, but clear that ultimately all 8 states needed to agree to participate in order for the idea to gain their full support.

In 1993, both Canada and the United States had changes in government that delayed, but did not terminate, Canada's efforts to establish an Arctic Council. In 1994, the Canadian government, led by Jean Chrétien, took the further step of inviting Mary Simon (former ICC President and member of the Arctic Council Panel) to become Canada's first Circumpolar Ambassador. She then worked with Foreign Affairs Minister Lloyd Axworthy to continue to champion the creation of the Arctic Council. The Clinton administration in the United States was more open to multilateral cooperation than had been the Bush administration; however, they remained opposed to a multilateral institution with a mandate related to security. As a result, Canada made the decision to abandon this aspect. The United States also rejected Canada's offer to host a small secretariat to support the Council - a step that was seen by Arctic Council Panel members as a further watering down of its original vision (T. S. Axworthy \& Dean, 2013). 
However, there were still important governance features proposed by the Panel that were integrated into the initial design of the Arctic Council. First and foremost, the Arctic Council Panel championed a meaningful role for the region's Indigenous peoples. They argued that their involvement and participation was critical to ensure the incorporation of local knowledge, empower the Arctic people and increase the legitimacy of the Arctic Council within the region (1991). Canada was a strong champion of this during negotiations to create the Arctic Council and proposed the creation of the permanent participant role that was ultimately adopted by the Council (T. S. Axworthy \& Dean, 2013; English, 2013; Slipchenko \& Hannigan, 2010). The status of permanent participant gave Indigenous people an elevated position over observers, while still providing the distinction from member states that the Arctic states were looking for. Organizations representing the region's Indigenous peoples would participate and have an equal voice at meetings with Ministers and SAOs to set the Council's priorities and direction. Furthermore, permanent participants could participate in all meetings and activities of the working groups of the Arctic Council. This governance feature is recognized as a unique and defining governance feature of the Arctic Council as yet not repeated by any other international institution. ${ }^{31}$ The Arctic Council Panel and the Government of Canada played critical roles in ensuring that Indigenous groups would have this unique position. The importance and evolution of this governance feature is the focus of attention in future chapters.

\footnotetext{
${ }^{31}$ Indigenous groups are taking on greater roles in various international institutions, including throughout the United Nations system; however, these other institutions provide Indigenous groups a status equivalent to other non-state actors.
} 
A closely related feature that was introduced through the Canadian Initiative was a strong emphasis on integrating a "human dimension" into all Council work. Up until this point, polar environmental research, perhaps in part because Antarctica was uninhabited, tended to study the environment with limited recognition of the people that lived in the region. The Arctic Council Panel sought to put the people of the Arctic at the centre of its agenda and emphasize the importance of articulating the value and significance of the Council's work for its inhabitants. The Arctic Council Panel recognized the importance of environmental protection that was being championed by the Arctic Environmental Protection Strategy (AEPS), but it placed more attention on considering and responding to the impacts of these environmental issues on the people that lived in the region, including important health, social and economic issues. Based on this focus, the Canadian Initiative pushed to have the agenda move beyond environmental protection and proposed that it should stand on the pillars of environmental protection and sustainable development (Arctic Council Panel, 1991).

Finally, the Arctic Council Panel prioritized defining the nature and quality of cooperation within the Arctic Council over any specific policy area. The Arctic Council Panel encouraged an inclusive organizational culture. To this end, the Panel not only championed the participation of non-Arctic states in the Council's work as observers, they also proposed that inter-governmental (IGOs) and non-governmental organizations (NGOs) should be able to participate (Arctic Council Panel, 1991). The Panel proposed that observers would not have the status or role afforded to permanent participants; however, their experience and expertise in formulating policy was recognized as 
important to support the work of the Arctic Council. Furthermore, the Panel championed the establishment of a consensus-based decision-making approach among participants, in particular representatives of Arctic states and Indigenous organizations, for all Council activities. They argued that a critical responsibility of the Council was building understanding between the region's Indigenous peoples, science and politics.

The governance model envisioned by the Arctic Council Panel was focused more on the governance model than on specific policy outcomes - in particular, they emphasized a specific organizational culture. This culture enhanced the position of the region's Indigenous peoples and non-state actors and created a governance space reflective of the cultural values of the region's Indigenous peoples (Abele \& Rodon, 2007; Huebert, 2009). In fact, there are ICC leaders, who claim that the organizational culture envisioned by the Arctic Council Panel and enacted through the Arctic Council was inspired by the governance approach of the ICC (Lynge, 1993). The lasting impact of this organizational culture is explored in subsequent chapters. In Chapters 5 and 6, I directly examine the organizational culture of the Arctic Council over time and, in Chapter 7, I explore the deeper significance of the Council's organizational culture when I examine the Council's multiple institutional logics and their contribution to its institutional effectiveness.

These are the most prominent governance features proposed through the Canada Initiative that were adopted with the creation of the Arctic Council. Through the work of these actors, the governance model of the Arctic Council is believed to embody a 
uniquely "Arctic" understanding of the way the world works and how the region should be governed (Dodds, 2012; English, 2013; Griffiths, 2012b).

In September 1996, Arctic states signed the Ottawa Declaration formally creating the Arctic Council that assumed the responsibilities and work of the AEPS, while injecting a broader vision for Arctic governance conceived of through the Canadian Initiative. This section has explored how three initiatives that preceded the creation of the Council played important parts in shaping the institutional design of the Council. This analysis highlights that the creation of the Arctic Council was not the product of one cohesive effort to establish an institution for circumpolar cooperation; rather it is the result of the merging of diverse interests and ideas about how such an institution should be designed.

An analysis of these three initiatives reinforces the findings presented in the previous section. Specific state and non-state actors, who recognized a need for cooperation at the circumpolar level and institutions that involved multiple actor-types, mobilized to advance these initiatives - confirming that recognizing an institutional gap and defining a unique position for the Arctic Council in the existing network of institutions was a factor that would contribute to the Council's effectiveness. The analysis of these initiatives also confirms that the perceived relevance of an institution like the Arctic Council for different actors in the region was also an important factor. In particular, the Finnish and Canadian Initiatives were advanced by the individual and collective efforts of policy entrepreneurs within the scientific community who were interested in 
establishing region-wide scientific cooperation and environmental protection, Arctic Indigenous groups who were seeking more meaningful roles in Arctic policymaking and NGOs who were interested in facilitating peaceful cooperation and demilitarization in the Arctic. Furthermore, officials within the Finnish and Canadian governments shared a mix of these interests and were willing to champion their advancement.

In addition, the analysis in this section emphasizes the critical role policy entrepreneurs played in shaping the governance model of the Arctic Council, articulating the responsibilities it would assume and identifying the policy shaping role the Council would undertake related to Arctic environmental management and sustainable development. While politics may have dampened or watered down the visions of these policy entrepreneurs, their distinctive ideas about how a multilateral institution in the Arctic should be designed, what it should do and how it should work were still present in the institution that was established in 1996. For example, scientific and expert advice would be a foundation of the Arctic Council's work as proposed in the Finnish Initiative and Indigenous representatives would have a distinct role and participate in all aspects of the Arctic Council's meetings and activities as envisaged through the Canadian Initiative. Moreover, as I examine further in subsequent chapters, this section provides the first indications of the importance of Levy et al's (2001) proposition that the Arctic Council's effectiveness depended on an alignment between its institutional design and the role it was positioned to play in the policy process. To conclude my analysis of the Arctic Council's formation, I examine how the Finnish and Canadian Initiatives contributed to the policy issues that were initially placed on the Arctic Council agenda. 


\section{Problems to be Solved}

Looking at the Ottawa Declaration (Arctic Council, 1996) that set out the mandate of the Arctic Council, it would be easy to claim that the Arctic Council mandate is clearly defined and focused on environmental protection and sustainable development in the Arctic region. However, examining the period leading up to the creation of the Arctic Council confirms that there were multiple policy issues facing the region that spurred efforts to establish a multilateral institution at the circumpolar level. As a result, the final determinant of institutional effectiveness that I examine is the policy issues articulated through the Finnish and Canadian Initiatives with the intention of assessing the impact of these policy issues on the Council's effectiveness over the short and longer term. As I examine here and in future chapters, I propose that the nature of the policy issues placed on the Council's agenda and the framing of these issues are factors that explain the effectiveness of the Council. This section also introduces the policy issues identified at the inception of the Arctic Council as a baseline to support further analysis of how the issues on the Arctic Council agenda evolved over time.

To support this analysis, I conducted a content analysis of the Arctic Environmental Protection Strategy (AEPS) and the Arctic Council Panel Report. I selected these two documents because they capture the core issues and priorities of the Finnish and Canadian Initiatives. I began this analysis by coding the text of each document by key themes (e.g. traditional knowledge, natural resources, pollution). Table 4.1 outlines the themes identified and indicates the frequency of references for each of these themes in the documents. This initial analysis highlights where there is convergence and 
divergence between the documents in the policy priorities identified. This coding also provides goalposts for a deeper content analysis of the dominant policy issues identified and an examination of how these issues were framed in each document (see Appendix 3 for more details about the method used and coding decisions taken).

Table 4.1: Results of content analysis to identify frequency of references to themes in the AEPS and the Arctic Council Panel Report.

\begin{tabular}{|c|c|c|}
\hline & $\begin{array}{l}\text { AEPS } \\
(1991)\end{array}$ & $\begin{array}{r}\text { Arctic Council } \\
\text { Panel Report } \\
(1991) \\
\end{array}$ \\
\hline Regional cooperation, including: & 39 & 35 \\
\hline military-security & 0 & 23 \\
\hline Indigenous peoples, including: & 25 & 68 \\
\hline Traditional knowledge & 4 & 4 \\
\hline Human dimension, including: & 13 & 24 \\
\hline Health & 3 & 0 \\
\hline Social-Cultural & 7 & 2 \\
\hline Education & 0 & 0 \\
\hline Capacity building & 0 & 0 \\
\hline $\begin{array}{l}\text { Environmental protection, } \\
\text { including: }\end{array}$ & 54 & 5 \\
\hline Biodiversity/conservation & 1 & 0 \\
\hline Environmental emergencies & 4 & 0 \\
\hline Marine environment & 4 & 0 \\
\hline Pollution & 29 & 3 \\
\hline Climate change & 4 & 4 \\
\hline Scientific-research collaboration & 39 & 2 \\
\hline $\begin{array}{l}\text { Sustainable development, } \\
\text { including: }\end{array}$ & 18 & 5 \\
\hline $\begin{aligned} \text { Economic } \\
\end{aligned}$ & 3 & 2 \\
\hline Natural resources & 5 & 1 \\
\hline Infrastructure & 2 & 0 \\
\hline Business & 0 & 0 \\
\hline Energy & 0 & 0 \\
\hline
\end{tabular}

Complete list of issues identified in Arctic Council-related documents, 1991-2015, presented in Appendix 3.

At the forefront of both documents is the theme of regional cooperation. The AEPS has 39 references and the Arctic Council Panel has 35 references. While this may not 
constitute a classic policy issue (e.g. health, agriculture, education) or a problem as traditionally identified in the environmental governance literature, this was a core policy issue facing the region during a period that drove actors in and outside government to dedicate time and resources to establish relationships and build trust. With Gorbachev's speech, various actors through multiple means (e.g. IASC, ICC, CPAR, AEPS and the Arctic Council Panel) set out on a path to transform the Arctic into a region of "peace and cooperation."

Further analysis of the Arctic Council Panel Report confirms that the Panel was explicit in proposing regional cooperation be the primary goal of the Arctic Council. They were unapologetic in their position that how actors worked together was more important in this context than what policy issues were on the agenda. They went so far as to introduce a full shopping list of potential agenda items (outlined in Table 4.2). Although the authors were also pragmatic about what could be expected from a fledgling Arctic Council, stating:

But a fully operative institution for circumpolar collaboration will not be created in a single act. Nor, of course, can the full range of arctic social, environmental, human rights, economic, or military problems be attacked all at once. An Arctic Council will evolve from a beginning. To start with, it will have to be fitted into the institutional setting that is taking shape today (Arctic Council Panel, 1991, p. 6).

The Panel's logic was echoed by one interviewee, who explained that the Arctic Council rose "from modest beginnings" to facilitate "confidence building," so it had to "start with what it knew best - the environment" (personal communication, January 16, 2015). 
Table 4.2: Potential Arctic Council Agenda Items

\begin{tabular}{|l|l|}
\hline $\begin{array}{l}\text { Origins and } \\
\text { Solutions }\end{array}$ & $\begin{array}{l}\text { Arctic Problems: Exchange of Experience, Joint Action, } \\
\text { Standardization of Performance }\end{array}$ \\
\hline $\begin{array}{l}\text { Arctic- } \\
\text { specific }\end{array}$ & $\begin{array}{l}\text { Aboriginal self-determination; arts and cultural exchange; } \\
\text { cessation of low-level flight training; cessation of "tickler" flights } \\
\text { by strategic bombers; codification and dissemination of } \\
\text { aboriginal traditional science; co-operatives; creation of a } \\
\text { central arctic data bank; cold regions technology development } \\
\text { and transfer, education; environmental impact assessment } \\
\text { procedures and techniques; fisheries research and } \\
\text { management; regionally generated food contamination; habitat } \\
\text { protection; health services delivery; housing; human resource } \\
\text { development; hydrocarbon, hard mineral and other } \\
\text { megaprojects; land-use planning; marine transportation; oil spill } \\
\text { clean-up in arctic waters; parks creation; prohibition of } \\
\text { amphibious landing exercises; removal of hazardous materials } \\
\text { from active and decommissioned military sites; remote sensing; } \\
\text { search and rescue; sewage disposal and water management; } \\
\text { small business development; tourism; violation of aboriginal and } \\
\text { other human rights; weather and ice forecasting; wildlife } \\
\text { management and co-management. }\end{array}$ \\
\hline $\begin{array}{l}\text { Amendment of international legal instruments to meet arctic } \\
\text { external } \\
\text { requirements; arctic business cycle and counter-cyclical action; } \\
\text { attack submarine limits; cruise missile testing; depressed fur } \\
\text { prices; establishment of demilitarized zones; food } \\
\text { contamination; high-latitude effects of global warming; long- } \\
\text { range airborne and oceanic transport of pollutants; military data } \\
\text { exchanges; naval deployment and exercise limitations; nuclear } \\
\text { weapons testing; nuclear weapons reductions. }\end{array}$ \\
\hline
\end{tabular}

(Arctic Council Panel, 1991, p. 14)

By contrast, the AEPS' references to regional cooperation are primarily linked to issues

related to its overarching mandate of environmental protection. In order of frequency, regional cooperation was referenced in connection to pollution, scientific collaboration, environmental emergencies, the marine environment and sustainable development. Furthermore, in contrast to the Arctic Council Panel recommendations, there are no references to demilitarization, security or trust building - although perhaps this is not surprising given that the AEPS was signed by Arctic states. 
The second most prominent issue identified in the documents falls under the theme of Indigenous peoples. The Arctic Council Panel Report references Indigenous peoples 68 times. The authors' main focus is the direct involvement of the region's Indigenous peoples in a governance body, such as the Arctic Council, because of their knowledge of the issues that the region faced (including the impacts of military tensions, environmental changes, and socio-cultural issues) and because they were the most affected (along with other Arctic residents) by the policy decisions taken in the region. The Panel took the view that Indigenous peoples' unique position gave them a unique understanding of the issues facing the region; therefore, their participation in the Arctic Council would lend legitimacy to this institution.

The AEPS also places prominence on the theme of Indigenous peoples with 25 references. Again many of these references comment on the unique knowledge that the region's Indigenous peoples can offer because of their knowledge of environmental changes in the region and the social, cultural and health impacts of environmental changes and pollution on the people living in the region. Interestingly, the AEPS also references the region's Indigenous peoples when explaining the importance of sustainable development; however, given that the AEPS is an intergovernmental agreement, the document limits the proposed involvement of Indigenous peoples to observer status.

In a similar vein, the documents both take time to consider the interests and needs of all people that live in the Arctic (i.e. the human dimension). The AEPS specifically focuses 
on the health and well being of the people in the Arctic as a "call to action" to better understand and address the effects of pollution and environmental changes in the region. In contrast, the Arctic Council Panel draws on this theme to emphasize the importance of allowing the people in the region to take a leadership role in articulating the priorities of the Council and to participate in the Council's work. Again, this is consistent with the overall message of the Panel, which is less focused on driving toward specific policy issues and more interested in communicating a need for inclusive and cooperative forms of governance in the region.

Following these top issues, the two documents diverge in their identification of issues that are of critical importance. As discussed above, the AEPS places a high priority on environmental protection and the sub-theme of pollution in particular. The AEPS complements its focus on environmental protection with an emphasis on the need for scientific and research collaboration. However, these themes are understated in the Arctic Council Panel Report. The final two themes identified in Table 4.1, climate change and sustainable development, are clearly of low significance in both documents being analyzed; however, although these issues were not prominent, their presence in these documents confirms that they were part of the Arctic discourse that had gained international recognition and attention.

Overall, my analysis shows that the dominant problems in the years leading up to the creation of the Arctic Council included regional cooperation, the participation of Arctic Indigenous peoples and other inhabitants in multilateral policy discussions, and 
environmental protection. However, these initiatives also sent mixed messages. There were notable differences between the AEPS and Arctic Council Panel in how issues were understood, framed and prioritized. The AEPS articulated a narrow, but concrete action plan for understanding and responding to pollution problems in the Arctic; whereas, the Arctic Council Panel prioritized continuing to talk, collaborate and build trust among a diversity of actors with less emphasis on a small number of specific policy issues.

This section introduces two additional factors that contributed to how the Arctic Council worked and to what extent it was effective. First, closely linked to the discussion introduced in the previous sections about the perceived relevance of an institution within the network of institutions involved in Arctic policy, policy entrepreneurs involved in the Finnish and Canadian Initiatives were motived to mobilize because of their interests in particular policy problems - it was the perceived salience of these policy issues that motivated various actors to invest effort, despite inertia and explicit resistance, to ensure the creation of new multilateral institutions.

The second factor that this section highlights is that the AEPS and the Arctic Council Panel Report included different types of policy issues that shaped the actions that the Council could or should take. For example, as discussed in the institutional effectiveness literature, policy problems have different characteristics and levels of complexity that may make them more or less amenable to management or solution. The AEPS identified the resolution of several transboundary pollution concerns with 
multiple causes, sources and interconnected symptoms (e.g. persistent organic pollutants, heavy metals and acidification). The features of the policy problems could be seen as a factor that would reduce the effectiveness of the responsible institution. However, an institution's ability to respond to a particular policy issue is also a product of how it is framed. Using the example of pollution concerns identified through the AEPS again, the institution's specific task was to collect and analyze data to generate knowledge and policy advice and it focused specifically on the causes and effects of pollution in the Arctic region. This framing contained and shaped the policy issue on the agenda in a manner that matched the mandate and resources available to the Arctic Council. Finally, the policy issues that are not included on the agenda (e.g. security) can also explain the effectiveness of the Arctic Council. Overall, this was a period when the policy issues considered for inclusion on the agenda during the negotiations among states were deliberately framed to be uncontroversial to enable discussion and trust building - subsequently, the issues proposed for the Council's agenda attracted minimal attention at the political level in Arctic states and almost no attention globally.

\section{Conclusion}

This chapter emphasizes key factors that were critical in transforming the governance of the Arctic region and the creation of the Arctic Council. In particular, it highlights that these governance activities advanced despite or even because of the Arctic's peripheral status in larger Cold War dynamics. It maps the governance environment of "peace and cooperation" that grew to define the Arctic in this context. What an analysis of this period underlines is that the current governance environment in the Arctic generally and the Arctic Council governance model specifically was not established despite the 
region's low global political salience, but are better understood as a direct product of the dynamics during this period.

With this in mind, this chapter also provides important insights about the factors during this formative period that contributed to the institutional effectiveness of the Arctic Council. There were exogenous factors, such as changing geopolitics, which provided a window of opportunity to establish new regionally focused institutions. However, this analysis also highlights that policy entrepreneurs from in and outside government recognized this window of opportunity and took on the work to establish new multilateral institutions in the region despite delays and resistance.

Furthermore, this chapter demonstrates that the decisions taken in the creation of the IASC and the AEPS structured and contained the institutional design of the Arctic Council. The AEPS was instrumental in setting the initial agenda for the Council that placed scientific cooperation at its core. By contrast, the Canadian Initiative played a notable role in shaping how the Arctic Council would work by championing a unique role for Arctic Indigenous groups and an organizational culture of consensus and inclusivity. As I examine in more detail in Chapter 7, the Finnish and Canadian Initiatives left imprints on the Council that shaped its institutional logics.

Finally, this chapter demonstrates a close alignment between the factors that would contribute to the effectiveness of the Arctic Council - there was a good institutional fit between the institutional designs articulated in the Finnish and Canadian Initiatives, the 
governance environment and the immediate policy needs of the region. The institutional design, including the mandate and priorities, proposed for the Arctic Council through the Finnish and Canadian Initiatives may have differed, but they were both a product of real-time dynamics within the Arctic governance environment and the geopolitical and environmental problems the region faced. The interests and the priorities of actors outside the Arctic region were largely absent with the exception of a broader scientific community that was active in the region. The next chapter builds on the analysis presented here by examining the Arctic Council's first 10 years (19962005). Chapter 5 uses the same determinants of institutional effectiveness to structure an analysis of how the Arctic Council worked and to what extent it was effective in its fledgling years. 


\section{Chapter 5: Boundary Work Through the Arctic Council (1996- 2005)}

After close to a decade of work by Arctic states, Indigenous groups and civil society actors, the Arctic Council was established in 1996 as a forum that "provide[s] a means for promoting cooperation, coordination and interaction among the Arctic States, with the involvement of the Arctic Indigenous communities and other Arctic inhabitants on common Arctic issues; in particular, issues of sustainable development and environmental protection in the Arctic" (Arctic Council, 2013b).

This chapter analyzes how the Arctic Council worked and to what extent it was effective during its first decade in existence. I begin by considering how the governance environment evolved between 1996 and 2005 as the network of institutions in the Arctic moved beyond Cold War dynamics and various state and non-state actors sought to rebrand the region as a "zone of peace and cooperation." Through a thematic analysis of the Arctic Council declarations during this period, I then study the policy issues (problems to be solved) that were placed on the Arctic Council agenda. I conclude by examining the institutional design of the Arctic Council. As discussed in Chapter 3, the analysis of this last determinant is supported by the explanatory power of the concept of boundary work - the governance mechanisms that support the co-creation of knowledge between actors from different social worlds - to understand how the Arctic Council worked and highlight the Council's unique governance features. 


\section{Governance Environment}

When the Arctic Council was officially established in September 1996, the region remained at the periphery of global attention. World leaders were preoccupied with issues to the South, such as events in Kosovo and Afghanistan. As the 1995 governance map presented in Chapter 4 demonstrates (Figure 4.2), at the beginning of this period, there were still only a small number of multilateral institutions that were focused on governance at the circumpolar level. In 1996, the Arctic was largely managed through the domestic policies of the Arctic states with influence from multilateral institutions at the sub-regional (e.g. Nordic Council of Ministers (NCM), Barents Euro-Arctic Council (BEAC)) and international levels (e.g. the Vienna Convention for the Protection of the Ozone Layer (VC), International Maritime Organization (IMO)). This was a period when the position of the Arctic Council in the network of multilateral institutions in the region and the relevance of the Council for actors with the motivation and capacity to mobilize were important factors for its institutional effectiveness.

By the beginning of this period, the UNCLOS III had come into force (1994). Iceland had ratified the Convention (1985), which made it eligible to prepare and submit a claim to extend its exclusive economic zone to the Commission on the Limits of the Continental Self (CLCS) under the new rules that had been established. Furthermore, during this period Norway ratified UNCLOS III in 1996, Russia in 1997, Canada in 2003 and Denmark in 2004. This meant that these states now had an established mechanism to 
confirm their sovereignty and expand their jurisdictions for accessing natural resources in the region. ${ }^{32}$

With these developments in mind, this was a point when there was sufficient interest and openness, especially from leaders and policymakers in Canada, Finland and Russia, to establish a multilateral institution at the circumpolar level (English, 2013; Slipchenko \& Hannigan, 2010; Stone, 2016). However, because the United States would not permit security to be on the agenda of the Arctic Council, this young institution was limited to issues related to environmental protection and sustainable development. These policy issues were not as politically sensitive and did not attract the dedicated attention of senior government officials (English, 2013). This meant that non-state actors, such as Indigenous and research representatives, had more freedom to participate in, and power to influence, the multilateral institutions being established in the region (T. S. Axworthy \& Dean, 2013).

\footnotetext{
${ }^{32}$ It should be noted that the Commission on the Limits of the Continental Shelf does not facilitate resolving overlapping claims (Annex II, article 9 of UNCLOS); therefore, submitting Canada's territorial claim to the Commission will not directly resolve its boundary issues with the United States.
} 
Indigenous \& Community

Organizations

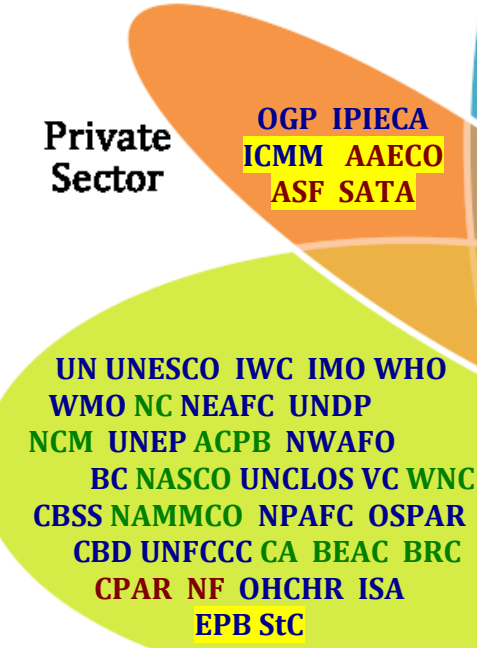

Government

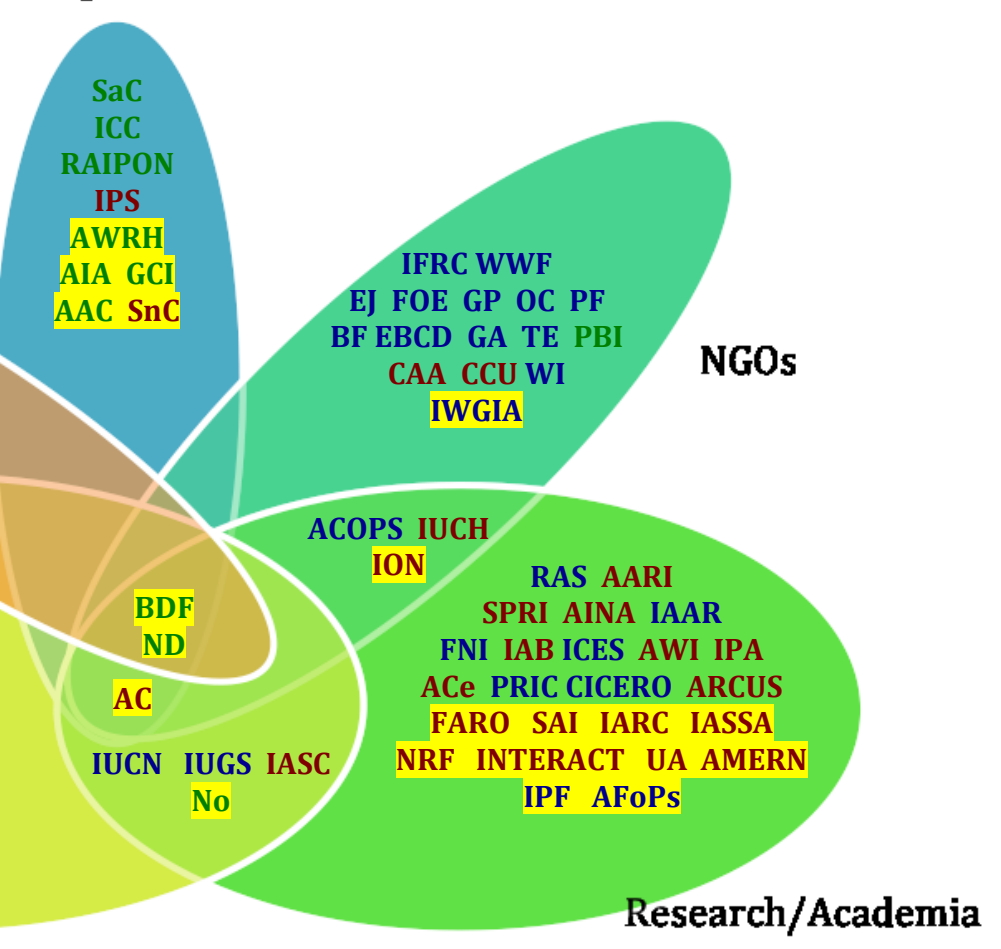

FNI IAB ICES AWI IPA

ACE PRIC CICERO ARCUS

FARO SAI IARC IASSA

IPF AFoPs

Figure 5.1: Arctic governance map 2005

Blue: International institutions, Red: Circumpolar institutions, Green: Subregional institutions. Institutions highlighted in yellow were established between 1996 and 2005 (Full list of institutions in Appendix 2).

Figure 5.1 maps the multilateral institutions with mandates related to environmental management and sustainable development in the Arctic in 2005. This governance map provides a visual representation of important changes to the governance environment that took place in the region during the Arctic Council's formative years. Overall, the number of multilateral institutions involved in Arctic governance continued to grow. Between 1996 and 2005, 28 new multilateral institutions emerged and a majority of the growth was the formation of institutions working at the circumpolar level (red text). The total number of regionally focused institutions went from 11 in 1995 to 26 in 2005, which serves to emphasize that the idea of managing the Arctic as a region was taking hold 
and the importance of establishing multilateral governance mechanisms at this level was believed to be useful. By way of contrast, the growth in international institutions (blue text) with Arctic-relevant mandates was relatively limited with only 7 new institutions joining the 45 that were established in the period leading up to 1996. Furthermore, only 7 sub-regional institutions (green text) were created during this period and 4 were Indigenous organizations.

Perhaps the more interesting findings from this period are the changes in the composition of the multilateral institutions created during this period. First, the most immediate and substantial growth was in the institutions in the research/academia zone; therefore, the data collected about institutions reinforces interviewees' observations that organizations dedicated to scientific research and environmental protection were active in the region during this period. Researchers recognized that the information they needed to understand environmental change in the region depended on forming collaborative links across state boundaries (personal communication, November, 2014). Furthermore, most of these new research and science-focused institutions had mandates dedicated specifically to the Arctic region with only 2 internationally focused institutions emerging early in the 2000s.

This period also observed a further growth in Indigenous organizations. The Saami Council (SaC), the Inuit Circumpolar Council (ICC), and the Russian Association of Indigenous Peoples of the North (RAIPON) continued to strengthen their connections across state lines, while new organizations were established in the region, including: 
- the Association of World Reindeer Herders (AWRW) in 1997 that obtained Arctic Council observer status in 2000 ,

- Aleut International Association (AIA) in 1998 that gained permanent participant status in the Arctic Council that same year,

- Gwich'in Council International (GCl) in 1999 that gained permanent participant status in the Arctic Council in 2000,

- Arctic Athabaskan Council (AAC) in 2000 that gained permanent participant status in the Arctic Council in 2000, and

- Snowchange Cooperative (SnC) in 2002 that has no direct affiliation with the Arctic Council. ${ }^{33}$

The creation of these multilateral institutions highlights continued efforts of Indigenous groups in the region to form connections across boundaries during this period. The mobilization of the Arctic Indigenous peoples set an important tone for the region's institutions. Interviewees proposed that the participation of Arctic Indigenous groups guided the early organizational culture and institutional design of the Arctic Council, a proposition that is examined in more detail later in the chapter.

The latter part of this period (2001 to 2005 ) also saw the creation of 4 private sector institutions. Although this zone remained relatively small, the number of institutions in this zone tripled during this period. New institutions included the International Council of

\footnotetext{
${ }^{33}$ SnowChange Cooperative is based in Finland and undertakes a variety of projects and activities across the Arctic region with a focus on documenting traditional knowledge and working with local communities to inform climate and Indigenous policies (SnowChange Cooperative, 2017). Although their website indicates that they have worked with the Arctic Council, they have no formal affiliation with it.
} 
Mining and Metals (ICMM), which had an international focus, and the Association of Arctic Expedition Cruise Operators (AAECO), the Arctic Shipping Forum (ASF) and the Sustainable Arctic Tourism Association (SATA), which all had a circumpolar focus. The emergence of these institutions provides support for interviewees' accounts that the Arctic, as a region, started to become the focus of growing economic attention in the early part of the 2000 s.

In contrast, the number of new government institutions remained almost unchanged after notable growth in the period between 1987 and 1995. Interviewees emphasized that the geopolitics of fading Cold War tensions still provided Arctic states with incentives to engage in circumpolar cooperation; however, these states increasingly recognized the Arctic Council as the regional forum that would provide this mechanism for discussion and cooperation on mutually acceptable issues and projects. During this period, there were no discussions regarding the need to establish other institutions to support regional cooperation by states. Furthermore, no new non-Arctic states expressed public interest in participating in the region's multilateral institutions, including the Arctic Council. In fact, as late as 2003 and 2004, Arctic Council officials began to recognize the global significance of the changes in the Arctic. They, therefore, approached several countries, including the E.U. and China, to encourage their participation in the Arctic Council, but they received no interest (personal communication, January 16, 2015). 
The final important feature of the governance environment observed through Figure 5.1 is that between 1996 and 2005 there was a shift toward more inclusive institutions. In addition to the Arctic Council, which engaged actors from government, Indigenous organizations, research/academia and NGO zones, the 2005 governance map demonstrates a growth in institutions at the sub-regional, circumpolar and international levels that enabled discussion and collaboration among different actor-types, including Nordregio (No), the Institute of the North (ION), the Baltic Development Forum (BD) and Northern Dimensions (ND). This could suggest that designing more inclusive institutions was part of a broader international shift to accept and even foster more inclusive governance approaches in multilateral institutions. Irrespective of the cause of this change, it meant that the Council was not heading down this path alone.

Overall this analysis builds our understanding of the interests, actors and dynamic governance environment in which the Arctic Council existed during its early years. Furthermore, this review of the governance environment confirms the importance of two factors that explain the effectiveness of the Arctic Council. First, this analysis demonstrates that the Arctic Council's position in the network of multilateral institutions was an important criterion for its effectiveness during this period. The Arctic Council was at the centre of a broader trend to establish multilateral institutions at the circumpolar level and to involve different actor-types. Furthermore, during this period, Arctic states initiated no other efforts to establish institutions to support broad Arctic cooperation and collaboration. For Arctic states, the Arctic Council had filled this institutional gap in the network of institutions involved in Arctic policy. 
However, Arctic states' commitment to the Arctic Council, as the focal point for circumpolar cooperation, should not be confused with a high level of political interest in the Arctic Council. The Arctic Council held sufficient relevance for Arctic states to retain their support to exist and fulfill its policy shaping functions; however, it held relatively limited interest with political leaders from these states. This is contrasted by the continued strength and prominence of Indigenous organizations and scientific communities activities in the region during this period, who were highly motivated to contribute to the work of the Arctic Council. This reinforces the proposition that a criterion for the effectiveness of the Arctic Council was its relevance for actors with the capacity and motivation to mobilize to support its position in the network of institutions in the region.

Nevertheless, this analysis also indicates that not all actors placed the same level of relevance on the Arctic Council. In fact, the difference in the levels of interest helps to reinforce observations made by interviewees that scientific and Indigenous actors held notable influence over the policy priorities, organizational culture and institutional design of the Council in its formative years. Furthermore, interviewees involved in the establishment of the Council argue that the relatively low political salience of the Arctic, as a scale for governance, allowed the space for less conventional institutional features to be considered and adopted. In the following section I examine the policy issues that the Council had on its agenda in its early years. 


\section{Problems to be Solved}

In Chapter 3, the nature of the problem to be solved was introduced as a determinant of institutional effectiveness. In this category, I examine the types of policy priorities included on the Arctic Council agenda, how they are framed and the broader salience of these issues to understand how these factors explain the effectiveness of the Arctic Council during this period.

To support an analysis of the policy issues on the Arctic Council agenda between 1996 and 2005, I conducted a content analysis of the Arctic Council declarations released by ministers during this period. The Council's declarations are released every two years at the ministerial meetings that mark the conclusion of one chairmanship and the beginning of the next. These documents are negotiated by the member states with the participation of permanent participants using a consensus-based decision-making approach over several months. The document is finalized during the ministerial meeting (which includes permanent participants) and signed by the ministerial representative of each member state. Each declaration recognizes the activities and actions of the Council during its past chairmanship and sets out the priorities for the next chairmanship. Table 5.1 identifies the key themes identified in the five declaration released during this period and indicates the frequency that each themes is referenced. 
Table 5.1: Results of content analysis to identify frequency of references to themes in Arctic Council declarations (1996 to 2005)

\begin{tabular}{|c|c|c|c|c|c|}
\hline & $\begin{array}{r}\text { Ottawa } \\
(1996)\end{array}$ & $\begin{array}{r}\text { Iqaluit } \\
(1998 b)\end{array}$ & $\begin{array}{r}\text { Barrow } \\
(2000)\end{array}$ & $\begin{array}{r}\text { Inari } \\
(2002)\end{array}$ & $\begin{array}{r}\text { Reykjavik } \\
(2004 \mathrm{c})\end{array}$ \\
\hline $\begin{array}{l}\text { Regional cooperation, } \\
\text { including: }\end{array}$ & 7 & 7 & 17 & 14 & 15 \\
\hline military-security & 1 & 0 & 0 & 0 & 0 \\
\hline $\begin{array}{l}\text { Indigenous peoples, } \\
\text { including: }\end{array}$ & 6 & 6 & 6 & 5 & 5 \\
\hline Traditional knowledge & 0 & 1 & 0 & 3 & 2 \\
\hline $\begin{array}{l}\text { Human dimension, } \\
\text { including: }\end{array}$ & 6 & 8 & 5 & 8 & 10 \\
\hline $\begin{array}{ll}\text { Health } \\
\end{array}$ & 0 & 4 & 3 & 1 & 1 \\
\hline Social-Cultural & 2 & 2 & 1 & 1 & 0 \\
\hline Education & 1 & 2 & 0 & 1 & 2 \\
\hline Capacity building & 0 & 0 & 1 & 2 & 4 \\
\hline $\begin{array}{l}\text { Environmental } \\
\text { protection, including: }\end{array}$ & 4 & 15 & 24 & 21 & 22 \\
\hline Biodiversity/conservation & 1 & 0 & 2 & 1 & 3 \\
\hline $\begin{array}{r}\text { Environmental } \\
\text { emergencies }\end{array}$ & 0 & 1 & 1 & 2 & 3 \\
\hline Marine environment & 0 & 1 & 2 & 1 & 2 \\
\hline Pollution & 0 & 5 & 6 & 8 & 5 \\
\hline Climate change & 0 & 1 & 3 & 11 & 10 \\
\hline $\begin{array}{l}\text { Scientific-research } \\
\text { collaboration }\end{array}$ & 2 & 5 & 17 & 12 & 21 \\
\hline $\begin{array}{l}\text { Sustainable } \\
\text { development, including: }\end{array}$ & 5 & 7 & 12 & 10 & 15 \\
\hline Economic & 1 & 1 & 2 & 2 & 2 \\
\hline Natural resources & 1 & 2 & 3 & 6 & 4 \\
\hline Infrastructure & 0 & 2 & 1 & 1 & 1 \\
\hline Business & 0 & 0 & 0 & 1 & 0 \\
\hline Energy & 0 & 0 & 0 & 0 & 0 \\
\hline
\end{tabular}

Complete list of issues identified for Arctic Council, 1991-2015 presented in Appendix 3.

The policy issues and sub-issues itemized in Table 5.1 inform our understanding of what policy issues were on the Arctic Council agenda during each chairmanship and give us an indication of how the prominence of these issues evolved during the first 10 years of the Council's life (see Appendix 3 for more details about the methods and 
coding decisions). This thematic review provides evidence of the continuing influence of the issues identified through the Arctic Environmental Protection Strategy (AEPS) and the Arctic Council Panel Report, including regional cooperation, Indigenous participation, the human dimension, and environmental protection. This data is supplemented by an analysis of the substance of these references and input from interviewees and survey respondents to provide a deeper and more refined understanding of the priorities of the Council during its early years. Based on this analysis, there were three core policy priorities that dominated the agenda of the Arctic Council - cooperation and trust building, environmental protection and Indigenous peoples/human dimension. Sustainable development is also regularly referenced; however, the sub-issues associated with this theme tell us as much about what the Arctic Council was not working on as what was included on the agenda. Each of these themes is discussed in turn below.

\section{Cooperation and trust building}

The importance of regional and international cooperation and the Arctic Council as a mechanism for this cooperation is at the forefront of the Arctic Council declarations released between 1996 and 2005. The primary focus of this theme relates to cooperation between Arctic states; however, declarations released by the Arctic Council also recognized the importance of cooperation with sub-regional institutions (such as Barents Euro-Arctic Council, Nordic Council of Ministers and the Council of Baltic Sea States) and international institutions and initiatives - in particular the United Nations. Although military activity and security issues are absent from the Arctic Council's agenda (except in the 1996 Ottawa Declaration that specifies that it will not be part of 
the Arctic Council's mandate ${ }^{34}$ ), these declarations' emphases on the importance of cooperation stress that trust building and how Council representatives work together was as important as the specific activities or projects that the Arctic Council worked on. During this period, the Arctic Council was positioned as a flagship initiative by the Arctic Council member states because it established the region as a "zone of peace and cooperation" as proposed by Gorbachev in 1987. For many interviewees and survey respondents involved with the Arctic Council in these early years, the Arctic Council's purpose was foremost as a forum for Track Two diplomacy. ${ }^{35}$ Furthermore, survey respondents who were directly and indirectly involved with the Arctic Council during this period consistently ranked increases in international cooperation as the most important impact of the Arctic Council between 1996 and 2005 (Kankaanpää \& Young, 2012b).

\section{Environmental protection}

With the launch of the Arctic Council in 1996, environmental protection, complemented by scientific collaboration, was recognized as a core theme. In particular, the Ottawa Declaration confirmed that the work of the AEPS would be "integrated within the Council” (1996). As a result, environmental protection generally, and pollution

\footnotetext{
${ }^{34}$ The inaugural declaration of the Arctic Council (1996) included a brief footnote intended to explicitly clarify that security issues would not form part of the Arctic Council mandate. This reflected a firm position by the United States that it would not endorse the Arctic Council without this limitation being visibly articulated. As a result, the Council was limited to matters related to the environment and sustainable development.

${ }^{35}$ Track Two diplomacy is "unofficial dialogue and problem-solving activities aimed at building relationships and encouraging new thinking that can inform the official process. Track Two activities typically involve influential academic, religious, and NGO leaders and other civil society actors who can interact more freely than high-ranking officials" (United States Institute of Peace, 2016).
} 
prevention and response specifically, were consistently dominant themes between 1996 and 2005. Where cooperation and trust building could be seen to set the tone for how the Arctic Council would work, the environmental protection priorities set through the AEPS established the core subject matter for the early work of the Arctic Council. As Arctic states had learned through bilateral activities for several decades, scientific collaboration and the environment provided a indirect approach to improving relations and building trust (Fenge, 2012a; Griffiths, 2011; Rhemann, 2012; Slipchenko \& Hannigan, 2010). These activities also provided immediate opportunities to deal with very real safety concerns caused by pollution and nuclear waste in the region.

A foundational component of this work was the scientific monitoring and assessment that had been initiated under the AEPS through the Arctic Monitoring and Assessment Programme (AMAP). The importance of collaborating across borders to fill information gaps and conduct scientific research in the region remained central to the Arctic Council's work during this period. This is a policy area were the influence of the two precursor initiatives most closely intersected - with the Canadian Initiative being most interested in how scientific research was conducted and the Finnish Initiative being focused on the resulting products of this collaboration to support environmental protection in the region.

Furthermore, while the AEPS and Arctic Council Panel Report referenced climate change, initial references to climate change in the Arctic Council declarations were limited to justifying further research to understand climate change and its impacts in the 
Arctic. Despite the prominence that this issue now holds in the region and globally, "climate change was not known as an issue" in the late 1990s and early 2000 s in the region by people outside the scientific community (personal communication, March 9 , 2015). This was not inconsistent with public awareness more broadly that remained low during this period (Weart, 2017).

The global significance of signs of climate change in the Arctic was not identified in the declarations during this period and the relationship between changes in the Arctic and the global climate change phenomenon was not the focus of the Council's work. That being said, the Arctic Council's work to understand climate change culminated in the acceptance of the Arctic Climate Impact Assessment (ACIA) by the Arctic Council ministers in the 2004 Declaration. Although, several accounts of the preparation and release of this report suggest that there was resistance from certain member state officials, the United States in particular, to recognizing and releasing this report publically (English, 2013; Watt-Cloutier, 2015). The political sensitivities of member states about the release of this report were the first signs that climate change would assume a place of prominence on the Arctic Council agenda and that this policy issue would become the source of political tension in the Arctic and more broadly.

\section{Indigenous participation and the human dimension}

The importance placed on the knowledge and participation of the region's Indigenous peoples, which was championed through the Arctic Council Panel and became a cornerstone of the Canadian Initiative, was consistently included in all of the Arctic Council declarations between 1996 and 2005. References to Indigenous peoples were 
general in nature - acknowledging their "unique" or "essential" roles in the work of the Arctic Council. These references lacked specifics about how Indigenous peoples would be involved. Furthermore, the importance of including traditional knowledge in the work of the Arctic Council was first introduced in the 2002 Declaration when the the Sustainable Development Working Group (SDWG) was tasked with preparing the first Arctic Human Development Report. Traditional knowledge, as a theme in the declarations, assumed a small but consistent place in subsequent declarations.

The 'human dimension' that figured prominently in the Canadian Initiative also assumed a regular place in the Arctic Council agenda after its inception. In some cases, this involved general recognition that the work of the Arctic Council was intended to serve or meet the needs of the region's inhabitants. However, other instances included specific references to health, socio-cultural and education activities of the Arctic Council. Furthermore, the need for capacity building was first introduced as a focus in 2000 . These early references to capacity building acknowledged that human capacity, and the capacity of Indigenous peoples in particular, in the Arctic was a critical component of scientific research and sustainable development in the region.

\section{Sustainable development}

Sustainable development was also referred to in the Council's declarations; however, during this period, it took a back seat to environmental protection. Although sustainable development was mentioned in the AEPS and the Arctic Council Panel Report, this concept and the specific role that the Arctic Council would play related to sustainable development remained vaguely defined in the early years of the Council's work. The 
Arctic Monitoring and Assessment Programme (AMAP) continued the work it started under the AEPS to monitor and assess the environmental impacts of development in the region. The Sustainable Development Working Group's (SDWG's) most prominent contribution came at the end of this period with the 2004 release of the Arctic Human Development Report. This report placed a heavy emphasis on the "human dimension" of sustainable development with a strong focus on human health and the social and cultural impacts of development. The declarations paid minimal attention to the economic components of sustainable development, such as natural resources, infrastructure, energy and business. The absence of references to the economic theme is notable given that it is recognized as a pillar of sustainable development, as outlined in the Brundtland report (United Nations World Commission on Environment and Development, 1987), which inspired the creation of the SDWG. One person interviewed about this period indicated that in the early 2000s there were discussions about including economic issues on the agenda of the Arctic Council, but officials determined that the "timing was not right." There was a general agreement to "avoid sensitive topics" to keep everyone at the table (personal communication, January 16, 2015).

This section has provided an overview of the policy areas that the Arctic Council initially placed on its agenda and also considered some of the issues that were absent. This analysis confirmed that the policy issues on the Council's agenda had the features necessary to meet one of the criteria for its effectiveness during this period. Consistent with the issues introduced through the Finnish and Canadian Initiatives, the policy issues on the agenda were framed to be of particular importance to the people that lived 
in the Arctic. As has been discussed previously, at this early stage the issues facing the Arctic Council were neither visible at an international level nor seen by the Council as international in nature. This analysis also highlighted that the issues included on the agenda were framed to be uncontroversial and any issues that had the potential to generate conflict (e.g. security or economic issues) were left off the agenda entirely.

As a result, consistent with the analysis presented in the previous section about the relevance of the Arctic Council for different actors in the region, this analysis of the policy issues on the Arctic Council agenda demonstrated member states were committed to general cooperation at the circumpolar level to the point that they were willing to dedicate sufficient human and financial resources for the institution to continue to function; however, the salience of the specific environmental policy issues on the agenda did not warrant the dedicated attention of political representatives. Instead, member states delegated much of the work to government officials with scientific expertise, who considered the environmental issues on the Council's agenda to be salient and were committed to advancing its programme of work. Furthermore, Arctic Indigenous organizations also recognized the salience of the issues on the Council's agenda and were committed to actively participating and shaping the Council's policy priorities. This analysis confirmed that the salience of the policy issues on the Council's agenda was an important criterion of effectiveness for the Council during this period; however, this did not mean that all participants needed to agree on the salience of the Arctic Council's programme of work or dedicate the same level of effort to advance the Council's work. In the following section, I consider the institutional design of the Arctic 
Council and the role this determinant played in enabling the Council to respond the issues on its agenda.

\section{Institutional Design}

This section explores the institutional design of the Arctic Council and considers to what extent this determinant contributed to the Council's effectiveness between 1996 and 2004. In particular, this analysis examines how the relationship between the Arctic Council governance model and the role the Council was established to play as a factor to explain its institutional effectiveness. In Chapter 3, I suggested that because of the Arctic Council's role in generating knowledge and policy advice, our understanding of the Arctic Council would be enhanced by introducing the concept of boundary work, which analyzes the governance mechanisms that engage actors from different social worlds to co-create knowledge and policy advice. It draws our attention to the flow of ideas within an institution that contribute to the creation of products that hold a meaning and have an impact on each side of a boundary (boundary object). I proposed that the Council's ability to bridge the boundaries between political, scientific and Indigenous social worlds was a key contributor to the Arctic Council's institutional effectiveness in its early years.

Through field observation and interviews, I was exposed to the distinct knowledge and value systems that exist within the Arctic Council and the role the Council plays to work across the boundaries that exist between these different social worlds. I saw that the concept of boundary work has explanatory power to elucidate how the Arctic Council governance model initially worked, and to advance our understanding of how and to 
what extent the Council's design contributed to its effectiveness. The analysis presented in this section is organized into 3 components: the Council's raison d'être, organizational culture and governance features. These categories are the product of a thematic analysis of interview and survey data.

\section{Raison d'être}

The nature of the policy issues on the agenda of the Arctic Council and the raison d'être of the Council are intimately linked, but distinct. In analyzing the raison d'être of the Arctic Council, we observe a strong alignment between the institutional design, issues that the Council set out to work on and the governance environment during this period. Furthermore, the raison d'être of the Council during its fledgling years maintained clear links to the Finnish and Canadian Initiatives that drove its creation.

The 1996 Ottawa Declaration stated that the Arctic Council would be "a means for promoting cooperative activities" (1996, p. 2) and a Joint Communiqué of the Governments of the Arctic Countries published with this declaration stated that "Ministers viewed the establishment of this new intergovernmental forum as an important milestone in their commitment to enhance cooperation in the circumpolar North" (1996, p. 6). Interviewees' agreed that the main purpose of the Arctic Council from 1996-2005 was creating a "model" or "platform" for peaceful cooperation for actors in the region. Moreover, consistent with the analysis in previous sections, state-to-state trust building was referenced by many interviewees as an important aspect of the Arctic Council's work during this early period. Furthermore, the Council's focus on environmental protection meant that in many cases the best way to build trust and 
establish constructive relationships amongst the region's states was through collaboration amongst scientists. As a result, one of the outcomes of the creation of the Arctic Council was providing the scientific community with new mechanisms to connect with policymakers throughout and beyond the region (personal communication, November 2, 2014) - providing scientists and researchers with increased power to influence policy. Similarly, the region's Indigenous peoples, as permanent participants and observers, also had new mechanisms to foster cooperative relations with state officials and scientists to influence policy. Through their access to Arctic Council meetings and activities, Arctic Indigenous groups had opportunities to inform what information was collected, how and where it was collected, the translation and interpretation of that information and the policy advice that it generated.

The second core purpose of the Arctic Council was organizing meetings and projects where actors with different experiences, expertise and ways of understanding the world could come together to share information and collectively build knowledge that informed public policy - opportunities to generate knowledge that was relevant and meaningful to different types of actors. Without being aware of the concept of boundary work, interviewees and survey respondents acknowledged the importance of the functions of communicating, translating and mediating the boundaries between people from different social worlds and recognized these functions as a raison d'être of the Council (Kankaanpää \& Young, 2012b; Miller, 2001). 
Interviewees involved with the Council during this period described "creating mechanisms to share data and information," (personal communication, June 21, 2016), "translating to understand technical information" (personal communication, November 19, 2014), "talking and trying to understand" (personal communication, January 21 , 2015), building a "vehicle to turn data into knowledge" or "interpret data for policymakers" (personal communication, November 2, 2014), and "preparing the ground for other fora" at the domestic and international levels (personal communication, January 21,2015$)$. Interviewees and survey respondents gave the sense that the work of the Arctic Council was "leveraging existing links" with policymakers and other institutions (e.g. IPCC, UNEP, NCM, IASC) (personal communication, March 6, 2015). For some, it was important to clarify that "the actions related to [sustainable development] locally and regionally are the purview of the individual Arctic states" (Kankaanpää \& Young, 2012b); therefore, the purpose of the Arctic Council was to inform and influence domestic policy. While others focused on how the Council was "feed[ing] into global processes" such as the Stockholm Convention on Persistent Organic Pollutants, the Convention on Biological Diversity and the Intergovernmental Panel on Climate Change (personal communication, November 2, 2014 and January $15,2015)$ and therefore they saw the Council's primary purpose as feeding international policy. Participants saw the Arctic Council as a forum for knowledge generation and policy shaping that provided good quality and relevant information and knowledge that was intended to inform (and by extension hopefully influence) institutions that held the authority to make policy decisions at the domestic and international levels. 
Finally, the Arctic Council provided a model for cooperation by actors in the region intended to focus on topics that were specifically related or relevant to the Arctic. The institutional design of the Council was influenced by a desire to identify and respond to issues of interest to Arctic inhabitants - this was central to its raison d'être and, as we will see in the next section, was important in defining the organizational culture of the Arctic Council.

\section{Organizational culture}

This regionally focused institution with a low political profile adopted practices that fostered an organizational culture consistent with its stature and purpose. Interviewees and survey respondents described the Council as small, informal, loose and flexible. The Arctic Council's day-to-day work was highly technical and research-driven - its work was low profile relative to the more politicized international arenas of international security, diplomacy and finance. As a result, senior government officials largely ignored its day-to-day work and mid-level bureaucrats, technical experts and Indigenous representatives were left to advance the priorities on the Council's agenda. Normative terms used to describe the Council's organizational culture included "apolitical," "pragmatic" and "problem-focused." However, the most prominent feature of the organizational culture introduced by interviewees was the central importance placed on good relationships, working collaboratively, and building trust over time.

Maintaining a collegial and even friendly organizational culture was feasible because there was little turnover in the core group of people involved. Interviewees' accounts of the Arctic Council in its early days consistently refer to the small and informal nature of 
the meetings. Interviewees referenced the "Arctic Council family," discussions taking place over coffee or beer, and the critical importance of the friendly relationships that existed between a core group of "regulars" involved in Arctic Council work. This dynamic existed at the working group level, but it was also present at Senior Arctic Official (SAO) meetings. Interviewees spoke about the relaxed and informal structure of meetings that allowed members, permanent participants, working group chairs and even observers to participate in policy discussions - discussing findings, considering options and debating recommendations. Interviewees' descriptions of the size of meetings are corroborated by recent work by Knecht (2016), who is conducting research on participation in Arctic Council meetings over time and is currently examining the implications of an increase in participation on the Arctic Council (2017).

This is an environment where boundary work was integrated into the discussions without intention or forethought. Boundary objects, products designed to be used in multiple social worlds, were created through an unstructured and informal process that was facilitated by a small number of participants who had an intimate knowledge of the region's issues and had established close working relationships. Interviewees proposed that during this period "the approach was as important as the content" (personal communication, March 9, 2015). In fact, one Indigenous representative explained that their organization was willing to avoid sensitive topics (such as human rights) in order to keep everyone at the table and focus on issues and activities that they could agree on (personal communication, March 11, 2015). There was a sense that Arctic Council participants had a collective "sense of ownership" for the work they produced together 
(personal communication, January 16, 2015). Furthermore, interviewees referenced the freedom and flexibility "to get work done" that was facilitated by a decentralized approach to work (personal communication, January 16, 2015).

The Arctic Council created a space where representatives of scientific, political and Indigenous social worlds could co-exist and work collaboratively. Furthermore, because these different social worlds were present and important to the work of the Arctic Council, it is not surprising that interviewees specifically mentioned the importance of good communication and the use of a consensus-based decision-making approach at all levels. Several interviewees argued that agreement was reached at even the highest levels because of the organizational culture of the Arctic Council. As I discuss further in Chapter 7, this organizational culture can be understood as a critical component of the early institutional logics that shaped the day-to-day practices of the Council in its early years.

\section{Governance features}

Since its inception, the Arctic Council brought together actors from Indigenous, scientific and political social worlds. The Council was designed to facilitate boundary work internalize the negotiation process between these different social worlds and establish governance mechanisms for mutual understanding and co-creation of knowledge. This is not to suggest that the Arctic Council was intentionally designed to do boundary work; rather, the design features, combined with the organizational culture and nature of the issues the Arctic Council was tasked with working on, enabled and benefited from governance mechanisms that facilitated boundary work. 
The concept of boundary work encourages us to differentiate Arctic Council participants by the social world that shapes their values, norms and knowledge systems rather than by the organization they represent. Using Figure 5.2 to illustrate the point, the circles in the Venn diagram represent the information, knowledge and expertise of the social worlds that participate in Arctic Council activities. Actors from each social world contribute information, knowledge and experience defined by the norms, values and knowledge system of that social world. The black lines represent the boundaries of each social world and the spaces where the circles overlap represent spaces for boundary work where these social worlds co-create knowledge and policy advice. The act of working across these boundaries requires communication, translation and mediation - the products of the negotiation between social worlds are therefore referred to as boundary objects.

In this context, scientists that work for Arctic states are classified as scientific experts rather than policymakers, if that is the social world they are connected to and the function they are tasked with performing at the project, working group or SAO levels. Furthermore, there are Arctic Council observer NGOs that are connected to the Indigenous social world and focus on advancing Indigenous interests and priorities (e.g. the Association of World Reindeer Herders (AWRH) and the International Work Group for Indigenous Affairs (IWGIA)). Finally, member states obviously hold the most prominence as policymakers in the region; however, IGOs and non-Arctic states that 
participate as observers, in some cases, are best understood as policymakers as well (e.g. UNEP, IMO, Netherlands, France).

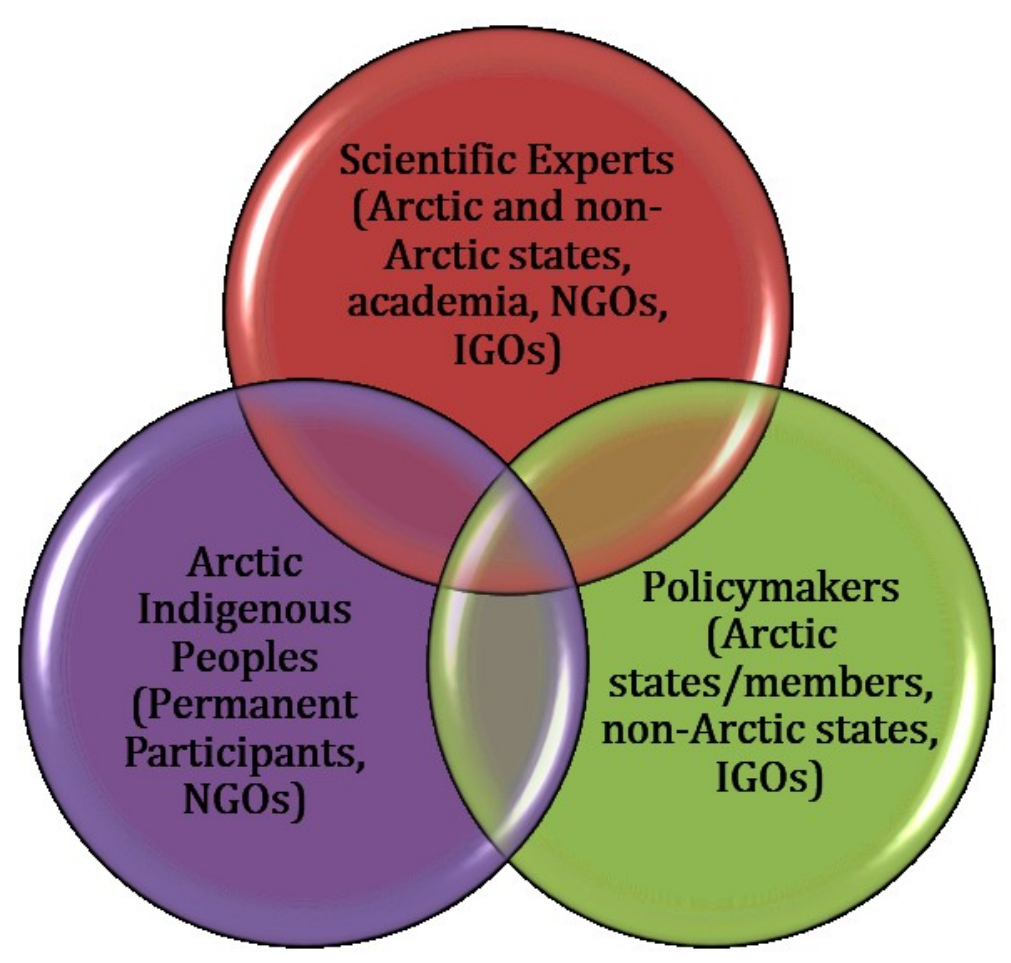

Figure 5.2: Social worlds of the Arctic Council

As I introduced in Chapter 3, Guston $(1999,2001)$ proposes that boundary work involves three features:

1. Involvement of actors from both sides of a boundary;

2. Provision of opportunities or incentives to work across social worlds; and

3. Maintenance of distinct lines of responsibility and accountability to their respective social worlds.

These features provide important guideposts to analyze the governance features of the Arctic Council. 
To examine the governance structures that supported boundary work in the Council, it is appropriate to start at the working group level. Based on the accounts of interviewees, during the early years of the Arctic Council the "real work" was done by the working groups (personal communication, September 16, 2015). In fact, some interviewees suggested that the most important work was done at an even lower level through the different projects run by the working groups. It was at the working group and project levels that information was collected and discussions took place to translate information into knowledge. At the project level, technical reports were prepared and it was at the working group level that this knowledge was translated into policy advice. It was also at these levels that there was often close cooperation with other institutions at the local, national, regional and international levels.

This is not to suggest that all working groups functioned in the same way. The capacity and level of engagement varied significantly in the early years. The Arctic Monitoring and Assessment Program Working Group (AMAP), which was well established before the Arctic Council's creation, had already mobilized to do the work that it had been tasked with doing under the Arctic Environmental Protection Strategy (AEPS). By contrast, the Conservation of Arctic Flora and Fauna (CAFF) and Emergency Preparedness, Prevention and Response (EPPR) working groups struggled in these early years to get the support necessary to fulfill their mandates. Meanwhile, the newly formed Sustainable Development Working Group (SDWG) had access to resources, but suffered from a lack of clear direction about its purpose or priorities. Survey respondents and interviewees involved with the Arctic Council during this period 
perceived notable variations in the effectiveness of the Arctic Council working groups between 1996 and 2005 (Kankaanpää \& Young, 2012b).

The boundaries that were managed at the working group level varied depending on the working group and the particular projects that are being worked on. In theory, you could have projects or policy issues that require the bridging of boundaries between any combination of social worlds. For example, boundary work between Arctic Indigenous peoples and policymakers, between scientific experts and Arctic Indigenous peoples, between scientific experts and policymakers, or among all three social worlds.

In some cases an issue was so technical that there was little or no need for boundary work. For example, Phase I of the Arctic Council Action Plan (ACAP) project on Brominated Flame Retardants (BFRs) that brought together BFR experts to establish an inventory of sources and identify BFR alternatives (Arctic Council, 2004a). This is a highly technical and focused exercise that rests with specific scientific experts. The report that was generated from this exercise was then used to inform more broadly relevant discussions about contaminants in the Arctic; however, this particular project did not involve policymakers or Indigenous representatives.

By way of contrast, in 2004, the Arctic Monitoring and Assessment Programme (AMAP) conducted a project entitled Persistent Toxic Substances, Food Security and Indigenous Peoples of the Russian North (2004). Permanent participants initiated this project as a follow up to AMAP's first Arctic assessment report (1998). The project was co-chaired 
by a representative from RAIPON and the Executive Director of AMAP and the project brought together representatives of Indigenous communities in Russia's North, permanent participants, scientific experts from inside and outside the Arctic, member states, NGOs, and IGOs. This was a project where scientific, political and Indigenous social worlds needed to be bridged.

No matter what the focus, government representatives chaired all Arctic Council working groups. In some cases, the chair was a technical or scientific expert in their own right and in other cases they had limited scientific expertise and were more focused on translating science to policy. Irrespective of their individual capacities and experience, one of their functions, as chair of a working group, was to bridge the boundary between the working groups and the Senior Arctic Officials (SAOs), which could be best understood as the main boundary between science and policy within the Arctic Council.

The picture of the Arctic Council during these early years, as sketched by interviewees, is of a small and informal organization in which the connection between the scientific and the political social worlds was very direct. Working group chairs and participants had opportunities for discussions at the SAO level - whether it was to discuss the working group's future work and priorities, to respond to questions about the work that they had done, or to consider how working group reports and other products might best be used to inform policy at the domestic, regional and international levels. Furthermore, SAOs would draw on these discussions to advise and shape discussions with ministers. 
Interestingly, permanent participants held a unique position as a result of how the Arctic Council was structured. They not only participated at the working group level, they also participated in SAO and ministerial meetings and discussions. This meant that they had the opportunity to inform the work of the Arctic Council at every stage and level. In fact, because of the limited number of representatives supporting permanent participants, it was often the same person that participated on behalf of a permanent participant organization at every level of discussion (project, expert group, working group, SAO and Ministerial levels). Figure 5.3 visualizes how the Arctic Council worked using the boundary work concept. It illustrates that boundary work in the Arctic Council took place at multiple stages and levels in the process of knowledge generation and the translation of that knowledge into policy advice.

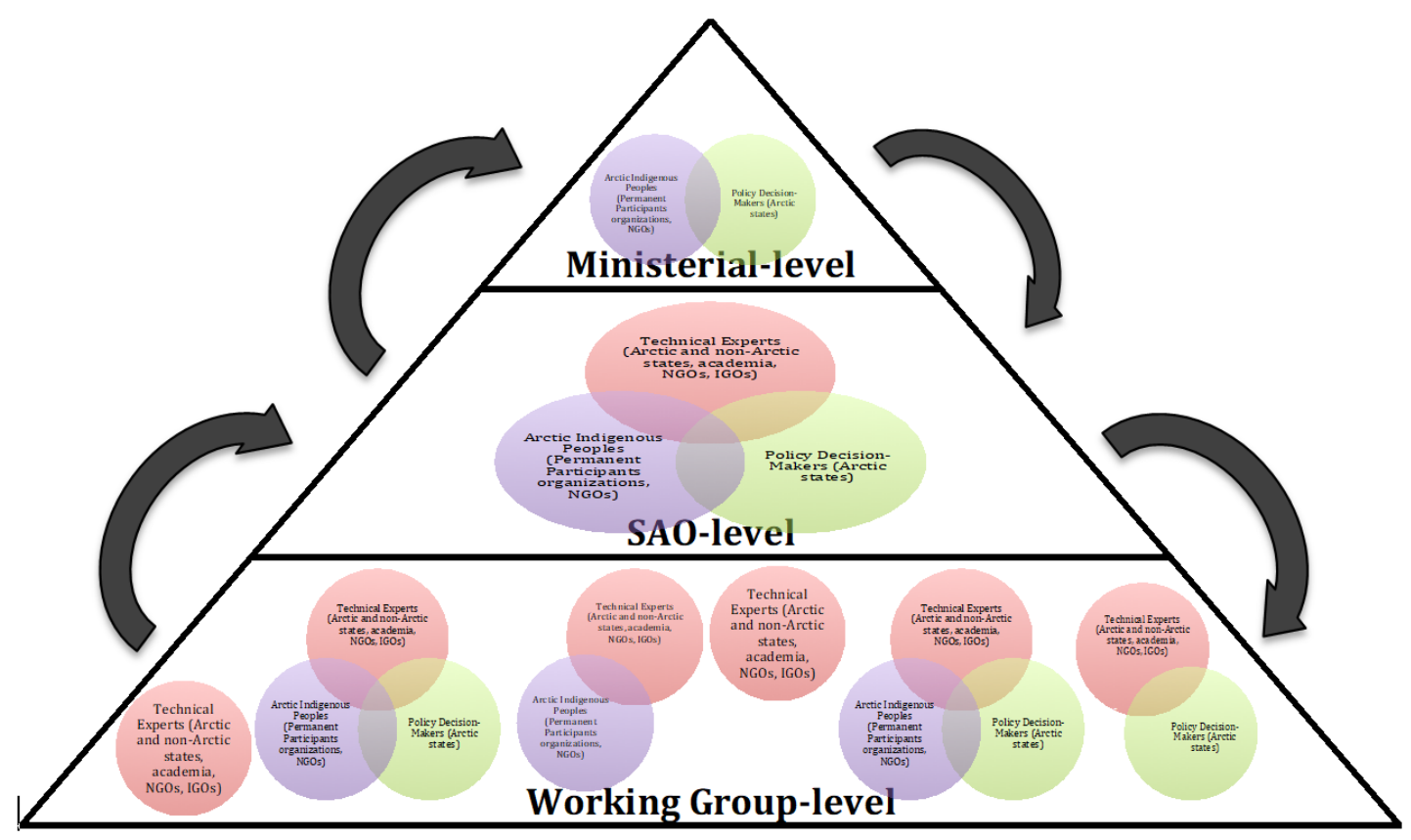

Figure 5.3: Multiple stages of boundary work in the Arctic Council. 
Understanding the Arctic Council through the lens of boundary work emphasizes the importance of governance mechanisms that facilitate communication, translation and mediation across boundaries (Cash et al., 2003). It also highlights the important role of those positioned within the Arctic Council to act as knowledge brokers between the different social worlds and between different layers of the Arctic Council (Clark et al., 2010). Finally, the concept of boundary work reminds us that in order for the Council to retain its stability it must respect each social world and participants need to remain accountable and responsive to their social worlds (Guston, 2001).

\section{Meeting needs and interests}

With this in mind, it is useful to consider what the needs of the actors from the different social worlds were during this period and how the Council met them. For the social world of politics and policymakers, interviewees were quite blunt that the Council's low political salience meant that this social world was primarily represented by civil servants, whose main interest was in the Arctic Council as a forum for relationship and trust building. The domestic architecture supporting each country's participation in the Council varied during this period, but Arctic states were consistent in indicating that their coordination of issues was ad hoc and informal. With the exception of endorsing the environmental protection objectives established through the AEPS, endorsing new priorities for the Arctic Council agenda and providing scientific experts with the mandate to focus on the Council's established priorities, policymakers from the Arctic states played a minimal role in the day-to-day substance of the Council's work during this period. Meanwhile, interest in the work of the Council by policymakers from non-Arctic states and IGOs was very limited. 
For scientific experts, the Arctic Council provided the mandate to collect data and conduct research that these researchers and scientists had already recognized was important to do. As the governance maps in Chapters 4 (Figures 4.1 and 4.2) and earlier in this chapter (Figure 5.1) illustrate, research-related institutions held a strong presence in the region and, in these early years, the Arctic Council provided the forum for scientists and existing science-based institutions to cooperate more systematically. Furthermore, the Arctic Council connected them with funders and policymakers both within the Arctic Council and in other institutions that had interests in specific projects or reports done by the Council.

Finally, Indigenous representatives found a unique avenue through the Arctic Council to engage and influence research and policy agendas in the region. Although Arctic states, including Canada, Norway and the United States, had provided opportunities domestically for Indigenous groups to participate, there was no multilateral institution in the region that had ever provided this opportunity to Arctic Indigenous groups before. ${ }^{36}$ During this period, different Indigenous groups organized themselves for the express purpose of taking advantage of this opportunity to access policymakers and those officials and experts involved in the policymaking process. This included the creation of the Aleut International Association (AIA), Gwich'in Council International (GCI) and the Arctic Athabaskan Council (AAC). Despite varying levels of capacity to meaningfully

\footnotetext{
${ }^{36}$ In 2015 , to the author's knowledge, there were still no other international institutions that provided Indigenous organizations with an equivalent status to permanent participant.
} 
participate, these groups took the opportunity to participate seriously and they recognized and reiterated their unique position in understanding and representing the needs and interests of the region's peoples.

\section{A unique governance model}

The Arctic Council governance model created a very different space to tackle common Arctic issues from the formalized regimes common to international fora that have the authority (either directly or indirectly) to set international and domestic rules and establish standards. The institutional design of the Arctic Council offered a unique form of international governance. For some, it represented a new phase of global politics that challenged the traditional state-dominated system and created a legitimate place for non-state actors (Heininen, 2010). It offered an alternative model for policymaking where knowledge and meaning were generated through an open and participatory process. It created the opportunity for new relationships, legitimized the perspectives of the region's people and acknowledged the contributions of non-state actors (English, 2013; Griffiths, 2012b; Young, 2013).

In this context, one of the main features that made the Arctic Council stand out as an institution, was the unique role created for Arctic Indigenous peoples. With only a few exceptions, the participation of permanent participants was the most prominent governance feature referenced by all interviewees. This is not to suggest that there were not challenges or concerns with this governance feature; however, the participation of Arctic Indigenous peoples as permanent participants became the "symbol of the Arctic Council" (personal communication, January 22, 2015). It was a 
governance feature that gave the Arctic Council unique legitimacy and, by extension, gave legitimacy to policymakers taking actions under the auspices of the Council (personal communication, November 10, 2014).

During this period, permanent participants ensured a consistent focus on the human dimension of the environmental issues facing the region. By sitting at the table with state representatives and scientific experts, permanent participants changed the dynamic of discussions and influenced results (personal communication, November 2, 2014). In particular, permanent participants introduced different approaches and cultures of governance that changed how work was done and how issues were discussed. Permanent participants did not allow issues to be isolated into distinct boxes. As one interviewee commented, permanent participants "build the capacity of states" to understand the interconnected issues facing the region (personal communication, January 22, 2015).

Permanent participants challenged the governance practices of states and scientific experts in the Arctic Council because they "talk[ed] freely" and did not conform to the hierarchal protocols common in international diplomacy (personal communication, January 22, 2015). Ultimately, what many interviewees acknowledged was that the work of the region's Indigenous peoples on the Arctic Council demonstrated again and again that they are "effective spokespeople for issues in the Arctic" (personal communication, January 7,2015$)$. However, it is important to stress that there are limits to the claims that can be made about the impact of their participation. Permanent participants' 
involvement contributed to the moral legitimacy of the Arctic Council. The Arctic Council gained procedural legitimacy from "embracing socially accepted techniques and procedures" and structural legitimacy because its governance model was considered "valuable and worthy of support" (Suchman, 1995, pp. 580-1). Nevertheless, the data collected does not substantiate any assertion that these regional or international policy discussions translated into the implementation of policies that better meet the needs and interests of the peoples of the Arctic.

\section{The results}

The mechanisms within the Arctic Council that supported boundary work generated an impressive collection of reports, analyses and policy recommendations during this period. Although scientists had been expressing concern about signs of significant environmental change evident in the region for several decades, broader public concern for the Arctic environment was not ignited until the early 2000s and the Arctic Council's Arctic Climate Impact Assessment (ACIA)(2004b) has received credit for contributing to growing public awareness of the impacts of climate change (English, 2013; Jackson School of International Studies Arctic Task Force, 2013; Koivurova, 2010). The Arctic Human Development Report (Niels, Larsen, \& Nilsson, 2004), issued that same year, also attracted attention not only for the quality of its analysis of the issues and circumstances facing the people of the Arctic, but also for the inclusive process that was used by the Council's SDWG to prepare the report (Dodds, 2012; English, 2013). The work of the Arctic Council was acknowledged for its high caliber research and analysis and its ability to raise the profile of environmental, social and health policy issues that were relevant to the region and, in many cases, the globe. As a result of the quality of 
its work and its governance model, the Arctic Council began to be recognized as an important voice for the Arctic both regionally and in global fora.

The analysis in this section once again confirms Levy et al's (2001) proposition that a factor to explain the institutional effectiveness of the Arctic Council is the relationship between the Council's governance model and the role the Council was established to play in the policy process. During this early period, the Council's organizational culture and governance features enabled boundary work within and between the different levels of the Council. From its inception, the Council was tasked with bridging the gap between traditional, state-dominated international relations and the interests and perspectives of the Indigenous peoples of the region. In the early years of the Arctic Council's work, this also translated into a need to manage the boundary between Western science and Indigenous social worlds simply because of the actors involved and the priorities that the Arctic Council established. Moreover, the quality and legitimacy of the work produced (boundary objects) reinforced the value of boundary work as a means to generate knowledge and policy advice. In other words, this analysis confirms that a criterion to assess the institutional effectiveness of the Arctic Council is a match between its governance model and the policy shaping role the Arctic Council was established to play during this period - influencing policymaking processes at the domestic and international levels.

\section{Conclusion}

In this chapter, I used the determinants of institutional effectiveness to structure an analysis of the Arctic Council. The chapter identifies the factors that explain the 
Council's institutional effectiveness in its early years. To begin, I examined distinct changes in the governance environment in the Arctic that confirm that the network of multilateral institutions in the region was continuing to grow and the idea of establishing institutions that serve the region as a whole had taken root. Indigenous groups and institutions in the research/academia zone were still central in defining the policy priorities for the region; while governments' main interest was in supporting cooperation and trust building. This was also a period when a small number of private sector institutions emerged in the region and there was a growth in multi-stakeholder institutions. Overall, this was a governance environment where the Arctic Council could find partnerships and develop relationships, but it would not attract a lot of political attention whether or not it was effective in its endeavors. The governance environment, as presented, demonstrates the factors that contributed to the Council's effectiveness during this period included the position it established for itself in the network of multilateral institutions involved in Arctic environmental management and sustainable development and the relevance that the Arctic Council held with those actors that were motivated and had the capacity to advance its work in these early years.

Overall, the policy priorities set for the Arctic Council were internally driven and regionally focused. These issues did not attract high-level political interest; however, they were salient for those actors committed to the work of the Arctic Council. The merging of Finnish and Canadian Initiatives resulted in complementary themes on the Council's agenda including: cooperation and trust building, scientific research and environmental protection, and Indigenous participation and the human dimension. None 
of the policy issues on the Council's agenda could be classified as easy; however, the level of responsibility that Arctic Council assumed for solving these issues was primarily limited to knowledge generation and policy advice, which seemed reasonable and achievable given the governance environment.

Finally, I examined the institutional design of the Arctic Council - in particular, its raison d'être, organizational culture and governance features. This last determinant of institutional effectiveness received the most attention because the Council's governance model has often been credited with contributing to its effectiveness. Ultimately, I argue that the match between the Council's governance model and policy shaping role is a criterion for its institutional effectiveness during this period. Furthermore, I propose that our understanding of the Council's governance model is enhanced by the concept of boundary work because it explains how political, scientific and Indigenous social worlds worked together to effectively advance the work of the Council.

However, to fully understand the effectiveness of the Arctic Council during this period, it is equally important to consider the interplay between each of these determinants of institutional effectiveness. While it is not unreasonable to attribute the Council's effectiveness in its early years to its governance model, it is more appropriate to propose that the institutional design was effective because it was well aligned with the policy issues on the Council's agenda and the governance environment of the time the Arctic Council's effectiveness during this period confirms the importance of institutional fit. 
In the next chapter, I again adopt the determinants of institutional effectiveness to study the Arctic Council and its work between 2006 and 2015. This chapter exposes drastic changes in the governance environment, policy priorities on the Council's agenda and its institutional design. Throughout Chapter 6, I examine the implication of these changes for the Council's institutional effectiveness. 


\section{Chapter 6: The World Finds the Arctic Council (2006-2015)}

While many commentators would agree that the Arctic Council made a meek entrance on to the international scene in 1996 , by the end of its first decade in existence, it was attracting attention both inside and outside the region. The tensions between Arctic states generated by the Cold War had dissipated and were being replaced with more confidence by both state and non-state actors that the region was becoming the "zone of peace and cooperation" imagined by Gorbachev. The Arctic Council was producing reports that were being heralded by international experts for their quality and salience all the signals suggested that the Arctic Council was in the right place at the right time to become a leading multilateral institution for the region with a healthy measure of international influence.

This chapter examines the Arctic Council between 2006 and 2015. I once again use the determinants of institutional effectiveness - governance environment, problems to be solved and institutional design - to structure an analysis of the Council. This chapter demonstrates that the Council's work and its governance model were evolving. Both endogenous and exogenous forces were pushing the Council to take on new responsibilities and meet new expectations. In particular, there were a number of forces pushing the Council to evolve from a policy shaping to a policymaking institution. In this chapter, I pay particular attention to the forces that were affecting the Arctic Council's boundary work and what this meant for how the Arctic Council worked and its institutional effectiveness. 


\section{Governance Environment}

The governance environment in the Arctic evolved rapidly in the period between 2006 and 2015. Based on the 2005 governance map (Figure 5.1 presented in the previous chapter), we know that the period leading up to 2006 saw a notable growth in regionally focused institutions and an explosion of institutions in the research/academia zone. We also know that Indigenous organizations held a strong presence in the region, a small number of institutions in the private sector zone emerged and there were a growing number of institutions that brought together multiple actor-types.

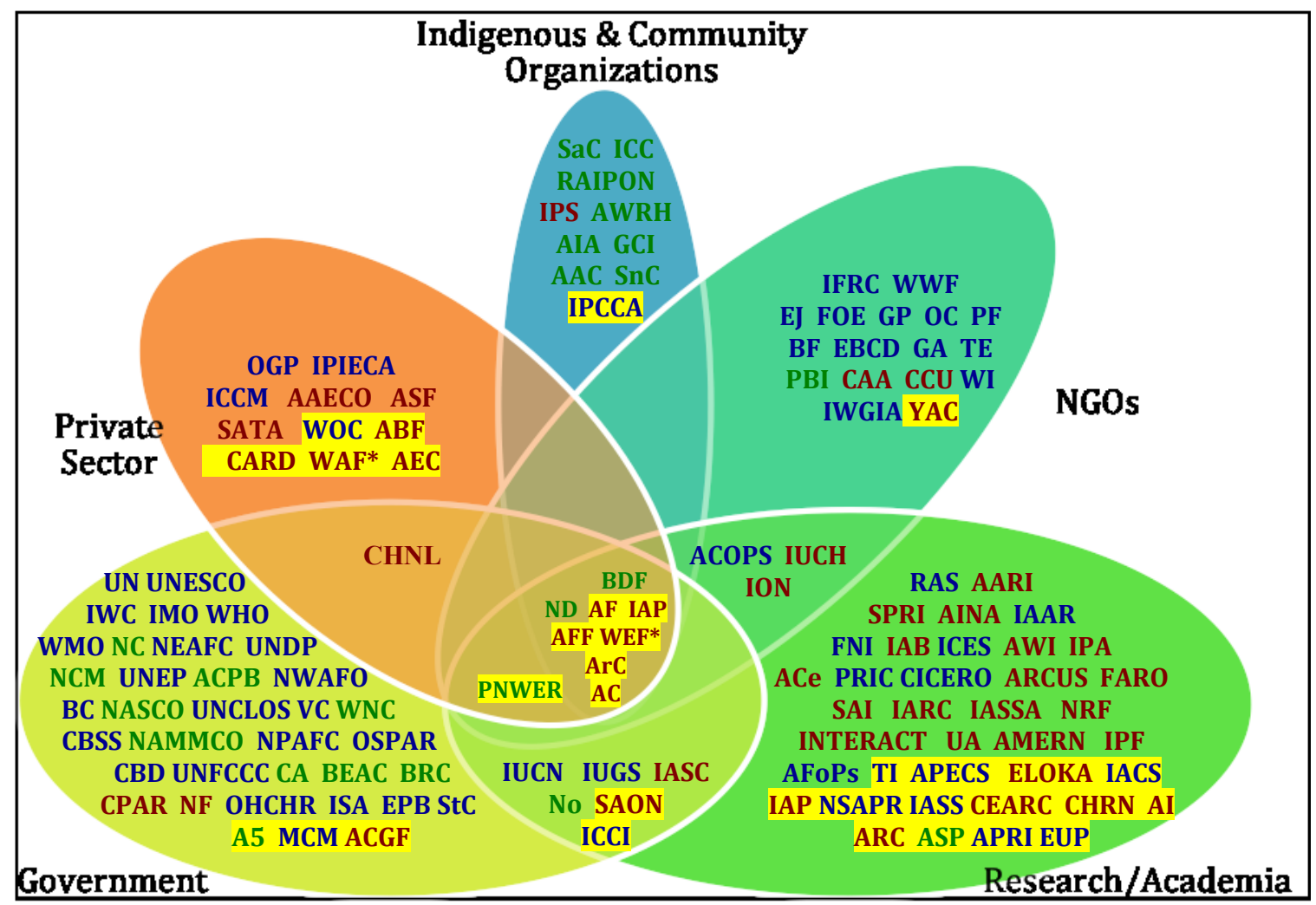

Figure 6.1: Arctic Governance map 2015

Blue: International institutions, Red: Circumpolar institutions, Green: Subregional institutions. Institutions highlighted in yellow were established between 1996 and 2005 (Full list of institutions in Appendix 2).

* no longer active 
There are four notable developments during this period discussed by interviewees and survey respondents that stand out as being critical in shaping the Arctic governance environment. These include: 1) international concern about environmental changes in the Arctic, 2) an increased interest in potential economic and development opportunities, 3) growing political salience and prominence of the region, and 4) changes in the norms of international governance. While there were of course other changes in the governance environment during this period, these four developments had the most direct impact on the Council's institutional effectiveness. They did this by enhancing the position and relevance of the Arctic Council in the region's network of institutions and altering the conditions under which the Arctic Council functioned.

\section{Environmental changes}

Climate change, as a global phenomenon, is now a prominent global policy issue, but public attention to this issue lagged behind the science that observed and speculated on its future global impacts (Weart, 2017). Early scientific reports of climate change date back to the 1950s. By contrast, public concern for this issue did not gain sustained attention until the mid-2000s (Weart, 2017). Survey respondents and interviewees proposed that graphic reports of the impact of climate change in the Arctic were pivotal in providing climate change with the profile and sense of urgency that was needed to attract public attention internationally. The scientific community could point to dramatic environmental changes, such as increasing water and air temperatures, the resulting melting ice and permafrost, decreased ocean surface salinity observed in certain areas, and changes to the circulation of the region's air and sea currents. Meanwhile, NGOs, including WWF and Polar Bears International, initiated global fundraising campaigns to 
protect "emblematic" Arctic species. These issues resonated with global audiences (Bravo \& Rees, 2006; Heininen, 2010; Kankaanpää \& Young, 2012a, 2012b). In the period being analyzed, the Arctic assumed a symbolic role as a harbinger of global climate change. In particular, the Arctic offered something that its sister pole could not, a glimpse of the human implications of climate change. Furthermore, Indigenous communities of the Arctic are intimately connected to their natural environments and, as that environment began to show signs of being fundamentally altered, Indigenous leaders expressed concern that the lives of the people of the Arctic could be profoundly affected (English, 2013; Watt-Cloutier, 2015).

Figure 6.1 shows that the research/academia zone saw the creation of 14 additional institutions with an interest in the Arctic (7 at the international level, 6 at the circumpolar level and 1 sub-regional institution) - many that placed at least some of their attention on climate change research.

\section{Economic opportunities}

While some actors were focused on the environmental challenges facing the region, there were others that directed their attention to the Arctic as a region of new opportunity with a wealth of natural resources, new transportation routes and exotic tourism (Kankaanpää \& Young, 2012b). As a result of climate change, during this period non-Arctic states, such as China, South Korea and Singapore, and businesses interested in transportation, shipping, oil, gas and other mineral resources began turning their attention to the Arctic as a "last frontier" of untapped natural resources and development opportunities (Brown, 2013; Koivurova, 2010; Young, 2009b). These 
actors saw a link between the Arctic and the global economy that it had been largely peripheral to. They also increasingly looked for opportunities to be involved in Arctic governance (Young, 2009a)

Figure 6.1 highlights a growth of institutions in the private sector zone with the addition of 5 institutions ( 4 circumpolar and 1 international) with mandates related to Arctic business. This almost doubled the number of institutions in this zone. Furthermore, if there are doubts that the region's natural resources were an important draw for both public and private actors, it is worth pointing out that public and private interest and investment in the region fell with the decline in the value of oil and minerals that began in 2014. In 2015, Royal Dutch Shell, who had invested significant funds to explore opportunities in the waters off of Alaska, put a hold on future activity - signaling doubt that certain parts of the region were viable places for profitable oil and gas extraction. Furthermore, the World Arctic Forum (WAF*), a Toronto-based business association started in 2013, closed its doors after less than 2 years in existence. And finally, after committing 2 years to a multi-stakeholder initiative to develop a framework for business and investment in the region that began in 2013, the World Economic Forum (WEF*) quietly disbanded its organizing committee in 2016.

\section{Political prominence}

As a result of both the challenges and opportunities perceived in the Arctic, the region took on a new political prominence and global relevance. During this period, Arctic states were preparing their claims for extensions to their coastal exclusive economic zones through the UNCLOS and, through this process, laying claim to a majority of the 
region (recall Figure 2.2) (7) $^{37}$ signaling to the outside world that "the Arctic was not an open and unclaimed region" (personal communication, November 17, 2014). More dramatic examples of efforts to send this message were also seen with the Russian flag planting at the North Pole ${ }^{38}$ in 2007 and the release of the llulissiat Declaration (2008) by the five Arctic littoral states, which emphasized the sovereign rights of the signatory countries.

These actions by Arctic states did not deter a growing number of non-Arctic states, businesses, and NGOs from looking to participate in a variety of Arctic-related institutions and events - including Arctic Frontiers (AF), the Arctic Circle (ArC) and the Arctic Economic Council (AEC). As global interest in the region increased, Arctic states placed more attention on their Northern boundaries and policies (Kankaanpää \& Young, 2012b). After a decade of relative calm, the region, the policy issues that affected it and its network of multilateral institutions were facing renewed political interest.

\footnotetext{
${ }^{37}$ Norway submitted its territorial claim in 2006 and it was approved in 2009. Russia first submitted its claim in 2001 and it was asked to provide additional data, which it submitted in 2015. Denmark submitted its claim in 2014. Canada submitted a partial claim in 2015 and it has indicated that it will submit a full claim in 2018. The United States has been collecting data about the sea floor off Alaska; however, it is not eligible to file an official claim until it ratifies UNCLOS.

${ }^{38}$ On August 1, 2007, two Russian mini-submarines travelled to the seabed floor and planted a titanium Russian flag on the Lomonosov ridge in the Arctic Council to symbolically emphasize their claim that this area was an extension of its continental shelf and therefore part of its exclusive economic zone under the UNCLOS (Parfitt, 2007)
} 


\section{International governance norms}

The period between 1996 and 2006 also saw a broader transformation in the norms of international governance. Interviewees talked about important shifts to more information sharing and open access policies in the region and globally (personal communication, November 19, 2014). This normative shift was facilitated and accelerated by innovative technologies that enabled fast, and even real-time, access to unparalleled amounts of information and allowed people to connect and work collaboratively in previously inconceivable ways (personal communication, November 2 , 2014). Given the small, remote communities that comprise many parts of the Arctic, these technological advancements had huge implications for enabling information sharing and knowledge generation. ${ }^{39}$

Another important development in international governance norms was increased attention and growing expectations for institutions to exhibit "good governance" traits and features. In particular, interviewees focused on external pressures to be "transparent," "inclusive" and demonstrate "results." Consequently, gone were the days that policy decisions affecting the Arctic were assumed to be legitimate because of the participation of governments. The legitimacy of this type of policymaking was

\footnotetext{
${ }^{39}$ Some communities in the Arctic, especially in Russia and Canada, still have extremely limited access to telecommunication technologies and, therefore, have not been able to connect and participate in this broader transformation. Recognizing how important telecommunications is to the future of the region, the United States' 2015 Arctic Council chairmanship programme included the creation of a task force specifically to "develop a circumpolar infrastructure assessment as a first step in exploring ways to improve telecommunications in the Arctic" (Arctic Council, 2015c).
} 
increasingly challenged by civil society groups (particularly in the West) because of a perceived "accountability deficit" (Held \& Koenig-Archibugi, 2004). Citizens expected policymakers to be accountable to those affected by their decisions and criticized institutions that appeared disconnected or isolated from the broader network of actors. This meant that institutions involved in forming public policy were expected to be inclusive and transparent in their policy discussions and decisions (Pal, 2014).

Interestingly, this trend in the Arctic is confirmed by the data presented in Figure 6.1, which demonstrates that, between 2006 and 2015, there was a limited growth in multilateral institutions dedicated to one actor-type (e.g. government, NGO, Indigenous groups). Instead, we observe a growing number of multi-stakeholder institutions, including the Arctic Circle (ArC), the Arctic Forum Foundation (AFF), and the Arctic Caucus of the Pacific Northwest Economic Region (PNWER). In fact, under the leadership of the Canadian chairmanship (2013-2015), the Arctic Council made efforts to become even more inclusive by seeking opportunities to increase connections with the private sector. Figure 6.1 portrays a drastically different governance environment from when the Arctic Council was conceived and designed in the late 1980s and early 1990s (Figures 4.1 And 4.2). Overall, we observe that in just under 30 years the Arctic governance environment was transformed into a complex network of multilateral institutions involved with environmental management and sustainable development in the region. 
Overall, we see a growth of institutions working in most zones of the governance map and a particular growth in institutions working at the circumpolar level. The governance environment is no longer dominated by governments, but has followed a trend observed in other regions and globally of a complex and diverse network with multiple actor-types and multilateral institutions with various governance models. Overall, the Arctic, as a region, evolved from being a political backwater to holding global environmental, economic and political importance that translated into unprecedented strategic significance. One interviewee stated "quite frankly the Arctic has more interest than it can handle" (personal communication, January 15, 2015); while another expressed concern that growing international interest would translate into excessive influence by outside actors (e.g. China, India, South Korea, and large private sector actors with an interest in resource development and new transportation routes) with more power, resources or capacity than many actors in the region (personal communication, October $31,2014)$ - in particular the organizations representing the region's Indigenous peoples. The elevated importance of the region during this period can be understood as both a source and a symptom of ongoing change.

In 1987, Gorbachev proposed that the region be a "zone of peace and cooperation." What we see almost 30 years later is that this idea had taken hold and endured. In fact, it could be argued that this idea became a governance "brand" for the region that has been publicly maintained and reinforced by Arctic states. In interviews and public statements, those involved in the region's institutions regularly referenced this "spirit of cooperation" as a defining feature of how Arctic institutions are organized and how 
people have worked together and should work together - a "model of successful regional governance that other parts of the world can learn from" (personal communication, November 16, 2014). In much of the Arctic governance literature, the Arctic has assumed an identity of cooperation, synergies and partnership. Recently, the importance of these governance norms has been publicly reiterated by many leaders of Arctic states in response to concerns about ripple effects caused by tense relations between Arctic states as a result of Russia's activities in the Ukraine and Syria. The Arctic as a region of "peace and cooperation" may have begun as an organizing principle, but it has evolved over time to be valued by many actors as a fundamental norm - a defining feature - that is central to the Arctic governance environment.

Changes in the governance environment between 2006 and 2015 exposed powerful exogenous forces that fundamentally altered the operating conditions for the Arctic Council. The Arctic in 2015 included a complex and dynamic network of multilateral institutions that involved all actor-types with an interest in a diverse range of policy issues. Research/academia and Indigenous actors still held a strong presence in the region's institutions, but, unlike the early years of the Arctic Council, political interests (state and non-state actors) from in and outside the region were on the rise. We also observe that the number of multi-stakeholder institutions continued to grow. Moreover, their growth was part of a broader trend towards more transparent, inclusive and accountable governance internationally and changing expectations regarding the role that international institutions play and how they function. 
Returning to the factors that explain the Council's effectiveness, there are some notable changes. The Arctic Council not only held a distinct position in the network of multilateral institutions in the Arctic, it emerged as a focal point in the network which may have meant more influence, but certainly meant more attention, higher expectations and growing political pressure. We might expect that this would translate into increased effectiveness for the Council; however, as I examine later in the Chapter, the positive contribution of this factor was dependent on the Council's ability to deliver on these increased expectations.

The empirical analysis of this period demonstrates that the criterion related to the relevance of the Arctic Council for the actors committed to its work must also be refined. Whereas, in the previous chapter I proposed that the relevance of the Council contributed to its effectiveness, the changes during this period demonstrate the causal relationship between the relevance of the Council and its effectiveness is altered by the interplay between this factor and other factors related to the problems to be solved and the institutional design. In the following sections, I examine observed changes to the policy priorities placed on the Council's agenda and notable changes to the Council's institutional design with a particular interest in changes to the effectiveness of its boundary work functions.

\section{Problems to be Solved}

With the dramatic changes being observed in the governance environment in the region, it is not surprising to see changes in the policy issues emerging on the agenda of the Arctic Council. The analysis in this section demonstrates that the types of issues 
on the Arctic Council agenda and their salience for different actors both in and outside region are factors that explain the Council's effectiveness; however, there are indications that the criteria used to assess the effectiveness require more nuance to capture the relationship between the Council's policy priorities and its institutional design.

Based on a content analysis of the five Arctic Council ministerial declarations issued between 2006 and 2015, I confirmed that the themes introduced during the previous decade remain. These include: peaceful cooperation, environment, indigenous participation and the human dimension, and sustainable development (Table 6.1). However, an in-depth analysis of references to these themes in more recent ministerial declarations and the input of interviewees reveals that the focus of work related to each of these themes evolved as relationships between these issues were strengthened, governance mechanisms became more established and early work was completed. Certain issues were reframed and the mandate of the Council seemed to broaden as the region gained more profile, issues were seen as more interrelated and complex, and new issues arose. In the following subsection, I examine changes in the agenda related to these themes. 
Table 6.1: Results of content analysis to identify frequency of references to themes in Arctic Council declarations (2006 to 2015).

\begin{tabular}{|c|c|c|c|c|c|}
\hline & $\begin{array}{r}\text { Salekhard } \\
(2006) \\
\end{array}$ & $\begin{array}{r}\text { Tromso } \\
(2009) \\
\end{array}$ & $\begin{array}{r}\text { Nuuk } \\
(2011 b) \\
\end{array}$ & $\begin{array}{l}\text { Kiruna } \\
(2013 d)\end{array}$ & $\begin{array}{r}\text { Iqaluit } \\
(2015 \mathrm{c})\end{array}$ \\
\hline $\begin{array}{l}\text { Regional cooperation, } \\
\text { including: }\end{array}$ & 34 & 25 & 11 & 16 & 13 \\
\hline military-security & 0 & 0 & 0 & 0 & 0 \\
\hline $\begin{array}{l}\text { Indigenous peoples, } \\
\text { including: }\end{array}$ & 15 & 9 & 4 & 5 & 6 \\
\hline Traditional knowledge & 5 & 4 & 2 & 1 & 2 \\
\hline $\begin{array}{l}\text { Human dimension, } \\
\text { including: }\end{array}$ & 30 & 15 & 9 & 10 & 15 \\
\hline Health & 3 & 1 & 3 & 4 & 7 \\
\hline Social-Cultural & 10 & 2 & 0 & 2 & 6 \\
\hline Education & 3 & 2 & 1 & 0 & 0 \\
\hline Capacity building & 9 & 3 & 2 & 2 & 2 \\
\hline $\begin{array}{l}\text { Environmental } \\
\text { protection, including: }\end{array}$ & 25 & 29 & 21 & 13 & 22 \\
\hline Biodiversity/conservation & 5 & 7 & 2 & 3 & 5 \\
\hline $\begin{array}{r}\text { Environmental } \\
\text { emergencies }\end{array}$ & 2 & 1 & 2 & 1 & 1 \\
\hline Marine environment & 1 & 3 & 2 & 2 & 8 \\
\hline $\begin{array}{l}\text { Pollution } \\
\end{array}$ & 13 & 13 & 7 & 7 & 9 \\
\hline Climate change & 15 & 12 & 8 & 8 & 7 \\
\hline $\begin{array}{l}\text { Scientific-research } \\
\text { collaboration }\end{array}$ & 35 & 31 & 13 & 16 & 28 \\
\hline $\begin{array}{l}\text { Sustainable } \\
\text { development, } \\
\text { including: }\end{array}$ & 28 & 23 & 8 & 13 & 20 \\
\hline Economic & 8 & 3 & 0 & 5 & 6 \\
\hline Natural resources & 1 & 3 & 1 & 2 & 3 \\
\hline Infrastructure & 4 & 6 & 2 & 3 & 3 \\
\hline Business & 2 & 1 & 1 & 2 & 2 \\
\hline Energy & 1 & 4 & 0 & 0 & 2 \\
\hline
\end{tabular}

Complete list of issues identified for Arctic Council, 1991-2015 presented in Appendix 3.

\section{Cooperation and trust building}

Despite any reframing taking place and the broadening of the Arctic Council agenda during this period, the general theme of cooperation remained one of the most prominent themes in the Arctic Council declarations. In fact, with growing tensions 
between Russia and NATO countries over the activities in the Ukraine and Syria, there was initial concern that geopolitics outside the region would compromise Arctic Council activities. Instead, interviewees observed that the Arctic Council continued its work despite these tensions (personal communications, June 21 and 22, 2016). One survey respondent went so far as to suggest that the "Arctic Council as a venue could play an important role in the coming years and help solving problems arising due to the growing political tensions [between Arctic states outside the region]" (Kankaanpää \& Young, 2012b).

All of the Arctic states went to great lengths to publicly emphasize their commitment to participating in the activities of the Arctic Council irrespective of events taking place in other regions. During this period, statements made by Arctic Council officials, members and permanent participants reinforced that international cooperation, peaceful dialogue and trust building were at the core of the Arctic Council's mandate - with the most prominent example being a joint statement from ministers of the Arctic states on the occasion of the Arctic Council's $20^{\text {th }}$ anniversary entitled Arctic Council: A Forum for Peace and Cooperation that stated: "Today, we celebrate twenty years of Arctic cooperation and look forward to a long term future of peace and stability in the region" (2016).

Participants emphasized that peace and cooperation, as an issue for the Arctic Council, worked because it is "different" - it was "science-based" and security was not on the agenda, so the Council was "able to continue despite geopolitical issues elsewhere" 
(personal communication, November 6, 2014). In fact, one interviewee suggested that the Arctic Council becomes even more important when actors cannot talk in other fora. The Arctic Council was a forum where civil servants continued to talk when politicians could not (personal communication, November 19, 2014). This is not to suggest that the Council was not affected by geopolitical tensions outside the region. During the Canadian chairmanship, a large outreach event planned in Ottawa in the lead up to the 2015 Iqaluit ministerial meeting was abruptly cancelled because of "security-related concerns" (McDiarmid, 2015); however, member states and permanent participants regularly went out of their way to express their commitment to peaceful cooperation during the latter half of the period being analyzed.

\section{Environmental protection}

The theme of environmental protection also continued during this period. The strength of the Arctic Council in facilitating and supporting scientific research (e.g. data collection, synthesis and analysis) and policy advice retained a strong position in the work that was acknowledged in the declarations between 2006 and 2015. Moreover, the Arctic Council converted the Arctic Contamination Action Plan, originally a project under the Arctic Monitoring and Assessment Programme (AMAP), into the Arctic Council's sixth working group in 2006 and, in 2013, the Arctic Council Project Support Instrument (PSI) was operationalized after many years of work to create a mechanism to finance priority pollution mitigation projects approved by the Arctic Council.

However, environmental protection did not dominate the agenda in the way that it had in the previous decade. Instead, following the release of the Arctic Climate Impact 
Assessment (ACIA) in 2004, issues that had previously been introduced under the banner of environmental protection (e.g. acidification and marine pollution) were reframed under the theme of climate change. Interviewees consistently referenced the 2004 release of the ACIA as a turning point for the Arctic Council and the region. In fact, one survey respondent went so far as to say that: "in my view [the ACIA was] by far the most important Arctic Council outcome so far" (Kankaanpää \& Young, 2012b). In addition to exposing dramatic changes in the Arctic environment, the $2004 \mathrm{ACIA}$ brought global attention to the major health impacts of global environmental degradation and climate change on the peoples of the Arctic. In fact, this attention was purposefully generated at the time the ACIA was released by Sheila Watt-Cloutier, then president of the ICC, who made a number of high profile speeches where she proposed to the world that the Indigenous peoples of the North be recognized as the human face of the impacts of climate change (English, 2013; Watt-Cloutier, 2015).

While documents as early as the Arctic Environmental Protection Strategy (AEPS) and Arctic Council Panel Report made reference to climate change, initial references to climate change in the Arctic Council declarations were focused on supporting research to understand climate change and its impacts in the Arctic. But as one interviewee explained, in the latter half of the Council's existence people started to "realize the repercussions for the world at large." The changes observed in the Arctic "became the bellwether for global changes much more than the Antarctic because [in the Arctic] the biological food chain includes humans and health and safety of Indigenous peoples" (personal communication, January 16,2015$)$. This reframing was important because a 
focus on climate change shifted the scope of the problems to be global in nature.

Climate change served to highlight the interconnections between issues that were often managed in isolation - Fisheries, migratory birds, and ocean acidification could all be linked to climate change.

More recently, the discussions about the Arctic's role in global climate change evolved further. As the impacts of climate change accelerated, changes in the Arctic directly contributed to global weather changes and sea level rise that were affecting places far to the south - attracting even more global attention to the Arctic Council. Framing Arctic Council policy priorities around the theme of climate change pushed the Council and its work into the fray of an increasingly politicized, global issue that continued to grow in prominence from 2006 to 2015 . Issues that were easily differentiated as regional in nature, such as marine transportation or resource development, were now intertwined with a complex mix of global policy issues.

\section{Indigenous participation and the human dimension}

The human dimension also maintained its position as a central, cross-cutting component of the Arctic Council's agenda and, in fact, took on more attention. In the same way that framing persistent organic pollutants as a human health issue provided the issue with profile and urgency, now mercury, biological diversity and climate change were framed to emphasize their impact on the region's people - issues that often were sidelined as remote and impersonal or the purview of small groups of extreme environmentalists became issues of human rights and human security. 
This reinforced the need for Arctic states to engage the people living in the Arctic in the Council's policy discussions in order to ensure that their needs and interests were at the center of the Council's agenda. The agenda of the Arctic Council related to its residents began to take on more shape with specific attention being paid to health, education, and the social, economic and cultural well being of the people living in the Arctic. Under this larger banner, the knowledge and involvement of the region's Indigenous peoples continued to hold a place of particular priority, including, in 2015, when the Arctic Council released recommendations on the use of traditional and local knowledge to guide how this knowledge would be incorporated in its work (Arctic Council, 2015c).

\section{Sustainable development}

Sustainable development, as a policy issue, also increased in weight and broadened in scope during this period as more issues where introduced under this theme on the Arctic Council agenda. The Arctic Council's focus on sustainable development was still linked to the needs and interests of the region's people. However, under the banner of sustainable development, the themes of food security, mental wellness, Indigenous cultures, transportation, infrastructure, tourism, and energy all made an appearance on the agenda. The theme of capacity building peaked in 2006 , but continued to maintain a presence on the Council's agenda until 2015, including being a prominent part of the 2013-2015 Canada's chairmanship programme entitled "Development for the People of the North" (Government of Canada, 2013). 
In 2006, the presence of the private sector in the Arctic and its potential impacts became a regular theme. ${ }^{40}$ And then in 2013 , the focus shifted to a need for the Arctic Council to engage with business. Overall, business was not a largely referenced theme in the declarations, but throughout this period references to business were constant. In addition, for several interviewees, the Arctic Council's increasing attention to economic opportunities in the region and its discussion of issues related to economic opportunities served to increase the global profile of the Arctic Council's work, draw more attention from the private sector, and further politicize its activities.

My analysis of the issues on the Arctic Council agenda from 2006 to 2015 highlights that although the general themes identified remained the same, the agenda of the Arctic Council had changed significantly. In the previous chapter, I proposed that a criterion to assess the effectiveness of the Arctic Council was its ability to match its mandate and resources to the types of problems on its policy agenda. The empirical analysis presented in this section indicates the policy issues on the Council's agenda expanded in scope, scale and complexity during this period. This raises questions about whether the mandate and resources of the Council were still an appropriate match for the issues on the agenda, which is examined further in the following section.

As one interviewee said: "The mandate of the Arctic Council is broadening... increasing the involvement and importance of other players" (personal communication, January 15 ,

\footnotetext{
${ }^{40}$ There is one earlier reference in 2002 , but business is listed as one of many actors that should be included in dialogue about the consequences of climate change.
} 
2015). Ultimately, the reframing and broadening of the Arctic Council agenda raises questions about what impact the Arctic Council was expected to have in relation to each of these issues and whether it had the necessary governance tools. The changes in the agenda also generated confusion. Was the Arctic Council a forum for regional cooperation on regional issues? A forum for regional cooperation on global issues? Or perhaps a forum for global cooperation on regional issues? Considering the policy issues on the agenda during this period, there is a sense that it was trying to be a little bit of all these things, which offers the possibility that the nature of the problems to be solved could become a determinant of the Arctic Council's ineffectiveness.

Based on the analysis of this period, the salience of the issues on the Arctic Council agenda remained high for Indigenous groups and the scientific community; however, it notably increased for member states. Not only was climate change and its affects a hot political topic globally, but the Arctic Council's programme related to sustainable development was now taking on more shape and the prospects of accessing the region's substantial stores of oil, gas and minerals seemed imminent. The salience of the issues on the Arctic Council agenda also attracted the attention of growing numbers of state and non-state actors from outside the region with diverse interests and perspectives. Once again, these developments provide nuance for how we understand the relationship between the salience of the issues on the Arctic Council's agenda and its institutional effectiveness that is examined further in the institutional design section. 


\section{Institutional Design}

In the previous sections of this Chapter, we saw that the governance environment in the Arctic and the issues on the Arctic Council agenda had changed dramatically. This section examines several changes in the Council's institutional design between 2006 and 2015. In particular, I examine to what extent the Council's governance model continued to enable boundary work, which was a key contributor to the Council's effectiveness in its early years. Furthermore, I consider how the relationship between the Arctic Council's governance model and the role that it is positioned to play stands out as a critical factor to explain the institutional effectiveness - in particular when the interplay between the Council's institutional design and the other factors of effectiveness are considered collectively. Once again, the analysis is organized into three components: the Council's raison d'être, organizational culture and governance features.

\section{Raison d'être}

In Chapter 5, I outlined the core purpose of the Arctic Council as a forum for regional cooperation, knowledge generation and policy shaping. I also examined how these functions were supported through boundary work between political, scientific and Indigenous social worlds. This raison d'être was also present in the period between 2006 and 2015. Interviewees and survey respondents continued to emphasize the important role that the Arctic Council played in regional cooperation. However, there were also indications that the Arctic Council was expected to assume a role in facilitating global cooperation on Arctic-relevant policies. 
Over time, the Arctic Council was adding issues to its policy agenda and increasingly shifting the framing of these issues to take on a broader scope. For example, by shifting attention from the impacts of pollution due to military activities in the Barents region to the impacts of climate change due to pollutants from southern states, the scale and scope of the policy problem expands and the policy solutions require the actions of actors both within and outside the region. Add to this the fact that environmental changes in the Arctic have global impacts and there should be no surprise that the Arctic Council had a growing line up of states, NGOs, and private sector organizations from outside the region wanting to participate in Arctic Council activities and seeking to influence its policy decisions. For one survey respondent, the participation of non-Arctic states, NGOs and IGOs in the Arctic Council made it "a useful communication channel with outside actors." This respondent was frank that including outside actors was "to some extent important to prevent formation of parallel forums" (Kankaanpää \& Young, 2012b). However, another survey respondent made an equally important observation: "Due to more difficult and growing political tension between the Arctic countries themselves and between the Arctic countries and non-Arctic countries, I fear the overall effectiveness of the Arctic Council will decline in the next decade" (Kankaanpää \& Young, 2012b).

The Arctic Council's work and its role in knowledge generation and policy shaping also continued to be a prominent theme during the second half of the Council's existence; however, this was combined with an emerging debate about the Arctic Council's role in policymaking, policy action and binding agreements. There were those people involved 
and interested in the Arctic Council that saw binding agreements as its future. For those that held this perspective, it was time for the Arctic Council to make "policy instead of just making reports" (Kankaanpää \& Young, 2012b). They pointed to the recent signing of binding regional agreements under the auspices of the Arctic Council as a natural evolution and maturing of peaceful cooperation in the region (Kankaanpää \& Young, 2012b).

For some interviewees and survey respondents, taking on this increased responsibility was a natural outcome of its previous success. It signalled its maturity as an international institution that it was now recognized and credible enough to play this role. Some people emphasized that this was an opportunity for the Arctic Council to make "decisions that work for Northerners" (personal communication, May 6, 2016). Of course, many interviewees recognized that there were benefits and downsides to the Council assuming a role in establishing binding agreements. They acknowledged that negotiating and managing binding agreement required more energy and resources, but going "backwards" was not an option. By making decisions rather than shaping the decisions of others, the officials from Arctic states could also leverage more domestic attention and support for the issues on the Arctic Council agenda. Of course, as one interviewee pointed out, this did not mean that every issue required a formal agreement, but there was a sense that the Council should have the ability to enact binding agreements "where worthwhile" (personal communication, May 6, 2016).

Other interviewees and survey respondents observed with concern the dissonance between the 1996 Ottawa Declaration and the direction being taken by the Arctic 
Council. They raised issues about "mandate creep," "capacity issues" and a "lack of resources" to take on this new role. For the most sceptical commentators, the Arctic Council had worked well because of its "soft-law" approach and a shift to focusing on binding agreements would mean that it was harder to get people to agree. Still others cautioned that an "agreement is only as good as our ability to implement and support it" (personal communication, June 21, 2016).

Finally, there were those participants that were surveyed and interviewed that felt that the pressures to change the Arctic Council were overstated. One interviewee indicated: "The Arctic Council does not do operational work. It's scientific... [There is] too much talk of transition to decision making. This is not correct" (personal communication, November 17,2014$)$. Other participants were willing to acknowledge the pressure to change, but argued that it should be resisted. These people pointed to the important role played by the Arctic Council in maintaining peaceful cooperation, scientific research, facilitating pan-Arctic policy discussion and influencing other institutions. One survey respondent commented that the "legally-binding vs soft-law debate is an unnecessary distraction - focus needs to remain with the Arctic 8 and Indigenous peoples, to be a voice for the region" (Kankaanpää \& Young, 2012b).

The comments of interviewees and survey respondents prompt questions about whether the Arctic Council had access to the tools, resources and capacity to assume a different or expanded role. They also illustrate a growing divergence in views by participants regarding what the raison d'être of the Arctic Council was or should be. As I 
explore later in this chapter and the next, this divergence of perspectives also raises questions about whether the leadership of the Arctic Council had a definitive position on what the raison d'être of the Arctic Council was and whether there was alignment between that raison d'être, organizational culture and governance features.

\section{Organizational culture}

As has been discussed above, in the period from 2006-2015, the Arctic Council gained a new prominence with actors inside and outside the region and, with its new profile, there was an increase in the number of delegates at Arctic Council meetings (Knecht, 2016). This growth in the number and type of participants brought with it observable changes in the organizational culture of the Council. In particular, a more formal and hierarchical atmosphere replaced the informality of the Council's practices.

Arctic states themselves placed more attention on the Arctic and the Arctic Council both in terms of time and resources. Interviewees from several member states described an increase in domestic processes and procedures to support their participation in Arctic Council meetings. They were expected to ensure that relevant departments were included and that the people with appropriate expertise and authority participated in or endorsed the Council's work. In fact, an interviewee from one member state indicated that beginning in 2013 , officials began preparing formal instructions for SAO meetings something that had never been done before (personal communication, January 15 , 2015). 
This increased formality was also illustrated by renewed effort by the Council to codify its governance arrangements. The Arctic Council Rules of Procedure were renewed in 2013 and, in 2015, the procedures on how to integrate traditional and local knowledge were documented (Integration of Traditional and Local Knowledge in the Work of the Arctic Council (2015d)) and provided to working groups to direct when and how traditional knowledge would be included in projects and activities. Furthermore, perhaps the most controversial and debated action, the Council released the Arctic Council Observer Manual for Subsidiary Bodies (2013c) that set out more formal procedures and restricted how observers could participate in Council business. For one survey respondent: "the [Arctic Council] has moved away from an open forum where all organizations were welcome to one that has become closed, lacks transparency, and shuns involvement of outside organizations" (Kankaanpää \& Young, 2012b).

The organizational culture was also affected by a change in who participated in the Council's activities and meetings. The small Arctic Council "family" was transformed into a global congregation. As one interviewee observed: "Now everyone wants to be part of the Arctic Council... but it was built during a different time" (personal communication, January 15,2015$)$. However, it was not only the number of people participating that was the issue; it was the type of people involved in the work of the Council that was also changing. Arctic-issue "lifers" that had participated in the Council since its inception rubbed elbows with a "revolving door" of policy generalists. There were "too many 'seat warmers' and bureaucrats without Arctic knowledge and commitment" (Kankaanpää \& Young, 2012b). This shift in who participated transformed 
the working relationships within the Council at all levels and created tensions between those that had lived and breathed the Arctic Council long before it reached global star status and those that had no experience with the Arctic or particular expertise related to the region's environmental management and sustainable development. In fact, there was a sense that a growing number of people involved with the Arctic Council did not understand its raison d'être or how it worked - as one interview explained "there is a lot of myth to work through when explaining the Council" (personal communication, January 16,2015$)$.

Finally, participants observed that the Council had shifted from a highly technical and research-driven institution to a highly politicized organizational culture. As one interviewee explained, there was no concern about the research and scientific work of the Council: "more is better" in terms of more information, more people and more collaboration (personal communication, November 2, 2014). It was in the process of translating the knowledge generated into policy advice where there was more concern about who was present and who had an opportunity to influence the advice and decisions of the Council (personal communication, March 11, 2015). Interviewees contrasted the early days of the Arctic Council as a "political backwater" with the more recent sense of urgency and the desire of those in the region to claim control of policymaking. Interviewees described a sense of pressure from increased expectations and the impression that there was more at stake. In particular, some interviewees expressed concern that the Arctic Council was "trying to appear apolitical, but it is all 
political now.... politics is playing into the priorities and the selection of projects" (personal communication, March 10, 2015).

Another effect of this politicization that some interviewees referenced was more of a sense of competition between participants in the selection of projects and who was involved. One interviewee commented that there was "more competition for the same sized pie" (personal communication, November 1, 2014). Ultimately, interviewees argued that, as the Arctic Council grew and became more politicized, it should be no surprise that there were more in camera meetings and backroom negotiations.

Along similar lines, the consensus-based decision-making approach at all levels of the Arctic Council was still acknowledged as an important governance feature. However, many participants acknowledged that there were pros and cons to consensus-based decision making in its application. In the more recent context, there were certain shortcomings identified regarding the consensus-based approach. One interviewee observed that some issues that the Arctic Council has chosen to focus on, such as identifying pollution hotspots, were not easy to reach consensus on (personal communication, March 5, 2015); while another interviewee suggested that the elevated profile of the Council caused pressures that resulted in insufficient time to build consensus (personal communication, November 2, 2014).

\section{Governance features}

The period between 2006 and 2015 was also marked by a number of changes to the governance features of the Arctic Council. To draw out the key findings, I have broken 
the analysis into three segments: first, I look at the changes that were explicitly made to strengthen the Arctic Council's governance model, next I examine how changes to the Council's governance features had an impact on the ability of the Council to meet the interests of political, scientific and Indigenous actors, and finally, I consider the implication of these changes for how the Arctic Council worked and to what extent it was effective.

\section{The "strengthening" agenda}

With the increased prominence of the Arctic Council and its work, the Council began an agenda to "strengthen" its governance beginning with the 2004 Reykjavik Declaration. ${ }^{41}$ In some cases, this involved changes to existing governance features and in other cases the Council introduced new governance features. In this section, I discuss key developments and their effects on the Council's institutional design.

\section{Working groups and task forces}

In the second half of the Arctic Council's existence, Council officials still consistently indicated that the working groups were where the "real work gets done" (personal communication, September 16, 2014). As one interviewee explained "SAOs come and go. Working groups are there to do something" (personal communication, November 17, 2014). However, they also recognized that the working groups had very different approaches to their work. They had different rules, organized their work differently and involved very different expertise. This meant that as new actors became involved in the Arctic Council "it takes time to figure out how it all works, how best to be involved...how

\footnotetext{
${ }^{41}$ In 1998, there was a review of Arctic Council working groups because of a recognized need to reconcile legacy issues of incorporating AEPS working groups into the Arctic Council; however, the first reference to "strengthening" the Arctic Council appears in 2004.
} 
best to have an impact" (personal communication, January 22, 2015). For example, whereas the Protection of the Arctic Marine Environment (PAME) working was slower to get up and running, during this period, it took on work related to a diversity of high profile issues of global interest - from oil and gas regulation, pollution prevention, shipping safety and tourism. By way of contrast, the Emergency Prevention, Preparedness and Response (EPPR) working group had a much less international focus, but depended much more heavily on private sector involvement to understand the search and rescue needs and capacities in the region. The Arctic Council Action Plan (ACAP) working group was recognized as "more an action programme, while other working groups [are] more providing data" (personal communication, November 19, 2014). And finally, while most of the working groups included experts and specialists relevant to their specific policy focuses, participants at the Sustainable Development Working Group (SDWG) meetings were generalists (with member states most commonly represented by officials from ministries of foreign affairs and permanent participants represented by their leadership). SDWG managed a broad diversity of issues; therefore, representatives at meetings functioned "more as coordinators for their government or organization" (personal communication, January 19, 2015).

On an even more micro-scale, each of the working groups had a growing number of projects and many established smaller expert groups to support specific areas of work. Under the 2013-15 Canadian chairmanship, there was an effort to itemize all of the Arctic Council projects. It was confirmed that there were 84 different projects that had been running for different periods of time and were all at different stages (2015a). These 
projects varied in scale and in scope, the types of actors involved and how they were involved. Some projects involved partnerships with other regional and international institutions (e.g. the Sustaining Arctic Observing Networks (SAON) started in 2007 and based in Norway); while others established links at the levels of sub-national governments (e.g. the Arctic Adaptation Exchange Portal started in 2013 and led by the Yukon government) and communities (e.g. Salmon Peoples of the Arctic Rivers started in 2015 that was championed by the Arctic Athabaskan Council (AAC)). Based on discussions with interviewees, it was clear that there was no consistency in how projects were selected or managed. The project tracking tool created during the Canadian chairmanship was an effort to establish transparency regarding work being done through the Arctic Council and a tool for monitoring progress. It was also an effort to encourage consistency in the types of projects being done and how they were managed. This brief review highlights that working groups evolved to function quite differently; therefore, it was extremely difficult for new participants to understand and follow the work that was taking place at this level.

In addition to the 6 core working groups, starting in 2009, SAOs began creating task forces to support certain Council priorities. The first task forces, created through the Tromso Declaration, provided one task force with a mandate "to develop and complete negotiations by the next Ministerial meeting in 2011 of an international instrument on cooperation on search and rescue operations in the Arctic." The second task force had a mandate "to identify existing and new measures to reduce emissions of [short-lived climate] forcers and recommend further immediate actions that can be taken" (Arctic 
Council, 2009). Following the establishment of these two task forces, by 2015 , the leadership of the Council had created 8 additional task forces to work on everything from marine oil pollution preparedness and respond (2011) to institutional issues (2011) and telecommunications infrastructure (2015). The rational provided by the SAOs for creating task forces was "to work on specific issues for a limited amount of time. The Task Forces are active until they have produced the desired results, at which point they become inactive" (Arctic Council, 2015e). While not every task force was assigned the responsibility to establish binding agreements, the agreements signed by the Arctic states under the auspices of the Arctic Council were all the result of task force negotiations and there was a clear sense that these groups are more "action-oriented" (personal communication, March 6, 2015).

For those involved with or knowledgeable about the Arctic Council working groups, the use of task forces rather than assigning this work to working groups was cause for concern. The establishment of task forces to respond to urgent and high priority issues "challenges the structure of the Council" and "compromises the capacity of the working groups and the continuity of the work being done" (personal communication, November $6,2014)$. For example, how does the work done by the task force on short-lived climate pollutants relate to the Arctic Monitoring and Assessment Programme (AMAP) working group and what is the appropriate relationship between the work on marine cooperation and the Protection of the Arctic Marine Environment (PAME) working group? 


\section{Senior Arctic Official level}

Significant changes were observed at SAO meetings as well. One long-time participant contrasted the chaotic and lively SAO meetings that took place in the early years with the more structured and formal meetings that had taken place more recently. For some interviewees, these meetings are now "a theater and decisions have already been made" (personal communication, January 19,2015 ), the Council was now a forum that valued "process over substance" (personal communication, November 2, 2014) and one interviewee even characterized the SAO level as "narcissistic" with very little real interest in understanding the issues being raised by the working groups (personal communication, March 5, 2015). Many interviewees acknowledged that the Arctic Council was receiving more senior representation from governments at its meetings. Some saw this as a sign of increased importance and more opportunities to influence domestic and global policymaking (personal communication, January 22, 2015), while others expressed concern that senior representation, combined with high turnover in state representatives, meant that those present often had a weak understanding or experience with Arctic issues, a circumstance that could eventually weaken the Council's influence.

Irrespective of the positive or negative sentiments placed upon it, as political interest increased, more delegates from member states, permanent participants and observer organizations asked to participate in meetings. As a result, SAO meetings were changed to consist of two events: an executive meeting, which was only open to two representatives from each member state and permanent participant organization, and 
the official SAO meeting, which was open to full delegations of member states, permanent participants, observer organizations and Arctic Council staff. By all accounts, it was the executive meeting where "real" discussion took place and decisions were taken; however, based on reports from interviewees who participated in these events, even these executive discussions were often constrained by time limits and the quality of the contributions. Representatives from member states that participated in these executive meetings were most often senior bureaucrats from ministries of foreign affairs, who specialized in maintaining a broader view of their governments' priorities and considering the domestic policy implications of commitments made through international institutions. These representatives rarely held technical or scientific expertise to inform policy discussions. Instead, these representatives most commonly established policy positions in consultation with experts from other departments in advance of meetings or through sidebar discussions.

In some cases, permanent participants were also represented at these executive meetings by delegates who held leadership positions in their organizations. Although these delegates were not beholden to the same formalized processes to establish their policy positions prior to meetings, there were two main challenges that permanent participant organizations faced that directly affected the nature of their contribution in these discussions. In the first instance, often the leadership had little or no advance knowledge that a particular issue was going to be discussed, or with advance knowledge, an opportunity to consider all of its complexities. In some cases, this was because a representative of the permanent participant organization had not been 
involved in technical or scientific discussions that had taken place in working groups, task forces and other subsidiary bodies (either by choice or because of limited capacity). In other cases, the leaders that held a seat at these meetings had limited time to commit to Arctic Council work beyond attending these meetings. ${ }^{42}$ Therefore, they had insufficient time to be properly briefed or there were weak lines of communication between the leadership and the experts that could help to prepare them.

By contrast, in some cases, because permanent participant organizations were smaller and had more limited capacity and resources, the same person participated in working group meetings or had a close working relationship with the delegates that participated in working group meetings. These delegates tended to have more knowledge than SAOs about the discussions and debates that had produced the policy issues and advice that were being presented at these executive meetings; therefore, these delegates were in a unique position to inject otherwise generalized discussions with specific details of knowledge generated from specialized discussions. These two very different scenarios for permanent participant involvement in executive meeting demonstrate the unique influence that permanent participants can have as well as the facility of that influence depending on the capacity and resources of a particular organization or the individuals that represent them.

\footnotetext{
${ }^{42}$ The leadership of most permanent participant organizations also hold leadership positions either with their local governments or with other institutions.
} 
Furthermore, working group chairs did not have a seat at these executive meetings. Instead, they were invited to present and discuss specific agenda items at the invitation of the SAO chair. Interviewees suggested that this governance decision was contributing to the erosion of communication between the working groups and SAOs. This arrangement was changing the nature of the relationship between SAOs and working group chairs and also reducing opportunities for discussion and understanding amongst the working groups themselves.

At official SAO meetings, member states and permanent participants were permitted to include their full delegations, working group chairs held a seat at the table and observers were invited to observe the proceedings. These plenary meetings were now primarily short, high-level presentations, canned statements, and official recognition of decisions already taken at executive meetings. Limited unscripted discussions were expected to take place and any remaining debate or disagreements were sanitized and deferred to future executive meetings or offline discussions between member states, permanent participants and invited experts or stakeholders, as required. Presentations by working group chairs were brief and focused on providing high-level updates on their work. These presentations were primarily for information-only because any direction provided by the SAOs had already taken place during executive meetings. Furthermore, during Canada's 2013-2015 chairmanship, working group presentations were primarily focused on briefing participants on the progress made on the priorities set for the chairmanship. There simply was not sufficient time to talk about other projects included in a working group's work plan. 
As the importance and political profile of the Arctic Council grew, interviewees observed that states' behavior also changed. In particular, interviewees noted that domestic issues and priorities largely drove the Canadian and United States' chairmanships. For Canada this meant a programme heavily focused on economic development and a much softer position on climate change (personal communication, March 11, 2015). For the United States, the Arctic Council was used as a platform to "sell climate change mostly to a domestic audience" (personal communication, September 29, 2014). ${ }^{43}$ Some interviewees proposed that the priorities of the Arctic Council had changed with every chairmanship at a certain level; however, others expressed concern that domestic politics were driving the agenda of each chairmanship more and more, which affected the continuity of the Arctic Council's work. There was a sense that this was a "dangerous route" (personal communication, November 6,2014 ) that could see the work of the Council hijacked by domestic politics and the agenda of the Council further politicized.

\section{Secretariat}

A new governance feature officially introduced in 2013 was the creation of a permanent secretariat. ${ }^{44}$ The Arctic Council established this secretariat to support the administrative management of the Council's work, including internal and external

\footnotetext{
${ }^{43}$ This concern is further supported given that the United States' chairmanship of the Arctic Council will continue through to the Trump administration, which will introduce new domestic priorities to the agenda that has been set.

${ }^{44}$ In 2006, a temporary secretariat was set up in Tromso, Norway to support the chairmanships of the Norway, Denmark and Sweden. This secretariat became permanent through the Kiruna Declaration (2013d).
} 
communications, organizational support, document archives, record keeping, etc. (Arctic Council, 2015b). Member states recognized that with the increasing prominence of the Council and its broadening mandate, there was a need for coordination and a secretariat to manage its activities. This represents a change of position by United States officials, who would not support the creation of a secretariat when the Council was created. Although in negotiating the creation of the secretariat, the United States took a firm position that the secretariat was not to develop policy capacity and the human and financial resources initially contributed to the secretariat by member states further enforced this limitation (personal communication, September 16, 2014).

By all accounts, the Arctic Council Secretariat (ACS) has improved the transparency, document management and general operation of the Arctic Council for both internal and external audiences. Improvements to the website and regular communication about Arctic Council's work and activities demonstrated efforts to increase awareness of the Arctic Council, more clearly explain how the Arctic Council worked and do a "better job of telling the story of the Arctic Council" (personal communication, March 5, 2015). The ACS took on the responsibility of tracking and reporting Council decisions, instructions to working groups, and progress on implementation. This work was intended to improve the institutional memory of the Council and increase its "credibility as an organization that does meaningful work" (personal communication, November 10, 2014).

As the ACS matured, it also became an important resource for observers "both by sharing information and seeking their input" (personal communication, January 22, 
2015). The secretariat could also play a role in building relationships with other organizations "directly or indirectly involved in the Arctic region - to find synergies, avoid duplication and maintain continuity between chairmanships" (personal communication, January 22, 2015).

Another key area of work that the ACS took on was trying to improve the flow of information between the SAOs and the working groups. The secretariat took on responsibility for providing secretarial support to the Emergency Prevention, Preparedness and Response (EPPR) and Arctic Council Action Plan (ACAP) working groups, which they did not have previously. However, for working groups with their own well-established secretariats, there was more tension and questions about what role it was appropriate for the ACS to play. There was a perception that the ACS might function as an extra layer between SAOs and working groups that were already feeling sidelined. There was an impression that the ACS represented the centralization and formalization of the Arctic Council that would increase the top-down processes and direction of decision making compared to the much more bottom-up "feel" of the Arctic Council work during its early years (personal communication, November 2, 2014). Ultimately, the ACS was responsible and accountable to the Arctic Council chair. $\underline{\text { Role of observers }}$

Increasing interest in attaining observer status and the role that observers played and should play received growing public attention starting in the early 2010s. This increasing interest by state and non-state actors created opportunities and challenges. The participation of more observers meant access to more information and expertise to 
inform the work of the Arctic Council; however, it also meant bigger meetings and the need to manage increasingly diverse interests. In 2013, the Arctic Council responded to the increased interest and participation of observers by creating an Observer Manual (2013c) that served to set clear limits on observers' participation. Whereas in the early years, observers were able to co-lead projects and actively participate in working group and SAO meetings, as the number of observers increased, their ability to participate decreased. As outlined in the Observer Manual, "the primary role of observers is to observe the work of the Arctic Council" (Arctic Council, 2013c, p. 7).

Also in support of this objective, the Observer Manual created a rule that Arctic Council projects must have more than $50 \%$ member state and permanent participant funding support to proceed. In other words, observers could no longer lead Arctic Council projects. These administrative changes in how projects were managed and monitored formed part of the agenda to strengthen the governance of the Arctic Council. However, where some participants saw increased clarity and transparency in the Council's governance; others were less convinced that these rules served a productive purpose. As one interviewee pointed out, there was "already a mechanism [to contain observer involvement]. Projects still have to be approved by consensus. I don't understand the fear. There are other safeguards. [These new rules] are restricting opportunities" (personal communication, October 31, 2014).

For some interviewees, the proper role for observers was to "learn and take what they learn back home" (personal communication, January 16, 2015). However, both 
observers that have been working with the Council since its inception and those more recently accepted, have questioned this limited role. Interviewees from state and nonstate observer organizations were unanimous in their assertion that they can and should have a more meaningful role in the Council. Most interviewees acknowledged that defining the role for observers in the "new" Arctic Council was still a work in progress. Interviewees recognized that restrictions on the participation of observers were put in place based on a fear by member states, permanent participants and existing observers (or at least uncertainty) about the real interests of observers in the Arctic Council and the Arctic. For example, some interviewees raised concerns about how a growing number of observers might affect the unique role of permanent participants in the Arctic Council. As a result, one interviewee advised that the "best work of observers is to build trust, then [work with member states and permanent participants] to figure out when and how to get involved" (personal communication, January 22, 2015).

\section{Arctic Economic Council}

The final new governance feature that deserves attention is the creation of the Arctic Economic Council (AEC), a forum for business in the Arctic. Launched during the Canadian chairmanship in 2013 , there is disagreement about what its creation really meant and what role it will play in relation to the Arctic Council. Those that supported the creation of this business forum saw it as a means for business to give advice to government by identifying priorities, creating knowledge, informing policy advice and partnering on the implementation of policies. For supporters of the AEC, the meaningful involvement of business gave the Arctic Council more credibility. Businesses involved in the AEC were aware of the potential authority they held collectively to establish and 
enforce standards within their respective industries - whether it was resource extraction, transportation or tourism. Several interviewees from the AEC proposed that under the right conditions, and with the appropriate opportunities to influence Arctic policy, they would be willing to draw on that authority to support the policy decisions of the Arctic Council.

For those people that were more sceptical of the purpose or value of creating a business forum that was affiliated with the Council, there were three common concerns raised: First, that inviting business to have a relationship with the Council undermines the unique role of permanent participants because it "positions them to compete with big corporations with greater resources and capacity" in both the agenda setting and the creation of policy advice (personal communication, March 5, 2015); second, that business would have inappropriate access to policymakers (personal communication, September 29, 2014); and third, that a forum created to focus on business and economic issues in the region could take attention away from the Arctic Council itself that, to date, had been relatively weak in considering business-relevant issues and policies (personal communication, January 19, 2015).

Having spoken with people both directly involved with the AEC and those that were only aware of its creation, I have concluded that a clear role for the AEC had not yet been clearly defined by the end of the period of my research. What was clear was that very little thought or effort had been put into considering the relationship between the Arctic 
Council and the AEC to ensure that their work was coordinated to support informed policymaking and to limit overlap and duplication.

\section{Meeting needs and interests}

In Chapter 5, I proposed a new approach for understanding how the Arctic Council worked in its early years (Figure 5.3). I introduced the importance of boundary work to support the Council's role in knowledge generation and policy shaping. Using this concept, I examined how the interests of policymakers, scientific experts and Indigenous actors were met through the institutional design of the Council. Having reviewed a number of changes between 2006 and 2015 in the raison d'être, organizational culture and governance features of the Council, I now consider what these changes mean for the Council's ability to meet the needs and interests of these different actors and to what extent it changes how they work together.

\section{$\underline{\text { Political interests }}$}

To begin with, there was increased interest from actors in the political sphere, including Arctic states, non-Arctic states and IGOs. Political actors from Arctic states were relatively unengaged in the work of the Arctic Council in its early years. Primarily lower level diplomats and scientific experts from Arctic states participated in activities for the purposes of supporting relationship and trust building. In more recent years, the growing prominence of the Council has had an impact on the interest of Arctic states and how they relate to the Arctic Council. Instead of a few government officials dedicated to Arctic issues, one interviewee explained that there was "really an army of people behind each government representative" (personal communication, March 9, 2015). Each representative had consulted, worked with and sought the expertise of multiple people 
in multiple departments. However, the level of interest and involvement of government departments with mandates related to the work of the Arctic Council was not uniform. Interviewees explained that the ability to mobilize officials to contribute to Arctic Council work depended on how that work aligned with the domestic priorities set by a the government or even a specific minister.

Furthermore, as one survey respondent observed: "as political interest [in the Arctic Council] increased so does the desire of the foreign ministries of some countries to ensure that Arctic Council reports, such as those coming from Arctic Monitoring and the Assessment Programme (AMAP) or Conservation of Arctic Flora and Fauna (CAFF) working groups, are supportive of that country's national policies on an issue" (Kankaanpää \& Young, 2012b). Member states were increasingly sensitive about the framing and wording of Arctic Council documents that their governments "acknowledge," "endorse" or "support." In a world where discussions were growing about global interests and responsibilities in the Arctic, member states had to carefully weigh the domestic and international implications of what they were committing to, or may be perceived to be committing to, by acknowledging Arctic Council products.

Governments also needed to carefully assess what action they were perceived to be committing to as a result of their involvement in Arctic Council work. Government officials had a sense that more was at stake and every word mattered. This made the translation and mediation work of the Arctic Council that much more delicate and time consuming - often frustratingly so for technical and scientific experts who were more 
focused on the urgency being dictated by the environmental, socioeconomic and health challenges observed in the region. One interviewee expressed amazement at the attention that the most recent Arctic Human Development Report (AHDR) (2014) received from certain ministries of foreign affairs of member states. Government officials "analyzed every word of the report...cautious about how it would be portrayed because of the impact on domestic and international geopolitics and law" (personal communication, March 9, 2015). There were so many challenges in reaching consensus on the final text of the ADHR report that it was ultimately released by the authors with the Ministerial declaration "not[ing]" the report rather than Arctic Council ministers providing their endorsement.

The involvement (or limited involvement) of sub-national governments in the Arctic Council has also gained attention more recently. Canada, the United States and Denmark often include sub-national governments in their delegations at Arctic Council meetings. However, as the Arctic Council's agenda expanded - "especially with a shift to more local issues [including] renewable energy, agriculture and fisheries" (personal communication, March 6, 2015) - and focused more on policymaking rather than policy shaping, representatives of sub-national governments were asking "where are the [subnational] governments?" "Why don't we have a seat? We are policymakers. We have the authority" (personal communication, March 6, 2015). Interviewees working at the local and sub-national levels criticized the Arctic Council for being "far down into their own knapsack" (personal communication, March 11, 2015). From their vantage point, "the Arctic Council is not constructed to handle work at the local level" (personal 
communication, January 15,2015$)$ and providing a role for the local and sub-national governments would provide a natural link between the Council and the people in the Arctic. During the Canadian chairmanship, the Yukon government led an Arctic Council project for the first time under the supervision of Natural Resources Canada. The creation of the Arctic Adaptation Exchange Portal, an online "information hub for communities, researchers, and decision-makers across a variety of sectors" (Arctic Council, 2015a), provided a clear example of how and where sub-national governments could take a leadership role. This project specifically focused on providing a platform where local experiences and expertise could be shared regionally and internationally. However, involvement at the project level has not provided sub-national governments with a defined role in the Arctic Council's agenda setting.

Finally, the involvement of observers and potential observers represents a diversity of actors with political needs and interests - either because they are positioned to influence or enact (e.g. China, India, UNEP, WWF, AEC) policies that have an impact on the Arctic either directly (e.g. management of migratory species and development investment in the region) or indirectly (e.g. climate change and environmental protection). Irrespective of whether these actors had a formal place at SAO and working group meetings, they had an elevated political interest in the Arctic Council and they were continuing to look for opportunities to participate and influence its work. $\underline{\text { Indigenous interests }}$ In Chapter 5, I explored the important role that Indigenous representatives played in bringing the human dimension into policy discussions about environmental 
management and sustainable development. Arctic Indigenous peoples became global spokespeople for the Arctic. Permanent participants provided the Council with legitimacy and credibility because of the position they hold at Arctic Council meetings and the role they played in shaping the institutional design of the Council.

The period between 2006 and 2015 saw some notable changes for Indigenous participation in the Arctic Council. Of course, concerns about a lack of support for permanent participants to meaningfully participate in the work of the Arctic Council were not new. This has been an issue that has plagued the Council since its inception. Some interviewees talked about insufficient resources to "keep the lights on" (personal communication, March 9, 2015), while others discussed efforts to fundraise from private sources to "fill the gaps" (personal communication, November 2, 2014). The need for financial support to meaningfully participate in Arctic Council work was coupled with the need to support permanent participants in other ways to build their capacity, especially as the mandate of the Arctic Council expanded and the number of meetings and activities grew. Interviewees from permanent participant organizations talked about the challenges of identifying people with an understanding of their communities' needs and interest combined with the appropriate technical expertise and language (English) to participate in Arctic Council work. As a result of financing issues and a limited number of experts, permanent participants may be invited to participate in all the activities of the Arctic Council, but they cannot always attend. Instead, they have to focus their energy and attention on Arctic Council work that is a priority for their communities and where 
they could best contribute. As one interviewee put it “we can't be involved in everything. It's too much" (personal communication, January 22, 2015).

For those interviewees close to the permanent participant organizations over the life of the Arctic Council, there was also a sense that the permanent participant organizations were not as well coordinated in these later years. There was a sense of nostalgia for earlier days when the permanent participants, as a group, were key players in the launch of the ACIA. There was a sense by permanent participant representatives and other Arctic Council representatives that permanent participants collectively played a critical role by mobilizing to give the ACIA report a global profile and a human dimension that significantly enhanced the report's legitimacy, credibility and salience and, by extension, its influence on a global scale. In later years, some interviewees expressed concern that permanent participants were "more passive" (personal communication, January 7,2015 ) - That they were "spread too thin" and "lack a sense of direction" (personal communication, March 9, 2015). One permanent participant representative emphasized that the bar was set higher for permanent participants - they "can't just sit in a seat, [They] have to fill that seat" (personal communication, January 22, 2015). For one interviewee, with the move away from their advocacy roots, permanent participants were not as well coordinated as a group and there were more tensions around their differences and the "haves and the have nots" in terms of human capacity and financial resources amongst the permanent participant organizations (personal communication, March 9, 2015). 
Despite these concerns, there was still a recognition and sense of pride for many involved with the Arctic Council that the permanent participants "punch above their weight" (personal communication, May 6, 2016). Some point to the fact that there was much less turn over in the representatives of the permanent participant organizations, which meant that permanent participants "know the Arctic Council better at all levels and over time - [they have] the corporate memory and the back story on final products" (personal communication, November 2, 2014). As the turn over of member state and observer representatives accelerated over the years, permanent participants held the institutional memory of the Arctic Council and "have to train new people" (personal communication, January 22, 2015). Some suggest that permanent participants also held more influence because they were culturally more comfortable and adept at participating in an institution that had adopted a consensus-based decision-making approach.

A shift to more policymaking was cause for concern for some representatives because it might reduce the impact and influence that permanent participants have. Furthermore, one interviewee questioned whether it was really appropriate for permanent participants to have the position at meetings that they do when member states are negotiating binding agreements or issues that have direct impacts on states responsibilities (personal communication, March 9, 2015); while an interviewee from an Indigenous government suggested that as the Arctic Council moved to policymaking, they may be compelled to follow the work of the Council more carefully and seek a more direct role than currently available through member states or permanent participant delegations 
(personal communication, January 21, 2015) - bringing to the fore delicate tensions and questions about who speaks for whom.

\section{$\underline{\text { Scientific interests }}$}

Finally, it is important to examine the changes in how scientific interests were met. As I discussed in some detail previously, the Arctic Council in its early years had a strong scientific focus. Technical interests were at the heart of the Council's agenda dedicated to knowledge generation and policy advice. Working groups were the engines of the Council and the main boundary between scientific and political interests was through the knowledge and advice of working groups being transferred to the SAO level. Several interviewees referenced the growing cultural gap that existed in later years between the diplomats that worked at the SAO level and the scientists and experts that participated at the working group level. Some suggested that this was not unique to the Arctic Council; rather, it was common at the interface between science and policy in many fora, including various United Nations bodies. However, others sensed that the tensions between the SAO and working group levels had notably increased because of more top-down management approaches and governance changes that centralized decision making with the SAOs and sidelined the interests of working groups that had worked with a high level of independence in earlier years. Interviewees from working groups perceived a growing gap and argued that it had an impact on their work.

In the first decade of the Arctic Council's existence, there was the strong perception from those both within and outside the Council that the "real" work was done by the working groups. However, as the importance of the Arctic Council grew and it became 
more structured, some participants had the impression that the working groups were being "sidelined" (personal communication, November 6, 2014). Getting time and space to "sell" initiatives proposed by working groups and their sub-groups at the SAO level was becoming increasingly difficult. And priorities set at the ministerial or SAO level often demonstrated a lack of knowledge or understanding of the mandates and activities of the working groups or how they functioned. "There is a growing distance between SAOs and the working groups" (personal communication, March 5, 2015). Not surprisingly, this sense of distance was exacerbated by the increasing tendency of SAOs to establish task forces on particular issues rather than referring these issues to an existing working group. As a result, working group members began to rely more frequently on informal connections to policymakers instead of depending on the Arctic Council's formal governance mechanisms.

\section{Impact on the governance model}

Some interviewees saw these changes in the institutional design of the Arctic Council as a "natural evolution and maturing" as the Council became more established and important - policymakers should be setting the agenda and "working groups must report and get permission to do work" (personal communication, November 19, 2014). Others were concerned that the Arctic Council was becoming too top heavy (personal communication, January 15,2015$)$ and the Council "risks moving too far from its roots" (personal communication, March 5, 2015). While there were different opinions about the institutional design that best supported the work of the Arctic Council, it is hard to ignore the gaps emerging between the different levels and areas of work within the Arctic Council - in particular amongst the working groups, between the working groups 
and task forces, and between working groups and the SAOs. Joined together, these gaps illustrate broader fragmentation that was taking place within the Council (Figure 6.2). This fragmentation played a role in compromising the effectiveness of the Arctic Council. Moreover, there were diverging opinions about the role the Council could or should play in regional policymaking and these differences often fell along political, Indigenous and scientific lines.

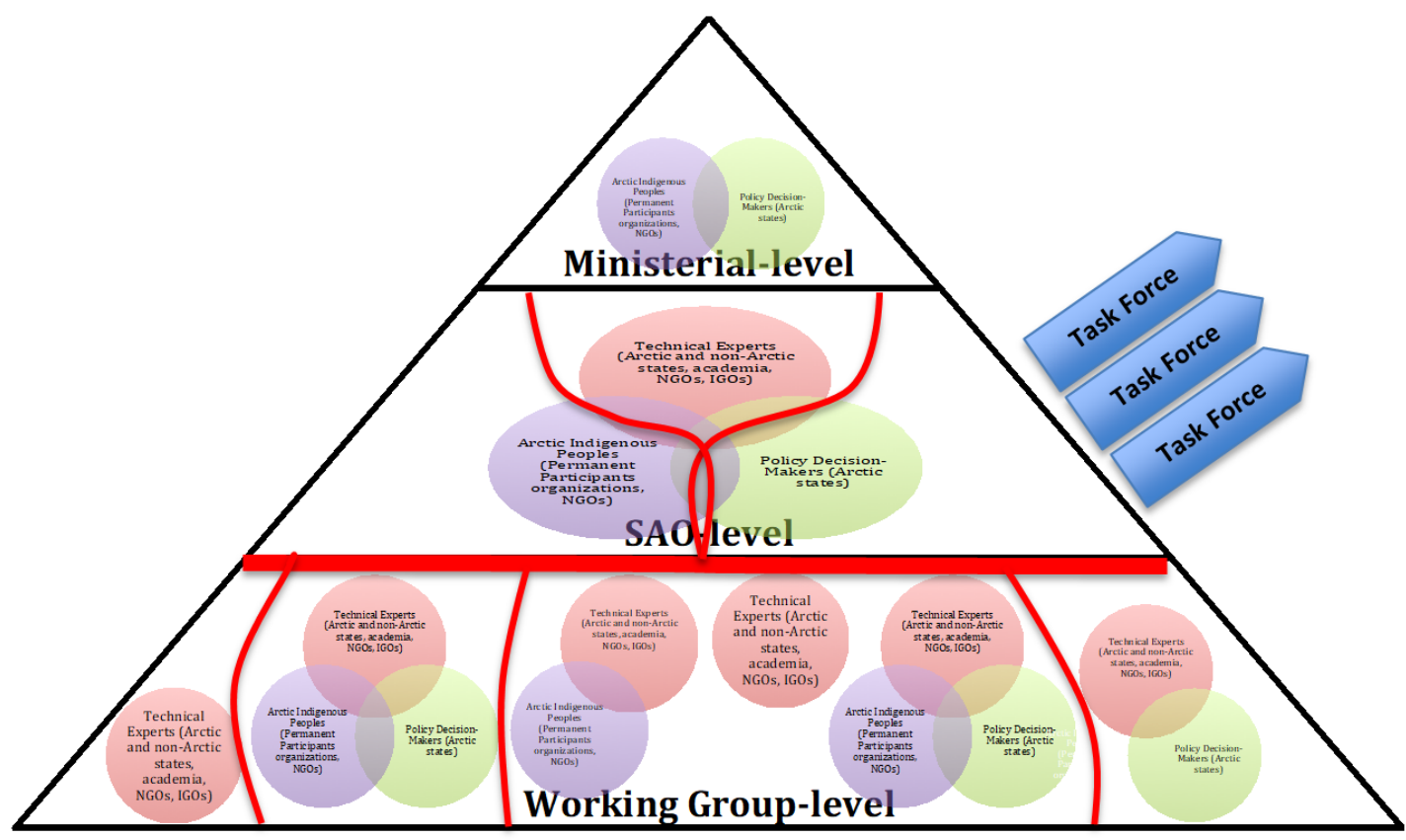

Figure 6.2: Fragmentation within the Arctic Council

The red lines presented in the figure illustrate the fragmentation that is taking place at different level of the Arctic Council and the gaps between levels within the Council.

The significance of these gaps and fragmentation is still unclear; however, if we accept the proposition that the Council's boundary work in its early years contributed to its institutional effectiveness, then this concept of boundary work might also inform our understanding of the gaps and fragmentation being observed. Guston (2001) points out that boundary objects, the products created through co-creation, by definition require 
the consent of actors on both sides of a boundary. By extension, the Arctic Council can only maintain the credibility, saliency and legitimacy assumed for its boundary work as long as actors on each side of the boundaries consent to participate in its work and endorse its work (Cash et al., 2002). This is what provided the Council with legitimacy and credibility in its early years. However, we observe that the dynamics between these social worlds is changing and there are signs that, in some cases, this may be making it hard for scientific experts, Indigenous organizations and policymakers to maintain the lines of responsibility and accountability to their respective social worlds. This in turn may compromise the Council's boundary work across social worlds and, by extension, its stability as an institution for knowledge generation and policy shaping.

Another way to explain the fragmentation that is emerging is to return to Levy's et al's (2001) proposition that there needs to be alignment between the Arctic Council's governance model and the role that it assume in the policy process. Revisiting the criteria for effectiveness introduced in the earlier sections, we observe that during this period the Council held an established and prominent position in the network of institutions, the relevance of the Council increased for actors inside and outside the institution and the salience of the issues on the Arctic Council agenda also increased dramatically. Individually, the hypothesis was that each of these criteria was necessary for the Arctic Council to be effective; however, as I indicated in these earlier sections, this analysis is incomplete without an assessment of its institutional design over this period. Based on a detailed analysis of the changes in the institutional design, I argue that the overall effectiveness of the Arctic Council has declined because of a growing 
misalignment between the role that the Council is expected to play and the Council's governance model.

\section{Conclusion}

This chapter introduced a very different Arctic Council. It still produced high caliber and well-recognized reports and policy advice (boundary objects); however, in just 10 years it also became the creator of binding agreements, the convener of a global congregation of interested actors, and was positioned as the "the preeminent forum for international diplomacy on Arctic matters" (Ziff, 2015).

This chapter demonstrates that these changes in the Arctic Council were the product of a complex mix of endogenous and exogenous factors that had observable implications for the Council's institutional effectiveness. The governance environment was dramatically transformed because of concerns by some people about the environmental changes in the Arctic and the enthusiasm of others about the prospect of a new frontier for development and economic opportunity. The elevated prominence of the Arctic increasingly politicized the governance environment of the region and attracted attention to its institutions. The Arctic Council was at the epicenter of the network of institutions garnering this attention.

The priorities on the Arctic Council agenda exhibited similar trends of significant change in the space of just 10 years. Although the touchstones of "peace and cooperation" and environmental protection were still present, they were both notably transformed. Climate change served to link once segregated policy issues - the health of Arctic 
Indigenous peoples was linked to the activities of industries far to the South and melting sea ice implied new transportation routes from Asia to Europe and North America. Overall, the number of issues on the Council's agenda grew and so did their scope and scale.

The most notable developments during the period were observed changes in the Council's institutional design. As a result of its increased prominence, various efforts to "strengthen" the Council were initiated - new and revised guidelines and procedures, more structured and formalized meetings, the creation of a secretariat to support better communication and administration. These were all efforts you would expect to see as the Council attracted more attention; however, the analysis in this chapter suggests that the changes in the Council's institutional design may in fact be causing fragmentation in its governance mechanisms that facilitated policy shaping through boundary work. Examining the interplay between the factors that explain institutional effectiveness, the concerns for the Arctic Council's institutional design are only magnified. The alignment observed between these factors in the Council's early years were largely gone. It was replaced by the strong impression that the Arctic Council was suffering from poor institutional fit and a sense of uncertainty about the direction that it will (or perhaps should) take.

However, in examining the data, there is another piece of the puzzle that has not been exposed through the analysis based on these three determinants of institutional effectiveness. This missing piece was exposed by the sense of confusion among 
participants of the Arctic Council about the role that the Council played in its last decade and, perhaps more importantly, the uncertainty about the role it could or should play in the future. These diverse ideas and opinions about the rightful place of the Arctic Council exposes underlying logics that are shaping how participants understand the Arctic Council and how they judge its effectiveness. This is the focus of Chapter 7. 


\section{Chapter 7: The Unexplored Determinant of Effectiveness}

While an analysis of the governance environment, issues on the Arctic Council agenda, and the Council's institutional design provide important insights regarding to what extent the Arctic Council has been effective over time, the data collected indicated that there was a determinant of institutional effectiveness that had not been captured through this initial analysis - the institutional logics within the Arctic Council. As previously mentioned, institutional logics are defined as "socially constructed, historical patterns of cultural symbols and material practices, including assumptions, values and beliefs, by which individuals and organizations provide meaning to their daily activity, organize time and space, and reproduce their lives and experiences" (Thornton \& Ocasio, 2008, p. 101). By examining the institutional logics behind how people involved and knowledgeable about the Arctic Council defined and measured its effectiveness, I exposed a factor of effectiveness that highlights the interplay between actors, institutions and their operating environment. Evidence of different institutional logics emerged in the different ways interviewees and survey respondents spoke about what had made the Arctic Council effective or how the effectiveness of the Council could be improved.

Some people offered general comments along the lines of: I very much believe that the [Arctic Council] has a strong role to play, and that they will need to continue the strong work they are doing to help address these complex issues (Kankaanpää \& Young, 2012b). Others were more prescriptive: 
- We should not try to make the [Arctic Council] a body which creates new sovereignty in the Arctic. It is primarily a communications and learning mechanism that has been very successful with its assessments (Kankaanpää \& Young, 2012b); or

- Since more and more activities in the [A]rctic region is to be foreseen the [Arctic Council] is the best forum to take necessary actions to protect the environment in the region. This will need a high political commitment from all member states and the role of [the Arctic Council] will be to implement the political decisions made into real actions through the working groups (Kankaanpää \& Young, 2012b).

What these statements expose are two very different ideas about how the effectiveness of the Arctic Council is defined. It introduces the meta-level question: effective at what? Despite a diversity of perspectives by interviewees and survey respondents, I observed in the interview data three dominant, co-existing identities within the Arctic Council, which create different (and at times conflicting) pressures that have an impact on how the Arctic Council is understood, what is expected of it and how it is managed. In other words, a discussion about how effectiveness is defined uncovers a less explicit determinant of institutional effectiveness - distinct identities that exist within the Council. However, it is important to note that the existence of multiple institutional logics within the Council does not mean that these institutional logics cannot co-exist (Thornton et al., 2012). 
This chapter examines this unexplored determinant of effectiveness and considers its implications for our understanding of to what extent the Council has been effective. To support this analysis, I revisit the three time periods studied in Chapters 4,5 and 6 to examine the different institutional logics that existed and how these logics developed and evolved over time. I consider what this tells us about the ways that effectiveness has been defined and measured for the Arctic Council. I begin by exploring the period prior to the Council's creation to identify the institutional logics that informed the Finnish and Canadian Initiatives. Next, I analyze the institutional logics that co-existed within the Council during the early years with a particular focus on the Arctic Council's role as a policy shaping institution. This is contrasted, in the subsequent section, with an examination of the tensions that emerged during the next 10 years between these first institutional logics and an alternate logic for the Council that defines effectiveness by the role the Arctic Council can or should play in policymaking and policy action. In the final section of this Chapter, I explore the implications of introducing this new determinant for how we understand the institutional effectiveness of the Arctic Council.

\section{Institutional Formation and Defining Effectiveness (Pre-1996)}

Consistent with the analysis presented in Chapter 4, an analysis of how effectiveness was defined for the Arctic Council and what this tells us about the Council's underlying institutional logics begins with an examination of the period leading up the formation of the Council in 1996. Taking the time to study the relationship between the expectations that were placed on the Council prior to its official establishment and consider what contributed to its early institutional logics provides important goalposts to understand its 
early work and consider observed changes in these logics and how effectiveness is defined over time.

This is a unique moment in the formation of an institution where we might expect to see a cohesive institutional logic and clear alignment between the institutional design, problem definition, and how effectiveness is defined. What is interesting (although perhaps not unique) about the Arctic Council is that its formation was the product of the merging of two distinct initiatives - the Finnish and the Canadian. The origins of the institutional logics that shaped these two initiatives is beyond the scope of this study; however, as I explained in Chapter 4, these initiatives introduced different perspectives on the issues that the Arctic Council should seek to address and how it should be designed. Recognizing this, it is not surprising that the people involved in these two precursor initiatives also introduced distinct institutional logics that aligned with their vision and priorities for the institution. Again using a thematic analysis of the Arctic Environmental Protection Strategy (AEPS) and the Arctic Council Panel Report as a foundation and data from the survey and interviews, we observe effectiveness for these two initiatives was articulated in very different ways that exposes very different logics.

For the authors of the AEPS, this intergovernmental cooperation was presented as a means to the end of "protecting the Arctic environment." This translated into a series of specific policy priorities (persistent organic pollutants, oil pollution, heavy metals, noise, radio activity and acidification) and a strategy focused on taking collective action at the national and regional levels. The Finnish Initiative was motivated to create an institution 
that would contribute to "solving" the pressing issue of pollution in the region - it had a problem-oriented institutional logic. This is an institution that was envisioned to play the primary role of boosting concern and facilitating agreement between the Arctic states on specific pollution issues (Levy et al., 2001). Therefore, effectiveness was defined as solving immediate pollution issues in the region.

Another reason to focus on the AEPS when examining the Council's institutional logic is because the governance structures established to support the AEPS were, for the most part, assumed by the Council. In particular, the working groups retained the responsibilities assigned to them through the AEPS. As a result, the deliverables set for these working groups under the AEPS were carried over to the Council and the Council's ability to deliver on the commitments set in the AEPS served to directly inform how effectiveness would be defined and measured.

Like the AEPS, the Arctic Council Panel placed its attention at the local, sub-regional and circumpolar levels. By contrast, although the Arctic Council Panel Report acknowledged that the Arctic Council's goals should be both "substantive and procedural," the Panel's main criterion for defining the scope of the Arctic Council's work was that the "ultimate mandate of an Arctic Council should be to make the circumpolar region into a domain of enhanced civility," which as we saw in Chapter 4 (Table 4.2) ultimately meant the potential inclusion of any circumpolar issue. In contrast to the AEPS, the Arctic Council Panel dedicated much more attention and importance to procedural goals. For the authors of this report, the core issue was the meaningful 
participation of the region's Indigenous peoples and ensuring that the Arctic Council was designed to directly incorporate the knowledge and experiences of Indigenous peoples. In other words, they proposed to assess the effectiveness of the Arctic Council by how it functioned to facilitate inclusive and productive cooperation in the Arctic rather than issue-specific results.

Linking this back to Levy et al's (2001) proposition that effectiveness be assessed based on the Council's proposed function in the policy process and Underdal's (2002a) attention to what motivated efforts to establish the Arctic Council, the focus would be on the general desire to facilitate cooperation in the Arctic. Furthermore, the motives of the Arctic Council Panel draw our attention much more toward the question: effective for whom? For the authors of the Arctic Council Panel, effectiveness would be defined as meaningfully engaging the Indigenous peoples of the region and establishing an agenda focused on meeting their needs and interests. This served to link how effectiveness was defined to "good governance" features and provided a very different logic for how the Arctic Council was deemed to be legitimate and credible. It placed more attention on how the Arctic Council functioned ahead of what the Arctic Council achieved. It adopted a process-oriented institutional logic.

Through a review of how these early initiatives defined effectiveness, we can already see the existence of distinct logics that provide different understandings of how effectiveness should be measured. The AEPS, with a contained and specific problemfocus, established very concrete actions (or goalposts) against which effectiveness 
could be measured. The AEPS established a mandate for environmental protection in the region. It sought to collect data on contaminants and pollutants in the region, provide information about the impact of these contaminants and offer expert advice on how these contaminants could be addressed or mitigated. It even funded pilot projects to conduct pollution clean up in the region. In this context, the AEPS established an easily definable role in responding to a clearly defined problem.

By contrast, efforts to measure the effectiveness of the Council, as articulated by the Panel, by facilitating cooperation or ensuring meaningful involvement of the region's Indigenous peoples was much more vague and difficult to measure. The policy area is not clearly defined and places the emphasis on measuring the effectiveness of the Council's governance process. While you might be able to develop measures related to the level of participation of different types of participants at Council meetings, the ability to assess the quality or impact of participants' contributions is much harder to trace.

What an analysis of the period leading up to the formation of the Arctic Council demonstrates is that its creation brought together two distinct institutional logics (Friedland \& Alford, 1991) - a problem-oriented logic of the AEPS and the processoriented logic of the Arctic Council Panel. While these two logics shared a dedication to the same region, they differed in their "worldviews by providing relevant structures and frames to construct issues, problems, and solutions as well as script actions"(Meyer \& Hammerschmid, 2006, p. 1000). The next section explores how the definition of 
effectiveness evolved and what this tells us about how these two logics co-existed and evolved.

\section{The Original Institutional Logics (1996-2005)}

As we know from the analysis presented in Chapter 5, when the Arctic Council was established in 1996, few people within and outside the region were even aware of the Council's existence, let alone having expectations of what it should or could do. As a result, the Arctic Council's effectiveness was primarily defined and driven by internal pressures and motivations. What we also know from this earlier analysis is that the Arctic Council in its fledgling years was dedicated to knowledge generation and policy shaping, which it did through boundary work among actors from political, scientific and Indigenous social worlds. This section builds on this earlier analysis by examining the Council's co-existing institutional logics. This begins with an analysis of how effectiveness was defined for the Council. I then draw on the boundary work literature again to consider how effectiveness was measured for the Council and what this tells us about the Council's identity and institutional logics.

\section{Defining effectiveness}

Based on the input provided by interviewees and survey respondents, there are three dominant themes regarding how the Council's effectiveness was defined during this period. Not surprisingly, the Council's role in facilitating regional peace and cooperation is once again front and centre. Participants also discussed the Council as an effective model to "get things done" - a vague, but attractive definition of effectiveness. And finally, participants focused on specific achievements of the Arctic Council to confirm its effectiveness during this period. This section examines each of these themes. 


\section{Peace and cooperation}

During this early period, for many participants effectiveness was defined simply as the fact that the Arctic Council continued to exist and meet. Interviewees talked about "science as a tool to get people talking" (personal communication, March 11, 2015) or "keep[ing] the door open through science" (personal communication, November 16, 2014). As one survey respondent observed: "There is comparatively little turnover in actors at the Council allowing for the establishment of interpersonal trust. I believe this is a primary factor" (Kankaanpää \& Young, 2012b). The focus was on keeping the dialogue and discussion going.

Despite any concrete deliverables assigned at the working level, those that sought to keep the Arctic Council alive primarily focused on its importance as a mechanism for renewed peace and cooperation in the region. This was not a period when any of the working groups had many results to share. The Council was young and the working groups would need time to produce concrete results. This was a period for establishing relationships and building trust among and between different types of actors. Recalling the governance environment map for 1995 (Figure 4.2), we know that the Arctic Council was formed during a period of growth of institutions with a single actor-type. Institutions that involved multiple actor-types at the circumpolar level were extremely limited; therefore, with its creation, the Arctic Council established an important mechanism within the region for sustained dialogue and collaboration within and between different actor-types. For many that reflect on the success of the Arctic Council during this 
period, this was its greatest strength and contribution (T. S. Axworthy \& Dean, 2013; Fenge, 2012b; Stone, 2016).

In this context, the Arctic Council had the time and space to focus on the process for doing its work - it could take to heart the vision of the Arctic as a "zone of peace and cooperation." Because the Council was not the focus of intense political pressure and the issues on its agenda were not politically charged, the focus was more on bridging boundaries because of the types of actors involved and the mandate that the Arctic Council had. It could only hope to influence policy and not expect to make policy itself. That meant it needed to focus on generating high quality knowledge and policy advice because this was its main avenue to recognition and influence. Whether by design or by circumstance, this is how the Arctic Council defined itself and its effectiveness. It did this work by facilitating boundary work between scientific, political and Indigenous peoples.

\section{Model for getting things done}

Another theme that emerged from the input of interviewees and survey respondents was that the Arctic Council was an example for other international institutions because it provided a "model for how to get important things done" (personal, communication, November 19, 2014). Participants held the Arctic Council apart from other international institutions because they perceived that the Council was faster and more efficient and productive than "traditional" international institutions. Participants attributed the Council's enhanced effectiveness to its "modest beginnings," "incremental change" and "realistic goals." It focused on the "nitty-gritty." One interviewee attributed the Arctic 
Council's effectiveness to being "a bloodhound with its nose to the ground instead of a soaring eagle" (personal communication, January 16, 2015). Participants knew that the Council did not have the authority or political profile to make policy decisions, so in the first decade of its existence it set out to influence those governments and international bodies that did.

\section{Achievements of the Arctic Council}

Cash et al. conclude that effectiveness for an institution involved in boundary work must be measured based on its ability to influence "the evolution of social responses to public issues" (2003, p. 8086). Ultimately, Cash et al. propose that knowledge produced through a process that is perceived to be credible, salient, and legitimate is more likely to be influential. As a result, they argue that an institution's effectiveness depends on paying close attention to its boundary work functions, in particular facilitating communication, translation and mediation across boundaries. In the context of the Arctic Council, interviewees participating in the work of the Council at the project, working group, and SAO levels specifically referenced the Council's important role in "translating" technical and scientific information for policymakers. Furthermore, several interviewees commented on how the effectiveness of the Arctic Council in communicating, translating and mediating across these boundaries to conduct its work was dependent on "everyone being involved, engaged, enthusiastic" and "taking the work seriously". One interviewee specifically suggested that the early work of the Arctic Council would not have been possible in an impersonal and anonymous work environment" (personal communication, January 16, 2015). 
During this period, survey respondents indicated that there were two reports released that placed the Council on the map internationally (Kankaanpää \& Young, 2012b) - the Arctic Human Development Report (2004) and the Arctic Climate Impact Assessment (2004b). These two reports established the Arctic Council as a credible, legitimate and salient voice for the region (Bravo \& Rees, 2006; Fenge, 2012b; Huebert, 2009;

Kankaanpää \& Young, 2012a; Koivurova, 2010; Stone, 2016; Watt-Cloutier, 2015) and both of these reports can be understood as classic boundary objects - products that hold a purpose and maintain an identity in each social world (Cash et al., 2003; Guston, 2001; Star \& Griesemer, 1989).

While much of the commentary about these reports has focused on their timeliness and relevance that attracted attention to the Arctic and the Arctic Council, interviewees shared their thoughts on important features of these reports that once again draw us back to the effectiveness of the Council's boundary work. First, interviewees reference the quality and depth of the scientific work done to produce these reports. These were products that included data and analysis that was recognized and respected by the scientific and expert communities in their fields; therefore, the scientists doing work in the Arctic could stand behind and endorse it. Furthermore, these reports were designed to bridge the boundary with policymakers by translating the findings of various scientific communities into concrete policy recommendations. As a result, Arctic Council officials could understand the direct and immediate policy relevance of these reports at the domestic, regional and international levels. Finally, both of these reports dedicated specific attention to integrating the perspectives and ideas of the region's Indigenous 
peoples on the policy issues being discussed and considered how the findings affected the inhabitants of the region. These reports were recognized as unique by several interviewees because of the direct involvement of permanent participants and other Indigenous organizations in their preparation. Several interviewees (both representing permanent participants and other Arctic Council actors) felt that the involvement of permanent participants in every stage of the preparation of these reports ensured that the reports did not forget the human dimension of the work being done by the Arctic Council and spoke "to the concerns of the region's Indigenous peoples" (personal communication, January 7,2015$)$. Overall, what we observe, based on the accounts of interviewees representing each social world, is that both of these reports were the product of a significant amount of effort to communicate, translate and mediate across boundaries.

These products are credited by interviewees inside and outside the Arctic Council as being important tools that have influenced the domestic policies and programs of the Arctic states and international agreements, such as the Stockholm Convention on Persistent Organic Pollutants - establishing the Council as a valued institution. These products are seen as a gauge of the Arctic Council's effectiveness and emerging prominence. It is the credibility, legitimacy and saliency of this boundary work that allowed the Council to assume a role in policy shaping (Bravo \& Rees, 2006; English, 2013; Fenge, 2012b; Kankaanpää \& Young, 2012a; Stone, 2016; Watt-Cloutier, 2015; Young, 2009b). The recognition that these two reports received also set a precedent for the type and quality of work that the Council did and how the Council did its work. 


\section{How effectiveness is measured}

The Arctic Council experience serves to demonstrate that an institution that does boundary work can play a role in policy action; however, the unique functions (communication, translation and mediation across boundaries) it performs to contribute to policy action suggest that the measures used to assess its effectiveness are also unique. Cash et al. (2003) propose institutions involved in boundary work must have three tightly coupled features in order to be effective. First, the work must be credible to relevant actors. Secondly, the work must be salient. And finally, the authors emphasize the importance of the legitimacy of the institution. This section now considers what the Arctic Council experience tells us about how these features have been defined.

\section{Credibility}

In assessing the credibility of boundary work or a boundary objects, Cash et al. directly link the credibility of an institution to its scientific adequacy. This is consistent with the commentary of survey respondents and interviewees that specifically recognized the Council for its high quality scientific work and the Council's contribution to building the capacity of Arctic and non-Arctic states, other institutions and the region's inhabitants. However, using the Arctic Council experience as a case study, it is useful to broaden Cash et al.'s criteria for how the credibility of an institution is defined to recognize the value of other sources of information and knowledge. For example, in the context of the Arctic Council, the sources of credibility extend beyond a focus on scientific data or analysis to ensure the inclusion of traditional and local knowledge. From wildlife management, to the changing nature of ice, to assessing the impacts of climate change or land and water transportation routes - the region's Indigenous peoples have 
thousands of years of knowledge that can be incorporated to lend credibility to policymaking in the region. The Arctic Council Panel recognized the importance of including these voices in the process and the value of the knowledge that Arctic Indigenous peoples brought to the Council's work (Griffiths, 2012a; Lamb, 2012).

Limiting the credibility of an institution to scientific adequacy ties its credibility to the types of information and knowledge that are produced and structured by this social world. By recognizing other sources of knowledge, Cash et al.'s credibility criterion acknowledges that other actors can contribute to the credibility of an institution. Furthermore, it confirms the potential existence of multiple boundaries between social worlds that need to be managed in order to maintain the stability of the institution.

\section{Saliency}

Cash et al. propose the work produced must be salient to the needs of decision makers. Again, many interviewees commented on the relevance and timeliness of the Council's work; however, interviewees did not confine the Council to meeting the articulated or conscious needs of policymakers. Interviewees did comment on the salience of the Council's work to Arctic states; however, the reports that the Council prepared during this period were strongly focused on building understanding of the environmental issues in the region - to audiences in the region and internationally. Furthermore, it was through understanding the salience of these issues for the region's people that the Arctic Council's reports were able to capture international attention. Overall, the experience of the Arctic Council would suggest that the flow of influence might not be contained to the articulated needs of policymakers. As previously touched on, the Arctic 
Council was given a mandate to work in the areas of environmental management and sustainable development before participating governments fully recognized the importance of having a multilateral institution to perform these functions - policymakers had not yet acknowledged the saliency of the Arctic Council's work.

The path that led to the recognized saliency of the Arctic Council was less direct. It was the release of the Arctic Climate Impact Assessment (ACIA) (2004b) and the attention it received from the media that launched the Arctic Council to international prominence. Scientists in various fora had been sounding the climate change alarm bell for well over a decade with very limited popular (and by extension political) traction; however, the very graphic and credible evidence of climate change that the ACIA provided and the active promotion of this report by the region's Indigenous peoples facilitated a new level of public concern (English, 2013; Young, 2013). In fact, as discussed in Chapter 6, the United States attempted to block the public release of the report. It was after international recognition of the saliency of this Arctic Council product that the Council was launched onto the radar screens of Arctic policymakers. All this to emphasize that the process by which saliency is determined and who has the power to determine what is salient can be more complex - a process that can happen within an institution, but may also draw on outside actors and influences. Therefore, the experience of the Arctic Council refines Cash et al.'s definition of saliency in two ways: first, it clarifies that the work of an institution may come before policymakers are aware of its need and second, policymakers may in fact resist recognizing the saliency of an institution's work and even play an active role in trying to reduced its perceived salience. 


\section{Legitimacy}

The final feature explored by Cash et al. is legitimacy. In their work, the authors focus on the internal process of legitimizing boundary work - the perception that the process of generating boundary objects is unbiased, respectful of different values and beliefs, and fairly treats opposing views and interests (2002). The authors focus on how these are important factors to ensure the internal stability of the organization; however, the experience of the Arctic Council highlights that the perceived legitimacy of an institution by external actors can also be an important factor in determining the perceived effectiveness of that organization by participants. In interviews with representatives of member states, permanent participants and observers, there were a significant number of references to how the Arctic Council enjoys a unique level of legitimacy because of the meaningful governance role established for the region's Indigenous peoples. This enhanced legitimacy, for many interviewees, is linked to the "moral authority" that the permanent participants hold because they represent the Indigenous peoples that have lived in the region for generations and they are most affected by the policy decisions that are made for the region. With their involvement in the Arctic Council, permanent participants provide the Arctic Council with legitimacy (Suchman, 1995).

Issues related to the Arctic Council's legitimacy were also raised by some interviewees to explain the importance of efforts to include business. In these cases, interviewees focused on the fact that policy actions in the region can have a significant impact on the region's businesses; therefore, using and integrating the knowledge and considering their interests in the knowledge generation process ultimately supports the realization of 
policy actions. For example, safe shipping policies in the Arctic can focus on standards for ship construction, regulations that guide ship operation, or penalties for negative environmental impacts. All of these are viable policy options from a government's perspective; however, business may be able to contribute information to inform these policy options and make some options more attractive, while others may be more challenging to implement, monitor or enforce.

\section{Institutional logics of boundary work}

As I discussed in the previous section, the early identity of the Arctic Council was the product of two initiatives with two distinct institutional logics. Therefore, with their merger, we might expect to see the logic of the AEPS or the Arctic Council Panel dominate or a new institutional logic emerge (Thornton et al., 2012). However, the institutional logics literature also recognizes that there are institutions where multiple institutional logics can co-exist (Thornton et al., 2012) the analysis of how effectiveness was defined and measured in the Arctic Council's early years demonstrates that the logic of the AEPS and the Arctic Council Panel were able to co-exist and complement each other. One logic providing the policy focus, while the other provided the governance approach.

Through these two institutional logics, the Arctic Council was able to develop a collection of relatively stable practices around its boundary work - "constellations of socially meaningful activity that are relatively coherent and established (Thornton et al., 2012, p. 128). These practices supported and reinforced a collective identity for those 
involved in the Arctic Council and these practices played an important role in reproducing the Council's institutional logics (Thornton et al., 2012).

Overall, what this analysis highlights is that the Arctic Council was perceived as effective in its early years and its effectiveness was linked to the credibility, saliency and legitimacy of its boundary work. It is through its effectiveness at knowledge generation and policy shaping that the Arctic Council gained international profile as the policy forum in the Arctic region. However, its effectiveness also increased interest and expectations regarding what the Arctic Council could do and how it did worked. With its growing prominence, the Arctic Council faced criticism from some interviewees and survey respondents as a slow, opaque "talk shop." There were a growing number of calls for the Arctic Council to "grow teeth" and focus on creating and implementing binding policy - the Arctic Council was being pushed to become an institution of policymaking and action.

\section{Navigating Conflicting Institutional Logics (2006-2015)}

Through the analytical framework of the determinants of institutional effectiveness, Chapter 6 demonstrates that, as a result of many exogenous and endogenous factors, the Arctic Council began to change. This analysis also exposes signs of fragmentation within the Arctic Council and touches on a growing divide in how the Arctic Council is perceived and understood. What Chapter 6 does not touch on is the changes and growing tensions observed as a result of events in the Arctic that served to "transform the interpretation and meaning of cultural symbols and social and economic structures" (Sewell, 1996, p. 844) and their subsequent impact on the effectiveness of the Arctic 
Council. Framing these observed tensions as a consequence of competing institutional logics therefore complements the analysis in Chapter 6. As one interviewee explained, actors involved with the Arctic Council are "not talking with the same voice" (personal communication, January 20,2015). Through an analysis of how effectiveness is defined during this period, this section demonstrates that the "original" institutional logics of the early Arctic Council were still in evidence and informed the perspectives of certain actors. However, the collective identity formed around the original logics now coexisted with a new institutional logic that provided a different vision of what the Arctic Council did and what would improve its effectiveness. This section presents the unique features of this new institutional logic that was positioned to compete with the Arctic Council's original logics.

\section{Signs of original institutional logics}

The original identity of the Arctic Council persisted in the period between 2006 and 2015. As a result of earlier efforts, the Arctic governance "brand" was fundamentally transformed. Politicians and scholars alike celebrate the region as a space of "peace, stability and constructive cooperation" (Arctic Council, 2013d). Many commentators would go so far as to boast that the Arctic is one of the most peaceful regions of the globe (Mikkola \& Käpylä, 2013). At the heart of its new identity as a region of "peace and cooperation," sat the crown jewel - the Arctic Council. This narrative was bolstered in recent years, as member states continued to work together despite tensions between Russia and its Arctic neighbours playing out in other parts of the world. 
Furthermore, reports, such as the Arctic Marine Shipping Assessment Report (Protection of the Arctic Marine Environment, 2009), Snow, Water, Ice and Permafrost in the Arctic (Arctic Monitoring and Assessment Programme, 2011), the Arctic Biodiversity Report (Conservation of Flora and Fauna, 2013) and the second Arctic Human Development Report (Larsen \& Fondahl, 2014) demonstrate that the Arctic Council continued to produce salient and credible boundary objects that played an important role in bridging different social worlds. These products are credited by interviewees inside and outside the Arctic Council as being important tools that have influenced the domestic policies and programs of the Arctic states and international agreements, such as the Stockholm Convention on Persistent Organic Pollutants (2001) and Minamata Convention on Mercury (2013).

\section{Emergence of a new institutional logic}

However, "while actors may reproduce behaviors consistent with existing institutional logics, they also have the capacity to innovate and thus transform institutional logics" (Thornton et al., 2012, p. 4). In analyzing the interview and survey data there are four complementary and interrelated themes that arose that signalled the emergence of an alternative institutional logic within the Arctic Council. The first theme is a critique of the original logics and a sense that a window of opportunity existed to improve the Arctic Council.

\section{Improving the Arctic Council}

The first evidence of a new institutional logic is observed in critic of the work of the Arctic Council. Some interviewees and survey respondents who were involved with the Arctic Council argued that the observed increase in the Council's profile is not deserved. 
They propose that the impact of the Arctic Council has been exaggerated. Some suggested that the "light" status of the Council means that the Council does not deserve the time and resources that have been dedicated to it (personal communication, October 31,2014$)$; while others go so far as to suggest that the Council has failed because its discussions have not translated into the implementation of binding agreements (Kankaanpää \& Young, 2012b); or its "soft politics" have not produced any real follow through (personal communication, November 17, 2014). Similarly, some participants argue that the Arctic Council is a disappointment because "states make laws... [whereas] the Council has not done anything concrete" (personal communication, November 17, 2014) while others see that the Council's failure to follow up on its recommendations has led to a "systemic" failure to "shape or penetrate policies of governments" in contrast to the European Union that produces "regulations that penetrate" (personal communication, November 17, 2014).

In a similar vein, some of those people surveyed see the work of the Council more favourably; however, they note that there is now a window of opportunity to do more. These actors consistently indicate that the Council has "progressed beyond expectations" (personal communication, January 22, 2015), but the Council must now take advantage of its success and take on more responsibility for policymaking and implementation. They argue that avoiding this larger level of responsibility and accountability is to fail or risk becoming too bureaucratic and irrelevant (personal communication, November 10, 2014). 
What both these lines of thinking emphasize is the general logic that the effectiveness of the Arctic Council can be improved. Others focused on the specific ways that the Council could be improved. For example, there is a growing discourse in the popular and academic literature about the need for the Arctic Council to move from a policy shaping to a policymaking body (Exner-Pirot, 2011; Fenge, 2012a; Nord, 2016; Ronson, 2011). This idea was echoed in the comments made by interviewees and those surveyed. One interviewee referred to the search and rescue agreement as the Council's first binding agreement and agreed with a statement made by the Foreign Minister of Denmark that this agreement signalled the Council's "move from decision shaping to decision making" (personal communication, November 6, 2014). This interviewee and others held the position that this is the "rightful" future role of the Arctic Council. This institutional logic places a value on a more direct role for the Council in policy action, implementation and monitoring. It is articulated as "increasingly DOING policy," "making policy instead of just making reports," having a more "powerful role in the policy process", being a more "serious" institution, and "increasing in substance."

\section{Logic of actions and results}

A related theme in this new institutional logic is placing a high value on action and results. Implicit in this is a critique of the existing institutional logic, which placed an emphasis on process and enhanced relationships between actors. As one interviewee suggested "stability is not an end, it's a means...[and the focus on means] is running out of fuel" (personal communication, November 16, 2014) or as another participant indicated, the Council needs to "focus on concrete actions and deliverables. Science is 
critical, but using that science is the most important issue" (Kankaanpää \& Young, 2012b). For some, there can still be a value to "a non-binding discussion forum... if binding implementation is achieved" (Kankaanpää \& Young, 2012b). However, others are more sceptical that the Council in its current forum has demonstrated any value. Some suggest, "more talk causes frustration without results. It's easy to produce booklets and guidelines, but are countries really doing anything?" (personal communication, March 5, 2015). Based on this logic, several participants questioned whether the Council is worth all the money and effort; while others suggested that now is the time for the Council to be re-structured to enable policy action (Kankaanpää \& Young, 2012b). Based on this institutional logic, effectiveness is measured based on concrete actions, delivering results, establishing "real" common policies, observable outcomes, follow-through and implementation.

Recent Arctic Council statements and commitments imply that ministers have come to accept that the Council should be more oriented to action and results. Generating reports that inform policy is no longer deemed to be sufficient. The success of the Arctic Council is now measured by binding agreements and commitments, like the Agreement on Cooperation on Aeronautical and Maritime Search and Rescue in the Arctic (2011a) and the Agreement on Cooperation on Marine Oil Pollution Preparedness and Response in the Arctic (2013a). In fact, during its chairmanship (2013-2015), Canada was criticized for not committing to continue this trend by proposing another binding agreement as part of its chairmanship. Furthermore, the United States, who 
subsequently took over the Arctic Council chairmanship, expressed its intent to continue to lead the Arctic Council further down the path of policymaking.

\section{Emphasizing accountability and authority}

The final, closely related theme is an increasing emphasis on the accountability and authority of the Council as important features for assessing its effectiveness. If the logic was that the Council should assume a role in policymaking, "good input and ideas are important, but [we] depend on states to bring them up and take them forward" (personal communication, November 19, 2014). In other words, if the Council is "serious" it needs to emphasize state-to-state relations because "states are different. They have authority and resources" (personal communication, January 19, 2015). In the case of the Arctic Council, it is not surprising to observe that pressure to shift to policymaking and results is presumed to mean that member states need to take a more central place in the discussions. Although other actors involved the Arctic Council have the authority to commit themselves to certain projects or decisions, only member states have been vested with the authority to make public policy decisions for their citizens and would be held accountable by their citizens for their implementation. As a result, in observing Arctic Council meetings, we see less space being created for boundary negotiation and mediation. The legitimacy of a policy decision is no longer defined by shared knowledge or co-creation. A state must focus its attention on ensuring that the commitment fits within its existing legislative and policy framework or assess the consequences of making a transboundary commitment that will result in domestic changes that may require legislative approval. 
For example, in the process of preparing the Agreement on Cooperation on Aeronautical and Maritime Search and Rescue in the Arctic (2011a), the authority of member states to commit to provisions of the agreement was central to the negotiations. The moral or technical legitimacy and credibility that Indigenous and scientific representatives contribute to the Arctic Council and its work becomes less relevant because they were not signatories to the agreement and would not be held accountable for its implementation. Therefore, one interviewee specifically questioned the appropriateness of participation of Indigenous and scientific representatives in the negotiations except to provide advice to member states (personal communication, January 19, 2015).

Furthermore, in 2013 the Arctic Council began work on black carbon emissions standards. It was not insignificant that states agreed to initiate this discussion; however, it is important to note the careful language used and deference that ultimately needed to be showed to officials representing member states in the negotiation of this agreement. There was no question that scientific and Indigenous interests were critical in bringing this issue to the table; however, the authority of states and their ultimate responsibility to deliver on the commitments that were made meant that there was little room for negotiation of the substance. In this context, the authority and accountability of Arctic states to enact policy decisions changed the dynamic at the table. A focus on negotiating very specific, legal language meant that there is less space for broader, inclusive policy discussion. Ultimately the discussions are contained and controlled by the Arctic states. Whereas in earlier years, permanent participants enjoyed an equal 
opportunity to contribute in discussions on all issues, now there were some policy issues where member states took a more dominant role and the balance of power very clearly rested with states.

Similarly, there was increasing commentary about the need to make the Arctic Council accountable. During this period, there was increased criticism of the lack of monitoring and reporting of how Council's work affected policymaking and implementation. This criticism came not only from participants and followers of Arctic Council's work but also from the audit institutions of Denmark, Norway, Russia, Sweden and the United States. Further, it came both individually and in a joint memorandum that recommended improved monitoring and reporting to ensure there is a clear linkage between the Council's work and policy implementation (Office of the Auditor General of Norway et al., 2015). Once again, this focus on accountability places particular attention on states because "[it is] not really about what the Council is doing, but what states are doing aligned with Arctic Council priorities" (personal communication, October 31, 2014). By extension, if states "report back to the Council on implementation, [that] increases the credibility of the Council and the states" (personal communication, January 22, 2015).

\section{A struggle of institutional logics}

As I examined in Chapter 6, the Arctic Council governance is showing signs of fragmentation. Drawing on the institutional logics literature, this section has exposed some of the deeper causes of this fragmentation that cannot be addressed through tinkering with the institutional design. What we observe are contradictions and tensions between the original institutional logics of knowledge generation and policy shaping and 
a new emerging logic of policy action and authority. Therefore, it is important to understand that all of these logics are currently available to actors to inform their actions (Friedland \& Alford, 1991). However, each of these logics only has effects by informing concrete manifestations of the Council's practices. Therefore changes in the core practices of the Council are not only manifestations of a new institutional logic, but also tangible focal points for transforming the identity and institutional logics within the Council (Friedland \& Alford, 1991; Thornton et al., 2012). Interestingly, given that the original institutional logics still have a strong presence in the practices and identity of the Arctic Council, it is unclear at this point how the tensions between these contradictory institutional logics may be resolved.

The Council is clearly in a phase of ambiguity and instability; however, continued efforts to "strengthen" the Council suggest that this ambiguity has triggered efforts to resolve this instability. In other words, these efforts to resolve ambiguity "provides the motor that reproduces, alters or transforms practices and organizational identities...[through] a variety of interconnected mechanisms and processes that unfold over time and space" (Thornton et al., 2012, p. 133). The outcome of this process of change in practices, identity and institutional logics in the Arctic Council remains unclear at this point; however, the existence of these conflicting institutional logics has already had impacts on the Council and the various actors involved in the Council that are examined in the next section. 


\section{Implications of Conflicting Institutional Logics}

It is unclear when or how the conflicts between the institutional logics existing in the Arctic Council will be resolved. However, what is clear is that the existence of conflicting logics is already having an impact on the effectiveness of the Arctic Council. This section considers the implications for the Arctic Council itself, the member states, the permanent participants and observers.

\section{For the Arctic Council}

Can the Arctic Council take on an effective role in policymaking and policy action and still maintain its effectiveness at knowledge generation and policy shaping? Is it feasible to combine policy advice functions and policymaking functions in the same institution or are there certain functions or institutional logics that it is difficult to combine in the Council? Or put another way, having established its effectiveness in knowledge generation and policy shaping, are there limits to the role that the Arctic Council can or should play in policy action? The analysis above suggests that institutional logics within the Arctic Council have not yet been reconciled. However, drawing on the boundary work literature, we know that effective boundary work depends on "institutionalizing accountability" on each side of a boundary (Cash et al., 2003). By definition, this suggests that actors on either side of a boundary must continue to feel they can justify the Arctic Council's work and support and feel responsible for the knowledge that is being generated, how it is translated and what it is translated into. In reality, what we see is a growing gap between the working groups and the SAOs. Efforts to "strengthen" the Arctic Council have weakened the systems that facilitate communication, translation and mediation across the boundary between experts and policymakers. 
Presumably, these recent developments can be addressed by concerted effort to reinvigorate the communication, translation and mediation functions necessary to support effective boundary work. What seems like a more significant hurdle to overcome is reconciling the practices that support effective boundary work with an institutional logic and identity for the Arctic Council of policymaking and action. In particular, as discussed previously, how credibility, saliency and legitimacy are defined for boundary work places an emphasis on the process for generating knowledge and policy advice. By extension, the measures of effectiveness are process-oriented - who is involved and how? However, in an organization focused on policy action, it becomes necessary to consider outcome-oriented measures of credibility, saliency and legitimacy: What decision was taken? When will it be implemented and by whom?

Institutional logics can be understood as enabling; however, they can also be constraining as actors strive for consistency between an institution's logic, identity and practices (Thornton et al., 2012, p. 136). Furthermore, the Council's institutional logics must be embedded in its institutional design in order to ensure alignment between how effectiveness is defined, measured and what the Arctic Council is designed to do. This analysis suggests that the leadership of the Arctic Council may have the option to realign the Council's institutional design with its original institutional logics or transform the institutional design to support the new emerging institutional logic; however, this analysis raises doubts that the Arctic Council can reconcile the original institutional 
logics of policy shaping through boundary work with a new logic of policymaking and action.

\section{For member states}

In this context, Arctic states are uniquely positioned to direct change to the Arctic Council governance model to support their self-interest (DiMaggio, 1988). In fact, it is worth considering that Arctic states benefit from drawing on contradictory logics to serve their own purposes (Friedland \& Alford, 1991). During interviews with representatives of Arctic states, the value and logic of the Arctic Council as a policy advice institution was consistently acknowledged. Furthermore, interviews and observation of Council meetings produced no evidence that states have any desire to assign any new powers or responsibilities to the Council that would allow it to play a role in policymaking or action - "the eight Arctic states are strong; therefore, they make decisions domestically. They don't want the Arctic Council making decisions" (personal communication, October $31,2014)$. In fact, one state representative suggested that the Council is primarily a means to promote domestic positions and policies internationally (personal communication, January 15,2015$)$. Therefore, despite the recent discussion about the binding agreements of the Arctic Council, it is important to clarify that the Arctic Council itself has not been delegated any authority by the Arctic states.

However, representatives of Arctic states have committed a lot of energy to ensuring the Arctic Council is recognized internationally as THE policy body for the region. Although often expressing surprise or confusion that the Arctic Council has garnered such public attention, an analysis of statements made by Arctic states and Arctic 
Council officials about the central role that the Council plays in Arctic policy and decision making leaves little doubt about the public persona that has been established for the Council by Arctic states. For example, the Arctic Council and its member states have been pleased to celebrate the signing of the first binding agreements; however, these agreements are in fact agreements signed by Arctic states themselves "under the auspices of the Arctic Council" rather than being binding Arctic Council agreements. While the Council provided the forum for the Arctic states to negotiate these agreements, none of these agreements assign duties to the Council in their implementation, monitoring or enforcement. However, the Arctic states allow and even support communications by the Council that leave observers and analysts with the impression that these agreements mark a role for the Council in policymaking.

Further evidence of the efforts of Arctic states to "sell" the new policymaking logic of the Council was present in reactions to the creation of the Arctic Circle, a conference open to all countries and actors that was initiated by Iceland in 2012. Public commentary at its inception speculated that the Arctic Circle might be positioned to "take over" the role as the region's central policy forum. Although it became clear quite quickly that this concern was overstated, the efforts of Arctic states to reinforce the pre-eminence of the Arctic Council, in light of potential competition, were quite telling. Arctic states drew on and even bolstered the new institutional logic of the Arctic Council as a policymaker and "preeminent policy forum" to reduce the risk of other institutions taking on enhanced power or influence over the region's policies, mitigate a loss of interest in the Arctic Council and potentially trigging "forum shopping" - when actors seek out other 
institutions that best suit their interests - for more meaningful ways to influence or contribute to the region's policies (Raustiala \& Victor, 2004).

The Arctic states benefit from the confusion caused by the conflicting institutional logics within the Council. By supporting the original logics of the Arctic Council as a knowledge generator and policy shaper, there is no need to delegate enhanced authority to the Council that states prefer to maintain domestically. However, by simultaneously "selling" the Council as the central policy institution in the region, Arctic states are able to maintain and even enhance their control over circumpolar policy agenda. This has the added benefit of providing the Arctic states with a means to control and contain the role played by other actors (as I discuss in more detail below). The decision to maintain processes of boundary communication, translation and mediation in an action-oriented Arctic Council now rests heavily with Arctic states, which means that they have the ability to determine what issues and when in the process other actors can play a meaningful role.

\section{For permanent participants}

As I discussed in some detail in earlier Chapters, the legitimacy of the Arctic Council has been strongly tied to the unique role of permanent participants as representatives of the needs and interests of the region's Indigenous peoples. The opportunity for permanent participants to assume an "equal" position with member states at Arctic Council meetings was initially made possible because of the first institutional logics of the Council as a policy shaper. However, the moral legitimacy and credibility that Indigenous representatives contribute becomes less relevant when the institutional logic 
is focused on policymaking. For example, in the process of negotiating the Marine Oil Pollution Preparedness and Response in the Arctic (Arctic Council, 2013a), permanent participants had proposed language to acknowledge the importance of protecting areas of cultural and historical significance. During a final round of comments about the proposed text, a state indicated that they could not approve the text without approval from their capital. In the interests of time and achieving final agreement, the language was dropped by the chairs without further discussion. When a representative for one of the permanent participant organizations raised this issue with one of the co-chairs at the conclusion of the meeting, the chair's rational for allowing the language to be removed without further debate was that "sometimes better is the enemy of the good" (personal communication, November 2, 2014). Of course, while this observation may be true in a world of binding agreements, it begs the question how many other issues or concerns would the permanent participants have that might fall in this category of "better," when the bar has been set at "good"? Interestingly, although many permanent participants will acknowledge the shift in power that is taking place because of the unique authority that Arctic states bring to the table, several permanent participant representatives interviewed still value the unique position that they hold. They recognize that their position may be "less equal"; however, they see a value in the opportunity to have a direct voice in the policymaking process. These participants believe this as a "pragmatic approach" because it is still better than the access they have to other institutions; however, one interviewee expressed concern that permanent participants risk being coopted - lending their legitimacy to the Arctic Council by their presence, while not having a meaningful role. 


\section{For observers}

Arctic Council observers are often treated as a homogeneous group of actors, but in fact this group holds a broad mix of actors and interests, including locally focused NGOs, internationally focused IGOs and NGOs, and a diversity of states. In understanding the implications of the co-existence of competing logics, it is useful to distinguish between those observer organizations that were actively involved prior to 2006 and those observer organizations that have either joined or taken a more active interest in the Arctic Council since its rise to global prominence and the emergence of a "policymaker" logic.

For representatives of observer organizations that understand and have been involved with the Arctic Council as a knowledge generator and policy shaper, the increase in profile and the subsequent increase in interest in the Council is cause for concern. Several interviewees express doubt that they will be able to maintain the meaningful roles that they established for themselves at the working group and SAO levels. These representatives indicate that they have invested significant effort in understanding how the Arctic Council works and establishing trust and relationships with member states and permanent participants. They believe that these relationships are now at risk as more observers begin to participate and the Council takes action to restrict the participation of observers. These observers have seen the influence that the Council has had as a policy shaper and feel that they have had a meaningful role in the Council's work. Their concerns are linked to the potential implications of the Arctic Council assuming a policymaking institutional logic, which raises the prominence and 
potential power of those actors that have the authority to make and implement policy decisions.

By way of contrast, representatives of new observer organizations remained confused about what the Arctic Council does and what role they can or should play. Through the media and the statements of Arctic Council officials, these observers accepted the institutional logic that the Council was or has the potential to be a policymaker. In fact, several interviewees directly attribute their interest and attention to the Council's increasing role in policymaking. Following the high profile acceptance of China, India and other non-Arctic states as observers in 2013, there have been a number of meetings and conferences dedicated to clarifying the role of observers in the Council, including invitation-only side events organized by the Norwegian government at the Arctic Frontiers conference ${ }^{45}$ in 2014 and 2015. What these discussions highlight is that newer observers have sought this status without understanding what the Council does or how it really works.

The messaging of Arctic states around the involvement of observers is further evidence of the mixed messages drawn from the two institutional logics. For example, in the lead up to the United States' chairmanship, the United States and other Arctic States consistently called on observer states to demonstrate their support for Arctic Council work by taking appropriate actions domestically and by supporting relevant international

\footnotetext{
45 The Arctic Frontiers conference is an annual event that brings together academia, government and business to discuss "the management of opportunities and challenges to achieve viable economic growth with societal and environmental sustainability" (Arctic Frontiers, 2016).
} 
laws and policies - recent efforts to get Arctic Council observer states to support a fishing ban in Arctic international waters being a case in point. This expectation was articulated at the same time that the Council was putting in place new rules that reduced the chances for observers to participate in discussions at the SAO and working group levels and limited their ability to participate in projects.

Observers have been increasingly vocal that they want a meaningful role in the Arctic Council, a view that is met with consternation by Arctic states, who then often explain that the Arctic Council is really a regionally focused policy discussion forum for Northerners - consistent with the institutional logic of knowledge generation and policy shaping. However, the member states continue to express commitment to finding a meaningful role for these observers - generating expectations and more confusion. If observers determine that they cannot establish a meaningful role for themselves in the Council or (worse yet) that the Council is not worth influencing, these actors will likely look for other means to influence Arctic policies. By extension, reduced interest in the Council as THE policy body for the Arctic would likely have direct implications for its international credibility and legitimacy.

\section{Conclusion}

What the analysis in this chapter confirms is that an institution can accommodate and even benefit from the co-existence of multiple institutional logics. As we saw in the early years of the Arctic Council's life, the institutional logic introduced through the Arctic Council Panel facilitated a focus on a process-oriented definition of effectiveness that emphasized the importance of procedurally based measures of legitimacy, credibility 
and saliency. However, this emphasis on process delivered concrete achievements that were important to those actors committed to an institutional logic that defined effectiveness by the Council's ability to contribute to environmental protection. Through practices that aligned with both institutional logics, the Arctic Council was able to establish a cohesive identity that provided stability and a shared sense of purpose.

However, what we see in the second half of the Arctic Council's life is that when institutional logics are in conflict the effectiveness of the institution itself can be compromised as practices, at best, work at parallel purposes and, at worst, work at cross purposes. In this period we see the struggle to reconcile two very different identities for the Council, but we also see that there may be winners and losers in the ambiguity that these conflicting institutional logics generate.

This analysis highlights that, irrespective of academic efforts to identify objective determinants of institutional effectiveness, participants in the Arctic Council bring their own definitions of effectiveness based on their social worlds, experiences working with the Arctic Council and broader social experiences. As a result, participants' abilities to establish a common definition (or at least complementary definitions) of effectiveness that align and are supported by the Council's institutional logics, practices and identity becomes itself a critical criteria for institutional effectiveness. The Arctic Council may be able to sustain itself through a certain level of ambiguity, but over the longer term participants will seek to reconcile the day-to-day practices of the Council with their preferred institutional logic. If the Council is not able to reconcile its multiple institutional 
logics, some actors may continue to participate; however, others will likely opt to invest their time and energy in finding other ways to participate in Arctic policymaking. 


\section{Chapter 8: Conclusion}

In the words of one interviewee, "there is a lot of myth to work through when briefing non-Arctic states about [the Arctic Council] (personal communication, January 16, 2015). This dissertation confronts these myths by conducting a systematic analysis of the Council and its governance model. Constructing an analytical framework built on the concept of institutional effectiveness, I examined how the Arctic Council works and to what extent it has been effective. I studied the Council from its Cold War roots to its present day prominence using determinants of institutional effectiveness to structure the analysis. This chapter concludes the dissertation by reviewing its contributions. I consider the implications of the analysis for the governance of the Arctic region and explore the broader relevance of this project for other institutions, regions, and the scholarly literature. I conclude with some reflections on a future research agenda.

\section{Revisiting the Arctic Council's Effectiveness}

As one survey respondent observed, "Now everyone wants to be part of the Arctic Council. It needs to be reorganized - it was built during a different time" (personal communication, January 15,2015$)$. To reflect the remarkable changes that the region and the Arctic Council have undergone over the last 30 years that I organized an analysis of the Arctic Council into 3 distinct time periods - pre-1996, 1996-2005 and 2006-2015. This structure enabled a detailed analysis of the different factors that contributed to the Council's effectiveness and their interplay organized into determinants of institutional effectiveness. Figure 8.1 provides an overview of the 
factors and criteria for institutional effectiveness that emerged from the empirical analysis of the Arctic Council.

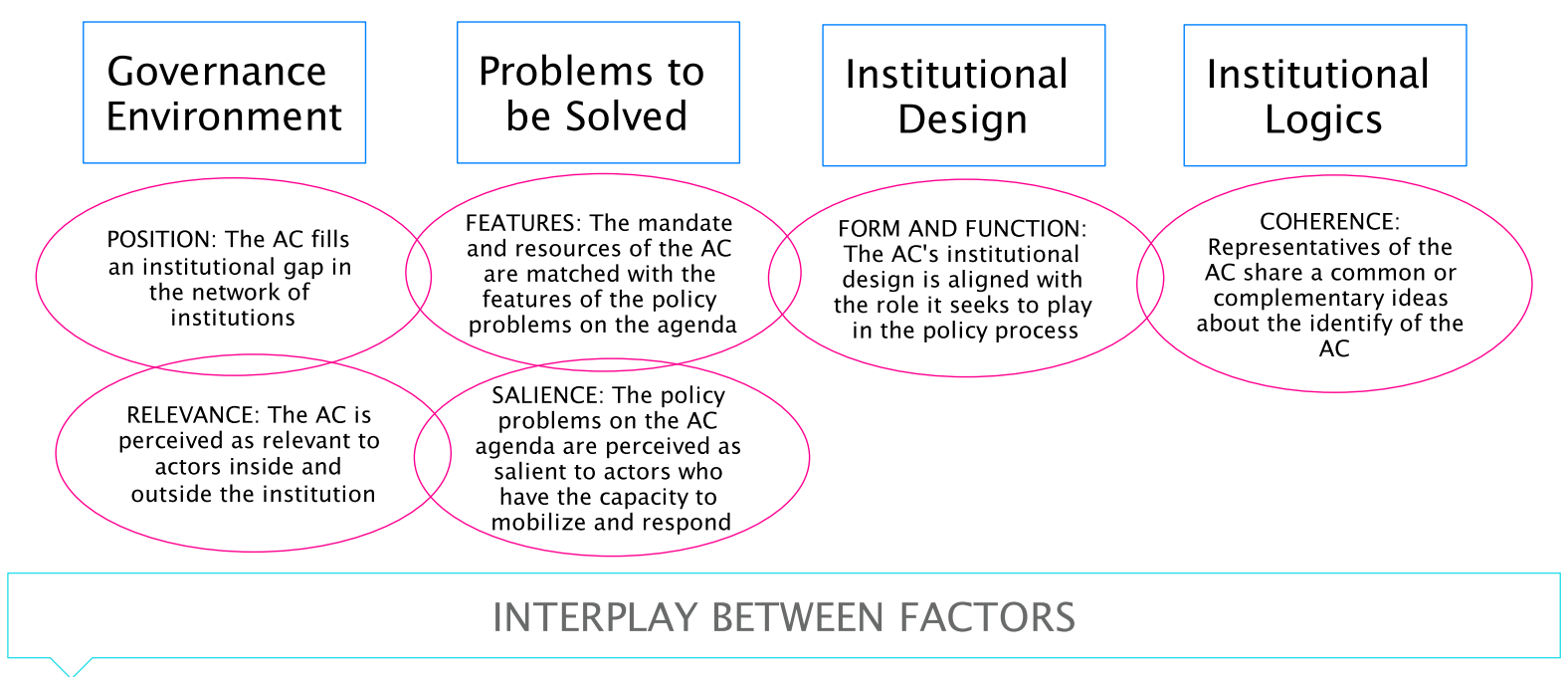

Figure 8.1: Factors and criteria for institutional effectiveness identified through an empirical analysis of the Arctic Council.

With regard to the governance environment, I conclude that Arctic Indigenous groups were a driving force behind establishing regional cooperation. The continued work of these groups to foster multilateral cooperation is a unique and defining feature of Arctic governance. Similarly, I argue that the research and scientific communities were equally active in creating institutions that enabled the sharing of information, data collection, knowledge generation and policy advice at a circumpolar level and the work done by these institutions continues to inform policy discussion and action at the local, national, regional and international levels. Furthermore, this dissertation demonstrates that multilateral cooperation in the Arctic was initially of peripheral importance to policymakers; however, as the prominence of the region increased, the interest of Arctic states, and subsequently non-Arctic states to actively participate in the Arctic's institutions also increased. Finally, I show that the governance environment of the Arctic 
has dramatically changed over the last 30 years. The number of multilateral institutions active in the region increased, as did the diversity of institutions in terms of scale, scope and actor-types. My analysis highlights the emergence of inclusive institutions that involve multiple actor-types (government, business, Indigenous and community organizations, NGOs, and research/academia). I confirm that the governance environment in which the Arctic Council functions has been transformed - introducing a level of institutional complexity and dynamism that the architects of the Arctic Council could not have imagined or anticipated.

Based on the analysis presented in Chapters 4, 5 and 6, I identify two factors related to the governance environment that explain the effectiveness of the Arctic Council. I demonstrate that the Arctic Council has assumed a distinct position in the network of multilateral institutions - filling an institutional gap at the circumpolar level. I also conclude that the Arctic Council's relevance to actors in and outside the institution contributed to its effectiveness.

In examining the policy issues that have been placed on the Arctic Council agenda, the analysis in the previous chapters identifies a similar trend. When the United States assumed the chairmanship of the Arctic Council in 2015, its chairmanship programme included a regional seas initiative intended to identify and implement a network of marine protected areas in the Arctic. This was a striking initiative from the state that was reluctant to sign on to the establishment of the Arctic Council in 1996. This could be dismissed as different policy agendas between the Clinton and Obama 
administrations; however, the engagement of all the member states has grown. Over time, the number of issues included on the Council's agenda has increased, but perhaps more importantly some of the policy issues have been reframed from being Arctic specific (e.g. contaminants from military activity) to how the Arctic is affected by global issues (e.g. Persistent Organic Pollutants) and even to how changes in the Arctic have an impact on the globe (e.g. melting of the Greenland ice cap due to climate change). These changes in the scope and scale of the issues that the Arctic Council includes on its agenda have implications for who has the information and knowledge to support informed policy discussions. Furthermore, as the policy issues on the Arctic Council's agenda grow in salience for a wider and larger audience, the prominence of the Arctic Council grows and so does the interest of various actors to participate in, and influence, the Council's activities.

The most extensive analysis in this dissertation concerned the impact of the Council's institutional design on its effectiveness. From its formation through to the mid-2000s, the Arctic Council was a forum for regional cooperation. While scientific experts and representatives of Arctic Indigenous organizations were interested and engaged in the policy issues related to environmental protection and sustainable development included on the Council's agenda; political representatives recognized the Council primarily as a forum for relationship and trust building. In this context, the Council held a low political profile and assumed a role in knowledge generation and policy shaping through a governance model that supported effective boundary work. The Arctic Council gained legitimacy, credibility and saliency to influence policymaking in other fora (at the national 
and international levels) by creating high quality reports and policy advice that were facilitated through effective communication, mediation and translation across political, scientific and Indigenous social worlds. The work of the Council during this early period was contained to technical and regionally focused issues. Furthermore, although there were variations in the capacity of the working groups, it was at this level that most of the work of the Council was conducted.

How the Council worked, and subsequently its effectiveness, began to change in the mid-2000s. The Council continued to conduct boundary work to generate knowledge and shape policy; however, the Council began to change. Consistent with the shift observed with the policy issues on the Council's agenda, the Arctic Council increasingly became a forum for international cooperation on Arctic policy issues. As the profile of the Arctic and Arctic Council grew, it gained increasing attention from policymakers, business, IGOs, NGOs, and other interested actors inside and outside the Arctic. Increased interest in the Council contributed to growing expectations about the role that the Council could or should play in policymaking processes in the region. The Council experienced internal and external pressures to assume a more direct role in policymaking and implementation. Growing interest and expectations on the Council, translated into an increasingly politicized organizational culture and formalized governance features, such as the creation of the Arctic Council Observer Manual (Arctic Council, 2013c). While these changes in the institutional design show signs of compromising the Council's ability to do boundary work to support knowledge generation and policy shaping, there are no indications that these changes are 
facilitating a sustainable role for the Council in policymaking. This study demonstrates the importance of the alignment of the Arctic Council's institutional design with its perceived role in the policy process to explain institutional effectiveness.

Furthermore, I conclude that the Arctic Council in its early years was supported by institutional logics that aligned the raison d'être of the Council with its organizational culture and features. These logics defined and measured effectiveness in a manner consistent with the Council's focus on knowledge generation and policy shaping. In contrast, in its later years, while the initial institutional logics persisted, I observed that an institutional logic of policy action emerged. This new logic provided conflicting definitions and measures of institutional effectiveness that were poorly aligned with the institutional design of the Council.

Finally, this study confirms that the interplay of the factors that explain institutional effectiveness can generate significant and at times contradictory effects on the effectiveness of the Arctic Council. For example, in recent years the relevance of the Arctic Council and the salience of the issues on its agenda have increased; however, this has not led to an overall increase in the Arctic Council's effectiveness because the Council's institutional design has not evolved to meet these increasing expectations. This strongly reinforces the need to identify and understand factors that explain institutional effectiveness; however, it is equally important to recognize and consider the impact of the interactions between these factors and how this contributes to the overall effectiveness of the Council. This reinforces the value of focusing on institutional fit 
(Young, 2002b) to consider the interplay between different factors that have an impact on the Arctic Council's effectiveness.

In summary, this analytical framework has provided a valuable structure for an in-depth and rich analysis of the Arctic Council's evolving institutional effectiveness and its governance model. This framework also provides interesting insights about the factors that explain the Council's effectiveness moving forward, which I focus on briefly in the following section.

\section{Informing the Future Effectiveness of the Arctic Council}

Overall, it is fair to say that the Arctic Council has exceeded the expectations of many participants and observers. In recent research focused on assessing the effectiveness of the Council, Kankaanpää and Young indicate that there is general agreement from participants and observers that "what the Arctic Council has done best is to identify emerging issues, carry out scientific assessments addressing these issues and use the results of the assessments both to frame issues for consideration and to set the agenda in policy settings" (2012). However, Kankaanpää and Young are also quick to point out that the effectiveness of the Council in the past is no guarantee that it will continue to be effective in the future-either in its capacity as a policy shaping, regionally focused institution or, perhaps more importantly, if it is to fulfill the larger role envisioned for it as the region's central policymaking institution.

In Chapter 1, I posed the question: To what extent might the governance model that contributed to the Council's effectiveness also presage its failure? What this analysis 
suggests is that the Council's current institutional design effectively supports neither policy shaping nor policymaking. Therefore, if the Council continues to struggle with conflicting institutional logics, the predictions of some interviewees and survey respondents that the Arctic Council will fail or be overtaken by other multilateral institutions seems increasingly possible. However, a more productive question to explore is what guidance does this dissertation provide us regarding the levers available to maintain or improve the effectiveness of the Arctic Council?

Recognizing and understanding the interconnected and evolving nature of the Arctic governance environment is itself an important planning tool in efforts to maintain the effectiveness of the Council. No one anticipated the changes that we have observed in the governance environment in the Arctic over the last 30 years and there is no reason to expect that the governance environment will be any less dynamic in the future. More specifically, maintaining an awareness of the mandate, scope and priorities of the network of institutions involved in environmental management and sustainable development in the Arctic will allow the Arctic Council leadership to determine what niche(s) the Council best fill(s). This type of analysis also provides insights on what institutions the Arctic Council could partner with and how it might work with them to achieve its priorities (whether they be process- or outcome-focused).

Similarly, the leadership of the Arctic Council needs to consider the nature of the policy issues they place on the Council's agenda, and in particular how policy problems are defined and framed. Is the issue purely regional (where cause and effect are contained 
to the region)? A sub-regional issue with regional implications (where the cause is from a sub-region of the Arctic and the effect is regional)? A global issue with region implications (where the cause is global and the effect is observed in the Arctic)? A regional issue with global implications (where the cause is in the Arctic and the effect is global)? Or a global issue with global implications (where the cause is global and the effect is global)?

These questions lead to two further questions whose answers could enhance the effectiveness of the Council: What niche can the Arctic Council appropriately fill to contribute to solving or managing these problems? And what does the nature of the problem tell us about what actors need to be involved and how they need to be involved in order to solve or manage the problem? The debate over what role observers should play in the Arctic Council is commonly linked to their potential to influence the work of the Council or the effects of a growing number of participants on the way the Arctic Council functions; however, the questions posed here encourage us to take a more nuanced approach to considering the appropriate role of the states, NGOs and IGOs that have or are seeking observer status in the Council. ${ }^{46}$ It challenges us to consider if it is appropriate for these actors to be relegated to observing the activities of the Arctic Council in all cases. Moreover, if the Council's leadership continues to limit the participation of observers, it may want to consider defining and framing policy issues in

\footnotetext{
${ }^{46}$ The same logic could apply in consider the relationship between the Arctic Council and the AEC or more generally between the Council and private sector actors.
} 
a manner that clearly contains the scope of the issues on its agenda to the regional level.

Finally, institutional design is where Arctic Council leadership is most likely to focus their attention in an effort to maintain or improve the Council's future effectiveness. Avoiding for a moment a normative assessment of the role the Arctic Council should play, the analysis in previous chapters signals that institutional effectiveness depends on an alignment between the raison d'être, organizational culture and governance features of the Arctic Council, as well as awareness of the interplay between those factors. For example, if the Council is dedicated, in whole or in part, to regional cooperation on Arctic environmental management and sustainable development policy issues (climate change mitigation, mental health and well being, communication connectivity in the Arctic), than the Arctic Council could focus attention on engaging and partnering with actors and institutions in the region to advance this programme of work. In contrast, if the Arctic Council's raison d'être is to be a forum for international cooperation for environmental management and sustainable development policy issues that are relevant to the Arctic (climate change, migratory birds, persistent organic pollutant), it is time to create more space for a broader array of non-Arctic actors that are part of the policy problems, part of the solution or both.

Furthermore, if the Council's primary focus remains on policy shaping, then decisions about how to strengthen its organizational culture and governance features should be focused on how to support high quality knowledge generation and policy advice. This 
means tackling the fragmentation observed in Chapter 6. On the other hand, if the Council intends to be a forum for policymaking and action, it needs to more carefully consider what role working groups and task forces will play to support this work and where the authority and capacity to make, implement, monitor and enforce these policies will rest. If that authority and capacity rests with Arctic states, what really is the role of the Council in policymaking?

Of course these examples sit on either end of a spectrum of what the raison d'être of the Arctic Council could be and there are variations and combinations of functions and responsibilities that the Arctic Council can assume. However, as Chapter 7 illustrates there may be limits to the mandates and functions that can be combined within the Council and it will be important to consider how effectiveness for the Council will be defined and measured moving forward. Furthermore, the perceived effectiveness of the Council depends on transparency about what role the Arctic Council is being positioned to play and how its governance model will support this work. Those inside and outside the Arctic benefit from a clear articulation of the "rules of the game."

Finally, providing prescriptive commentary about what the Arctic Council should be or do was not the intent of this study; however, interviewees and survey respondents offered a wealth of general and specific opinions and advice, for example:

- establishing better mechanisms for project funding that enable broader participation in Council projects, 
- prioritizing capacity building programmes to ensure better Indigenous participation,

- structuring the Council working groups to facilitate more interdisciplinarity across the social and natural sciences,

- providing opportunities for Arctic Council participants to engage with "other interested organizations on a science and policy level,"

- focusing SAO meetings on "overall issues rather than small projects of which they know little - ministry of foreign affairs should not spend 2 days discussing environmental monitoring, the status of sea birds or ice-balance flux of Greenland - this should be left with [working groups]," and

- developing a more sustained funding and backing of activities rather than having countries suggest various 'pet projects.'

For the most part, these observations and suggestions have been set aside and may be valuable for future research or commentary; however, based on the analysis presented in this dissertation there are a few normative observations that I think it is important to introduce. First, the question "who owns the Arctic?" has been posed in other discussions, in part, as a means to contest who has a right to participate in the region's governance and, in part, to try to differentiate the appropriate governance approaches for the Arctic from the international treaty-based model that has been established in Antarctica. We could similarly ask the question: "who owns the Arctic Council?" The self-evident answer is Arctic states; they are the only members and signatories to the Council's founding declaration. However, a response informed by the analysis found in 
this dissertation proposes that Arctic Indigenous organizations and the scientific/research communities that were instrumental in the Council's creation and the early years of its work, have as much, if not more, legitimacy and credibility to define what the future path of the Arctic Council should be. Therefore, despite the natural tendency of Arctic states to assume more control of what the Arctic Council does and how it works as the region and Council gains in global prominence, the true test of the Council's 'unique' governance model will be in its ability to respect the role and contributions of the region's Indigenous peoples and scientific communities in defining a future path for the Council.

Secondly, what this study proposes is that a world driven towards policy action and results should be careful not to overlook or undervalue credible and legitimate knowledge and policy advice and institutions that perform these functions in the policy process. Although it may be true that the causal relationship between this type of work and policy results is more difficult to trace and the effectiveness of an institution dedicated to this work may be harder to define and measure, this should not be a reason for shifting away from this work or changing the way it is done. If the leadership of the Arctic Council decides to place a lower priority on knowledge generation and policy shaping, those actors that recognize the value and importance of this type of work to policymaking processes should be asking themselves what institutions in the region can take on this responsibility? As one interviewee said: "the pressure for binding agreements will always be there" (personal communication, May 6, 2016); however, that does not mean that the Arctic Council needs to assume this role. 
The next challenge for the leadership of Arctic Council is to find ways to rise above national politics. As one survey respondent indicated: "The Arctic Council was created to address [environmental, social and economic issues in the Arctic], but unless it succeeds in finding ways to restrict NATIONAL interests over-riding Arctic interests and in clearly describing what it can practically do with regard to sustainable development, I anticipate that its role and visibility will decrease in the next decade" (Kankaanpää \& Young, 2012b). As I discussed in Chapter 6, as the prominence of the Council grows, Arctic states increasingly see the Council as a mouthpiece for domestic positions and priorities. This not only increases the schizophrenia of the Arctic Council policy agenda as each Arctic state assumes the Arctic Council chairmanship every two years, it reduces the Council's legitimacy and credibility as the voice of Arctic needs and interests.

Finally, the leadership of the Arctic Council should think more strategically about forging partnerships with other institutions to deliver on its priorities. In particular, the Council needs to more carefully assess how it can link with organizations working at the local level. The Arctic is a vast region made up primarily of small, isolated and remote communities. The geophysical environment is unique, fragile and inhospitable for much of the year. Physical infrastructure varies across the region, but it is consistently less developed than regions further to the South. The people that live in the region have knowledge and capacity to support policy development and implementation for the Arctic that is often poorly leveraged by national governments and the Arctic Council. 
People interviewed that work at the local level in Arctic communities across the region recognize that the Arctic Council provides an important coordination mechanism to learn from other communities and solve common policy problems (personal communication, March 9, 2015); however, these same people argue that the Arctic Council has not taken advantage of its position in the region to mobilize and coordinate Arctic institutions that are "able to deal with local or specific issues" (personal communication, March 10, 2015). The Arctic Council exists in a rich network of institutions that can benefit from the legitimacy and credibility that the Council has achieved and the work of the Council can benefit from the expertise and experience of this network of institutions to respond to the many challenges facing the region.

This dissertation shows that the governance model and institutional effectiveness of the Arctic Council cannot be assessed in a vacuum and it is not static. Its governance environment and the decisions taken over the last 30 years shape its future evolution there are limits to how it can change in the short and longer term. Decisions about the future path of the Arctic Council can be translated into guidance about how to strengthen the Arctic Council's governance model - an understanding of how the Arctic Council works can inform efforts to maintain or improve the effectiveness of the Council. Finally, the role that the Council can or will play and its ability to remain effective in that role depends on the political will and buy in of Arctic states, Indigenous peoples and the scientific communities that have led its work (Kankaanpää \& Young, 2012b). All of these actors must see a value in continuing to invest in this work and remain 
accountable back to their own social worlds and communities for the Council to maintain its legitimacy, credibility and saliency.

\section{Implications for Region}

Ultimately, the Council's future is dependent on factors such as the pace and predictability of future environmental changes, the global demand for natural resources in the Arctic, pricing of those resources, as well as the costs of extraction, processing, and transportation to markets (Dodds, 2010). A complex set of interdependent factors exist that may contribute to, or detract from effective stewardship of the Arctic and the sustainability of communities in the Arctic. While discussions about the governance of the region often centre on the Arctic Council, for many commentators, their primary interest is those actors and institutions that play a role (or could play a role) in the environmental management and sustainable development of the region. This study of the Arctic Council also contributes to this broader discourse.

My most direct contribution is to explain the role that the Arctic Council has played in the region and provide more clarity about where the Council is positioned in relation to other institutions involved in Arctic policy. We know that the network of institutions doing work in the region has grown rapidly; however, this analysis confirms that any inference that these new institutions pose a threat to the Arctic Council's position as the central policy forum in the region are overstated. With this in mind, a future line of inquiry that could benefit the Arctic region is to come back to an observation by Cash et al. that knowledge systems can be supported by multiple institutions (2003, p. 8090). This logic could be extended to encourage analysis of the broader network of institutions in the 
Arctic that support the full policy cycle - from policy development to implementation, monitoring, enforcement and evaluation. What other institutions in the region provide spaces for boundary work? Which institutions support policy implementation? How does this network of institutions work together (or not) to support environmental management and sustainable development? For many actors, it is challenging to work alone in the Arctic; therefore, there is a pressing need for cooperation between institutions to tackle the many policy problems and meet the needs of the region's people.

Some institutions are dedicated to serving specific types of actors (states, businesses, Indigenous organizations, NGOs), while others may be focused on specific issues (black carbon, community health, polar bears, mining), or institutions may involve multiple issues and actors. Irrespective of the governance features of each institution, understanding and analyzing the governance environment, as part of an Arctic governance ecosystem, depends on a recognition that these institutions co-exist in the region and they may, in some cases, complement each other and in other circumstances be contradictory. This is another rich area for future research that could further advance the institutional effectiveness and boundary work literature. It also ties in nicely with work by Abbott and Snidal (2010) that examines the orchestration of institutions and explores how to achieve better coherence in international governance.

\section{Relevance Beyond the Arctic}

While this qualitative study of the Arctic Council may not lend itself to generalizable findings, this does not mean that certain aspects of this dissertation are not relevant or 
potentially transferable to other regions or institutions. This section considers what lessons can be drawn from this study of the Arctic Council and how other institutions might benefit from the adopting institutional effectiveness as an analytical framework. This section then examines how this case study contributes to the literature about institutional effectiveness, boundary work and institutional logics.

First, this dissertation demonstrates that the Arctic Council is at a critical juncture because of a confluence of events, including a dynamic and complex governance environment and policy challenges that are multi-faceted with global, regional and local implications and impacts. In this context, the Council's institutional design has also evolved. None of these governance challenges are unique to the Arctic Council. This confluence of events can be observed in other institutions, other regions and other policy areas. Therefore, the light that this analysis shines on how these changes affect the institutional effectiveness of the Arctic Council offers opportunities to strengthen our understanding of institutions that support other regions and policy areas - in particular, that multiple social worlds exist to be reconciled and that the co-creation of knowledge and the solutions to the world's many complex issues requires the ideas, buy in and efforts of many diverse actors (Cash et al., 2002, 2006; Mollinga, 2010). As one survey respondent points out: "the Arctic states are powerful nations in a global context. Environmental, social and economic issues are more "overviewable" than in other regions" (Kankaanpää \& Young, 2012b). In fact, what initially drew my attention to this area of research was a curiosity about what the rest of the world could learn from the Arctic Council and its governance model. 
Similarly, institutional effectiveness is a concept that provides a valuable foundation to understand how international institutions work and to what extent they are effective. This analytical framework exposes factors and emerging patterns that have an impact on the effectiveness of institutions individually and collectively. This in-depth examination of the Arctic Council, using this analytical framework, can be treated as a call to action to recognize the importance of a more systematic and pragmatic analysis of multilateral institutions.

Furthermore, it is my hope that the methods used to apply this analytical framework can be useful for other international institutions. I drew on the concepts of network governance, boundary work and institutional logics to complement the overarching framework of institutional effectiveness. These concepts provided further depth and richness to our understanding of the Arctic Council, continue the trend of challenging our understanding of how international institutions contribute to policymaking and elucidate what role these institutions are best positioned to play in solving policy problems.

\section{Contributions to Theory}

My analysis demonstrates that the governance environment is a dynamic and evolving determinant, and its may vary substantially over time. As a result, the value of studying this determinant is to understand trends, examine an institution's position in a broader network of institutions, and identify critical junctures over time. Institutions are part of 
dynamic systems and the methods used to assess institutional effectiveness must begin from this premise.

Similarly, this dissertation complicates the relationship between the nature of the problem to be solved, as a determinant, and the effectiveness of an institution. The scholarly literature has dedicated substantial attention to the relationship between the nature of the problem to be solved and the effectiveness of an institution (Stokke, 2007, 2011; Underdal, 2002a). The Arctic Council is an important case study in this context because its mandate is not contained to a single policy area and the issues included on its agenda have evolved over time. The Council, like many other international institutions, is increasingly recognizing (whether by choice or by circumstance) that issues related to environmental management and sustainable development cannot be contained into distinct policy areas. For example, the evolving priorities of the Arctic Council demonstrate that environmental protection is intimately linked to a complex mix of social, economic, cultural, and health issues. In this context, I dedicated attention to analyzing how the Council defines and frames issues to complement our understanding of the intrinsic features of the problem to be solved. I propose that more research that takes this approach to studying institutional effectiveness is needed to complement the rich collection of research that objectively assesses the features of particular policy problems. Further understanding the relationship between how policy issues are defined and framed and an institution's effectiveness has the potential to expose how the leadership and participants within an institution have a role to play in defining an institutions contribution to solving particular policy problems. 
In studying institutional design as a determinant of institutional effectiveness, this dissertation demonstrates that an institution's design, from conception through to its current state, is the product of a dynamic and evolving process. Furthermore, although an institution's effectiveness is often judged based on an assessment of its institutional design, it is more appropriate to examine the alignment between the institutional design and the role the institution seeks to play in the policy process.

Finally, this dissertation advances the institutional effectiveness literature by introducing the concept of institutional logics as an unexplored determinant of institutional effectiveness. I propose that this is a rich area for future research that challenges us to acknowledge the cultural values imbedded in how effectiveness is defined and measured and the importance of exposing multiple institutional logics and considering the implications of co-existing or conflicting institutional logics on the effectiveness of an institution. Furthermore, this study of the Arctic Council raises questions about whether there is currently a dominant institutional logic that is driving how we define and measure the effectiveness of international institutions. More research is needed to consider how an emphasis on policy action and results is driving decisions about how policy issues are framed and how international institutions are designed. I propose that the pressure placed on the Arctic Council to take on a more substantial role in policymaking and policy action may be part of a larger international phenomenon that places a high value on actions and activities that are easy to measure or with an easily observable relationship to solving a policy problem (e.g. setting guidelines and 
standards, signing agreements, cleaning a contaminated site) over functions that are harder to measure or the contribution to resolving a policy problem is harder to demonstrate (e.g. Indigenous groups involvement in policy discussions, scientists providing policy advice to policymakers, preparing reports that integrate knowledge from different social worlds). Exposing and considering the implications of this potential cultural bias is a critical research priority that can be supported by more work to draw together the concepts of institutional logics and institutional effectiveness.

\section{Final Reflections on the Study}

I began this study of the Arctic Council because of an interest in the governance of the circumpolar region generally and the governance model of the Arctic Council specifically. When I set out to research and collect data on this topic, I had not clearly defined the specific research questions that I would answer or the analytical tools that I would employ to structure the empirical research and analysis. The research questions and the analytical framework that I developed are the result of an iterative process of collecting and analyzing data and examining the existing literature about the Arctic, Arctic Council and international institutions more broadly. The result of this process is an in-depth analysis of the Arctic Council and a new analytical framework that provides a useful structure for systematically assessing the institutional effectiveness of the Council. This approach generated a rich and fruitful study of the Council; however, this inductive approach also leaves research gaps that still need to be filled. For example, through the data I collected, I was able to observe boundary work taking place within the Council and recognize the significance of this for how the Arctic Council worked. However, during interviews, I did not ask Arctic Council participants questions related to 
their sense of responsibility and accountability back to their constituencies or communities. This is an important aspect of boundary work that this study cannot specifically analyze or comment on. Similarly, I would be interested in understanding more about how Arctic Council member states and permanent participants reach consensus on what issues are included on the agenda and how they are framed. This would be a concrete example of how to assess the relationship between the nature of the problem to be solved and a specific governance feature (consensus-based decision making) of the Council.

Furthermore, this dissertation made the Arctic Council and its governance model the focal point of this analysis. This provides important insights about the levers available to maintain or improve its effectiveness in the future; however, I placed only limited attention on actors and agency. As a result, I have not discussed in detail issues like the evolving power dynamics between actors in the Council or how power relations have had an impact on the effectiveness of the Arctic Council. Power dynamics generally, and power imbalances in particular, in the Arctic Council were raised in interviews and observed during field studies. This is an area that deserves more attention and dedicated research.

Finally, there are clearly important questions to be asked about capacity and resource issues in the Arctic Council, including the funding mechanisms for projects and working groups and the shortage of human and financial capacity available to permanent participants to meaningfully participate in Council activities. Concerns about the impact 
of limited capacity and resources on the effectiveness of the Arctic Council are legitimate and should be explored. However, discussing the resource needs of an institution often unreasonably dominate our attention and these issues are common challenges for all public institutions. These are issues that experts in public administration are better equipped to study.

Overall, this highlights some the weaknesses of the open research approach I used to study the Arctic Council and its governance model; however, it also provides me with an abundance of ideas about future research. As a next step, I am particularly interested in continuing to study the relationships within the complex network of multilateral institutions that advance Arctic environmental and sustainable development policies. I believe there is more work needed trace the connections between these multilateral institutions. Furthermore, I am interested in examining the interface between this network of multilateral institutions and domestic policymaking both in and outside the Arctic. 


\section{References}

Abbott, K. W., \& Snidal, D. (2009). Strengthening international regulation through transnational new governance: Overcoming the orchestration deficit. Vanderbilt Journal of Transnational Law, 42, 501-578.

Abbott, K. W., \& Snidal, D. (2010). International regulation without international government: Improving IO performance through orchestration. Review of International Organizations (Vol. 5). http://doi.org/10.1007/s11558-010-9092-3

Abele, F. (1989). Canadian contradictions: Forty years of Northern political development. In K. S. Coates \& W. R. Morrison (Eds.), Interpreting Canada's North (pp. 309-332). Toronto: Copp Clark Pitman Ltd.

Abele, F., \& Rodon, T. (2007). Inuit diplomacy in the global era: The strengths of multilateral internationalism. Canadian Foreign Policy Journal, 13(3), 45-63. http://doi.org/http://dx.doi.org/10.1080/11926422.2007.9673442

Andresen, S. (2002). The International Whaling Commission (IWC): More failure than success? In M. Kahler, A. Underdal, S. Andersen, J. Wettestad, J. B. Skjaerseth, \& E. M. Carlin (Eds.), Environmental Regime Effectiveness: Confronting Theory with Evidence (pp. 379-404). Cambridge: MIT Press.

Arctic Council. (1996). Declaration on the establishment of the Arctic Council. Ottawa.

Arctic Council. (1998a). Arctic Council rules of procedure. Iqaluit. Retrieved from https://oaarchive.arctic-council.org/handle/11374/940 
Arctic Council. (1998b). Iqaluit Declaration. Iqaluit: Arctic Council.

Arctic Council. (2000). Barrow Declaration. Barrow: Arctic Council.

Arctic Council. (2002). Inari Declaration. Inari: Arctic Council.

Arctic Council. (2004a). AMAP technical reports. Retrieved from https://oaarchive.arcticcouncil.org/handle/11374/726

Arctic Council. (2004b). Impacts of a warming Arctic: Arctic climate impact assessment. Cambridge. Retrieved from http://www.amap.no/documents/doc/impacts-of-awarming-arctic-2004/786

Arctic Council. (2004c). Reykyavik Declaration. Reykyavik: Arctic Council. Retrieved from http://www.arctic-council.org/index.php/en/about/documents/category/5declarations

Arctic Council. (2006). Salekhard Declaration. Salekhard: Arctic Council.

Arctic Council. (2009). Tromsø Declaration. Tromso: Arctic Council. Retrieved from http://scholar.google.com/scholar?hl=en\&btnG=Search\&q=intitle:TROMS?+DECLA RATION\#0\%5Cnhttp://scholar.google.com/scholar?hl=en\&btnG=Search\&q=intitle:T roms?+Declaration\#0

Arctic Council. (2011a). Agreement on Cooperation on Aeronautical and Maritime Search and Rescue in the Arctic. Nuuk: Arctic Council.

Arctic Council. (2011b). Nuuk Declaration. Arctic Council. Nuuk: Arctic Council. Retrieved from http://www.arctic- 
council.org/index.php/en/about/documents/category/5-declarations\#

Arctic Council. (2013a). Agreement on Cooperation on Marine Oil Pollution

Preparedness and Response in the Arctic. Retrieved from https://oaarchive.arcticcouncil.org/handle/11374/1260

Arctic Council. (2013b). Arctic Council: History. Retrieved from http://www.arcticcouncil.org/index.php/en/about-us/history

Arctic Council. (2013c). Arctic Council Observer Manual for Subsidiary Bodies. Kiruna. Retrieved from http://www.arctic-council.org/index.php/en/about-us/arcticcouncil/observers

Arctic Council. (2013d). Kiruna Declaration. Kiruna: Arctic Council. Retrieved from https://oaarchive.arctic-council.org/handle/11374/93

Arctic Council. (2015a). Amarok: Arctic Council tracker. Iqaluit. Retrieved from https://oaarchive.arcticcouncil.org/bitstream/handle/11374/608/ACMMCA09_Iqaluit_2015_SAO_Report_A nnex_2_Amarok_Arctic_Council_Tracker_AACT.pdf?sequence=1\&isAllowed=y

Arctic Council. (2015b). Arctic Council Secretariat terms of reference. Ancorage: Arctic Council. Retrieved from https://oaarchive.arcticcouncil.org/bitstream/handle/11374/1568/EDOCS-2884-v1151022_Terms_of_Reference_ACS_guiding_docs.pdf?sequence=1\&isAllowed=y Arctic Council. (2015c). Iqaluit Declaration. Iqaluit: Arctic Council. 
Arctic Council. (2015d). Recommendations for the integration of traditional and local knowledge in the work of the Arctic Council. Iqaluit.

Arctic Council. (2015e). Task Forces of the Arctic Council. Retrieved from http://www.arctic-council.org/index.php/en/about-us/subsidiary-bodies/task-forces

Arctic Council. (2016). The Arctic Council: A forum for peace and ooperation. Tromso: Arctic Council. Retrieved from http://www.arctic-council.org/index.php/en/ourwork2/20th-anniversary/416-20th-anniversary-statement-2

Arctic Council. (2017). Agreements. Retrieved from http://www.arcticcouncil.org/index.php/en/our-work/agreements

Arctic Council Panel. (1991). To establish an Arctic Council: A framework report. Ottawa. Retrieved from http://www.carc.org/pubs/v19no2/2.htm

Arctic Council Secretariat. (2015). Arctic Council Secretariat annual report 2015. Tromso.

Arctic Council Secretariat. (2016). Arctic Council funding: An overview. Fairbanks. Retrieved from https://oaarchive.arcticcouncil.org/bitstream/handle/11374/1721/EDOCS-3199-v4ACSAOUS202_Fairbanks_2016_5-1_Arctic-Council-funding-anoverview.pdf?sequence=1\&isAllowed=y

Arctic Environmental Protection Strategy. (1991). Arctic Environmental Protection Strategy. Rovaneimi. 
Arctic Frontiers. (2016). Arctic Frontiers. Retrieved from http://www.arcticfrontiers.com

Arctic Monitoring and Assessment Programme. (2004). Persistent toxic substances, food security and Indigenous peoples of the Russian north. AMAP Secretariat. Oslo. Retrieved from http://inchr.com/Doc/April05/Chapter1sv.pdf

Arctic Monitoring and Assessment Programme. (2011). Snow, water, ice and permafrost in the Arctic. Oslo, Norway.

Arctic Monitoring and Assessment Programme. (2015). Organisational structure. Retrieved February 13, 2015, from http://www.amap.no/about/organisationalstructure

Axworthy, L., \& Simon, M. (2015, March 4). Is Canada undermining the Arctic Council? Globe and Mail. Toronto.

Axworthy, T. S., \& Dean, R. (2013). Changing the Arctic aradigm from Cold War to cooperation: How Canada's Indigenous leaders shaped the Arctic Council. The Yearbook of Polar Law V, 7-43.

Berkes, F. (2009). Evolution of co-management: Role of knowledge generation, bridging organizations and social learning. Journal of Environmental Management, 90(5), 1692-1702. http://doi.org/10.1016/j.jenvman.2008.12.001

Bernauer, T. (1995). The effect of international environmental institutions: How we might learn. International Organization, 49(2), 351-377.

Bloom, E. (1999). Establishment of the Arctic Council. The American Journal of 
International Law, 93(3), 712-722.

Bravo, M., \& Rees, G. (2006). Cryo-politics: Environmental security and the future of Arctic navigation. Brown Journal of World Affairs, 13(1), 2005-2015.

Breum, M. (2012). When the Arctic Council speaks: How to move the Council's communication into the future. In T. S. Axworthy, T. Koivurova, \& W. Hasanat (Eds.), The Arctic Council: Its place in the future of arctic governance (pp. 113138). Toronto: Munk-Gordon Arctic Security Program and the University of Lapland.

Brown, M. (2013). The Arctic Council and non-Arctic interest. In C. Dubiel \& B. Vong (Eds.), Equatorial North: Centering the Arctic in global and local security (pp. 8694). Seattle: University of Washington Press. Retrieved from https://www.yumpu.com/en/document/view/17673167/equatorial-north-centeringthe-arctic-in-global-and-local-security

Buthe, T. (2002). Taking temporality seriously: Modeling history and the use of narratives as evidence. American Political Science Review, 96(3), 481-493.

Byers, M. (2009). Who owns the Arctic. Vancouver: Douglas and Mclntyre.

Canwest New Service. (2008). Conference could mark start of Arctic power struggle. Retrieved from https://web.archive.org/web/20090304204151/http://www.canada.com/topics/news/ world/story.html?id=d0135cd8-c15a-48a3-9579-0df5f8e185c1

Cash, D. W. (2001). "In Order to Aid in Diffusing Useful and Practical Information": 
Agricultural Extension and Boundary Organizations. Science, Technology \& Human Values, 26(4), 431-453. http://doi.org/10.1177/016224390102600403

Cash, D. W., Adger, W. N., Berkes, F., Garden, P., Lebel, L., Olsson, P., .. Young, O. (2006). Scale and cross-scale dynamics: Governance and information in a multilevel world. Ecology and Society, 11(2), 8. http://doi.org/8

Cash, D. W., Clark, W. C., Alcock, F., Dickson, N., Eckley, N., \& Jager, J. (2002). Salience, credibility, legitimacy and boundaries: Linking research, assessment and decision making. John F. Kennedy School of Government Harvard University Faculty Research Working Papers Series. Retrieved from http://www.ssrn.com/abstract=372280

Cash, D. W., Clark, W. C., Alcock, F., Dickson, N. M., Eckley, N., Guston, D. H., ... Mitchell, R. B. (2003). Knowledge systems for sustainable development. Proceedings of the National Academy of Sciences of the United States of America, 100(14), 8086-8091. http://doi.org/10.1073/pnas.1231332100

Cash, D. W., \& Moser, S. C. (2000). Linking global and local scales: dynamic assessment and management processes. Global Environmental Change, 10, 109120. http://doi.org/10.1016/S0959-3780(00)00017-0

Chater, A. (2015). Explaining the evolution of the arctic council. Electronic Thesis and Dissertation Repository, (Paper 3230). Retrieved from http://ir.lib.uwo.ca/etd/3230

Chaturvedi, S. (2012). Geopolitical transformations: "Rising" Asia and the future of the Arctic Council. In T. S. Axworthy, T. Koivurova, \& W. Hasanat (Eds.), The Arctic 
Council: Its place in the future of Arctic governance (pp. 226-260). Toronto: MunkGordon Arctic Security Program and the University of Lapland.

Clark, W. C., Tomich, T. P., Noordwijk, M. van, Dickson, N. M., Catacutan, D., Guston, D., \& McNie., E. (2010). Toward a general theory of boundary work: Insights from the CGIAR's natural resource management programs. Cambridge.

Coleman, W. D., \& Porter, T. (2000). International institutions, globalisation and democracy: Assessing the challenges. Global Society, 14(3), 377-398.

Collins, J. F., Virginia, R. A., Yalowitz, K. S., \& Sfraga, M. (2013). A Euro-Atlantic action plan for cooperation and enhanced Arctic security. Washington.

Conference of Parliamentarians of the Arctic Region. (2015). About. Retrieved from http://www.arcticparl.org/about.aspx

Conley, H. A., \& Melino, M. (2016). An Arctic redesign, (February).

Conservation of Flora and Fauna. (2013). Arctic biodiversity assessment report. Retrieved from http://www.arcticbiodiversity.is/the-report

DiMaggio, P. J. (1988). Interest and agency in institutional theory. In L. Zucker (Ed.), Institutional patterns and organizations (pp. 3-22). Cambridge: Ballinger.

Directorate-General for Internal Policies of the Union. (2015). Fisheries management and the Arctic in the context of climate change. Luxembourg: European Parliament.

Dobbin, F. R. (1994). Cultural models of organization: The social construction of rational organizing principles. In D. Crane (Ed.), The Sociology of Culture (pp. 117-141). 
Oxford: Blackwell.

Dodds, K. (2010). A polar mediterranean? Accessibility, resources and sovereignty in the Arctic Ocean. Global Policy, 1(3), 303-311. http://doi.org/10.1111/j.1758$5899.2010 .00038 . x$

Dodds, K. (2012). Anticipating the Arctic and the Arctic Council: Pre-emption, precaution and preparedness. In T. S. Axworthy, T. Koivurova, \& W. Hasanat (Eds.), The Arctic Council: Its place in the future of Arctic governance (pp. 1-28). Munk-Gordon Arctic Security Program and the University of Lapland.

Dosman, E. J. (1976a). Northern sovereignty and Canadian foreign policy. In E. J. Dosman (Ed.), The Arctic in question (pp. 1-12). Toronto: Oxford University Press.

Dosman, E. J. (1976b). The Northern sovereignty crisis 1968-70. In E. J. Dosman (Ed.), The Arctic in question (pp. 34-57). Toronto: Oxford University Press.

Dryzek, J. S. (2005). The politics of the Earth (Second). Oxford: Oxford University Press.

Ebinger, C. K., \& Zambetakis, E. (2009). The geopolitics of Arctic melt. International Affairs, 85(6), 1215-1232. http://doi.org/10.1111/j.1468-2346.2009.00858.x

Elferink, A. O. (1992). Environmental protection in the Arctic. The Rovaniemi process. Marine Pollution Bulletin, 24(3), 128-130. http://doi.org/10.1016/0025$326 \times(92) 90239-3$

English, J. (2013). Ice and water: Politics, peoples, and the Arctic Council. Toronto: 
Penguin Canada Books Inc.

Exner-Pirot, H. (2011). Canadian leadership in the circumpolar world: An agenda for the Arctic Council chairmanship 2013-2015. Northern Review, 33, 7-27.

Fenge, T. (2012a). Canada and the Arctic Council: Our turn to conduct the Arctic orchestra. Policy Options, (April), 63-67.

Fenge, T. (2012b). The Arctic Council: Promoting co-operation in the circumpolar world. In T. S. Axworthy, T. Koivurova, \& W. Hasanat (Eds.), The Arctic Council: Its place in the future of Arctic governance (pp. 1-9). Toronto: Munk-Gordon Arctic Security Program and the University of Lapland.

Friedland, R., \& Alford, R. R. (1991). Bringing society back in: Symbols, practices, and institutional contradictions. In W. W. Powell \& P. J. Dimaggio (Eds.), The New Institutionalism in Organizational Analysis (pp. 232-263). Chicago: University of Chicago Press.

Fujimura, J. H. (1992). Crafting science: Standardized packages, boundary objects, and "translation." In A. Pickering (Ed.), Science as Culture and Practice (pp. 168-211). Chicago: University of Alaska Press.

Gieryn, T. F. (1983). Boundary-work and the demarcation of science from Non-Science : Strains and interests in professional ideologies of scientists. American Sociological Review, 48(6), 781-795.

Gorbachev, M. (1987). Speech in Murmansk at the ceremonial meeting on the occasion 
of the Order of Lenin and the Gold Star Medel of the city of Murmansk, October 1, 1987. Rovaneimi: Barentsinfo.org. Retrieved from https://www.barentsinfo.fi/docs/Gorbachev_speech.pdf

Government of Canada. (2013). Development for the people of the North : The Arctic Council program during Canada's chairmanship ( 2013-15 ). Ottawa: Government of Canada. Retrieved from http://www.arcticcouncil.org/index.php/en/resources/news-and-press/news-archive/735-canadianchairmanship-program-2013-2015

Graczyk, P. (2012). The Arctic Council Inclusive of Non-Arctic Perspectives: Seeking a new balance. In T. S. Axworthy, T. Koivurova, \& W. Hasanat (Eds.), The Arctic Council: Its place in the future of Arctic governance (pp. 261-296). Toronto: MunkGordon Arctic Security Program and the University of Lapland.

Grant, S. D. (2010). Polar imperative: A history of Arctic sovereignty in North America. Vancouver: Douglas and McIntyre.

Gregg, P. M. (1974). Units and levels of analysis: A problem policy analysis in federal systems. Publius, 4(4), 59-86.

Griffiths, F. (2011). Arctic Council origins: A memoir, (March). Retrieved from http://gordonfoundation.ca/sites/default/files/images/Jan18 Griffiths_ArcticCouncilOrigins.pdf

Griffiths, F. (2012a). Arctic Council origins: A memoir. In The Arctic Council: Its place in the future of arctic governance. Toronto: Munk-Gordon Arctic Security Program and 
the University of Lapland. Retrieved from

http://gordonfoundation.ca/sites/default/files/images/Jan18 -

Griffiths_ArcticCouncilOrigins.pdf

Griffiths, F. (2012b). Stewardship as concept and practice in an Arctic context. In Cyberdialogue 2012: What is stewardship in cyberspace? Toronto: University of Toronto. Retrieved from http://www.cyberdialogue.citizenlab.org/wpcontent/uploads/2012/2012papers/CyberDialogue2012_Griffiths.pdf

Guston, D. H. (1999). Stabilizing the boundary between US politics and science: The role of the office of technology transfer as a boundary organization. Social Studies of Science, 29(1), 87-111. http://doi.org/10.1177/0306312705054591

Guston, D. H. (2001). Boundary organizations in environmental policy and science: an introduction. Science, Technology, \& Human Values, 26(4), 399-408. http://doi.org/10.1177/016224390102600401

Hacquebord, L. (2015). How science organizations in the non-Arctic countries became members of IASC. In IASC after 25 Years: Special Issue of the IASC Bulletin (pp. 21-26). Potsdam: International Arctic Science Committee.

Hafner-Burton, E. M., Kahler, M., \& Montgomery, A. H. (2009). Network analysis for international relations. International Organization, 63(3), 559-592. http://doi.org/Doi $10.1017 / S 0020818309090195$

Hajer, M., \& Wagenaar, H. (2003). Introduction. In M. Hajer \& H. Wagenaar (Eds.), Deliberative policy analysis: Understanding governance in the network soceity (pp. 
1-30). Cambridge: Cambridge University Press.

Hall, P. A. (2010). Historical institutionalism in rationalist and sociological perspective. In J. Mahoney \& K. Thelen (Eds.), Explaining institutional change: Ambiguity, agency, and power (pp. 204-223). Cambridge: Cambridge University Press.

Hall, P. A., \& Taylor, C. R. (1996). Political science and the three new institutionalisms. Political Studies, 44(5), 936-957.

Hamelin, L.-E. (1978). Canadian nordicity: It's your North, too. Montreal: Harvest House Ltd.

Heininen, L. (2005). Impacts of globalization, and the circumpolar north in world politics. Polar Geography, 29(2), 91-102. http://doi.org/10.1080/789610127

Heininen, L. (2010). Circumpolar international relations and cooperation. In L. Heininen \& C. Southcott (Eds.), Globalization and the circumpolar north (pp. 265-305). Fairbanks: University of Alaska Press.

Held, D., \& Koenig-Archibugi, M. (2004). Introduction. Government and Opposition, 39(2), 125-131.

Hoppe, R., Wesselink, A., \& Cairns, R. (2013). Lost in the problem: The role of boundary organisations in the governance of climate change. Wiley Interdisciplinary Reviews: Climate Change, 4(4), 283-300. http://doi.org/10.1002/wcc.225

Howlett, M. (1998). Predictable and unpredictable policy windows: Institutional and exogenous correlates of Canadian federal agenda-setting. Canadian Journal of 
Political Science, 31(3), 495-524.

Howlett, M., \& Fraser, S. (2007). Punctuating which equilibrium? Understanding thermostatic policy dynamics in Pacific Northwest forestry, 51(3), 532-551.

Huebert, R. (1999). Canadian Arctic security issues: Transformation in the post-Cold War era. International Journal, 54(2), 203-229.

Huebert, R. (2009). Canada and the changing international Arctic: At the crossroads of cooperation and conflict. In F. Abele, T. J. Courchene, F. L. Seidle, \& F. St-Hiliaire (Eds.), Northern exposure: Peoples, powers and propects in Canada's North (pp. 77-106). Montreal: The Institute for Research in Public Policy. Retrieved from http://archive.irpp.org/books/archive/AOTS4/huebert.pdf

Hulme, M., \& Mahony, M. (2010). Climate change: What do we know about the IPCC? Progress in Physical Geography, 34(5), 705-718. http://doi.org/10.1177/0309133310373719

IBRU Durham University. (2015). Maritime jurisdiction and boundaries of the Arctic. Retrieved from https://www.dur.ac.uk/ibru/resources/arctic/ Ilulissat Declaration. (2008). Ilulissat Declaration. Ilulissat. Retrieved from http://www.arcticgovernance.org/the-ilulissat-declaration.4872424.html International Arctic Science Committee. (2016). About IASC. Retrieved from http://iasc.info/iasc/about-iasc

Inuit Circumpolar Council. (2016). About ICC. Retrieved from 
http://www.inuitcircumpolar.com

Jackson School of International Studies Arctic Task Force. (2013). Equatorial North :

Centering the Arctic in global and local security. Seattle.

Jarashow, M., Runnels, M. B., \& Svenson, T. (2006). UNCLOS and the Arctic: The path of least resistance. Fordham International Law Journal, 30(5), 1587-1652.

Retrieved from http://ir.lawnet.fordham.edu/ilj

Jasanoff, S. (1990). The fifth branch: Science advisers as policymakers. Cambridge: Harvard University Press.

Jones, C., Hesterly, W., \& Borgatti, S. P. (1997). A general theory of network governance: Exchange conditions and social mechanisms. The Academy of Management Review, 22(4), 911-945.

Kahler, M. (2009). Networked politics: Agency, power, and governance. In M. Kahler (Ed.), Networked politics: Agency, power and governance (pp. 1-20). Ithaca: Cornell University Press.

Kankaanpää, P. (2012). Knowledge structures of the Arctic Council: For sustainable development. In T. S. Axworthy, T. Koivurova, \& W. Hasanat (Eds.), The Arctic Council: Its place in the future of Arctic governance (pp. 83-112). Toronto: MunkGordon Arctic Security Program and the University of Lapland.

Kankaanpää, P., \& Young, O. R. (2012a). The effectiveness of the Arctic Council. Polar Research, 1, 1-14. 
Kankaanpää, P., \& Young, O. R. (2012b). The Effectiveness of the Arctic Council [Data file]. Rovaneimi: Arctic Centre. Retrieved from http://www.arcticcentre.org/EN/research/Projects-and-ResearchNetworks/Other/Arctic-Council-study

Keohane, R. O. (1984). After hegemony: Cooperation and discord in the world of political economy. Princeton: Princeton University Press.

Keohane, R. O., Haas, P. M., \& Levey, M. A. (2001). The effectiveness of international environmental institutions. In P. M. Haas, R. O. Keohane, \& M. A. Levy (Eds.), Institutions for the Earth: Sources of effective international environmental protection (pp. 3-24). Cambridge: The MIT Press.

Kingdon, J. W. (2011). Agenda, alternatives, and public policies (Second). Boston: Longman.

Klijn, E. H. (1996). Analyzing and managing policy processes in complex networks. Administration and Society, 1(28), 90-119.

Klijn, E. H., \& Koppenjan, J. F. M. (2000). Public management and policy networks: Foundations of a network approach to governance. Public Management, 2, 135158.

Knecht, S. (2016). The politics of Arctic international cooperation: Introducing a dataset on stakeholder participation in Arctic Council meetings, 1998-2015. Cooperation and Conflict, 10836716652431. http://doi.org/10.1177/0010836716652431 
Knecht, S. (2017). Social constituencies, opportunistic legitimation and Arctic Council enlargement. Umea.

Koetz, T., Farrell, K. N., \& Bridgewater, P. (2012). Building better science-policy interfaces for international environmental governance: Assessing potential within the Intergovernmental Platform for Biodiversity and Ecosystem Services. International Environmental Agreements: Politics, Law and Economics, 12(1), 121. http://doi.org/10.1007/s10784-011-9152-z

Koivurova, T. (2010). Limits and possibilities of the Arctic Council in a rapidly changing scene of Arctic governance. Polar Record, 46(2), 146-156. http://doi.org/10.1017/S0032247409008365

Koivurova, T., \& Heinämäki, L. (2006). The participation of indigenous peoples in international norm-making in the Arctic. Polar Record, 42(2), 101-109. http://doi.org/10.1017/S0032247406005080

Koivurova, T., Molenaar, E. J., \& Vanderzwaag, D. L. (2009). Canada, the EU, and Arctic Ocean governance: A tangled and shifting seascape and future directions. Journal of Transnational Law and Policy, 18, 247-287.

Lackenbauer, P. W. (2014). Canada and the Asian observers to the Arctic Council: Anxiety and opportunity. Asia Policy, 18(1), 22-29.

http://doi.org/10.1353/asp.2014.0035

Lackenbauer, P. W., Arthur-Lackenbauer, J., Exner-Pirot, H., \& Lajeunesse, A. (2014). Enhancing permanent participant capacity at the Arctic Council: Analysis highlights. 
Lackenbauer, P. W., Lajeunesse, A., \& Exner-Pirot, H. (2014). Enhancing permanent participant capacity at the Arctic Council: Background report.

Lackenbauer, P. W., Lajeunesse, A., Exner-Pirot, H., \& Arthur-Lackenbauer, J. (2014). Enhancing permanent participant capacity at the Arctic Council: Options for discussion.

Lamb, J. (2010). Early history of the Arctic Council. Retrieved from http://gordonfoundation.ca/sites/default/files/images/EARLY HISTORY OF THE ARCTIC COUNCIL final.pdf

Lamb, J. (2012). Relections on the past and future of the Arctic Council. In The Arctic Council: Its place in the future of Arctic governance. Toronto: Gordon Foundation. Retrieved from http://gordonfoundation.ca/sites/default/files/images/Jan17 Lamb_ReflectionsonthePastandFutureoftheArcticCouncil.pdf

Larsen, J. N., \& Fondahl, G. (2014). Arctic Human Development Report. Copenhagen.

Lemos, M. C., \& Morehouse, B. J. (2005). The co-production of science and policy in integrated climate assessments. Global Environmental Change, 15(1), 57-68. http://doi.org/10.1016/j.gloenvcha.2004.09.004

Levy, M. A., Keohane, R. O., \& Haas, P. M. (2001). Improving the effectiveness of international environmental institutions. In P. M. Haas, R. O. Keohane, \& M. A. Levy (Eds.), Institutions for the Earth: Sources of Effective International Environmental Protection (pp. 397-426). Cambridge: The MIT Press. 
Lewis-Beck, M. S., Bryman, A., \& Futing Liao, T. (2004). The SAGE encyclopedia of social science research methods. Sage Publications.

Lynge, A. (1993). Inuit: The story of the Inuit Circumpolar Conference. Nuuk: Inuit Circumpolar Conference.

Mahoney, J., \& Thelen, K. (2010). A theory of gradual institutional change. In J. Mahoney \& K. Thelen (Eds.), Explaining institutional change: Ambiguity, agency, and power (pp. 1-37). Cambridge: Cambridge University Press.

McDiarmid, M. (2015, April 24). Does Canada's tough talk on Russia set back Arctic Council talks? CBC News. Ottawa. Retrieved from http://www.cbc.ca/news/politics/arctic-council-tensions-threaten-environment-ascanada-exits-chair- 1.3045975

Meyer, R. E., \& Hammerschmid, G. (2006). Changing institutional logics and executive identities: A managerial challenge to public administration in Austria. American Behavioral Scientist, 49(7), 1000-1014.

Mikkola, H., \& Käpylä, J. (2013). Arctic economic potential: The need for a comprehensive and risk-aware understanding of Arctic dynamics. Helsinki.

Miller, C. (2001). Hybrid management: Boundary organizations, science policy, and environmental governance in the climate regime. Science, Technology \& Human Values, 26(4), 478-500. http://doi.org/10.1177/016224390102600405

Mitchell, R. B. (2006). Part two: The effectiveness of international environmental 
regimes - Problem structure, institutional design, and the relative effectiveness of international environmental agreements. Global Environmental Politics, 6(3), 7289.

Mitchell, R. B. (2008). Evaluating the performance of environmental institutions: What to evaluate and how to evaluate it? Institutions and Environmental Change: Principal Findings, Applications, and Research Frontiers, 79-114.

Molenaar, E. (2012). Current and prospective roles of the Arctic Council system within the context of the Law of the Sea. In T. S. Axworthy, T. Koivurova, \& W. Hasanat (Eds.), The Arctic Council: Its place in the future of Arctic governance (pp. 139189). Toronto: Munk-Gordon Arctic Security Program and the University of Lapland.

Mollinga, P. P. (2010). Boundary work and the complexity of natural resources management. Crop Science, 50(March 2010), S-1-S-9. http://doi.org/10.2135/cropsci2009.10.0570

Munk-Gordon Arctic Security Program. (2012). Canada as an Arctic power: Preparing for the Canadian Chairmanship of the Arctic Council (2013-2015). Toronto.

Niels, E., Larsen, J. N., \& Nilsson, A. (2004). Arctic human development report. Akureyri, Iceland: Stefansson Arctic Institute.

Nielsson, E. T., \& Magnusson, B. M. (2015). The Arctic Five strike again. Retrieved from m.arcticjournal.com/opinion/1732/arctic-five-strike-again

Nord, D. C. (2016). The Arctic Council: Governance within the far north. Abingdon: 
Routledge.

North, D. C. (1991). Institutions. Journal of Economic Perspecitives, 5(1), 97-112.

Northern Forum. (2016). About the Northern Forum. Retrieved from http://www.northernforum.org/en/the-northern-forum/about-the-northern-forum

Nuelend, R. G. (2014). The EU in the Arctic region: Walking on thin ice? Montreal.

Office of the Auditor General of Norway, Accounts Chamber of the Russian Federation, Rigsrevisionen - SAI of Denmark, Swedish National Audit Office, \& U.S. Government Accountability Office. (2015). The Arctic Council: Perspectives on a changing Arctic, The Council's work, and key challenges. Arctic Council. Olso.

Ostrom, E. (1990). Governing the Commons: The evolution of institutions for collective action. Cambridge: Cambridge Univerity Press.

Pal, L. A. (2014). Beyond policy analysis: Public issues management in turbulent times (Fifth). Toronto: Nelson Education.

Parfitt, T. (2007, August 1). Russia plants flag on North Pole seabed. The Guardian. London. Retrieved from https://www.theguardian.com/world/2007/aug/02/russia.arctic

Pedersen, T. (2012). Debates over the role of the Arctic Council. Ocean Development \& International Law, 43(2), 146-156. http://doi.org/10.1080/00908320.2012.672289

Pierson, P., \& Skocpol, T. (2002). Historical institutionalism in contemporary political science. In I. Katznelson \& H. V. Milner (Eds.), Political science: State of the 
discipline (pp. 693-721). New York: W. W. Norton \& Company Inc.

Protection of the Arctic Marine Environment. (2009). Arctic Marine Shipping Assessment Report. Akureyri.

Raustiala, K., \& Victor, D. G. (2004). The regime complex for plant genetic resources. International Organization, 58(2), 277-309. http://doi.org/10.1017/S0020818304582036

Ravasi, D., \& Schultz, M. (2006). Responding to organizational identity threats: Exploring the role of organizational culture. Academy of Management Journal, 49(3), 433-458.

Rhemann, J. (2012). Looking within and outside of the Arctic to increase the governance capacity of the Arctic Council. In T. Axworthy, T. Koivurova, \& W. Hasanat (Eds.), The Arctic Council: Its place in the future of arctic governance (pp. 29-59). Toronto: Munk-Gordon Arctic Security Program and the University of Lapland.

Robinson, C. J., \& Wallington, T. J. (2012). Boundary work: Engaging knowledge systems in co-management of feral animals on indigenous lands. Ecology and Society, 17(2). http://doi.org/org/10.5751/ES-04836-170216

Rogne, O. (2015). Development of IASC. In IASC after 25 years: Special issue of the IASC bulletin (pp. 9-20). Potsdam: International Arctic Science Committee. Retrieved from http://iasc25.iasc.info 
Rogne, O., Rachold, V., Hacquebord, L., \& Corell, R. (2015). IASC after 25 years. Special issue of the IASC bulletin. Potsdam: International Arctic Science Committee. Retrieved from http://iasc25.iasc.info

Ronson, A. (2011). Political climate change: The evolving role of the Arctic Council. Northern Review, 33, 95-111.

Rothwell, D. R. (2008). The Arctic in international law: Time for a new regime? ANU College of Law Research Paper, 8(37).

Ryggvik, H. (2015). A short history of the Norwegian oil industry: From protected national champions to internationally competitive multinationals. Business History Review, 89(1), 3-41. http://doi.org/10.1017/S0007680515000045

Saami Council. (2016). About the Saami Council. Retrieved from http://www.saamicouncil.net/en/about-saami-council/

Saunders, A. (1991). Pondering an Arctic Council. Arctic Council: Canada Prepares for a New Era in Circumpolar Relations, 19(2).

Scott, A. (2000). The dissemination of the results of environmental research: A scoping report for the European Environmental Agency. Copenhagen.

Scott, W. R. (1994). Institutions and organizations: Toward a theoretical synthesis. In W. R. Scott \& J. W. Meyer (Eds.), Institutional environments and organizations (pp. 55-80). Sage Publications.

Sewell, W. H. J. (1996). Historical events as transformations of structures: Inventing 
revolution at the Bastille. Theory and Society, 25, 841-881.

Shadian, J. (2010). From states to polities: Reconceptualizing sovereignty through Inuit governance. European Journal of International Relations, 16(3), 485-510. http://doi.org/10.1177/1354066109346887

Skocpol, T. (1985). Bringing the state back in: Strategies of analysis in current research. In P. B. Evans, D. Rueschemeyer, \& T. Skocpol (Eds.), Bringing the state back in. Cambridge: Cambridge University Press. http://doi.org/10.1017/CBO9780511628283

Slipchenko, W., \& Hannigan, J. (2010). Canada's Arctic cooperation with the Soviet Union and Russia 1965 - 2000. Retrieved from http://walterslipchenko.com/pdf/FINAL REPORT WITH ATTACHMENTS_a.pdf

Snidal, D. (1985). Coordination versus prisoners' dilemma: Implications for international cooperation and regimes. The American Political Science Review, 79(4), 923-942.

SnowChange Cooperative. (2017). SnowChange Cooperative. Retrieved from www.snowchange.org/

Sorensen, E., \& Torfing, J. (2005). Network governance and post-liberal democracy. Administrative Theory and Praxis, 27(2), 197-237.

Spence, J. (2013). Strengthening the Arctic Council: Insights from the architecture behind Canadian participation. Northern Review, 37(Fall 2013), 37-56.

Spence, J. (2015). The Arctic Council leadership merry-go-round: Words of advice as 
the United States assumes the Arctic Council chairmanship. Waterloo.

Star, S. L., \& Griesemer, J. R. (1989). Institutional ecology, 'Translations' and boundary objects: Amateurs and professionals in Berkeley's Museum of Vertebrate Zoology, 1907-39. Social Studies of Science, 19(3), 387-420. http://doi.org/10.1177/030631289019003001

Stokke, O. S. (2007). International institutions and Arctic governance. In O. S. Stokke \& G. Honneland (Eds.), International cooperation and Arctic governance: Regime effectiveness and northern region building. London: Routledge.

Stokke, O. S. (2011). Interplay management, niche selection, and Arctic environmental governance. In S. Oberthür \& O. S. Stokke (Eds.), Managing institutional complexity: Regime interplay and global environmental change (pp. 143-170). Cambridge: MIT Press.

Stokke, O. S., Anderson, L., \& Mirovitskays, N. (1999). The Barents Sea fisheries. In O. R. Young (Ed.), The effectiveness of international environmental regimes: Causal connections and behavioral mechanisms (pp. 91-154). Cambridge: MIT Press.

Stone, D. P. (2016). The changing Arctic environment: The Arctic messenger. Cambridge: Cambridge University Press.

Suchman, M. C. (1995). Managing legitimacy: Strategic and institutional approaches. The Academy of Management Review, 20(3), 571-610.

Sugarman, M. (2013). Creative conservation: New paradigms of biodiversity 
management in the Canadian Arctic. In C. Dubiel \& B. Vong (Eds.), Equatorial North: Centering the Arctic in global and local security (pp. 50-58). Seattle: University of Washington Press.

Swidler, A. (1986). Culture in action: Symbols and strategies. American Sociological Review, 51(2), 273-286.

The Aspen Institute. (2011). The shared future: A report on the Aspen Institute Commission on Arctic climate change. Washington. Retrieved from http://www.aspeninstitute.org/policy-work/energy-environment/our-policywork/dialogue-commission-arctic-climate-change

Thelen, K. (1999). Historical institutionalism in comparative politics. Annual Review of Political Science, 2(1), 369-404. http://doi.org/10.1146/annurev.polisci.2.1.369

Thornton, P. H., \& Ocasio, W. (1999). Institutional Logics and the Historical Contingency of Power in Organizations: Executive Succession in the Higher Education Publishing Industry, 1958- 1990. American Journal of Sociology, 105(3), 801-843.

Thornton, P. H., \& Ocasio, W. (2008). Institutional logics. The handbook of organizational institutionalism.

Thornton, P. H., Ocasio, W., \& Lounsbury, M. (2012). The institutional logics perspective: A new approach to culture, structure, and process. Oxford: Oxford University Press.

Underdal, A. (2002a). Conclusions: Patterns of regime effectiveness. In E. L. Miles, A. 
Underdal, S. Andresen, J. Wettestrad, B. Skjaerseth, \& E. M. Carlin (Eds.), Environmental regime effectiveness: Confronting theory with evidence (pp. 433465). Cambridge: MIT Press.

Underdal, A. (2002b). One question, two answers. In M. Kahler, S. Andresen, E. M. Carlin, J. B. Skjaerseth, A. Underdal, \& J. Wettestad (Eds.), Environmental regime effectiveness: Confronting theory with evidence (pp. 3-45). Cambridge: MIT Press.

United Nations. (2001). Stockholm Convention on Persistent Organic Pollutants. Stockholm: United Nations.

United Nations. (2013). Minamata Convention on Mercury. Kuamoto: United Nations.

United Nations. (2016). Paris Agreement. Paris Agreement - Pre 2020 Action. Retrieved from http://ec.europa.eu/clima/policies/international/negotiations/paris/index_en.htm

United Nations World Commission on Environment and Development. (1987). Our Common Future. Oxford.

United States Institute of Peace. (2016). Tracks of Diplomacy. Retrieved from https://www.usip.org/node/43521

Vigni, P. (2013). The governance of the Arctic environment: The EU and US contribution (Transworld project). Fiesole Firenze. Retrieved from http://cadmus.eui.eu/handle/1814/27466

Waltz, K. N. (2010). Theory of international politics. Long Grove: Waveland Press.

Watt-Cloutier, S. (2015). The right to be cold. Toronto: Penguin Canada Books Inc. 
Weart, S. R. (2017). The discovery of global warming (Third). Melville: American Institute of Physics. Retrieved from http://history.aip.org/climate/index.htm\#contents

Weaver, R. K., \& Rockman, B. A. (1993). When and how do institutions matter? In R. K. Weaver \& B. A. Rockman (Eds.), Do institutions matter? Government capabilities in the United States and abroad (pp. 445-461). Washington: The Brookings Institution.

Wendt, A. (2001). Driving with the rearview mirror: On the rational science of institutional design. International Organization, 55(4), 1019-1049. http://doi.org/10.1162/002081801317193682

Wettestad, J. (2002). The Vienna Convention and Montreal Protocol on Ozone-Layer Depletion. In M. Kahler, A. Underdal, S. Andresen, J. Wettestad, J. B. Skjaerseth, \& E. M. Carlin (Eds.), Environmental regime effectiveness: Confronting theory with evidence (pp. 149-172). Cambridge: MIT Press.

Woods, N. (1999). Good governance in international organizations. Global Governance, 5(1), 39-61.

WWF. (2013). Opportunities for Canadian leadership at the Arctic Council, 2013-15.

Young, O. R. (1994). International governance: Protecting the environment in a stateless society. Ithaca: Cornell University Press.

Young, O. R. (2002a). Institutional interplay: The environmental consequences. In E. Ostrom, T. Dietz, N. Dolsak, P. C. Stern, S. Stonich, \& E. U. Weber (Eds.), The 
drama of the commons (pp. 263-292). Washington: National Academy Press.

Young, O. R. (2002b). The institutional dimensions of environmental change: Fit, interplay, and scale. Cambridge: MIT Press.

Young, O. R. (2009a). 2030 North: A national planning conference. In Arctic state changes: Implications for governance (pp. 1-4). Ottawa. Retrieved from http://2030north.carc.org/documents.php

Young, O. R. (2009b). The Arctic in play: Governance in a time of rapid change. The International Journal of Marine and Coastal Law, 24, 423-442.

Young, O. R. (2011). Effectiveness of international environmental regimes: Existing knowledge, cutting-edge themes, and research strategies. Proceedings of the National Academy of Sciences, 108(50), 19853-19860.

http://doi.org/10.1073/pnas.1111690108

Young, O. R. (2013). Governing the Arctic : From cold war theater to mosaic of cooperation. Global Governance, 11(1), 9-15.

Young, O. R. (2016). The Arctic Council at twenty: How to remain effective in a rapidly changing environment. UC Irvine Law Review, 6(1).

Ziff, B. (2015). U.S. leadership in the Arctic. Retrieved from http://www.arcticcircle.org/video2015 


\section{Appendix 1: Data Collection Methodology}

This dissertation draws on multiple data sources, including data collected from semistructured interviews, data collected about multilateral institutions, observation of Arctic Council meetings and other relevant events, and primary source material. In addition, this dissertation benefited from access to the data collected by Paula Kankaanpää and Oran Young in their earlier project, the Effectiveness of the Arctic Council (2012b).

Details about how this data was collected and managed are outlined below.

\section{Interview Data}

Interviews were conducted between September 2014 and June 2016 in: Canada

(Ottawa, Whitehorse, Yellowknife, Iqaluit), Iceland (Reykjavik), Norway (Tromso, Oslo), Denmark (Copenhagen), Finland (Helsinki, Rovaniemi), Russia (Murmansk) and the United States (Washington). 


\section{Breakdown of interview participants}

Table A1.1: Breakdown of Interview Participants

\begin{tabular}{|l|c|c|}
\hline TYPE OF ORANIZATION & $\begin{array}{l}\text { NUMBER OF } \\
\text { PARTICIPANTS }\end{array}$ & $\begin{array}{c}\text { INVOLVED WITH } \\
\text { ARCTIC COUNCIL }\end{array}$ \\
\hline ARCTIC COUNCIL STAFF * & 5 & 5 \\
\hline ARCTIC STATES & 17 & 6 \\
\hline $\begin{array}{l}\text { PERMENANT PARTICIPANT } \\
\text { ORGANIZATIONS }\end{array}$ & 6 & 3 \\
\hline NON-ARCTIC STATES & 3 & 2 \\
\hline $\begin{array}{l}\text { INTERGOVERNMENTAL } \\
\text { ORGANIZATIONS }\end{array}$ & 15 & 7 \\
\hline $\begin{array}{l}\text { NON-GOVERNMENTAL } \\
\text { ORGANIZATIONS }\end{array}$ & 5 & 5 ** \\
\hline PRIVATE SECTOR ORGANIZATIONS & 12 & $\mathbf{5 5}$ \\
\hline SUB-NATIONAL GOVERNMENTS & $\mathbf{6 7}$ & \\
\hline TOTAL & 4 & \\
\hline
\end{tabular}

*Secretariat staff from the Arctic Council and its working groups

${ }^{* *}$ Arctic Economic Council Members

\section{Interview procedures and conditions}

Before beginning an interview, interviewees were provided with basic information about the research project and invited to ask any questions they might have. They were also invited to sign an interview consent form that confirmed that their responses would be confidential and not for attribution and clarified that they could withdraw their responses at any time. A list of the types of questions asked is outlined below (Sample 1 and Sample 2). Interviews were semi-structured and customized based on the experience and position of the interviewee, the responses provided and the time available. Interviews lasted between 30-90 minutes (averaging 60 minutes). Interviews were audio recorded and/or hand-written depending on the preference of the interviewee. 


\section{Sample 1: Semi-structured interviews for those involved with the Arctic Council}

\section{QUESTIONS}

Introductory question

Do you or have you ever lived in the Arctic? Where and for how long?

Is your work related to environmental management and/or sustainable development local, sub-national, national, sub-regional, regional or international? (indicate all that apply)

When thinking about the future of environmental management and sustainable development, what do you think are the most important factors/drivers for the Arctic?

From your perspective, who should be involved in making decisions about the how the Arctic's environment is managed and how the region is developed? Why? How?

Which regional or international institutions do think are the most important for environmental management and sustainable development in the Arctic? What makes these institutions important?

\section{$\underline{\text { Arctic Council }}$}

What had you heard about the Arctic Council before becoming involved with it? (Prompt - how it works, how it is structured and organized, its role and accomplishments?)

How did you become involved in the work of the Arctic Council?

What do you know about how the Arctic Council is structured and organized?

How important do you think these features are to the work done by the Arctic Council?

From your perspective, what are the strengths and weakness of how the AC is organized and managed?

Are you aware of other institutions in the region that have adopted similar features?

Do you think other institutions should consider adopting this feature? Why?

In the time that you have been involved in the Arctic Council, how has it changed? Why do you think that is? What features of the Arctic Council have stayed the same? Why do you think that is? 
What is the current relationship between the Arctic Council and other international/regional institutions in the Arctic? How has that changed over time? (Prompt - Examples of shared activities and/or partnerships)

There has been growing interest the Arctic Council lately:

Why do you think that is?

How do you think it will affect the work of the Arctic Council moving forward?

What role do you think the Arctic Council is best positioned to play in the region in the future?

Closing questions for all interviewees

Is there anything else that you would like to add?

Is there anyone else you would recommend that I speak with about this project? 


\section{Sample 2: Semi-structured interviews for those not involved with the Arctic}

\section{Council}

\section{QUESTIONS}

$\underline{\text { Introductory question }}$

Do you or have you ever lived in the Arctic? Where and for how long?

Is your work related to environmental management and/or sustainable development local, sub-national, national, sub-regional, regional or international? (indicate all that apply)

When thinking about the future of environmental management and sustainable development, what do you think are the most important factors/drivers for the Arctic?

From your perspective, who should be involved in making decisions about the how the Arctic's environment is managed and how the region is developed? Why? How?

Which regional or international institutions do think are the most important for environmental management and sustainable development in the Arctic? What makes these institutions important?

\section{Arctic Council}

What do you know about how and why the Arctic Council was created? What do you know about how it has changed over time?

What do you know about how the Arctic Council is structured and organized?

How important do you think these features are to the work done by the Arctic Council?

Are you aware of other institutions in the region that have adopted similar features?

Do you think other institutions should consider adopting this feature? Why?

To your knowledge, what is the current relationship between the Arctic Council and other international/regional institutions in the Arctic?

There has been growing interest the Arctic Council lately:

Why do you think that is?

How do you think it will affect the work of the Arctic Council moving forward? 
What role do you think the Arctic Council is best positioned to play in the region in the future?

Would you like to be more involved in the Arctic Council? Why? Why not?

Closing questions for all interviewees

Is there anything else that you would like to add?

Is there anyone else you would recommend that I speak with about this project? 


\section{Observational Data}

With the permission of meeting organizers and participants, I attended several Arctic

Council meetings and events. I also participated in other events and meetings related to Arctic environmental management and sustainable development to observe and listen to the ideas and perspectives of different actors in the region.

At invitation-only meetings, I did not take verbatim notes of the discussions or take notes that would attribute any statements or comments to a particular individual. I did take handwritten or typed notes about general observations about the meetings and how these observations aligned with input provided by interviewees.

The list of events attended include:

Meetings

Arctic Council Sustainable Development Working Group meeting, Yellowknife, Canada, October 18-19, 2014

Arctic Council Permanent Participant Capacity Workshop, Yellowknife, Canada, October 20, 2014

Arctic Council Outreach Event, Yellowknife, Canada, October 20, 2014

Arctic Council Senior Arctic Officials Plenary meeting, October 22-23, 2014

SCPAR meeting, Helsinki, Finland, November 20, 2014

Arctic Council side event organized by Norway, Arctic Frontiers, Tromso, Norway, January 20, 2015

Arctic Council Outreach Event, Whitehorse, Canada, March 2, 2015

Arctic Council Senior Arctic Officials meeting, Whitehorse, Canada, March 3-5, 2015

Arctic Council Permanent Participant Capacity Workshop, March 17-18, 2015 


\section{Conferences}

Arctic Circle, Reykjavik, Iceland, October 11-14, 2013

Arctic Circle, Reykjavik, Iceland, October 31-November 2, 2014

Arctic Change Conference, Ottawa, Canada, December 8-12, 2014

Arctic Frontiers, Tromso, Norway, January 19-22, 2015

Northern Research Forum, Reykjavik, Iceland, October 14-15, 2015

Arctic Circle, Reykjavik, Iceland, October 16-18, 2015 


\section{Primary Source Material}

This dissertation was supported by the collection of primary source material, including Arctic Council declarations, records of meetings, reports, presentations and other publicly available documents.

All primary sources materials referenced in this dissertation are included in the Reference List.

Basic data about multilateral institutions involved in environmental management and sustainable development in the Arctic was collected from the websites of institutions and/or websites with information about Arctic institutions (e.g. UArctic, the Arctic Portal, the Arctic Governance Project). The data collected is presented in Appendix 2. 


\section{Survey Data}

The survey data from The Effectiveness of the Arctic Council project (Kankaanpää \& Young, 2012b) was provided by the authors in an Excel spreadsheet on August 1, 2016.

The authors removed the names of the respondents prior to sharing the data file to respect the anonymity of the respondents.

\section{Breakdown of survey respondents}

\section{Table A1.2: Breakdown of Survey Participants}

\begin{tabular}{|l|c|}
\hline Type of Participant & $\begin{array}{c}\text { Number of } \\
\text { Participants }\end{array}$ \\
\hline member state & 36 \\
\hline permanent participant & 2 \\
\hline $\begin{array}{l}\text { Arctic Council organization (e.g. } \\
\text { Council or Working Group } \\
\text { secretariat) }\end{array}$ & 6 \\
\hline Local or regional organization & 4 \\
\hline observer State & 6 \\
\hline $\begin{array}{l}\text { Non-governmental or international } \\
\text { observer organization }\end{array}$ & 17 \\
\hline Science sector Business or industry & 19 \\
\hline Total & $\mathbf{9 0}$ \\
\hline
\end{tabular}




\title{
Arctic Council effectiveness survey tool
}

\section{$0 \%$ completed \\ THE EFFECTIVENESS OF THE ARCTIC COUNCIL}

\begin{abstract}
Motivation
The goal of this study is to assess the effectiveness of the Arctic Council and to explore options for increasing its effectiveness in promoting Arctic sustainable development and environmental protection in the future. The study assesses (i) the scope of the AC's work, (ii) the success of the products of the AC, (iii) the consequences of participation on the part of different interest and knowledge groups in the work of the Council, and (iv) proposals for strengthening the Council. Responses to this questionnaire - supplemented by an analysis of primary documents - will provide the data for the study. The questionnaire is being sent to a sizable number of individuals who have been active in one way or another in the work of the AC. The project's findings will form the basis of a scientific article and a report to be presented to the Senior Arctic Officials of the AC.
\end{abstract}

\section{INFORMATION ON RESPONDENTS}

Information on respondents will be treated as confidential and not disclosed. Nevertheless, the following information is needed in order to analyze the data and interpret the results.

Profile

$\begin{array}{ll}\text { Lastname........* } & \text { Firstname } * \square \\ \text { Country.......... } * \square & \text { Region...... } \\ \text { Organization.... } & \text { Email...... }\end{array}$

Internet address

Gender and age *

Female $\bigcirc$ Male $\bigcirc$ under $20 \bigcirc 20-40 \bigcirc 41-60 \bigcirc$ over 60

What Arctic Council activities have you participated in? *

$\square$ SAO $\square$ ACAP $\square$ AMAP $\square$ CAFF $\square$ EPPR $\square$ PAME $\square$ SDWG $\sqsubset$ ACIA $\square$ other

During what time period(s) have you participated? *

$\left\ulcorner_{1991-1995} \varpi_{1996-2000} \varpi_{2001-2005} \varpi_{2006-2010}\right.$

What group do you most closely represent? *

Member State

2. EFFECTIVENESS/SUCCESS OF THE ARCTIC COUNCIL (AC) AND ITS PRODUCTS

2.1 Overall, how would you rate the effectiveness of the Arctic Council?

$1=$ No impact at all; $2=$ Very little impact; $3=$ Some impact; $4=$ Clear impact; $5=$ Considerable impact

$\mathrm{O}_{1} \mathrm{O}_{2} \mathrm{O}_{3} \mathrm{O}_{4} \mathrm{O}_{5}$

2.2 Assess the overall effectiveness of the Arctic Council's Working Groups

1 = No impact at all; 2 = Very little impact; 3 = Some impact; 4 = Clear impact; 5 = Considerable impac

Arctic Council Action Plan (ACAP)

Arctic Monitoring and Assessment Program (AMAP) 00000

Conservation of Arctic Flora and Fauna (CAFF)

Protection of Arctic Marine Environment (PAME)

Environmental Emergency Prevention, Preparedness, and Response (EPPR) 00000

Sustainable Development Working Group (SDWG) 
2.3 Assess the impact of the work of the Arctic Council and its Working Groups in the following areas.

$1=$ Useless; 2 = Very little use; $3=$ Some use; $4=$ Clearly useful; $5=$ Substantially useful

$\begin{array}{llllll}\text { Increases in general awareness about the Arctic } & 1 & 2 & 3 & 4 & 5 \\ \text { Increases in international co-operation in the Arctic } & 0 & 0 & 0 & 0 & 0 \\ \text { Increases in international co-ordination of national Arctic policies } & 0 & 0 & 0 & 0 & 0 \\ \text { Changes in international agreements, treaties, and conventions } & 0 & 0 & 0 & 0 & 0 \\ \text { New or revised public policies and strategies on the part of the Arctic States } & 0 & 0 & 0 & 0 & 0 \\ \begin{array}{l}\text { Ability of the Arctic's indigenous peoples to influence local, regional, or international } \\ \text { policies }\end{array} & 0 & 0 & 0 & 0 & 0\end{array}$

policies

Changes in attitudes and behavior on the part of:

- members of the general public in or outside the Arctic

- participants attending Arctic Council meetings

- decision makers in the Arctic States

- decision makers in other countries

$\begin{array}{lllll}1 & 2 & 3 & 4 & 5 \\ 0 & 0 & 0 & 0 & 0 \\ 0 & 0 & 0 & 0 & 0 \\ 0 & 0 & 0 & 0 & 0 \\ 0 & 0 & 0 & 0 & 0\end{array}$

Concrete actions relating to environmental protection locally and regionally in the Arctic with regard to:

- pollution control

$\begin{array}{lllll}1 & 2 & 3 & 4 & 5\end{array}$

- protection of biodiversity and protected areas

- protection of marine environment

- reduced risks of environmental emergencies

$\begin{array}{lllll}0 & 0 & 0 & 0 & 0\end{array}$

$\begin{array}{lllll}0 & 0 & 0 & 0 & 0 \\ 0 & 0 & 0 & 0 & 0\end{array}$

Concrete actions relating to sustainable development locally and regionally in the Arctic with regard to:

- individual health, education and welfare

- cultural integrity

- economic opportunities

- local and regional governance

$\begin{array}{lllll}1 & 2 & 3 & 4 & 5 \\ 0 & 0 & 0 & 0 & 0 \\ 0 & 0 & 0 & 0 & 0 \\ 0 & 0 & 0 & 0 & 0 \\ 0 & 0 & 0 & 0 & 0\end{array}$

If you feel other impacts are important, list them here as bulleted text:

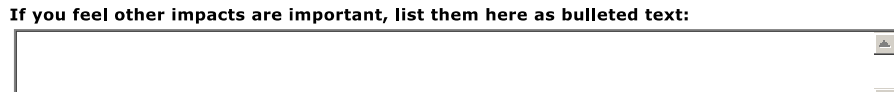

2.4 Assess the usefulness of the following types of Arctic Council products.

1 = Useless; 2 = Very little use; 3 = Some use; 4 = Clearly useful; 5 = Substantially useful

Scientific assessments (e.g. AMAP's state of the Arctic environment reports, ACIA) $\quad 0 \quad 0 \quad 6$

Overview assessments (e.g. AHDR, AMSA)

00000

Popular reports for the general public (e.g. ACIA overview report, CAFF book)

00000

Technical reports (e.g. action plans and strategies)

00000

Environmental monitoring programs

0000

Environmental guidelines, codes of conduct and best practices 600

Environmental emergency training

00000

Capacity building

0000

Demonstration projects for environmental improvement

00000

Arctic Council activities as the "Arctic voice" in global forums

0000

2.5 List three specific Arctic Council products that have made a difference in enhancing sustainable development and/or environmental protection in the Arctic.

Product 1

Product 1 Product 3 
General awareness about the Arctic

International co-operation in the Arctic

Harmonization of national Arctic policies

Changes in international agreements, treaties, and conventions

New or revised public policies and strategies of the Arctic States

Concrete actions locally and regionally in the Arctic

Political weight of the Arctic's indigenous peoples

Capacity building in the Arctic

\begin{tabular}{|c|c|c|}
\hline Product 1 & Product 2 & Product 3 \\
\hline$\Gamma$ & $\Gamma$ & $\Gamma$ \\
\hline Г & Г & Г \\
\hline$\Gamma$ & $\Gamma$ & $\Gamma$ \\
\hline$\Gamma$ & $\Gamma$ & Г \\
\hline$\Gamma$ & $\Gamma$ & $\Gamma$ \\
\hline$\Gamma$ & $\Gamma$ & Г \\
\hline$\Gamma$ & $\Gamma$ & $\Gamma$ \\
\hline$\Gamma$ & $\Gamma$ & $\Gamma$ \\
\hline
\end{tabular}

Changes in attitudes and behavior of:

- the general public in or outside the Arctic

- participants in the Arctic Council

- decision makers in the Arctic States

- decision makers in other countries

$\begin{array}{ccc}\text { Product 1 } & \text { Product 2 } & \text { Product 3 } \\ \square & \sqcap & \sqcap \\ \square & \square & \sqcap \\ \square & \square & \square \\ \square & \square & \square\end{array}$

Break

\section{SOURCES OF EFFECTIVENESS}

3.1 What are the most important factors contributing to the overall effectiveness or success of the Arctic Council (AC)?

$1=$ Not important at all; 2 = Very little importance; 3 = Some importance; $4=$ Important; 5 = Very important

The AC is a forum emphasizing informal discussions rather than legally binding $\begin{array}{lllll}1 & 2 & 3 & 4 & 5 \\ 0 & 0 & 0 & 0 & 6\end{array}$

decisions

The AC provides for participation by indigenous peoples' organizations as Permanent

Participants

The AC allows for dialogue among different knowledge groups (e.g. policy makers, $\subset \subset \odot$

(

The AC is a small body with only 8 member States

00000

The $A C$ is open to non-member States as observers

00000

The $A C$ is open to non-state actors as observers

$0 \circ 00$

Political interest in the AC's agenda is rising

00000

Knowledge brokers (individuals or groups that seek to facilitate science-policy 0000

If you believe other factors are important in this context, list them here as bullet points:

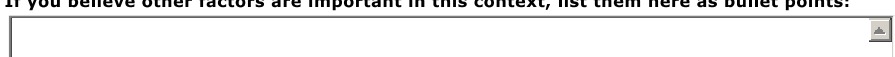

3.2 What are the most important factors contributing to the effectiveness of the Arctic Council's Working 3.2 What
Groups?

$1=$ Not important at all; $2=$ Very little importance; $3=$ Some importance; $4=$ Important; $5=$ Very important

Commitment on the part of national representatives

$\begin{array}{lllll}1 & 2 & 3 & 4 & 5\end{array}$

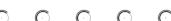

00000

Responsiveness to interests of local representatives and stakeholders

00000

Availability of material resources

00000

An efficient secretariat

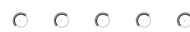

An effective chairman

Support from indigenous peoples

00000

Support from indigenous peoples

Links to relevant organizations outside the Arctic

00000

00000

List any other factors you feel are important as bullet points: 
3.3 What factors have made the AC less effective than it might have been?

$1=$ Not important at all; 2 = Very little importance; $3=$ Some importance; $4=$ Important; 5 = Very important

$\begin{array}{lllll}1 & 2 & 3 & 4\end{array}$

The $A C$ is a discussion forum that lacks the authority to make binding decisions $\quad 0 \quad 0 \quad 6$

The member States do not attach priority to Arctic issues 00000

The Senior Arctic Officials (SAOs) are not sufficiently committed to the work of the 0000

The AC makes decisions only by consensus $\quad 0 \quad 0 \quad C$

The $A C$ does not follow-up on implementation of its recommendations and uses of its $C .0 \quad 0$

Co-ordination with regional international organizations is weak 00000

Co-ordination with global international organizations is weak 0000

Participation of local stakeholders is weak 0000

Participation of the private sector and industry is weak 00000

Most AC materials are available only in English $\quad 00006$

The AC lacks a permanent secretariat 00000

The AC lacks a reliable source of funds for its overall functioning 00000

Co-ordination with the science sector is ad hoc in nature

\section{PARTICIPATION OF POLICYMAKERS, SCIENTISTS, AND OTHER STAKEHOLDERS}

Assess the effectiveness of different actors as participants in the work of the Arctic Council.

$1=$ None; 2 = Very little; $3=$ Some; 4 = Good; 5 = Very good

Member State government officials

$\begin{array}{lllll}1 & 2 & 3 & 4 & 5\end{array}$

Member State government officials

00006

00000

Local and regional officials

00000

Other Arctic residents

00000

Representatives of observer states

00000

Representatives of non-governmental and international observer organizations 00000

Representatives of scientific organizations

00006

Individual scientists

00000

Representatives of private businesses and industries $\quad 000 \mathrm{C}$

Men

00000

Women

00000

Youth

00000

Elders

00006

5. STRENGTHENING THE ARCTIC COUNCIL

Which of the following measures would improve the effectiveness of the Arctic Council in the future?

$1=$ not feasible at all; $2=$ poor; $3=$ feasible; $4=$ good; $5=$ preferred

The organization of the AC should be restructured

$\begin{array}{lllll}1 & 2 & 3 & 4 & 5\end{array}$

The secretariats of AC WGs and Task Forces should be strengthened

There should be more ministerial meetings at the sector level

0000

Member States should have high-level Arctic Ambassadors 00000

The senior representatives of the Arctic States should play a more pro active role in 6 the AC

There should be more opportunities for the introduction of policy perspectives

through bodies like the Standing Committee of Parliamentarians of the Arctic Region

The participation of indigenous peoples' representatives should be enhanced 0000

$0 \circ 00$

The participation of local decision makers and stakeholders should be improved 00000

The participation of private sector and industry representatives should be improved 00000

The participation of observers should be improved

00000

The SDWG should have closer contact with scientists who study social issues 00000

The science funding organizations of the Arctic states should co-operate in 0000

supporting research on issues identified by the $A C$
The $A C$ should have a permanent secretariat

The AC should meet at the heads of government/state level 00000

If you have other suggestions for strengthening the Arctic Council, list them in bullet form here:

\begin{tabular}{l} 
If you have other suggestions for strengthening the Arctic Council, list them in bullet form here: \\
\hline
\end{tabular} 
What would be an effective and feasible funding mechanism to support the Arctic Council as an organization in the future?

$1=$ Not feasible/effective at all; $2=$ Poor; $3=$ Feasible but not too effective; $4=$ Good; 5 = Preferred $\begin{array}{lllll}1 & 2 & 3 & 4 & 5\end{array}$

The current mechanism for providing resources is adequate

00000

The Arctic States should invest more resources on national participation to Arctic Council activities

Nationally controlled but coordinated budgets for overall Arctic Council activities 0000

A commonly subscribed and administrated budget for management activities of the Arctic Council (e.g. for main secretariat and running costs) funded by the member

states

A commonly subscribed and administered project budget funded by the member

states

A participation fee for observer countries

00000

A participation fee for non-state observers $\quad 00006$

0000

A participation fee for interested private sector actors 00000

An $\mathrm{AC}$ foundation or permanent fund $\mathrm{COCO}$

What would be an effective and feasible way to fund the project activities of the Arctic Council

$1=$ Not feasible/effective at all; 2 = Poor; $3=$ Feasible but not too effective; $4=$ Good; 5 = Preferred

$\begin{array}{lllll}1 & 2 & 3 & 4 & 5\end{array}$

The current method where the countries choose projects of interest to them and

allocate funding on a project-by-project basis

Nationally controlled but coordinated budgets for overall AC activities

00000

A commonly subscribed and administered project budget funded by the member 0000

States

7. STRENGTHENING THE SUSTAINABLE DEVELOPMENT WORKING GROUP

Select from the list of options below measures you feel would be feasible and effective in strengthening the SDWG:

$1=$ Not feasible at all; $2=$ Poor; $3=$ Feasible; $4=$ Good $; 5=$ Preferred

The SDWG should implement truly circumpolar projects $\quad 0 \quad 0 \quad 0 \quad 0 \quad 6$

The SDWG should reduce the number of small and unrelated projects. 0000

The SDWG should spread the word about opportunities for activities to become 0000

SDWG projects

The SDWG should organize ministerial meetings on economic development,

culture and art, and so forth.

The SDWG should reorganize into two or more groups dealing with economic 60000

development, social and cultural issues, capacity development, and so forth.

\section{The SDWG should concentrate on the following sustainable development themes:}

$1=$ Not feasible at all; $2=$ Poor; $3=$ Feasible; $4=$ Good; 5 = Preferred

$\begin{array}{llllll}1 & 2 & 3 & 4 & 5\end{array}$

Local and regional implementation of sustainable development strategies as set forth $0 \quad 0 \quad 0 \quad$
in Agenda 21

Precautionary and ecosystem -based approaches to resource management 0000

Environmental and social impact assessment procedures 00000

Cleaner production methods and environmentally friendly technologies

\section{OUTREACH AND COMMUNICATION}

Assess public perceptions of the Arctic Council including its Working Groups

$1=$ Not at all; 2 = Very little; $3=$ Somewhat; $4=$ Clearly; 5 = Very strongly

The AC is well known internationally

The $\mathrm{AC}$ is well known nationally

The $A C$ is well known locally and regionally

The general image of the $A C$ is positive

The goals and strategies of the AC are clear

The AC represents the global voice of the Arctic

The overall "brand" of the $\mathrm{AC}$ is strong

$\begin{array}{lllll}1 & 2 & 3 & 4 & 5 \\ 0 & 0 & 0 & 0 & 0 \\ 0 & 0 & 0 & 0 & 0 \\ 0 & 0 & 0 & 0 & 0 \\ 0 & 0 & 0 & 0 & 0 \\ 0 & 0 & 0 & 0 & 0 \\ 0 & 0 & 0 & 0 & 0 \\ 0 & 0 & 0 & 0 & 0\end{array}$


Asses the outreach and communication activities of the Arctic Council

$1=$ Not at all; 2 = Very little; $3=$ Somewhat; $4=$ Clearly; 5 = Very strongly

The SAOs have been successful with regard to outreach and communication

Some or all the Working Groups have been successful with outreach and

communications

$\begin{array}{lllll}1 & 2 & 3 & 4 & 5\end{array}$

00000

00000

The materials produced by the AC are widely distributed and easy to find

0000

9. THE "ARCTIC BOOM"

Break

Public attention regarding Arctic issues has increased dramatically over the last couple of years. How does this "Arctic boom" affect the work of the Arctic Council?

$1=$ Not at all; $2=$ Very little; $3=$ Somewhat; $4=$ Clearly; $5=$ Very strongly

Pressure to fous on outreach and communication has reduced resources for core activities

The capacity of the AC to work effectively grew during the IPY

The capacity of the AC to work effectively is growing now

Political support for the $\mathrm{AC}$ is rising $\quad 00000$

The ability of the SAOs to mobilize resources is increasing 00000

The ability of the Working Groups to mobilize resources is increasing $0 \quad 0 \quad 0 \quad 6$

The capacity of the $\mathrm{AC}$ is declining due to increased competition from other bodies 0000

10. CONCLUDING THOUGHTS

What is your expectation regarding the overall effectiveness of the Arctic Council during the next decade?

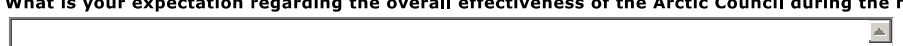

Are there any other comments about the effectiveness of the Arctic Council you would like to make at this

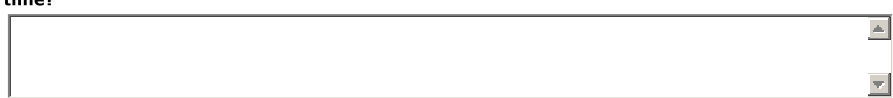

Submit Reset

FoF 


\section{Data Management}

All audio and handwritten notes from interviews and field observation were transcribed by the author.

All data used in this study was compiled in a password-protected Nvivo file.

Interviewees were assigned unique identifiers that were stored in a separate, passwordprotected document.

The Nvivo software was used to store and organize data. It was also used to code and identify common themes to support the analysis.

All references to interviewees and survey respondents in the analysis presented in this dissertation are anonymous and not for attribution. 


\section{Appendix 2: Multilateral Institutions Involved in Arctic Environmental Governance and Sustainable Development}

To support the analysis in this dissertation, I collected data about institutions involved with or relevant to environmental management and sustainable development in the region from 1945 until 2015. I limited the collection of data to transboundary institutions that involve multiple (three or more) public and/or private actors, which I refer to as multilateral institutions. I did not collect data on bilateral or domestic institutions because I did not want to overwhelm the network analysis and these types of institutions have very different governance characteristics and tend to have more focused mandates and responsibilities. I collected basic information about each institution, including: date of founding, main actors involved and primary scale of activity (international, regional or sub-regional). A summary of the data collect is presented below in Table A2.1.

Data about multilateral institutions was collected using a snowball sampling method. Key websites used to initiate the process of mapping the network of multilateral institutions with mandates relevant to Arctic environmental management and sustainable development included the Arctic Council (www.arctic-council.org), Arctic Governance Project (www.arcticgovernance.org), the Arctic Portal (http://arcticportal.org) and the University of the Arctic (http://www.uarctic.org). A snowball sampling method is not exhaustive; however, I continued data collection until after saturation. 
Institutions were classified as international if they had a global mandate (e.g. the Convention on Biological Diversity (CBD) or the International Union for the Conservation of Nature (IUCN)) or if their mandate included regions outside the Arctic (e.g. NorthEast Atlantic Fisheries Commission (NEAFC) or the International Polar Foundation (IPF)).

Table A2.1: Multilateral institutions involved in Arctic environmental management and sustainable development

\begin{tabular}{|r|l|l|c|}
\hline Zone & Abbr & Institution & Year \\
\hline 1 & UN & United Nations & 1945 \\
\hline 1 & UNESCO & $\begin{array}{l}\text { United Nations Educational, Scientific and Cultural } \\
\text { Organization }\end{array}$ & 1945 \\
\hline 1 & IWC & International Whaling Commission & 1946 \\
\hline 1 & IMO & International Maritime Organization & 1948 \\
\hline 1 & WHO & World Health Organization & 1948 \\
\hline 1 & WMO & World Meteorological Organization & 1950 \\
\hline 1 & NEAFC & Nordic Council & 1952 \\
\hline 1 & UNDP & United Nations Development Programme & 1959 \\
\hline 1 & NCM & Nordic Council of Ministers & 1965 \\
\hline 1 & UNEP & United Nations Environment Programme & 1971 \\
\hline 1 & ACPB & Agreement on the Conservation of Polar Bears & 1973 \\
\hline 1 & BC & $\begin{array}{l}\text { Convention on the Conservation of Migratory } \\
\text { Species of Wild Animals (Bonn Convention) }\end{array}$ & 1979 \\
\hline 1 & NWAFO & Northwest Atlantic Fisheries Organization & 1979 \\
\hline 1 & UNCLOS & $\begin{array}{l}\text { United Nations Convention on the Law of the Sea } \\
\text { III }\end{array}$ & 1982 \\
\hline 1 & NASCO & North Atlantic Salmon Conservation Organization & 1983 \\
\hline 1 & VC & $\begin{array}{l}\text { Vienna Convention for the Protection of the Ozone } \\
\text { Layer }\end{array}$ & 1985 \\
\hline 1 & WNC & West Nordic Council & 1985 \\
\hline 1 & CBSS & Council of the Baltic Sea States & 1992 \\
\hline 1 & NPAFC & North Pacific Anadromous Fish Commission & 1992 \\
\hline 1 & OSPAR & $\begin{array}{l}\text { Protection of the Marine Environment of the } \\
\text { North-East Atlantic Commission }\end{array}$ & 1992 \\
\hline 1 & CBD & Convention on Biological Diversity & 1992 \\
\hline
\end{tabular}




\begin{tabular}{|c|c|c|c|}
\hline 1 & UNCCC & $\begin{array}{l}\text { United Nations Framework Convention on Climate } \\
\text { Change }\end{array}$ & 1992 \\
\hline 1 & NAMMCO & North Atlantic Marine Mammal Commission & 1992 \\
\hline 1 & OHCHR & $\begin{array}{l}\text { Office of the United Nations High Commissioner } \\
\text { for Human Rights }\end{array}$ & 1993 \\
\hline 1 & CPAR & Conference of Arctic Parliamentarians & 1993 \\
\hline 1 & $\mathrm{NF}$ & Northern Forum & 1993 \\
\hline 1 & CA & $\begin{array}{l}\text { Agreement Between Denmark, Finland, Iceland, } \\
\text { Norway and Sweden Concerning Cooperation in } \\
\text { Measures to Deal with Pollution of the Sea by Oil } \\
\text { or Other Harmful Substances (Copenhagen } \\
\text { Agreement) }\end{array}$ & 1993 \\
\hline 1 & BEAC & Barents Euro-Arctic Council & 1993 \\
\hline 1 & $\mathrm{BRC}$ & Barents Regional Council & 1993 \\
\hline 1 & ISA & International Seabed Authority & 1994 \\
\hline 1 & EPB & European Polar Board & 1999 \\
\hline 1 & $\mathrm{StC}$ & $\begin{array}{l}\text { Stockholm Convention on Persistent Organic } \\
\text { Pollutants }\end{array}$ & 2001 \\
\hline 1 & A5 & Ilulissat Declaration (Arctic 5) & 2008 \\
\hline 1 & MCM & Minamata Convention on Mercury & 2013 \\
\hline 1 & ACGF & Arctic Coast Guard Forum & 2015 \\
\hline 2 & OGP & International Association of Oil \& Gas Producers & 1974 \\
\hline 2 & IPIECA & $\begin{array}{l}\text { International Petroleum Industry Environmental } \\
\text { Conservation Association }\end{array}$ & 1974 \\
\hline 2 & ICMM & International Council on Mining and Metals & 2001 \\
\hline 2 & AAECO & Association of Arctic Expedition Cruise Operators & 2003 \\
\hline 2 & ASF & Arctic Shipping Forum & 2004 \\
\hline 2 & SATA & Sustainable Arctic Tourism Association & 2005 \\
\hline 2 & WOC & World Ocean Council & 2008 \\
\hline 2 & $\mathrm{ABF}$ & Arctic Business Forum & 2009 \\
\hline 2 & CARD & Centre for Arctic Resource Development & 2011 \\
\hline 2 & WAF & World Arctic Forum (no longer active) & 2013 \\
\hline 2 & $\mathrm{AEC}$ & Arctic Economic Council & 2014 \\
\hline 3 & $\mathrm{NSaC}$ & Nordic Saami Council & 1956 \\
\hline 3 & ICC & $\begin{array}{l}\text { Inuit Circumpolar Council (formerly Inuit } \\
\text { Circumpolar Conference) }\end{array}$ & 1977 \\
\hline 3 & RAIPON & $\begin{array}{l}\text { Russian Association of Indigenous Peoples of the } \\
\text { North }\end{array}$ & 1990 \\
\hline 3 & $\mathrm{SaC}$ & Saami Council (replaces Nordic Saami Council) & 1992 \\
\hline
\end{tabular}




\begin{tabular}{|r|l|l|l|}
\hline 3 & IPS & Indigenous Peoples Secretariat & 1994 \\
\hline 3 & AWRH & Association of World Reindeer Herders & 1997 \\
\hline 3 & AIA & Aleut International Association & 1998 \\
\hline 3 & GCI & Gwich'in Council International & 1999 \\
\hline 3 & AAC & Arctic Athabaskan Council & 2000 \\
\hline 3 & SnC & Snowchange Cooperative & 2002 \\
\hline 3 & IPCCA & $\begin{array}{l}\text { Indigenous Peoples' Biocultural Climate Change } \\
\text { Assessment Initiative }\end{array}$ & 2009 \\
\hline 4 & IFRC & $\begin{array}{l}\text { International Federation of Red Cross \& Red } \\
\text { Crescent Societies }\end{array}$ & 1919 \\
\hline 4 & WWF & World Wide Fund for Nature & 1961 \\
\hline 4 & EJ & Earthjustice & 1971 \\
\hline 4 & FOE & Friends of the Earth & 1971 \\
\hline 4 & GP & Greenpeace & 1971 \\
\hline 4 & OC & Ocean Conservancy & 1972 \\
\hline 4 & PF & Pew Foundation, Environment & 1974 \\
\hline 4 & BF & Bellona Foundation & 1986 \\
\hline 4 & EBCD & European Bureau for Conservation \& Development & 1989 \\
\hline 4 & GA & GRID-Arendal & 1989 \\
\hline 4 & TE & $\begin{array}{l}\text { European Federation for Transport and } \\
\text { Environment }\end{array}$ & 1990 \\
\hline 4 & PBI & Polar Bears International & 1992 \\
\hline 4 & WI & Wetlands International & 1995 \\
\hline 4 & CAA & Circumpolar Agriculture Association & 1995 \\
\hline 4 & CCU & Circumpolar Conservation Union & 1995 \\
\hline 4 & BF & $\begin{array}{l}\text { Bellona Foundation (took on an international } \\
\text { mandate) }\end{array}$ & 1998 \\
\hline 4 & IWGIA & International Work Group for Indigenous Affairs & 2002 \\
\hline 4 & YAC & Youth Arctic Coalition & 2013 \\
\hline 5 & RAS & Russian Academy of Sciences & 1724 \\
\hline 5 & AARI & Arctic and Antarctic Research Institute & 1920 \\
\hline 5 & SPRI & $\begin{array}{l}\text { Scott Polar Research Institute (University of } \\
\text { Cambridge) }\end{array}$ & 1920 \\
\hline 5 & AINA & $\begin{array}{l}\text { Arctic Institute of North America (University of } \\
\text { Calgary) }\end{array}$ & 1945 \\
\hline & IAAR & $\begin{array}{l}\text { Institute of Arctic And Alpine Research } \\
\text { (University of Colorado) }\end{array}$ & 1951 \\
\hline 5 FNI & Fridtjof Nansens Institute & Institute of Arctic Biology (University of Alaska) \\
\hline
\end{tabular}




\begin{tabular}{|c|c|c|c|}
\hline 5 & ICES & International Council of the Exploration of the Sea & 1964 \\
\hline 5 & AWI & $\begin{array}{l}\text { Alfred Wegener Institute for Polar and Marine } \\
\text { Research }\end{array}$ & 1980 \\
\hline 5 & IPA & International Permafrost Association & 1983 \\
\hline 5 & PRIC & Polar Research Institute of China & 1989 \\
\hline 5 & $\mathrm{ACe}$ & Arctic Centre, University of Lapland & 1989 \\
\hline 5 & CICERO & $\begin{array}{l}\text { Center for International Climate and } \\
\text { Environmental Research }\end{array}$ & 1990 \\
\hline 5 & ARCUS & Arctic Research Consortium of the United States & 1998 \\
\hline 5 & FARO & Forum of Arctic Research Operators & 1998 \\
\hline 5 & SAI & Stefansson Arctic Institute & 1998 \\
\hline 5 & IARC & International Arctic Research Center & 1999 \\
\hline 5 & IASSA & International Arctic Social Sciences Association & 1999 \\
\hline 5 & NRF & Northern Research Forum & 1999 \\
\hline 5 & INTERACT & $\begin{array}{l}\text { International Network for Terrestrial Research and } \\
\text { Monitoring in the Arctic }\end{array}$ & 2001 \\
\hline 5 & UA & UArctic & 2001 \\
\hline 5 & IPF & International Polar Foundation & 2002 \\
\hline 5 & AMERN & Arctic Marine Ecosystem Research Network & 2002 \\
\hline 5 & $\mathrm{AFoPs}$ & Asian Forum for Polar Sciences & 2004 \\
\hline 5 & TI & Thule Institute & 2006 \\
\hline 5 & APECS & Association of Polar Early Career Scientists & 2007 \\
\hline 5 & IACS & International Association of Cryosphereic Sciences & 2007 \\
\hline 5 & ELOKA & $\begin{array}{l}\text { Exchange of Local Observations and Knowledge of } \\
\text { the Arctic }\end{array}$ & 2007 \\
\hline 5 & NSAPR & Norwegian Scientific Academy for Polar Research & 2008 \\
\hline 5 & IASS & Institute for Advanced Sustainability Studies & 2009 \\
\hline 5 & CEARC & $\begin{array}{l}\text { research centre CEARC (Cultures, Environment, } \\
\text { Arctic, Representation, Climate) }\end{array}$ & 2009 \\
\hline 5 & AI & $\begin{array}{l}\text { Arctic Institute: Center for Circumpolar Security } \\
\text { Studies }\end{array}$ & 2011 \\
\hline 5 & CHRN & Circumpolar Health Research Network & 2011 \\
\hline 5 & ARC & Arctic Research Centre, Aarhus University & 2012 \\
\hline 5 & ASP & Arctic Science Partnership & 2012 \\
\hline 5 & APRI & Austrian Polar Research Institute & 2013 \\
\hline 5 & EUP & EU-PolarNet & 2014 \\
\hline 6 & IUCN & International Union for the Conservation of Nature & 1948 \\
\hline 6 & IUGS & International Union of Geological Sciences & 1961 \\
\hline
\end{tabular}




\begin{tabular}{|r|l|l|c|}
\hline 6 & IASC & International Arctic Science Committee & 1990 \\
\hline 6 & AEPS & $\begin{array}{l}\text { Arctic Environmental Protection Strategy (replaced } \\
\text { by Arctic Council) }\end{array}$ & 1991 \\
\hline 6 & No & Nordregio & 1997 \\
\hline 6 & SAON & Sustaining Arctic Observing Networks & 2007 \\
\hline 6 & ICCI & International Cryosphere Climate Initiative & 2009 \\
\hline 7 & ACOPS & Advisory Committee on Protection of the Sea & 1952 \\
\hline 7 & IUCH & International Union for Circumpolar Health & 1981 \\
\hline 7 & ION & Institute of the North & 1996 \\
\hline 8 & CHNL & Centre for High North Logistics & 2009 \\
\hline 9 & AC & Arctic Council & 1996 \\
\hline 9 & PNWER & $\begin{array}{l}\text { Pacific Northwest Economic Region, Arctic } \\
\text { Caucus }\end{array}$ & 2009 \\
\hline 10 & BDF & Baltic Development Forum & 1998 \\
\hline 10 & ND & Northern Dimension & 1999 \\
\hline 10 & AF & Arctic Frontiers & 2007 \\
\hline 10 & IAP & Institute for Arctic Policy & 2008 \\
\hline 10 & AFF & Arctic Forum Foundation & 2010 \\
\hline 10 & WEF & $\begin{array}{l}\text { World Economic Forum, Global Agenda Council } \\
\text { on the Arctic (no longer active) }\end{array}$ \\
\hline 10 & ArC & Arctic Circle & $\begin{array}{l}\text { Arctic Council (with creation of Arctic Economic } \\
\text { Council) }\end{array}$ \\
\hline 10 & AC & Community \\
\hline 19 & - Government, Zone 2 Private Sector, Zone 3 Indigenous & 2013 \\
\hline
\end{tabular}

Zone 1 - Government, Zone 2 - Private Sector, Zone 3 - Indigenous \& Community Organizations, Zone 4 - NGOs, Zone 5 - Research/Academia, Zone 6 - Government \& Science/Academia, Zone 7 - Research/Academia \& NGOs, Zone 8 - Government, Private Sector \& Research/Academia, Zone 9 - Government, Indigenous and Community Organizations, NGOs and Research/Academia, Zone 10: Open to All 


\section{Appendix 3: Content Analysis of Arctic Council-Related Documents 1991-2015}

Content analysis, a research method used to study and classify text, was used to identify themes in Arctic Council-related documents, including all Arctic Council ministerial declarations issued between 1996 and 2015, the Arctic Environmental Assessment Strategy (1991) and the Arctic Council Panel Report (1991).

Each document was reviewed and coded multiple times using Nvivo, a qualitative and mixed methods research tool. Themes were initially identified in the documents inductively and then documents were reviewed again using identified themes. In a final round of coding, themes were organized into themes and sub-themes. Table A3.1 identifies the frequency of references of specific themes and sub-themes. After identify key themes in the documents, Nvivo was used to examine the context, framing and relationships between the themes within and between documents.

This content analysis provides insight on the themes that were present in the texts that were analyzed; however, it provides no guidance on issues or themes that were not included in the text. To overcome this limitation, the findings from the content analysis were cross referenced with interview, survey and observational data. 
Table A3.1: Results of content analysis to identify frequency of references to themes in key Arctic Council-related documents

\begin{tabular}{|c|c|c|c|c|c|c|c|c|c|c|c|c|}
\hline & $\begin{array}{r}\text { AEPS } \\
(1991)\end{array}$ & $\begin{array}{r}\text { AC } \\
\text { Panel } \\
\text { Report } \\
(1991)\end{array}$ & $\begin{array}{r}\text { Ottawa } \\
(1996)\end{array}$ & $\begin{array}{l}\text { Iqaluit } \\
\text { (1998b) }\end{array}$ & $\begin{array}{r}\text { Barrow } \\
(2000)\end{array}$ & $\begin{array}{l}\text { Inari } \\
(2002)\end{array}$ & $\begin{array}{r}\text { Reykjavik } \\
(2004 \mathrm{c})\end{array}$ & $\begin{array}{r}\text { Salekhard } \\
(2006)\end{array}$ & $\begin{array}{r}\text { Tromso } \\
(2009)\end{array}$ & $\begin{array}{r}\text { Nuuk } \\
(2011 b)\end{array}$ & $\begin{array}{r}\text { Kiruna } \\
\text { (2013d) }\end{array}$ & $\begin{array}{l}\text { Iqaluit } \\
(2015 \mathrm{c})\end{array}$ \\
\hline $\begin{array}{l}\text { Regional cooperation, } \\
\text { including: }\end{array}$ & 39 & 35 & 7 & 7 & 17 & 14 & 15 & 34 & 25 & 11 & 16 & 13 \\
\hline military-security & 0 & 23 & 1 & 0 & 0 & 0 & 0 & 0 & 0 & 0 & 0 & 0 \\
\hline $\begin{array}{l}\text { Indigenous peoples, } \\
\text { including: }\end{array}$ & 25 & 68 & 6 & 6 & 6 & 5 & 5 & 15 & 9 & 4 & 5 & 6 \\
\hline Traditional knowledge & 4 & 4 & 0 & 1 & 0 & 3 & 2 & 5 & 4 & 2 & 1 & 2 \\
\hline $\begin{array}{l}\text { Human dimension, } \\
\text { including: }\end{array}$ & 13 & 24 & 6 & 8 & 5 & 8 & 10 & 30 & 15 & 9 & 10 & 15 \\
\hline Health & 3 & 0 & 0 & 4 & 3 & 1 & 1 & 3 & 1 & 3 & 4 & 7 \\
\hline Social-Cultural & 7 & 2 & 2 & 2 & 1 & 1 & 0 & 10 & 2 & 0 & 2 & 6 \\
\hline Education & 0 & 0 & 1 & 2 & 0 & 1 & 2 & 3 & 2 & 1 & 0 & 0 \\
\hline Capacity building & 0 & 0 & 0 & 0 & 1 & 2 & 4 & 9 & 3 & 2 & 2 & 2 \\
\hline $\begin{array}{l}\text { Environmental } \\
\text { protection, including: }\end{array}$ & 54 & 5 & 4 & 15 & 24 & 21 & 22 & 25 & 29 & 21 & 13 & 22 \\
\hline $\begin{array}{l}\text { Biodiversity/ } \\
\text { conservation }\end{array}$ & 1 & 0 & 1 & 0 & 2 & 1 & 3 & 5 & 7 & 2 & 3 & 5 \\
\hline $\begin{array}{r}\text { Environmental } \\
\text { emergencies }\end{array}$ & 4 & 0 & 0 & 1 & 1 & 2 & 3 & 2 & 1 & 2 & 1 & 1 \\
\hline Marine environment & 4 & 0 & 0 & 1 & 2 & 1 & 2 & 1 & 3 & 2 & 2 & 8 \\
\hline Pollution & 29 & 3 & 0 & 5 & 6 & 8 & 5 & 13 & 13 & 7 & 7 & 9 \\
\hline Climate change & 4 & 4 & $\mathbf{0}$ & 1 & 3 & 11 & 10 & 15 & 12 & 8 & 8 & 7 \\
\hline $\begin{array}{l}\text { Scientific-research } \\
\text { collaboration }\end{array}$ & 39 & 2 & 2 & 5 & 17 & 12 & 21 & 35 & 31 & 13 & 16 & 28 \\
\hline $\begin{array}{l}\text { Sustainable } \\
\text { development, } \\
\text { including: }\end{array}$ & 18 & 5 & 5 & 7 & 12 & 10 & 15 & 28 & 23 & 8 & 13 & 20 \\
\hline Economic & 3 & 2 & 1 & 1 & 2 & 2 & 2 & 8 & 3 & 0 & 5 & 6 \\
\hline Natural resources & 5 & 1 & 1 & 2 & 3 & 6 & 4 & 1 & 3 & 1 & 2 & 3 \\
\hline Infrastructure & 2 & 0 & 0 & 2 & 1 & 1 & 1 & 4 & 6 & 2 & 3 & 3 \\
\hline Business & 0 & 0 & 0 & 0 & 0 & 1 & 0 & 2 & 1 & 1 & 2 & 2 \\
\hline Energy & 0 & 0 & 0 & 0 & 0 & 0 & 0 & 1 & 4 & 0 & 0 & 2 \\
\hline
\end{tabular}

